\title{
Recent Applications of Phosphane-based Palladium Catalysts in Suzuki- Miyaura Reactions Involved in Total Syntheses of Natural Products
}

\author{
Fabio Bellina*a ${ }^{* a}$ Marco Lessi ${ }^{\mathrm{a}}$, Chiara Manzini, ${ }^{\mathrm{a}}$ Giulia Marianetti ${ }^{\mathrm{b}}$, Luca A. Perego ${ }^{\mathrm{b}}$ and Renzo
} Rossi*a

${ }^{a}$ Dipartimento di Chimica e Chimica Industriale, Università di Pisa, Pisa, Italy; ${ }^{b}$ Scuola Normale Superiore, Pisa, Italy

\begin{abstract}
This review with 800 references illustrates applications of Suzuki-Miyaura (S.-M.) reactions in the total syntheses of 147 natural products that were made in the period 2010-2013. The review has been organized on the basis of the seven classes of phosphane-based Pd catalysts that have been used in the reported total syntheses. Emphasis has been given to describe and discuss the experimental conditions of the Pd-catalyzed (S.-M.) cross-coupling reactions also outlining the methods used to prepare the reactants. A focus has also been set on the biological and pharmacological properties of the reported natural products as well as on the most significant steps of the reported total syntheses.
\end{abstract}

Keywords: Chemoselectivity, Siteselectivity, Stereoselectivity, Carbon-carbon bond forming reactions, Transition metal catalyst 


\section{INTRODUCTION}

Over the past three decades the Pd-catalyzed SuzukiMiyaura (S.-M.) cross-coupling reaction of organoboron reagents with organic halides or pseudohalides (Scheme 1) has become one of the most important methods for the construction of $\mathrm{Csp}^{2}-\mathrm{Csp}^{2}$ bonds. [1]

$$
\begin{gathered}
\mathrm{R}^{1}-\mathrm{BY}_{2}+\mathrm{R}^{2}-\mathrm{X} \frac{\mathrm{Pd}_{\text {cat }}}{\mathrm{Base}} \mathrm{R}^{1}-\mathrm{R}^{2} \\
{\left[\mathrm{Y}=\text { alkyl, OH, OR; } \mathrm{X}=\mathrm{Cl}, \mathrm{Br}, \mathrm{I}, \mathrm{OTf}, \mathrm{OP}(=\mathrm{O})(\mathrm{OR})_{2}\right]}
\end{gathered}
$$

Scheme 1. The Suzuki-Miyaura cross-coupling reaction

The significant importance of this reaction in the areas of academia and industry was recognized awarding the 2010 Nobel Prize in Chemistry in part to Prof. Akira Suzuki. In fact, the reaction has proved of great utility in the synthesis of natural products,[2] biologically and pharmacologically active compounds[3] some of which have also been prepared on a large scale,[4] agrochemicals,5 and conjugated polymers useful in optoelectronic and electronic applications. [6] Several factors have contributed to the wide spread use of this reaction. They include: i) commercial availability of several organoboron reagents; ii) toleration of a broad range of functional groups; iii) water stability; iv) easy separation of the boron-containing by-products; v) environmentally benign nature of the organoboron reagents; and vi) the high regio- and stereoselectivity of the reaction. Moreover, during the last two decades many protocols have been developed that allow to carry out the reaction in mild conditions by using low loadings of the $\mathrm{Pd}$ catalyst precursors and make the reaction to proceed even with relatively inert electrophilic substrates such as unactivated aryl chlorides and very hindered aryl halides, $1 \mathrm{k}$ alkyl tosylates,[7] aryl and alkenyl triflates,[8] alkenyl mesylates and tosylates,[9] (hetero)aryl sulfamates,[10] aryl

imidazolylsulfonates,[11] allylic phosphates,[12] heteroaryl mesylates[13] and carboxylates,[14] vinyl acetate,[15] and phosphonium salts.[16]

Most early work in the S.-M. reaction, including the seminal studies by Suzuki[17] and the first application of this cross-coupling reaction in the synthesis of a natural product[18] was accomplished by using $\mathrm{Pd}\left(\mathrm{PPh}_{3}\right)_{4}$ as the catalyst precursor. Nowadays, the ever-growing catalogue of the Pd catalysts for the S.-M. reaction include: i) systems composed of a $\mathrm{Pd}(0)$ or a $\mathrm{Pd}(\mathrm{II})$ derivative and phosphorusbased ligands; $[19,20]$ ii) $\operatorname{Pd}(0)$ or $\operatorname{Pd}($ II) catalyst precursors containing $N$-heterocyclic carbene (NHC) ligands;[21] iii) palladacycles; [22] iv) systems composed of $\mathrm{Pd}(0)$ or $\mathrm{Pd}(\mathrm{II})$ derivatives and ligands different from phosphanes and NHCs;[23] v) ligandless Pd catalyst precursors;[24] vi) supported Pd derivatives;[25] vii) Pd nanocatalysts[26] including those supported on conventional supports or polymers,[27] cyclodextrins,[28] metal oxides and double hydroxides,[29] carbon nanotubes,[30] magnetic materials,[31] and dendrimer-containing supports; [32] viii) fluorous media-based nanocatalysts;[33] and ix) $\mathrm{Pd}$ nanoparticles in ionic liquids. [34]

Nevertheless, despite the wide variety of homogeneous and heterogeneous Pd catalysts currently available, the vast majority of S.-M. cross-couplings, which have been employed in the total syntheses of natural products described to date, have been carried out by using phosphane-based Pd catalysts and only few examples of total syntheses involving the use of Pd-catalyzed S.-M. reactions under ligandless conditions have recently been reported.[35]

This critical review with 800 references is aimed to present a broad overview of recent applications of S.-M. cross-couplings, which have been performed by using phosphane-based Pd catalyst systems, in the total synthesis of natural products many of which are known to exhibit interesting biological or pharmacological properties. The literature on this topic, which covers the results described in the period January 2010-December 2013, for the sake of clarity has been subdivided in seven sections interposed between the introduction and conclusions: (i) total syntheses via $\mathrm{Pd}\left(\mathrm{PPh}_{3}\right)_{4}$-catalyzed S.-M. cross-couplings; (ii) total syntheses via S.-M. reactions promoted by $\mathrm{PdCl}_{2}\left(\mathrm{PPh}_{3}\right)_{2}$ or a combination of $\mathrm{PPh}_{3}$ with $\mathrm{Pd}(\mathrm{OAc})_{2}$ or $\mathrm{Pd}_{2}(\mathrm{dba})_{3}$; (iii) total syntheses via trans-PdBr$(N-S u c c)\left(\mathrm{PPh}_{3}\right)_{2}$-catalyzed S.-M. reactions; (iv) total syntheses via S.-M. reactions promoted by a combination of $\mathrm{P}(\mathrm{oTol})_{3}$ or a tri(cyclo)alkylphosphane with a $\mathrm{Pd}(\mathrm{II})$ or a $\mathrm{Pd}(0)$ derivative; (v) total syntheses via S.$\mathrm{M}$. reactions promoted by a combination of a dicycloalkylbiarylphosphane with a $\operatorname{Pd}(\mathrm{II})$ or a $\operatorname{Pd}(0)$ derivative; (vi) total syntheses via $\mathrm{PdCl}_{2}$ (dppf)- or $\mathrm{PdCl}_{2}$ (dppf) $\cdot \mathrm{CH}_{2} \mathrm{Cl}_{2}$-catalyzed S.-M. reactions; and (vii) total syntheses via S.-M. reactions promoted by a combination of $\mathrm{PdCl}_{2}$ (dppf) with $\mathrm{AsPh}_{3}$. The specific aspects of some of these total syntheses have been discussed in detail.

It is also worth noting that the topics of these sections have not been covered in recent reviews and books on the S.M. reaction, though a small number of applications of the S.M. cross-coupling reaction in 20 total syntheses of natural products, which have been accomplished in the period 20102012 and involve the use of phosphane-based Pd catalysts, have been summarized in a review published in 2012 by Heravi and Hashemi.[2f] We wish also to point out that the present review shortly describes the origin and the biological and/or pharmacological properties of the examined natural compounds, but does not cover the use of the S.-M. reaction in the synthesis of fragments of natural products that have not yet been employed in the total synthesis of these natural products. 


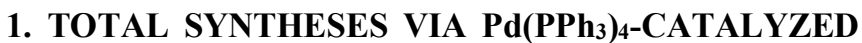 SUZUKI-MIYAURA (S.-M.) CROSS-COUPLING REACTIONS}

$\mathrm{Pd}\left(\mathrm{PPh}_{3}\right)_{4}$ is a commercially available compound, which is commonly used as catalyst precursor in S.-M. reactions, even it is an air- and moisture sensitive complex. Moreover, the products of $\mathrm{Pd}\left(\mathrm{PPh}_{3}\right)_{4}$-catalyzed S.-M. reactions involving the use of aryl halides as electrophiles sometimes have been found to be contaminated by biaryl products where an aryl group derives from the $\mathrm{PPh}_{3}$ ligand of the catalyst precursor via an aryl-aryl exchange reaction between the Pd center and the phosphane ligand in the intermediates $\mathrm{Pd}(\mathrm{II})$ complexes.[36] It should also be noted that $\mathrm{Pd}\left(\mathrm{PPh}_{3}\right)_{4}$ exists in solution primarily as complex $\mathrm{Pd}\left(\mathrm{PPh}_{3}\right)_{3},[37]$ which unfortunately does not feature the optimal catalytic activity of $\mathrm{PdL}_{2}$ species ( $\mathrm{L}=$ tertiary phosphane) present in the most widely accepted catalytic cycle for the S.-M. reaction. However, despite these drawbacks, as illustrated in this section, $\mathrm{Pd}\left(\mathrm{PPh}_{3}\right)_{4}$ continues to be widely employed as a catalyst precursor in S.-M. reactions involved in total syntheses of natural products.

Table 1 lists the structures and the literature data on the isolation of the naturally-occurring compounds that have been synthesized in the period January 2010-December 2013 by using $\mathrm{Pd}\left(\mathrm{PPh}_{3}\right)_{4}$-catalyzed S.-M. reactions. These natural substances include: methyl $(5 Z, 8 Z, 10 E, 12 E, 14 Z)$ eicosapentenoate (1), which was isolated from the red algae Lithothamnion coralloides; [38] protectin D1 (2), an antiinflammatory and proresolving metabolite of docosahexaenoic acid (22:6, $\mathrm{n}=3$, DHA); [39]meridianins $\mathrm{G}$ (3) and A (4), two indole alkaloids isolated from the tunicate Aplidium meridianum;[40] the diterpene oxepane 5, which was isolated from the leaves of Montanoa tomentosa (Asteraceae); [41] the pentacyclic pyrrolic alkaloid lamellarin $\mathrm{S}$ (6), which was isolated from the Australian tunicate Didemnum sp.;[42] (+)-vertine (7) an alkaloid isolated from the wild flowering shrub Heimia salicifolia (Lythraceae)[43a] and the plant Decodon verticillatus (Lythraceae);[43b] gymnopusin (8), a phenanthrene derivative isolated from the orchid Bulbophyllum gymnopus (Orchidaceae),[46a] whose revised structure[44b] is shown in Table 1; the cytotoxic quinoline alkaloid camptothecin (9), first isolated from the Chinese plant Camptotheca acuminate (Cornaceae);[45] camalexin (10), a cruciferous phytoalexin, which was first isolated from Camelia sativa and Arabidopsis thaliana (Brassicaceae); [46] the macrocyclic bis(bibenzyl) compound 11, which was isolated in 1984 from the liverwort Plagiochila acantophylla subsp. japonicas;[47] rhuschalcone VI (12), a potent antiplasmodial bischalcone isolated for the first time from the root bark of Rhus pyroides (Anacardiaceae); [48] the marine alkaloid hyrtinadine A (13), a cytotoxic bisindole derivative isolated from the Okinawan marine sponge Hyrtios sp.; [49] lamellarin -20-sulfate (14), isolated from an unidentified ascidian collected from the Arabian sea; [50] cassiarin F (15), a tetracyclic alkaloid, which was isolated from the flowers of
Cassia siamea (Fabaceae);[51] arcyriarubin A (16) a bisindolyl maleimide isolated from the fruiting bodies of the slime mold;[52] arcyriaflavin A (17), a bisindole alkaloid isolated from the marine ascidian Eudistoma sp.;[53] clausines C (18) and R (19), two carbazole alkaloids isolated from the bark of Clausena excavate (Rutaceae); $[54,55]$ the cytotoxic carbazole clauraila A (20) isolated from the roots of Clausena harmandiana (Rutaceae); [56 ]the antibiotic polyketide (-)-aurafuron A (21) isolated from the myxobacterium Stigmatella aurantiaca DW4/3-1;[57] (-)hamigeran B (22), a tricyclic compound isolated from the poecilosclerid sponge Hamigera tarangaensis; [58] the rearranged diterpene microstegiol (23) isolated from Salvia microstegia (Lamiaceae); [59] (+)-herboxidiene (24), a potent phytotoxic polyketide isolated from Streptomyces chromofuscus A7847;[60] the marine ladder-frame polyether toxin (-)-brevenal (25), which was identified in a laboratory culture of the marine dinoflagellate Karenia brevis[61a] and was found to bind to a previously unreported site on mammalian sodium channels;[61b] amorphastilbol (26), a compound isolated from a Robinia pseudoacacia var. umbraculifer (Fabaceae) seed extract[62a] and from Amorpha nana (Fabaceae)[62b] and was shown to exhibit antimicrobial[62b] and antidiabetic properties;[62c] cladoacetals A (27) and B (28), two benzofused dioxabicyclo[4.2.1]nonene derivatives isolated from fermentation cultures of an unidentified fungicolous isolate; [63] oteromycin (29), a novel antagonist of endothelin receptor first isolated from fungus strains MF 5810 and MF 5811;[64] isobongkreic acid [(E)-30], a fatty triacid which was obtained from the fermentation of Pseudomonas cocovenants; [65] bongkreic acid [(Z)-30], an anti-apoptotic agent produced by Burkholderia gladioli pathovar cocovenants (formerly Pseudomonas cocovenants) (Burkhoderiaceae);[66] vialinin A (terrestrin A) (31), a terphenyl compound isolated from the dry fruiting bodies of the mushroom Telephora vialis, which was shown to possess potent inhibitory activity of TNF- $\alpha$ production from RBL2113 cells; [67] sauristolactam (32), an alkaloid first isolated from the extracts of the aquatic weed Saururus cernuus,[68a] which was found to be active against a variety of tumor cells;[68b] carbazomadurin A (33) a polysubstituted carbazole alkaloid isolated from the microorganism Actinomadura madurae 2808-SV1;[69] (+)-carbazomadirin B (40), a neuronal cell-protecting carbazole alkaloid isolated from A. madurae 2808-SV1;[69,76] the potent antimitotic agent leiodermatolide (34), a macrolide isolated from the deep-water marine sponge Leiodermatium sp.; $[70](R)-$ trichostatin (35a), an antibacterial metabolite isolated from strains of the bacterial species Streptomyces hygroscopicus; [71a] (R)-trichostatic acid (35b), a compound isolated from $S$. sioyaensis, which was reported to induce differentiation of leukemia cells;[71b] prekinamycin (36), a metabolite produced by $S$. murayamensis mutant MC2;[72] 3-methoxy-2,5-diphenylcyclohexa-2,5-dien-1,4-dione (37), an ortho-quinone isolated from common coelomycetous soil fungi Phoma sp., which is an inhibitor of parasite cyclic GMP-dependent protein kinase;[73] ecteinascidin 743 (38), 
an extremely potent antitumor agent isolated from the Caribbean tunicate Ectinascidia turbinata; [74] $(S, 5 Z, 8 E, 10 E)$-12-hydroxyheptadeca-5,8,10-trienoic acid (39), a co-product of the pathway leading to thromboxane $A_{2}$ from $\mathrm{PGH}_{2}$, a metabolite of cyclooxygenase;[75] (+)gregatin B (41), a phytotoxic metabolite produced by the Deuteromycete fungus Phialophora gregata adzukicola, a causal agent of brown stem rot in adzuki beans;[77] rodgersinol (42), a 2-arylpropanol isolated from the aerial parts of Rodgersia podophylla (Saxifragaceae), which was found to exhibit significant inhibitory effect on iNOS and COX-2 expression in LPS-activated macrophages;[78] dictyodendrin B (43), a tyramine-based pyrrolocarbazole alkaloid isolated from the marine sponge Dictyodendrilla verongiformis, which was shown to completely inhibit telomerase;[79] benzo[j]fluoranthene-4,9-diol (44), a polyketide produced from the mantis-associated Daldinia eschschlolzii (Ascomycota, Xylariaceae); [80] and michellamine B (45), an axially chiral biaryl compound originally isolated from tropical liana Ancistrocladus korupensis (Ancystrocladaceae), which was shown to be a strong anti-HIV-1 and anti-HIV-2 agent.[8]

\section{TABLE 1 HERE}

Table 2 illustrates the $\mathrm{Pd}\left(\mathrm{PPh}_{3}\right)_{4}$-catalyzed S.-M. crosscoupling reactions employed in the total syntheses of the natural compounds listed in Table 1 . In particular, Table 2 shows the experimental conditions and yields of these reactions.

\section{TABLE 2 HERE}

The $\mathrm{Pd}\left(\mathrm{PPh}_{3}\right)_{4}$-catalyzed S.-M. reaction between $(E)-1,2-$ dichloroethene (B1) and the boronic acid, which was obtained by mild hydrolysis of the MIDA-protected boronate ester A1[121] with $1 \mathrm{M}$ aq. $\mathrm{NaOH}$, was a step of a convergent synthesis of methyl $(5 Z, 8 Z, 10 E, 12 E, 14 Z)$ $5,8,10,12,14$-eicosapentenoate (1) which was published in 2011.[82] The S.-M. cross-coupling reaction (entry 1, Table 2) provided compound $\mathbf{C 1}$ in $70 \%$ yield.[82] A subsequent Sonogashira reaction between compound $\mathbf{C 1}$, which was obtained in $70 \%$ yield from the Suzuki reaction, and 1alkyne 46 gave dienediyne $\mathbf{4 7}$, which was converted into the target compound by stereoselective reduction with $\mathrm{Zn}(\mathrm{Cu} / \mathrm{Ag})[122]$ in the presence of a catalytic amount of TMSCl in methanol (Scheme 2).[82]

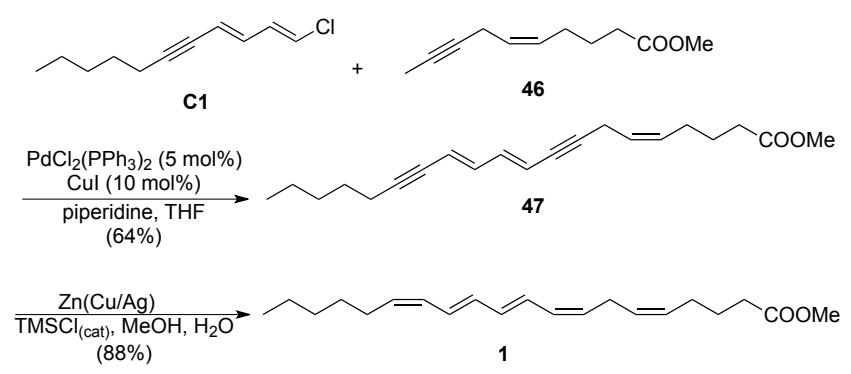

Scheme 2. Synthesis of compound 1 from dienyl chloride C1

In 2011, compound $\mathbf{C 2}$, an advanced intermediate in the total synthesis of the anti-inflammatory and proresolving agent protectin D1 (2), was synthesized in a satisfactory yield by $\mathrm{Pd}\left(\mathrm{PPh}_{3}\right)_{4}$-catalyzed $\mathrm{S}$.-M. reaction between the disiamylborane derivative A2 and vinyl iodide B2 (entry 2, Table 2).[83] (Z)-Enyne 50, the acetylenic precursor to $\mathbf{A 2}$, was prepared from alcohol $\mathbf{4 8}$ via a 10 -step reaction sequence involving the asymmetric epoxydation of racemic alcohol 49 (Scheme 3). [83]

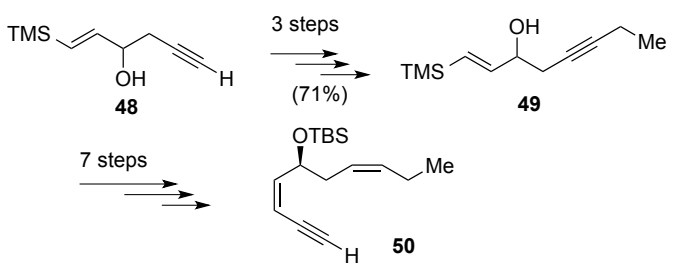

Scheme 3. Synthesis of enyne $\mathbf{5 0}$

On the other hand, vinyl iodide B2 was prepared by using a Wittig reaction between aldehyde $\mathbf{5 1}$ and the ylid obtained from phosphonium iodide 52, which gave enantiomerically pure compound $\mathbf{5 3}$ in $94 \%$ yield (Scheme 4).[83]

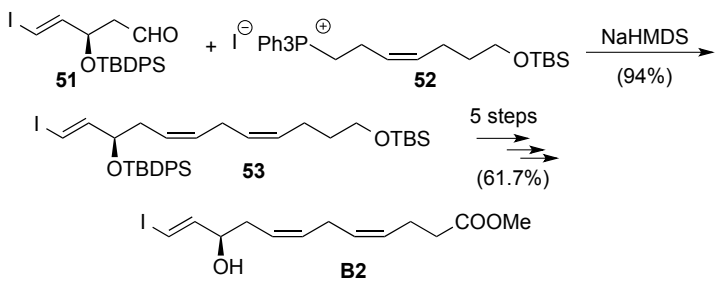

Scheme 4. Synthesis of compound 53, a precursor to B2

In the same year, Müller and co-workers employed the one-pot Masuda borylation-S.-M. coupling sequence for concise total syntheses of meridianins G (3) and A (4).[84] Remarkably, the typical catalyst for Masuda borylations, $\mathrm{PdCl}_{2}$ (dppf),[123] failed to give the required organoboron reagents A3 and A4 in a good yield. Nevertheless, these reagents, which were employed in the reactions of entries 3 and 4 of Table 2, were prepared in good yields by treatment of the corresponding 3-iodo- $1 H$-indole-1-carboxylates, 54 and 55, respectively (Figure 1), with 4,4,5,5tetramethyldioxaborolane (56) (Figure 1) in dioxane in the presence of $\mathrm{Et}_{3} \mathrm{~N}$ and a catalytic amount of $\mathrm{Pd}\left(\mathrm{PPh}_{3}\right)_{4}$.

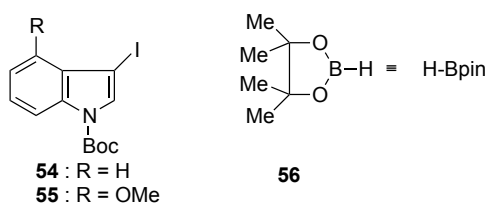

Figure 1. Structures of compounds 54-56 
Crude compounds A3 and A4 were then reacted with 2amino-4-chloropyrimidine (B3) yielding meridianin G (3) and compound $\mathbf{C} \mathbf{3}$ in 73 and $77 \%$ yield, respectively (entries 3 and 4, respectively, Table 2).[84] Demethylation of C3 with pyridine hydrochloride[124] provided meridianin A (4) in $85 \%$ yield (Scheme 5). [84]

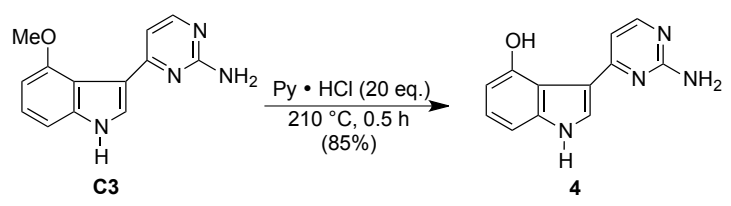

Scheme 5. Demethylation of compound C3

Still in 2011, compound C4, an early intermediate in the synthesis of $(+)\left(2^{\prime} S, 3^{\prime} R\right)$-zoapatanol (5), was synthesized in $81 \%$ yield by Raghvan and Babu using the $\mathrm{Pd}\left(\mathrm{PPh}_{3}\right)_{4}-$ catalyzed reaction between alkenyl triflate $\mathbf{B} 4$ and the 9alkyl-9-BBN derivative A5 (entry 5, Table 2). The latter compound was prepared by hydroboration of 1-alkene $\mathbf{5 7}$ (Figure 2) with 9-borabicyclo[3.3.1]nonane (9-BBN-H) dimer.[85]

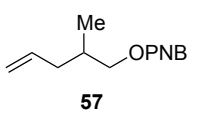

Figure 2. Structure of 1-alkene $\mathbf{5 7}$

On the other hand, compound 61, an advanced intermediate in the synthesis of $\mathbf{5}$, was prepared in $72 \%$ yield by $\mathrm{Pd}\left(\mathrm{PPh}_{3}\right)_{4}$-catalyzed coupling of $(Z)$-alkenyl iodide $\mathbf{6 0}$ with organoborane 59 and concomitant deprotection of the ethoxyethyl ether protecting group (Scheme 6). Compound 59 was in turn obtained by hydroboration of 1-alkene $\mathbf{5 8}$ with (9-BBN-H) (Scheme 6). [85]

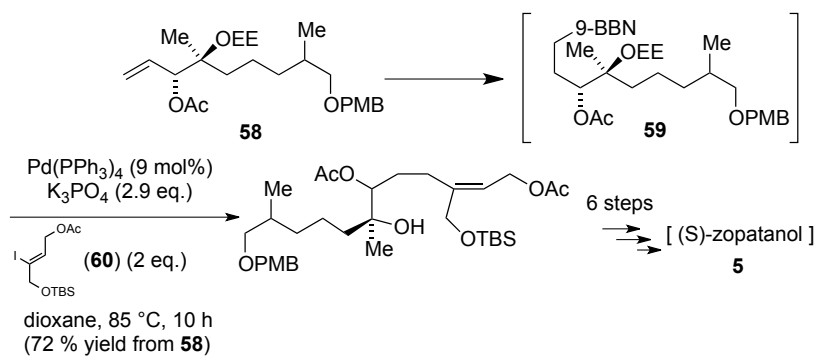

Scheme 6. Synthesis of (S)-zoapatanol (5) from compound 58

The first total synthesis of lamellarin $S$ (6) was accomplished in 2011 by Banwell and co-workers via a route in which compound $\mathbf{C 5}$, a key intermediate, was prepared in $92 \%$ yield by S.-M. cross-coupling of the key pyrrolic buiding block B5 with boronate ester A6 (entry 6, table 2).[86] Bromination of C5 with NBS followed by a Mitsunobu reaction of the resulting compound 62 with $\beta$ phenethyl alcohol 63 gave compound 64 in a high yield.
Microwave-assisted $\quad \mathrm{Pd}\left(\mathrm{PPh}_{3}\right)_{4}$-catalyzed cross-coupling reaction of 64 with boronic acid 65 then gave pyrrole 66 in $67 \%$ yield (Scheme 7). Finally, a subsequent $\mathrm{Pd}(\mathrm{OAc})_{2-}$ catalyzed decarboxylative arylation of carboxylic acid 67,[125] which was derived from 66, provided the pentacyclic compound $\mathbf{6 8}$, which by cleavage of all five isopropyl ether units gave lamellarin S (6) (Scheme 7). [86]

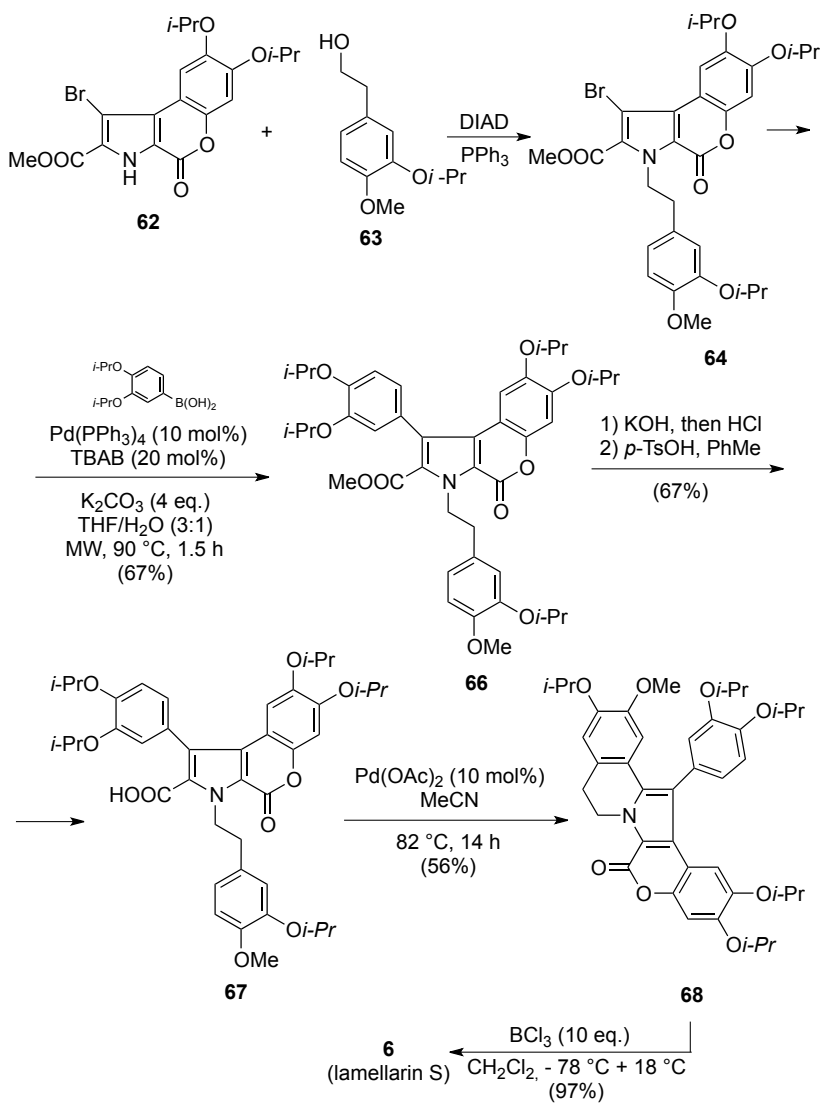

Scheme 7. Synthesis of lamellarin S (6) from compound 62

Lamellarin L 20-sulfate (14) had previously been synthesized from compound 69 (Figure 3), which in turn was prepared via a six-step reaction sequence that commenced with the $\mathrm{Pd}\left(\mathrm{PPh}_{3}\right)_{4}$-catalyzed coupling of bistriflate $\mathbf{B 6}$ with boronic acid A7. As shown in entry 7 of Table 2, this reaction occurred in $74 \%$ yield. [87]<smiles></smiles>

Figure 3. Structure of compound 69

A more advanced intermediate in the synthesis of $\mathbf{6 9}$, compound 72, was prepared in $95 \%$ yield by the $\mathrm{Pd}\left(\mathrm{PPh}_{3}\right)_{4-}$ 
catalyzed cross-coupling reaction of triflate $\mathbf{7 0}$ with 2 equiv of boronic acid 71 (Scheme 8). [87 ]

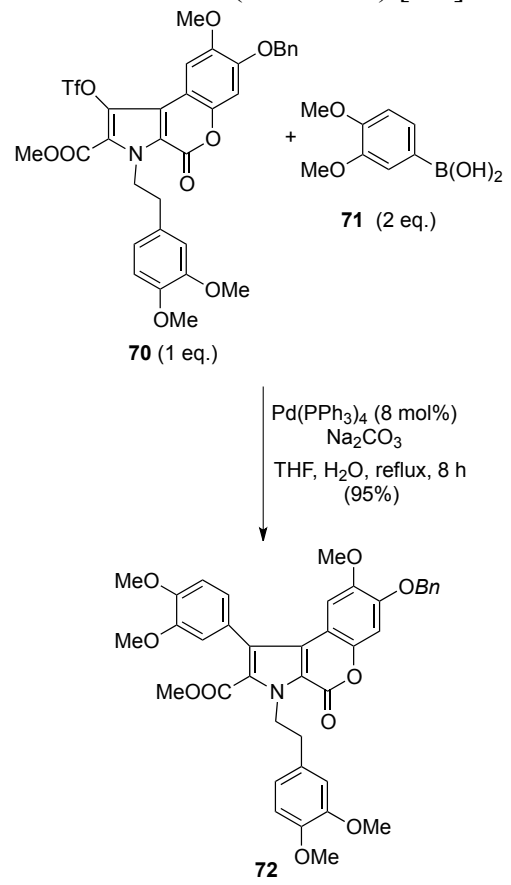

Scheme 8. Synthesis of compound $\mathbf{7 2}$ from triflate $\mathbf{7 0}$

In 2012, the S.-M. reaction between boronate $\mathbf{A 8}$ and quinolizidone $\mathbf{B} 7$ to give $\mathbf{C 7}$ (entry 8 , Table 2) was used as a key step of an asymmetric total synthesis of (+)-vertine (7).[88] Compound B7 was obtained via a condensation reaction between pelletierine $[(R)-73]$ and 6iodoveratraldehyde (74) (Figure 4). [88]

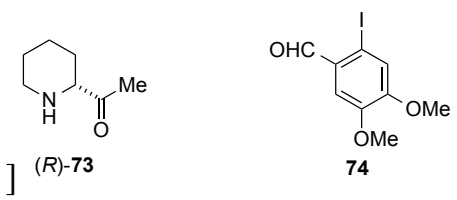

Figure 4. Structures of compounds $(R)-73$ and $74 \mathrm{~A}$

Again in 2012, Snieckus and co-workers demonstrated that the originally assigned structure for gymnopusin was incorrect and reported a total synthesis of this natural product possessing the revised structure $\mathbf{8}$ by using compound C8 (Table 2) as a key intermediate.[89 ]Biaryl C8 was prepared in $90 \%$ yield by S.-M. reaction of boronic acid A9 with bromophenyl carbamate $\mathbf{B 8}$ (entry 9, Table 2). The remote anionic Fries rearrangement of $\mathbf{C 8}$ by using an excess of LDA in refluxing THF and the subsequent methylation of the resulting compound gave the biaryl amide $\mathbf{7 5}$, which on treatment with BuLi provided phenanthrol 76 (Scheme 9). Methylation of $\mathbf{7 6}$ delivered compound 77, which was found to be unstable and therefore was immediately treated with $\mathrm{BCl}_{3}$ to afford gymnopusin (8) in an excellent yield (Scheme 9).[89]

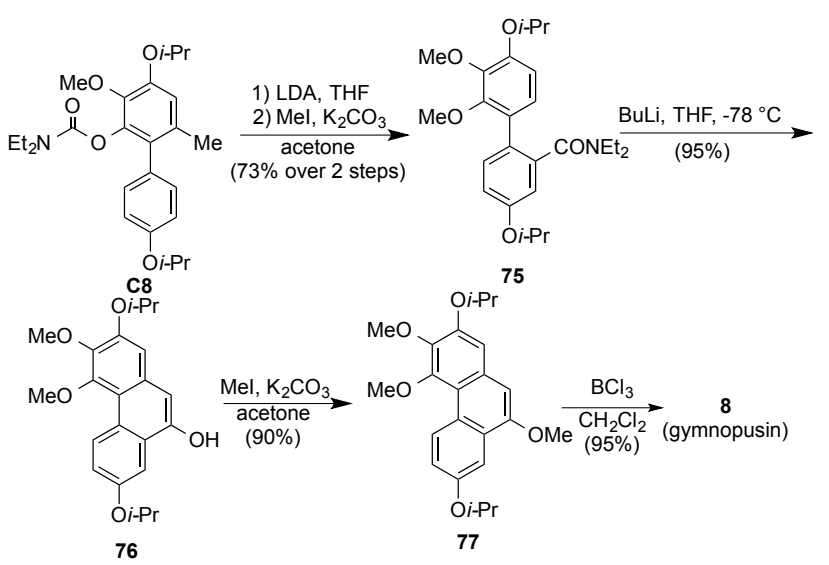

Scheme 9. Synthesis of gymnopusin (8) from compound C8

In 2013, Zhang and co-workers described a concise formal synthesis of camptothecin (9) in which a key step was the S.-M. reaction illustrated in entry 10 of Table 2.[90] The crude organoboron derivative $\mathbf{A 1 0}$ employed in this reaction was synthesized by $\mathrm{PdCl}_{2}(\mathrm{dppf})$-catalyzed boronation of heteroaryl chloride 78 (Figure 5) with bis(pinacolato)diboron (79) in DME in the presence of KOAc. Compound A10 was then converted to the corresponding boronic acid by treatment with $2 \mathrm{M} \mathrm{Na} \mathrm{CO}_{3}$ and this organoboron reagent was directly used in the $\mathrm{Pd}\left(\mathrm{PPh}_{3}\right)_{4}$-catalyzed reaction with chloride B9. A subsequent two-step reaction sequence allowed to convert the cross-coupling product $\mathbf{C 9}$ into the cyclized derivative 80, which, according to the literature,[126] was a precursor to camptothecin (9). Figure 5 shows the structures of compounds 78-80.
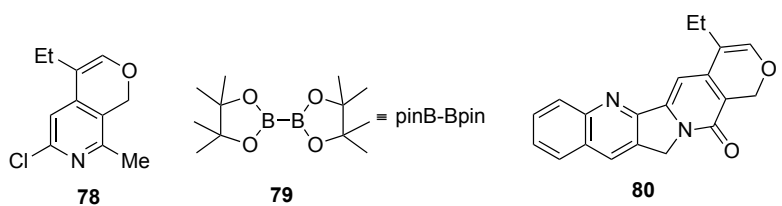

Figure 5. Structures of compounds 78-80

In the same year, Müller and co-workers reported a onepot, high-yielding synthesis of camalexin (10) that involved the cross-coupling reaction between crude boronate $\mathbf{A 3}$ and 2-bromothiazole (B10) (entry 11, Table 2).[91] Interestingly, the reaction conditions of this reaction caused the conversion of A3 into the corresponding boronic acid as well as the $N$ deprotection of the cross-coupling product.[91]

Abegaz and co-workers had previously synthesized compound $\mathbf{C 1 0}$ by S.-M. reaction of boronate ester A11 with bromochalcone B11 (entry 12, Table 2).[92] Methyl ketone 81, which was obtained by deprotection of $\mathbf{C 1 0}$ was then converted into compound $\mathbf{8 3}$ by solvent-free aldol condensation with anisaldehyde (82) in the presence of $\mathrm{NaOH}$. Finally, bichalcone $\mathbf{8 3}$ was demethylated by treatment with 6 equiv of $\mathrm{BBr}_{3}$ in $\mathrm{CHCl}_{3}$ to give 
rhuschalcone VI (12) in 39.2\% overall yield from C10 (Scheme 10).[92]
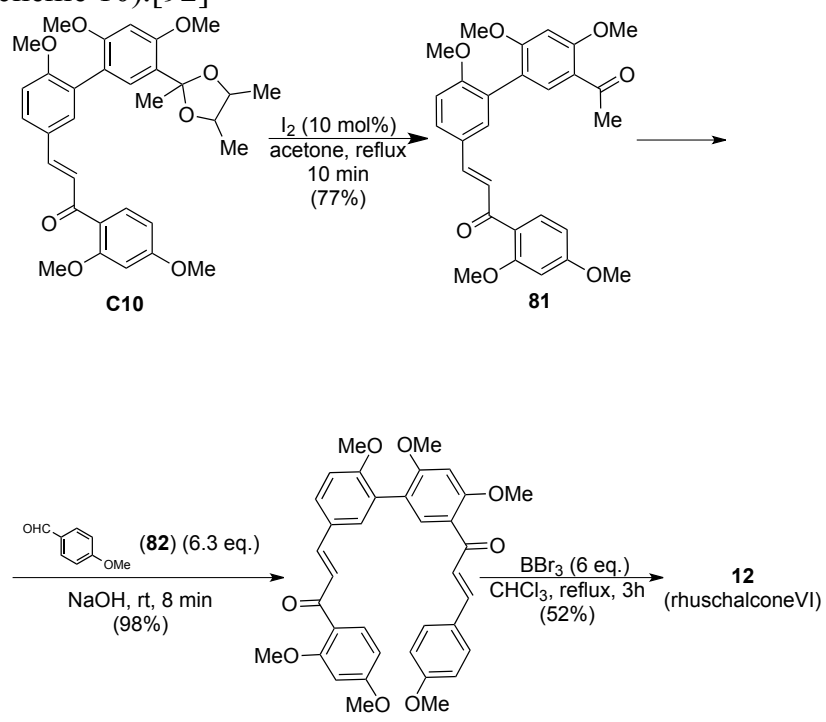

Scheme 10. Synthesis of rhuschalone VI (12) from compound $\mathbf{C 1 0}$

In 2011, González-Zamora and co-workers accomplished an interesting total synthesis of plagiochin D (11), a macrocyclic bis(bibenzyl) compound, in which compound C11 containing rings $\mathrm{B}, \mathrm{D}$ and $\mathrm{C}$ of the natural product, was obtained in $86 \%$ yield by $\mathrm{Pd}\left(\mathrm{PPh}_{3}\right)_{4}$ catalyzed reaction of boronic acid A12 with 2-(benzyloxy)-4-(2-bromo-5isopropoxyphenethyl)-1-isopropoxybenzene (B12) (entry 13, Table 2).[93] An intramolecular $\mathrm{S}_{\mathrm{N}} \mathrm{Ar}$ reaction involving compound 84, which was obtained from C11 via a 3-step reaction sequence, provided the 16-membered ring derivative 85 in $86 \%$ yield (Scheme 11). Finally, reductive deamination of the amine derivative, which was obtained by catalytic reduction of $\mathbf{8 5}$, followed by removal of the isopropyl groups furnished plagiochin D (11) in a good yield from 84 (Scheme 11). [93]

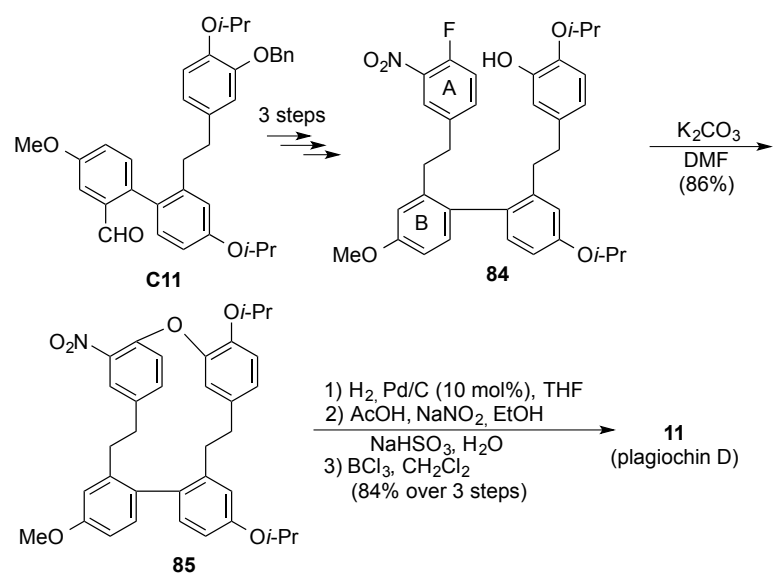

Scheme 11. Synthesis of of plagiochin D (11) from compound C11
In the same year, Müller and co-workers carried out a concise synthesis of the marine alkalod hyrtinadine A (13) which involved the preparation of compound $\mathbf{C 1 2}$ by the Masuda borylation-S.-M. coupling illustrated in entry 14 of Table 2. [94] Demethylation of $\mathbf{C 1 2}$ with 12 equiv of $\mathrm{BBr}_{3}$ in $\mathrm{CH}_{2} \mathrm{Cl}_{2}$ provided hyrtinadine $\mathrm{A}$ in $78 \%$ yield (Scheme 12). [94]

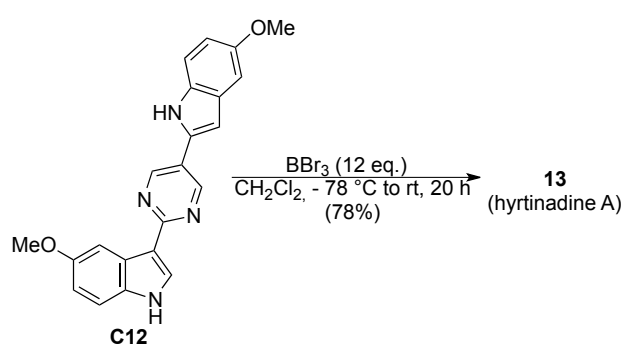

Scheme 12. Synthesis of hyrtinadine A (13) by demethylation of $\mathbf{C 1 2}$

Again in 2011, Morita and co-workers employed the S.M. coupling illustrated in entry 15 of Table 2 for the construction of the biaryl unit of cassiarin F (15), an alkaloid showing potent antiplasmodial activity against Plasmodium falciparum in vitro.[95] Key steps of the total synthesis of 15,[95] which involved 8 steps, were a nucleophilic aromatic substitution and a Houben-Hoesch type cyclization.[127] In the latter reaction compound $\mathbf{8 6}$ was treated with a 1: 1 mixture of sulfuric acid and $\mathrm{AcOH}$ at $60{ }^{\circ} \mathrm{C}$ to give the tetracyclic compound $\mathbf{8 7}$ in $30 \%$ yield (Scheme 13). The subsequent tris- $O$-demethylation of $\mathbf{8 7}$ by treatment with iodocyclohexane in refluxing DMF[128] gave 15 in $90 \%$ yield (Scheme 13).[95]

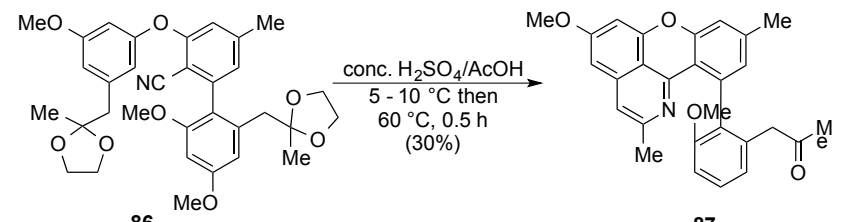

86

87

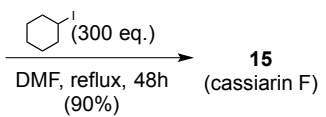

Scheme 13. Synthesis of cassarin F (15) from compound 86

A year earlier, a synthesis of arcyriarubin A (16) was accomplished by Wang and Liu via $\mathrm{Pd}\left(\mathrm{PPh}_{3}\right)_{4}$-catalyzed S.M. reaction of boronic acid A15 with dibromomaleimide (B15) (entry 16, Table 2).[96] A 3-step reaction sequence allowed the conversion of the cross-coupling product, C14, into 16 in $66.8 \%$ yield. It was also established that treatment of 16 with 1 equiv of $\mathrm{Pd}(\mathrm{OAc})_{2}$ in refluxing $\mathrm{AcOH}$ provided arcyriaflavin (17) in 72\% yield (Scheme 14).[96] 

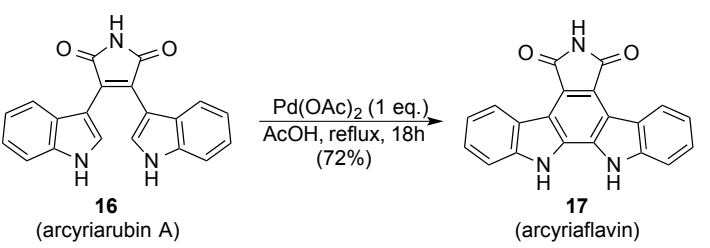

Scheme 14. Synthesis of arcyriaflavin (17) from arcyriarubin (16)

In 2011, Ren and co-workers synthesized clausine C (18) by S.-M. cross-coupling reaction of iodotriazene B16 with triazene boronic acid $\mathbf{A 1 6}$ followed by treatment of the resulting crude biaryl triazene with $\mathrm{BF}_{3} \cdot \mathrm{Et}_{2} \mathrm{O}$ (entry 17, Table 2).[97] The same procedure was the employed to prepare the carbazole derivative $\mathbf{C 1 5}$ in $90 \%$ yield from A16 and B17 (entry 18, Table 2). Demethyl of $\mathbf{C 1 5}$ with $\mathrm{BBr}_{3}$ afforded clausine R (19) in 68\% yield (Scheme 15).[97] Moreover, treatment of $\mathbf{C 1 5}$ with DIBAL-H followed by reaction of the resulting crude product with a solution of Dess-Martin periodinane in $\mathrm{CH}_{2} \mathrm{Cl}_{2}$ at $0{ }^{\circ} \mathrm{C}$ gave clauraila $\mathrm{A}$ (20) in $72 \%$ yield (Scheme 15).[97]

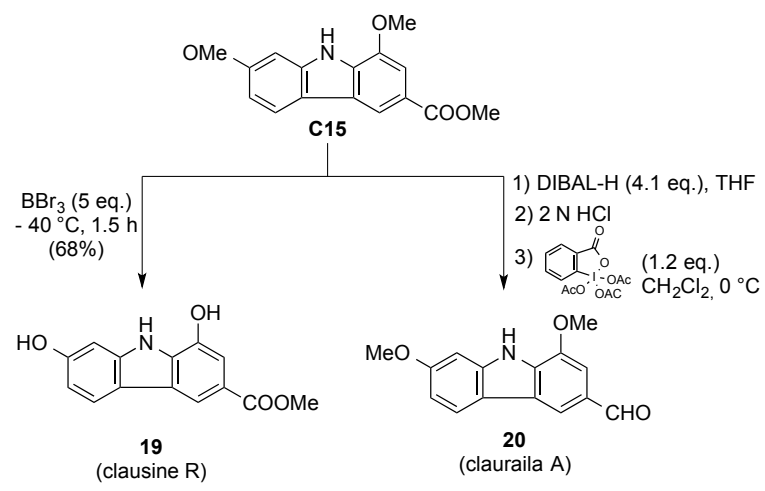

Scheme 15. Synthesis of clausine R (19) and clauraila A (20) from compound $\mathbf{C 1 5}$

In 2012, Hartmann and Kalesse reported the first total synthesis of (-)-aurafuron A (21).[98] As shown in the retrosynthetic analysis of this $3(2 H)$-furanone illustrated in Scheme 16, compound $\mathbf{8 8}$ was a key intermediate in which the $\mathrm{C} 4-\mathrm{C} 5$ bond was built via an aldol reaction between ethyl ketone $\mathbf{8 9}$ and an aldehyde generated at C5. On the other hand, the C9-C10 connection was established by using a $\mathrm{Pd}\left(\mathrm{PPh}_{3}\right)_{4}$-catalyzed S.-M. reaction between pinacol boronate A17 and vinyl iodide B18. As shown in entry 19 of Table 2, this coupling, which was performed at room temperature in $2-5 \mathrm{~h}$ by using TlOEt as the base, gave the required compound $\mathbf{C 1 6}$ in $68 \%$ yield. [98]

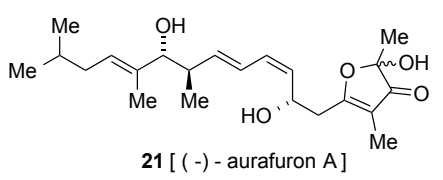

$\sqrt{7}$

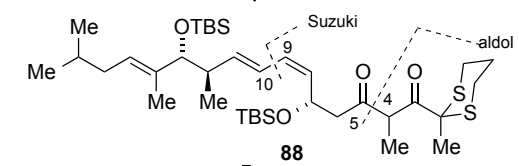

$\mathfrak{l}$

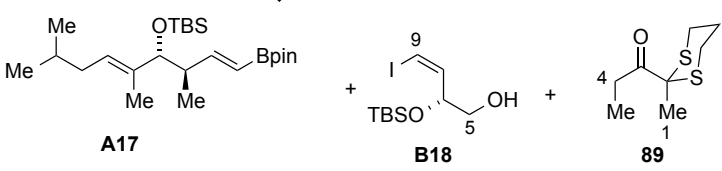

Scheme 16. Retrosynthetic analysis of (-)-aurafuron A (21)

More recently, Jiang and co-workers developed a concise, efficient and enantioselective formal synthesis of (-)hamigeran B (22).[99] Compound C17, which had been previously converted to 22 in 5 steps,[129] was prepared almost in quantitative yield by $\mathrm{Pd}\left(\mathrm{PPh}_{3}\right)_{4}$-catalyzed coupling of isopropenyl boronate A18 with alkenyl bromide B19 in a mixture of $\mathrm{EtOH}$, water and toluene at $90{ }^{\circ} \mathrm{C}$ in the presence of $\mathrm{Na}_{2} \mathrm{CO}_{3}$ as the base (entry 20, Table 2).[99] The key steps of this formal synthesis, which was free of protecting groups, involved an intermolecular Pauson-Kand reaction and a reductive Claisen rearrangement, which allowed the construction of the chiral quaternary carbon of the natural product.[99]

Taj and Green had previously employed the $\mathrm{Pd}\left(\mathrm{PPh}_{3}\right)_{4-}$ catalyzed S.-M. reaction of alkenyl boronate A18 with naphthyl bromide B20 to prepare compound C18, an early precursor to racemic microstegiol (23).[100] The crosscoupling reaction, which was performed in a mixture of DME and water in the presence of $\mathrm{LiCl}$ and by using $\mathrm{K}_{2} \mathrm{CO}_{3}$ as the base, gave compound $\mathbf{C 1 8}$ in $80 \%$ yield (entry 21, Table 2).[100]

In 2011 , a stereoselective convergent synthesis of (+)herboxidiene (24) was accomplished by Gosh and $\mathrm{Li}$ assembling the core structure of this natural compound by a S.-M. reaction between chiral pinacol boronate A19 and $(E, 2 R, 5 S, 6 S)$-vinyl iodide $\mathbf{B 2 1}$ in the presence of $5 \mathrm{~mol} \%$ $\mathrm{Pd}\left(\mathrm{PPh}_{3}\right)_{4}$ (entry 22, Table 2).[101a] The Pd-catalyzed crosscoupling reaction provided compound $\mathbf{C 1 9}$ in $71 \%$ yield, which was then converted into $\mathbf{2 4}$ via a 3-step reaction sequence involving treatment of $\mathbf{C 1 9}$ with $0.16 \mathrm{M} \mathrm{HCl}$ in $\mathrm{MeOH}$, epoxidation of the resulting alcohol 90 with $t$ $\mathrm{BuOOH}$ in $\mathrm{CH}_{2} \mathrm{Cl}_{2}$ at $-78{ }^{\circ} \mathrm{C}$ in the presence of a catalytic amount of $\mathrm{VO}(\mathrm{acac})$ which gave oxirane 91 and subsequent reaction of this compound with 10 equiv of $\mathrm{Me}_{3} \mathrm{SnOH}$ (Scheme 17).[101a] 


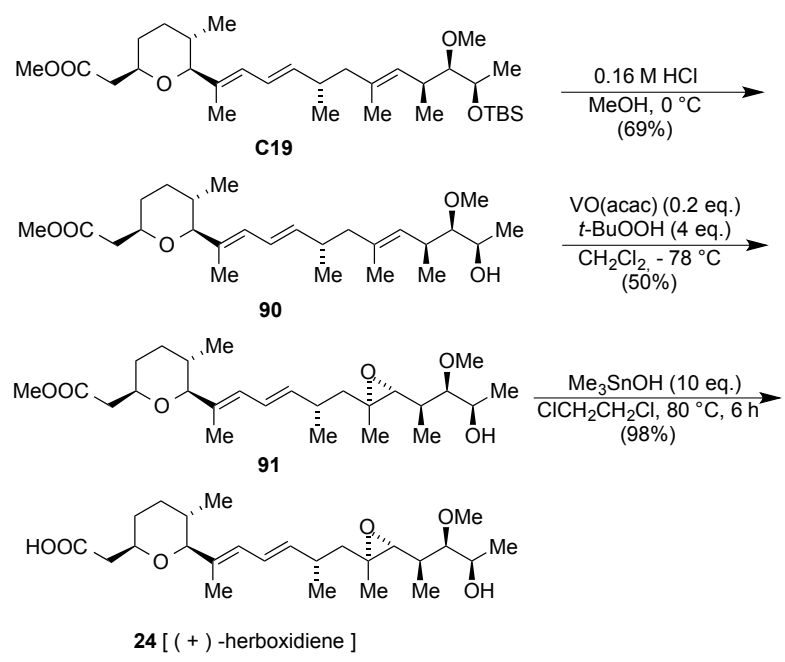

Scheme 17. Synthesis of (+)-herboxidiene (24) from compound $\mathbf{C 1 9}$

In the same year, Romea, Urpi and co-workers described a total synthesis of $\mathbf{2 4}$ via a multistep reaction sequence that involved hydroboration of alkyne 92 with catecholborane in the presence of a catalytic amount of dicyclohexylborane followed by hydrolysis of the resulting boronate.[101b] The $\mathrm{Pd}\left(\mathrm{PPh}_{3}\right)_{4}$-catalyzed coupling of the resulting boronic acid 93 with vinyl iodide 94 in a mixture of THF and water in the presence of $\mathrm{Tl}_{2} \mathrm{CO}_{3}$ as the base provided compound 95 in $91 \%$ yield. Finally, removal of the silyl protecting group and epoxidation of the resulting bis-homoallylic alcohol followed by saponification of the ethyl ester group furnished (+)herboxidiene (24) in 49.3\% yield from 95 (Scheme 18). [101b]
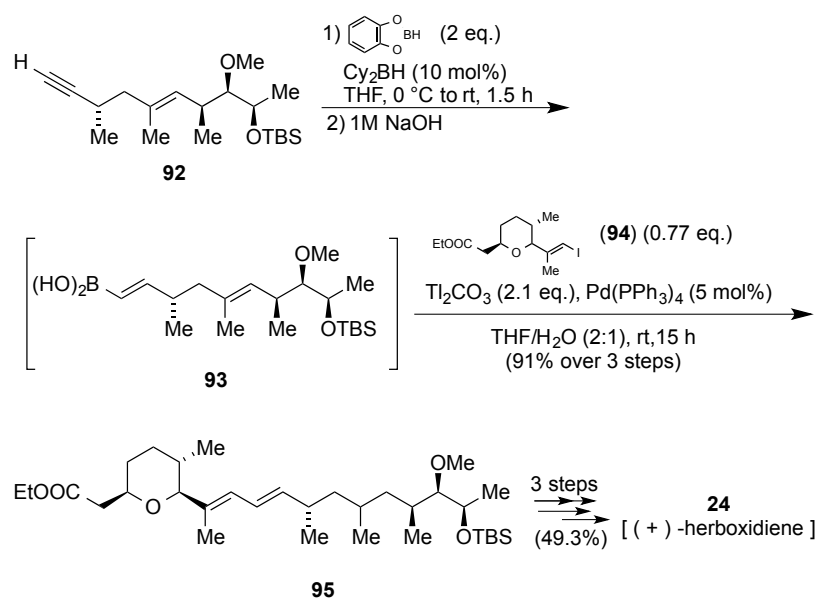

Scheme 18. Synthesis of (+)-herboxidiene (24) from 1alkyne 92

In the same year, Ebine, Fuwa and Sasaki described a concise total synthesis of (-)-brevenal (25) and accomplished the preparation of the DE-ring fragment 97 of this pentacyclic polyether through the $\mathrm{Pd}\left(\mathrm{PPh}_{3}\right)_{4}$-catalyzed S.-M. reaction illustrated in entry 23 of Table 2.[102] In particular, the DE-ring enol phosphate 97 was prepared from the cross- coupling product $\mathbf{C 2 0}$ in $76.2 \%$ yield via a 4-step reaction sequence and enol phosphate B22, which was the electrophile used in the S.-M. reaction with alkylborane A20, was synthesized from lactone $\mathbf{9 6}$ as shown in Scheme 19.[102]

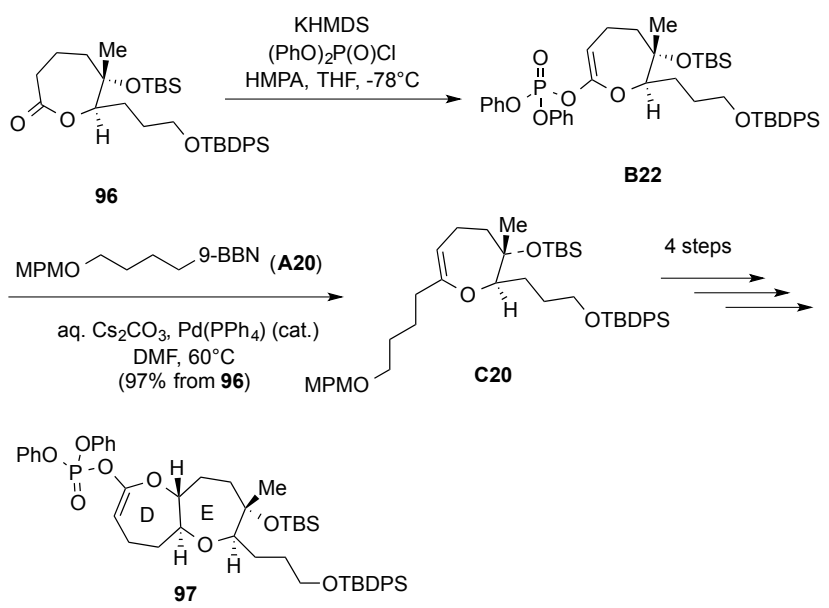

Scheme 19. Synthesis of compound 97 from lactone 96

Compound 97 was then employed as the electrophile in the $\mathrm{Pd}\left(\mathrm{PPh}_{3}\right)_{4}$-catalyzed S.-M. reaction with the alkylborane generated by hydroboration of the AB-ring exocyclic ether 98 with 9-BBN-H. This reaction (Scheme 20) gave the endocyclic enol ether $\mathbf{1 0 0}$ in $93 \%$ yield as a single stereoisomer, which was an advanced precursor to 25.[102]

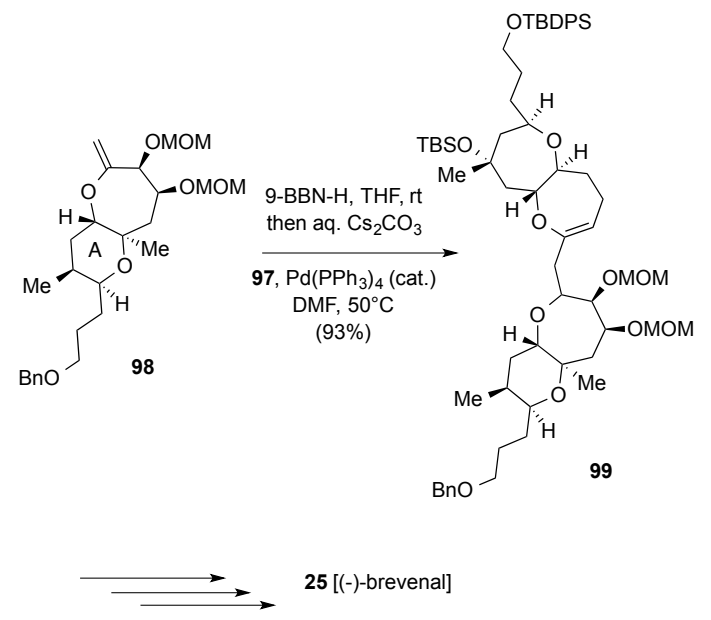

Scheme 20. Synthesis of (-)-brevenal (25) via $\mathrm{Pd}\left(\mathrm{PPh}_{3}\right)_{4}$ catalyzed S.-M. reaction between compound 97 and the alkylborane generated from 98

In 2012, Ham and co-workers synthesized (E)-styryl bromide B23 starting from methyl 3,5-dihydroxybenzoate (100) and employed this bromo derivative as electrophile in a $\mathrm{Pd}\left(\mathrm{PPh}_{3}\right)_{4}$-catalyzed reaction with potassium phenyltrifluoroborate (A21).[103] The coupling, which was performed under the conditions reported in entry 24 of Table 2, gave compound C21, which was then converted 
into amorphastilbol (26), a natural compound having a Cgenarylated 4'-dihydroxyveratrol structure, by treatment with 10-camphorsulfonic acid (CSA) in methanol at room temperature (Scheme 21).[103]

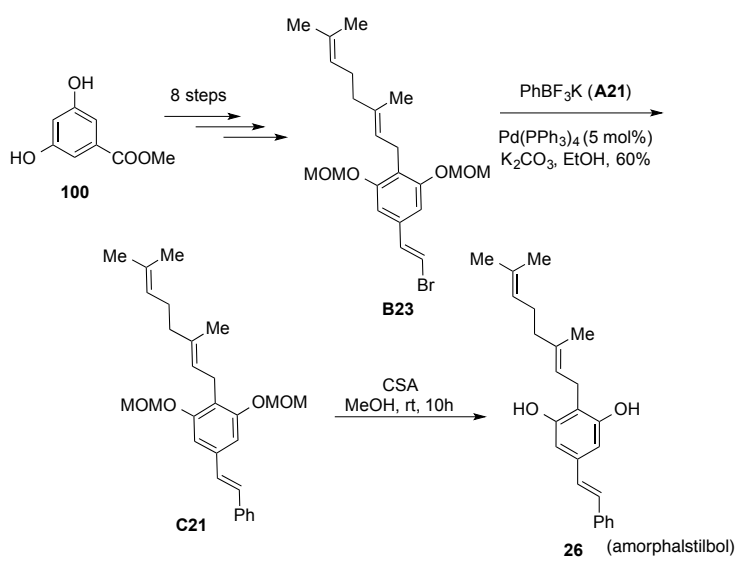

Scheme 21. Synthesis of amorphastilbol (26) from compound 100

In the same year, Hsu and Lin described the first enantioselective syntheses of (+)-cladoacetal A (27) and (-)cladoacetal B (28) in nine and seven steps, respectively.[104] A key feature of the synthesis of 27 was the $\mathrm{Pd}\left(\mathrm{PPh}_{3}\right)_{4-}$ catalyzed reaction between boronic acid $\mathbf{A 2 2}$ and $(Z)$-vinyl bromide B24, which produced compound $\mathbf{C 2 2}$ in $81 \%$ yield (entry 25, Table 2). Compound B24 was in turn prepared from crotonaldehyde (101) using a 6-step reaction sequence in which compound $\mathbf{1 0 3}$ was obtained by Sharpless asymmetric dihydroxylation of dibromoalkene $\mathbf{1 0 2}$ using AD-mix- $\alpha$ (Scheme 22).[104] The developed protocol also involved the selective protection of the hydroxyl group at C2 in $\mathbf{1 0 3}$ followed by inversion of the configuration of the allylic hydroxyl group under Mitsunobu conditions.

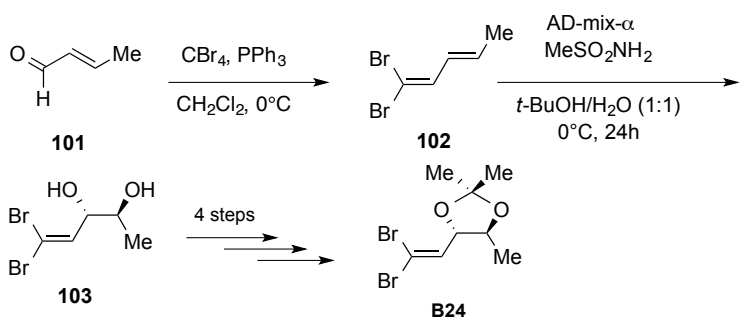

Scheme 22. Synthesis of compound B24 from crotonaldehyde (101)

On the other hand, a key step in the total synthesis of (-)cladoacetal B (28) was the S.-M. coupling of A22 with Z)vinyl bromide B25 (entry 26, Table 2).[104] The latter compound was obtained by protection with 2,2dimethoxypropane (103) of diol $\mathbf{1 0 4}$ as isopropylidene ketal 105 and subsequent hydrogenolysis of the resulting compound 105 by $\mathrm{Pd}$-catalyzed reaction with $\mathrm{Bu}_{3} \mathrm{SnH}$ (Scheme 23).[104]

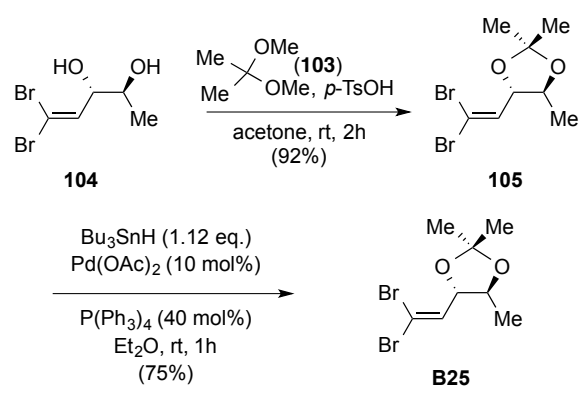

Scheme 23. Synthesis of compound B25 from diol 104

More recently, Uchiro and co-workers investigated the first total synthesis of oteromycin (29), an antagonist of the endothelian receptor,[105] and in this context they synthesized the conjugated tetraene $\mathbf{C 2 4}$ in $72 \%$ yield by the $\mathrm{Pd}\left(\mathrm{PPh}_{3}\right)_{4}$-catalyzed S.-M. reaction of trienyl catecholborane A23 with vinyl iodide B26 (entry 27, Table 2). Oxidation of C24 by using $\mathrm{SO}_{3}$-pyridine complex gave the corresponding aldehyde, which by treatment with $\mathrm{BF}_{3} \cdot \mathrm{Et}_{2} \mathrm{O}$ in $\mathrm{CH}_{2} \mathrm{Cl}_{2}$ at $78{ }^{\circ} \mathrm{C}$, gave the endo-type cyclization product 106 with almost perfect stereoselectivity (Scheme 24). The decalin aldehyde $\mathbf{1 0 6}$ was then used as a key precursor to 29.[105] In this study it was also established that the stereochemistry at C24 position of oteromycin (29) is the $S$-configuration.[105]

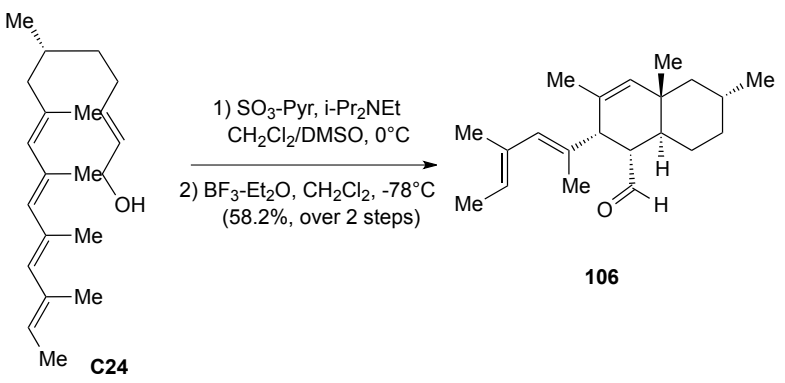

Scheme 24. Synthesis of the decalin aldehyde 106 from compound $\mathbf{C 2 4}$

Ley and co-workers had previously carried out the total syntheses of isobongkreic acid $[(E)-30]$ and bongkreic acid $[(Z)-30]$ on the basis of the retrosynthetic analysis depicted in Scheme 25 in which the target compounds were obtained via a Sonogashira coupling of vinyl iodide $\mathbf{1 0 7}$ with 1-alkyne 108 and compound $\mathbf{C 2 5}$ was an intermediate in the synthesis of the latter compound.[106a] 


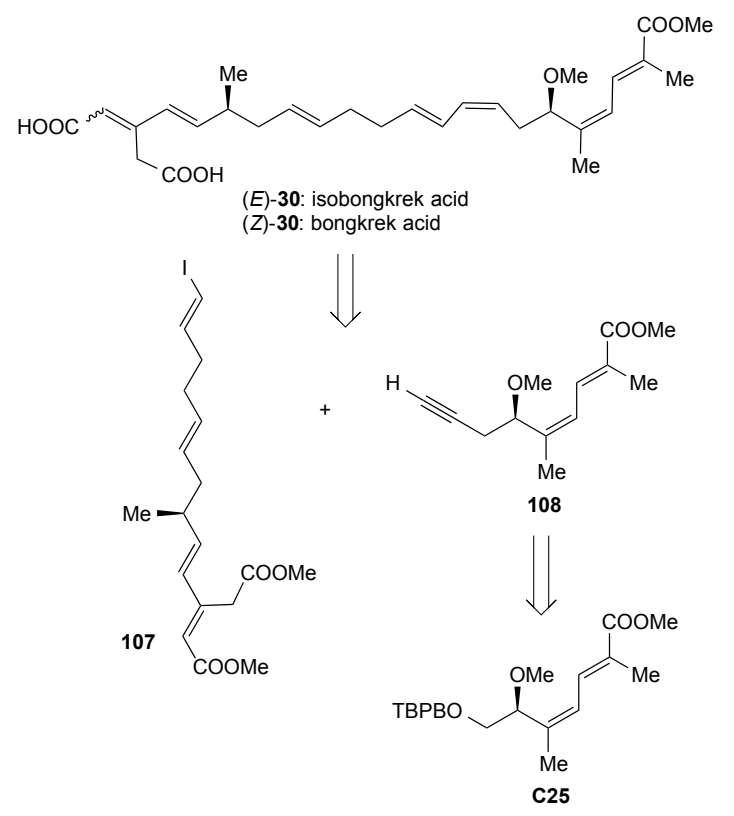

Scheme 25. Retrosynthesis of isobongkreic acid $[(E)-30]$ and bongkreic acid $[(Z)-30]$

As shown in entry 28 of Table 2, compound $\mathbf{C 2 5}$ was obtained in $92 \%$ yield by the S.-M. reaction of vinyl iodide B27 with boronic ester A24, which was carried out under the modified Kishi conditions.[130] Remarkably, only when these conditions involving the use of TlOEt as the base were employed, a complete stereospecific coupling occurred.[106a] It is also likely that the thallium base was employed because of the reported acceleration the counter cation carries on transmetalation.[106b]

In 2010, vialinin A (31), a powerful inhibitor of TNF- $\alpha$ production, was synthesized by Takahashi and co-workers through a series of reactions involving the double S.-M. coupling of bis-triflate B28 with boronic acid A25.[107] The reaction (entry 29, Table 2), which was carried out in the presence of $5.2 \mathrm{~mol} \% \mathrm{Pd}\left(\mathrm{PPh}_{3}\right)_{4}$, gave compound $\mathbf{C 2 6}$ in an excellent yield. Treatment of $\mathbf{C 2 6}$ with 2,3-dichloro-5,6dicyanobenzoquinone (DDQ) in the presence of $p-\mathrm{TsOH}$ in benzene at $50^{\circ} \mathrm{C}$ provided $o$-quinone 109 , which by reduction with $\mathrm{Na}_{2} \mathrm{~S}_{2} \mathrm{O}_{4}$ gave the corresponding catechol 110 (Scheme 26). Compound 111, which was obtained by acylation of 110, underwent reaction with 2.5 equiv of $\mathrm{Pb}(\mathrm{OAc})_{4}$ in benzene at $80{ }^{\circ} \mathrm{C}$ to provide $\mathbf{1 1 2}$ in a high yield. Finally, exposure of $\mathbf{1 1 2}$ to mild acidic conditions gave vialinin A (31) (Scheme 26).[107]
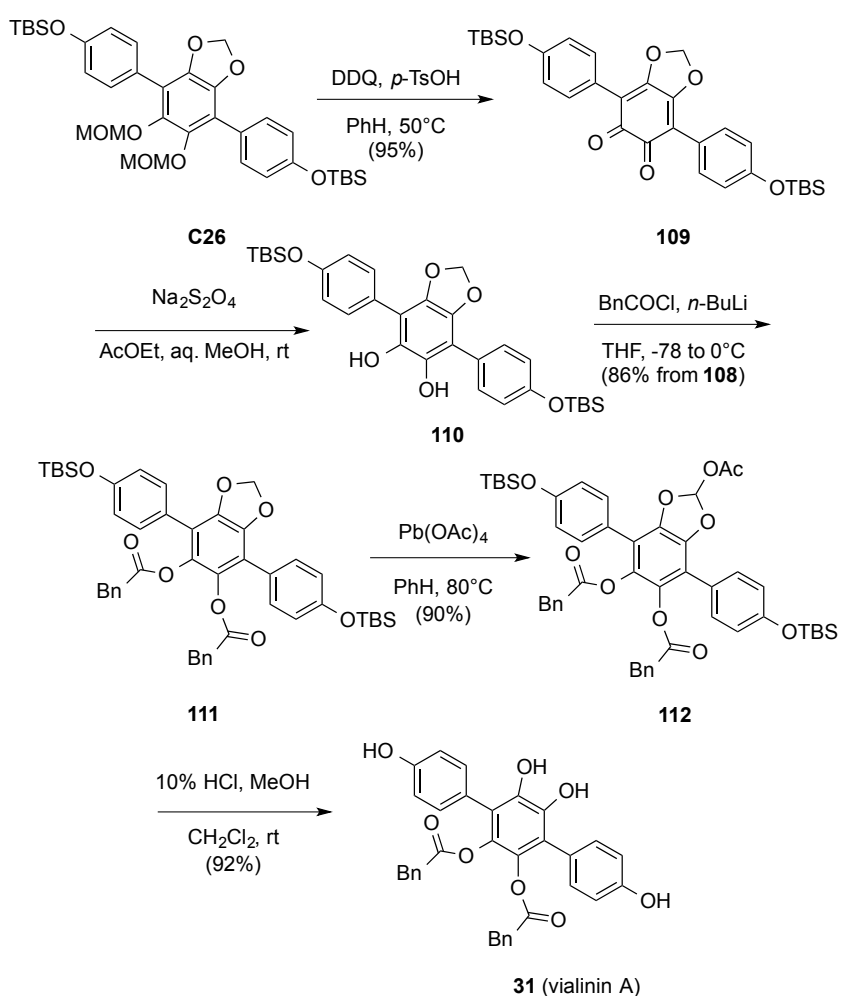

Scheme 26. Synthesis of vialinin A (31) from compound C26

A year later, an efficient and practical synthesis of the naturally-occurring alkaloid sauristolactam (32) was accomplished by Heo and co-workers on the basis of the retrosynthesis shown in Scheme 27 in which a S.-M. coupling/aldol condensation cascade reaction involving boronic acid A26 and isoindolone B29 was a key step.[108]

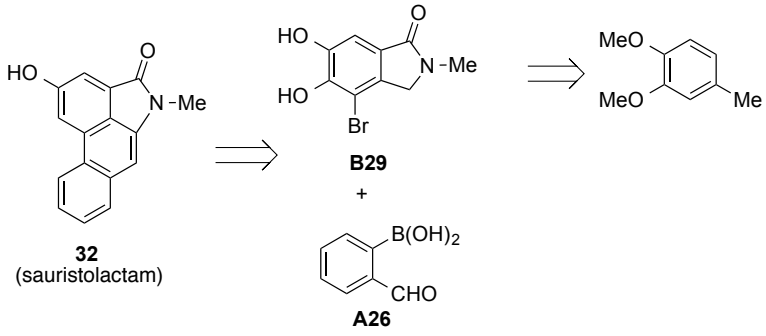

Scheme 27. Retrosynthesis of sauristolactam (32)

As shown in entry 30 of Table 2, the reaction of $\mathbf{B 2 9}$ with A26, which was performed in a mixture of toluene and $\mathrm{EtOH}$ under microwave irradiation in the presence of $4 \mathrm{~mol} \%$ $\mathrm{Pd}\left(\mathrm{PPh}_{3}\right)_{4}$ and 3 equiv of $\mathrm{Cs}_{2} \mathrm{CO}_{3}$, provided 32 in $80 \%$ yield.[108]

In 2010, Choshi, Hibino and co-workers described a total synthesis of the neuronal cell protecting carbazole alkaloid carbazomadurin A (33) in which the $(E)$-alkenyl side chain at the $\mathrm{C} 1$ position of carbazole was introduced by the $\mathrm{Pd}\left(\mathrm{PPh}_{3}\right)_{4}$-catalyzed reaction of pinacol boronate $\mathbf{A 2 7}$ with triflate B30 (entry 31, Table 2).[109] Unfortunately, the detailed experimental conditions of the coupling, which was carried out in DMF using $\mathrm{Na}_{2} \mathrm{CO}_{3}$ as base to provided compound $\mathbf{C 2 7}$ in almost quantitative yield, were not 
reported. Carbazole 115, which was a precursor to B30, was obtained from the 2-allenyl indole intermediate 114 generated by treatment of propargyl indole 113 with TBAF in THF at $80^{\circ} \mathrm{C}$ (Scheme 28). [109]

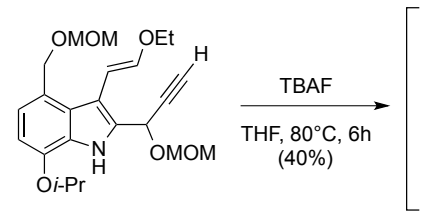

113

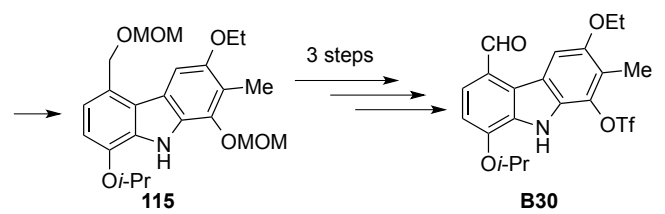

Scheme 28. Synthesis of carbazole triflate B30 from compound 113

In 2012, Fürstner and co-workers reported the first total synthesis of the structurally challenging and biologically highly promising antimitotic agent leiodermatolide (34).[110] Compound C28, an advanced intermediate to 34, was synthesized in $56 \%$ yield by the $\mathrm{Pd}\left(\mathrm{PPh}_{3}\right)_{4}$-catalyzed reaction of boronate A28 with vinyl iodide B31 (entry 32, Table 2). The latter compound was obtained in $72 \%$ yield by intramolecular metathesis of compound $\mathbf{1 1 6}$ in the presence of $40 \mathrm{~mol} \%$ of the molybdenum complex 117 activated with $\mathrm{CH}_{2} \mathrm{Cl}_{2}$ (Scheme 29).[131]
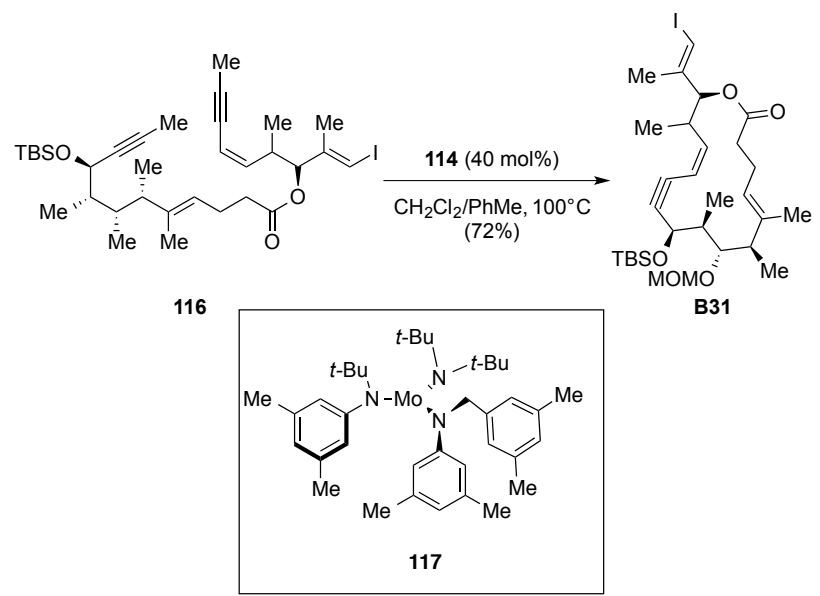

B31

Scheme 29. Synthesis of vinyl iodide B31

Remarkably, this total synthesis allowed for a conclusive assignment of the stereostructure of leiodermatolide.[110

]More recently, Helquist and co-workers accomplished an enantioselective synthesis on a gram scale of the potent histone deacetylase inhibitor $(R)$-trichostatin A (35a).[111] The synthetic intermediate $\mathbf{C 2 9}$ was synthesized by $\mathrm{Pd}\left(\mathrm{PPh}_{3}\right)_{4}$-catalyzed coupling of methyl (E)-3- bromopropenoate (B32) with the organoboron compound A29 followed by saponification (entry 33, Table 2). Compound $\mathbf{A 2 9}$ was in turn prepared by treatment of alkyne 118 (Figure 6) with (-)-Ipc $2 \mathrm{BH}$ in $\mathrm{THF}$ at $0{ }^{\circ} \mathrm{C}$.[111]<smiles>CC#CC(C)[C@H](OC)c1ccc(N(C)C)cc1</smiles>

Figure 6. Structure of alkyne 118

Compound $\mathbf{C 2 9}$ was then treated with DDQ to give $(R)$ trichostatic acid (35b), which was converted to $(R)$ trichostatin (35a) by conversion to a mixed anhydride followed by reaction with $O$-t-butyldimethylsilyl (TBS) hydroxylamine and subsequent $O$-desilylation (Scheme 30).[111 ]

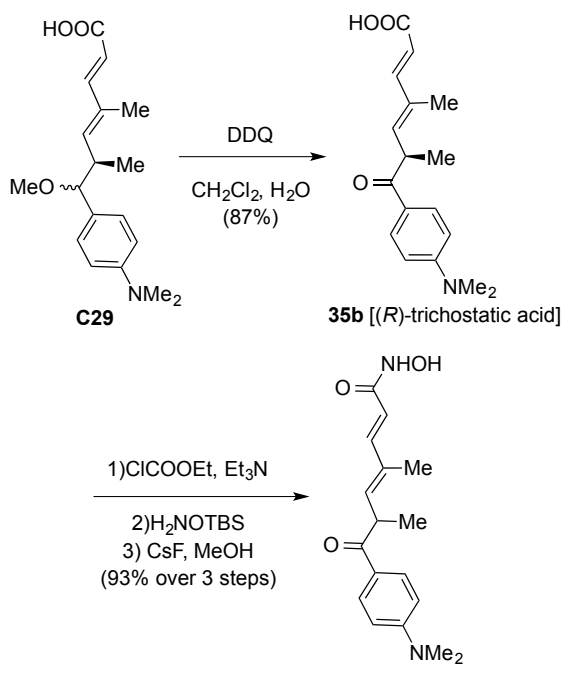

35a $[(R)$-trichostatin $\mathrm{A}]$

Scheme 30. Synthesis of $(R)$-trichostatic acid (35b) and (R)-trichostatin A (35a)

It should be noted that trichostatic acid of unknown absolute configuration is a natural product first isolated from Streptomyces sioyaensis, which was found to induce differentiation of leukemia cells.[132]

In 2011, Kumamoto and co-workers accomplished a total synthesis of the naturally-occurring diazoalkane prekinamycin (36) on the basis of the retrosynthetic analysis illustrated in Scheme 31.[112] 


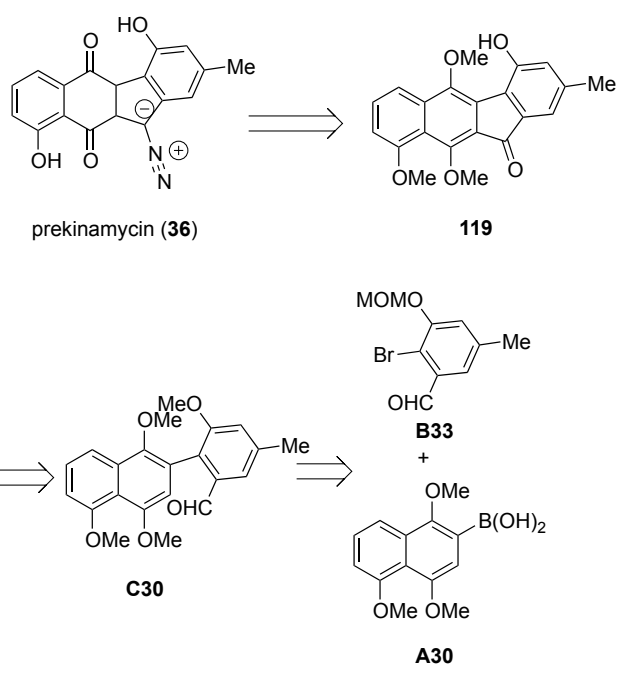

Scheme 31. Retrosynthesis of prekinamycin (36)

As shown in entry 34 of Table 2, compound C30, a precursor to 36, was synthesized in an excellent yield by the reaction of boronic acid A30 with aryl bromide B33 in DME at $90{ }^{\circ} \mathrm{C}$ in the presence of $\mathrm{Na}_{2} \mathrm{CO}_{3}$ as base and $2.7 \mathrm{~mol} \%$ $\mathrm{Pd}\left(\mathrm{PPh}_{3}\right)_{4}$. Aldehyde $\mathbf{C 3 0}$ was then converted into the corresponding carboxylic acid $\mathbf{1 2 0}$ using the system $\mathrm{H}_{2} \mathrm{O}_{2} / \mathrm{NaOH}$. Treatment of $\mathbf{1 2 0}$ with oxalyl chloride in $\mathrm{MeCN}$ at $80{ }^{\circ} \mathrm{C}$ gave crude $\mathbf{1 2 1}$, which was reacted with 9.7 equiv of $\mathrm{AlCl}_{3}$ in $\mathrm{CH}_{2} \mathrm{Cl}_{2}$ at room temperature providing 119 in $81 \%$ yield (Scheme 32). Demethylation of 119 with $\mathrm{BBr}_{3}$ in $\mathrm{CH}_{2} \mathrm{Cl}_{2}$ at $-40{ }^{\circ} \mathrm{C}$ gave tetraol $\mathbf{1 2 2}$, which was converted into hydrazone 123 by treatment with $\mathrm{TsNHNH}_{2}$. Finally, oxidation of 123 with Fetizon's reagent $\left(\mathrm{Ag}_{2} \mathrm{CO}_{3}\right.$ on Celite $\AA$ ) provided prekinamycin (36) in $47 \%$ yield from 123 (Scheme 32).[112]
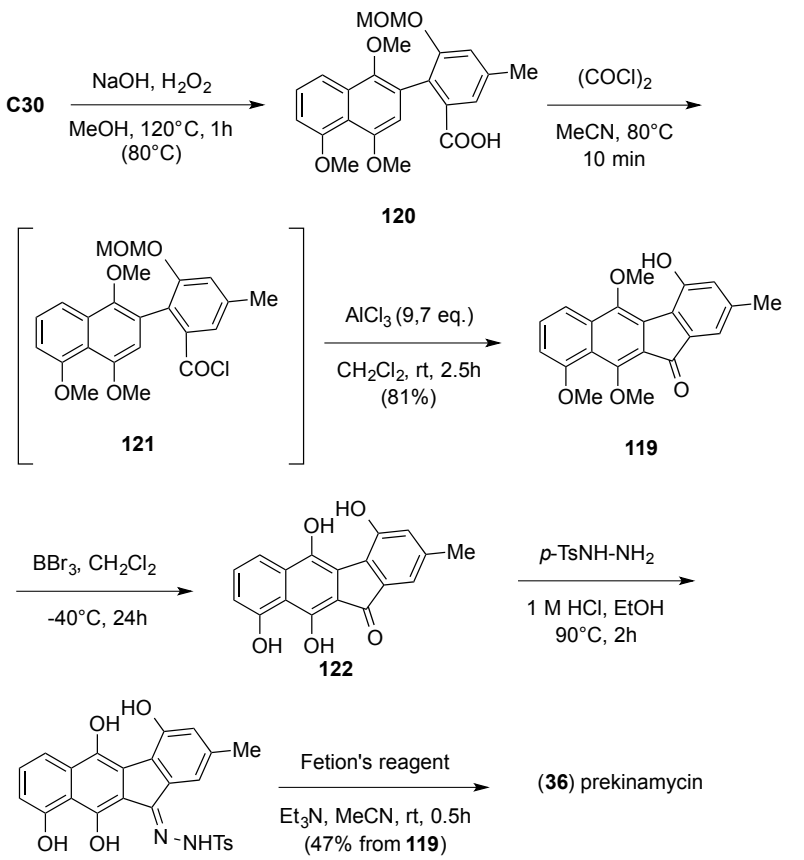

(36) prekinamycin
Scheme 32. Synthesis of prekinamycin (36) from compound $\mathbf{C 3 0}$

In 2013, Nishikawa and co-workers employed the S.-M. reaction illustrated in entry 35 of Table 2, involving boronic acid A31 and the dibromo derivative B34,[73b] to accomplish the synthesis of 3-methoxy-5,6-diphenyl-3,5.dien-1,2-dione (37), an ortho-quinone believed to be a natural product isolated from Phoma sp.[73a] However, the NMR spectra of synthetic $\mathbf{3 7}$ were found to be not identical to those reported for the compound isolated from Phoma sp... $[73 b$

]Still in 2013, Fukuyama and co-workers investigated the synthesis of the architectural complex tetraisoquinoline alkaloid ecteinascidin 743 (trabectedin) (38),[113] which is an antitumor agent of marine origin with peculiar cytotoxic activity in vitro and in vivo in a wide range of tumours.[133] The impressive total synthesis of 38, which was accomplished in 28 steps and $1.1 \%$ overall yield starting from $L$-glutamic acid (129) as a single homochiral source according to the retrosynthetic analysis shown in Scheme 32 ,[113] featured the construction of the B ring of compound 124 via a reaction sequence involving a stereoselective Heck reaction between enamide 121 and the diazonium salt prepared from amine $\mathbf{1 2 6}$, followed by an osmium-mediated dihydroxylation of the resulting compound which gave 1,2diol 125 in 93\% yield based on 121. Enamide 121 was in turn synthesized from $\mathbf{C 3 2}$, the cross-coupling product obtained in $91.6 \%$ yield by the S.-M. reaction between $\mathbf{B 3 5}$ and $\mathbf{A 3 2}$ (entry 36, Table 2). Compound $\mathbf{C 3 2}$ was prepared via a 6-step reaction sequence from diketopiperazine $\mathbf{1 2 8}$ available from $L$-glutamic acid (129) (Scheme 32).[113] 


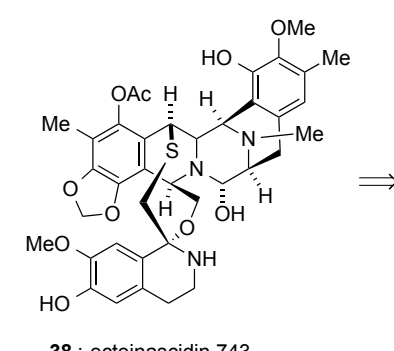

38 : ecteinascidin 743
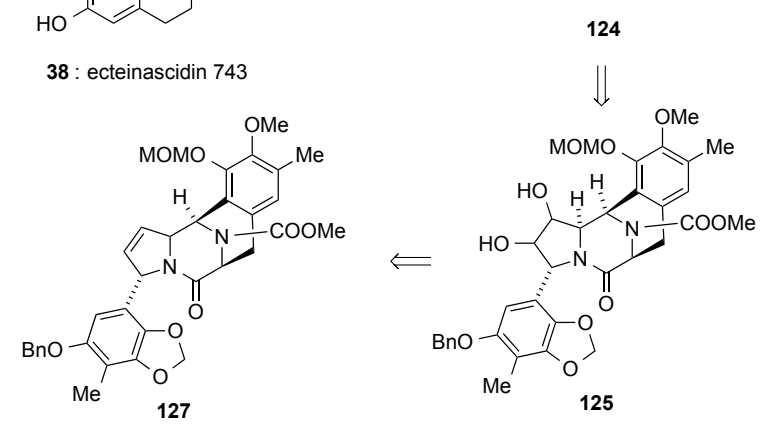

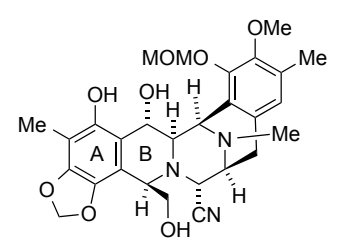

124

$$
126
$$

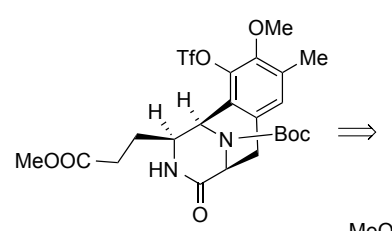

C32<smiles>C=CCCCCCCCCCC(=O)C(=O)O</smiles>

124

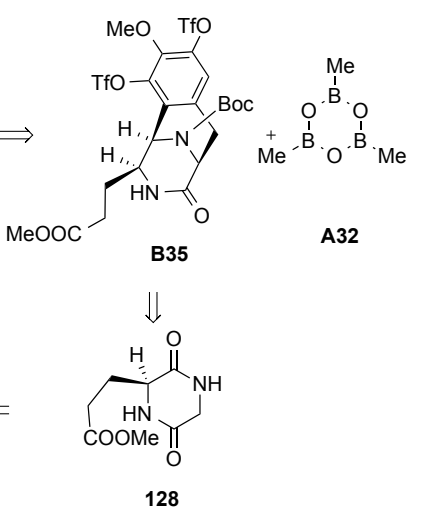

128
Scheme 32. Retrosynthesis of ecteinascidin 743 (38)

The S.-M. reaction between vinylborane $\mathbf{A 3 3}$ and $(E)$ vinyl iodide B36, illustrated in entry 37 of Table 2, was used by Kobayashi and co-workers for the construction of the $(8 E, 10 E)$ moiety of $(S, 5 Z, 8 E, 10 E)$-12-hydroxyheptadeca5,8,10-trienoic acid (12S-HTT) (39).[114] Iodide (S)-B36 was obtained by kinetic resolution of the corresponding racemic compound according to the literature[134] by using the Sharpless asymmetric epoxidation. Compound $\mathbf{C 3 3}$ resulting from treatment of the crude cross-coupling product with TBAF was then converted into $\mathbf{3 9}$ via the series of reactions illustrated in Scheme 33 in which the $5 Z$ double bond of the target compound was constructed by the Wittig reaction of aldehyde $\mathbf{1 3 1}$ with the ylid obtained by treatment of phosphonium iodide $\mathbf{1 3 0}$ with $\mathrm{NaN}(\mathrm{TMS})_{2}$ at $-78{ }^{\circ} \mathrm{C}$ in THF. This reaction provided compound $\mathbf{1 3 2}$ in $62 \%$ yield.[114]
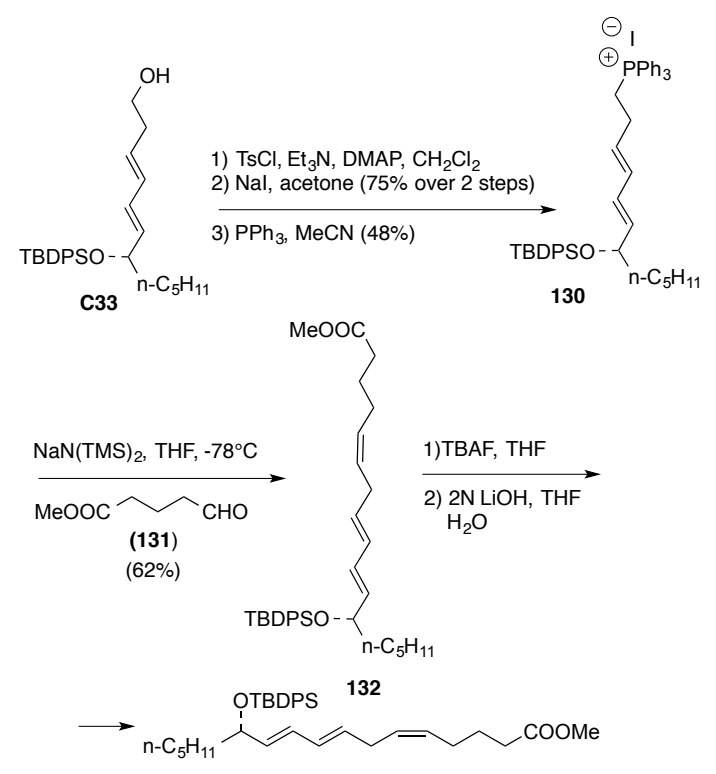

39

Scheme 33. Synthesis of compound (12S-HTT) (39) from dienol C33

Very recently, Coshi, Hibino and co-workers accomplished the total synthesis of $(S)(+)$-carbazomadurin B (40) via a series of 18 reactions in which the preparation of the carbazole ring of the natural product included an allenemediated electrocyclic reaction of the $6 \pi$-electron system involving the indole 2,3-bond.[115] As in the case of the total synthesis of carbazomadurin A (33), the alkenyl chain at the 1-position of the carbazole ring of $\mathbf{4 0}$ was introduced via the $\mathrm{Pd}\left(\mathrm{PPh}_{3}\right)_{4}$-catalyzed S.-M. reaction between the organoboron derivative $\mathbf{A 3 4}$ and triflate $\mathbf{B 3 7}$ that gave compound C34 in 83\% yield (entry 38, Table 2).[115]

In 2013, Kato and coworkers accomplished a total synthesis of (+)-gregatin B (41) by a synthetic approach in which this phytotoxic fungal metabolite was obtained in $80 \%$ yield by the stereoselective $\mathrm{Pd}\left(\mathrm{PPh}_{3}\right)_{4}$-catalyzed reaction of alkenyl boronate $\mathbf{A 3 5}$ with alkenyl iodide $\mathbf{B 3 8}$ under the condition reported in entry 39 of Table 2.[116] The synthesis of $\mathbf{B 3 8}$ was achieved in 8 steps and $29.3 \%$ overall yield from optically active propargyl acetate $\mathbf{1 3 0}$ (Figure 7),[116] which in turn was prepared I 7 steps according to the literature.[135]

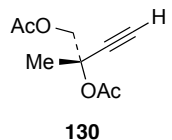

Figure 7. Structure of compound 130

In 2010, Suh and co-workers described the total synthesis of both enantiomers of rodgersinol (42),[117] a 2arylpropanol natural product. The final step of the synthesis of $(S)-42$ consisted of the $\mathrm{Pd}\left(\mathrm{PPh}_{3}\right)_{4}$-catalyzed reaction of aryl iodide $(S)$-B39 having $91 \%$ ee with $(E)$-propenylboronic acid (A36) (entry 40, Table 2). The coupling, which occurred 
with simultaneous removal of the TBS protecting group, provided 42 as a $6.5: 1$ mixture of $E$ and $Z$ stereoisomers. However, the $\mathrm{PdCl}_{2}(\mathrm{MeCN})_{2}$-catalyzed olefin isomerization of the mixture allowed to obtain $(S)-42$ as an exclusive $E$ stereoisomer.[117] It should be noted that Suh and coworkers had previously reported the first synthesis of $(S)$ rodgersinol in seven linear steps in $31 \%$ overall yield[136] and that this synthesis allowed the authors to determine the C-10 absolute configuration of the natural product.

Still in 2010, Ishibashi and co-workers carried out a formal synthesis of the telomerase inhibitory marine pyrrolocarbazole alkaloid dictyodendrin B (43).[118] The synthesis of compound 131, which had previously been employed as a precursor to 43,[137]was accomplished according to the retrosynthetic analysis shown in Scheme 34. [118]
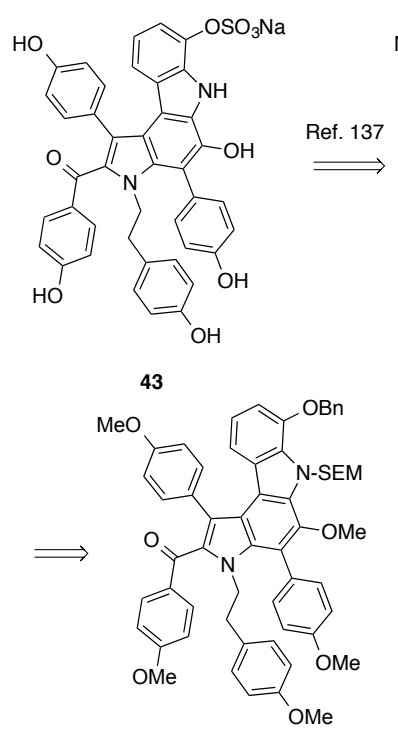

132
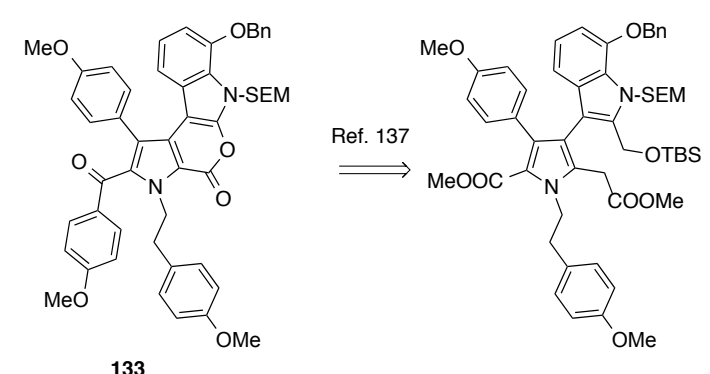

$133 \mathrm{MeO}$

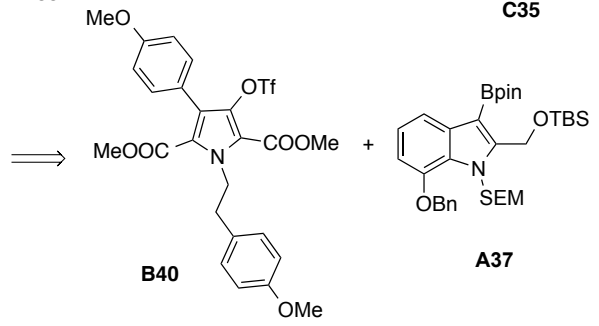

Scheme 34. Retrosynthetic analysis of dictyodendrin B (43)
In particular, compound $\mathbf{C 3 5}$, which was prepared in $72 \%$ yield by $\mathrm{Pd}\left(\mathrm{PPh}_{3}\right)_{4}$-catalyzed S.-M. reaction of triflate $\mathbf{B 4 0}$ with boronate $\mathbf{A 3 7}$ (entry 41, Table 2), was converted in two steps into lactone 133, which provided compound 131 via a 6-step reaction sequence involving the SmI"-promoted pinacol coupling[138] of pyrrole 132.[118] Triflate B40 had previously been synthesized in $78 \%$ yield by $\mathrm{Pd}\left(\mathrm{PPh}_{3}\right.$ (4- $^{-}$ catalyzed monoarylation of bistriflate 134 with 1 equiv of 4methoxyphenylboronic acid (A40) (Scheme 35).[139]

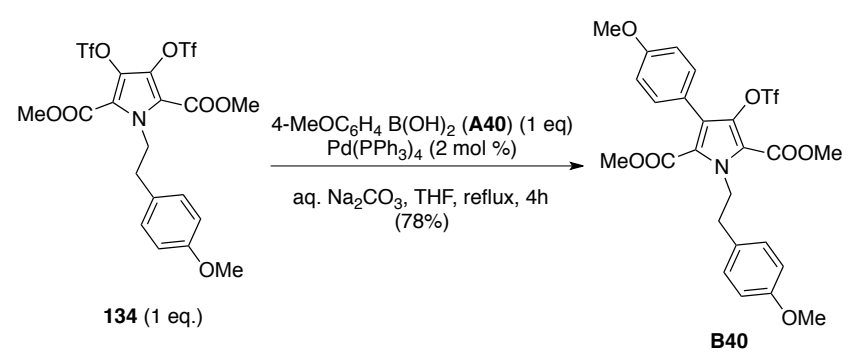

Scheme 35. Synthesis of compound B40 from bistriflate 134

In 2013, Dallavalle and co-workers described the first total synthesis of naturally-occurring benzo[j]fluoranthene4,9-diol (44).[119] It involved the $\mathrm{Pd}\left(\mathrm{PPh}_{3}\right)_{4}$-catalyzed S.-M. reaction between boronate $\mathbf{A 3 8}$ and 2-bromo-6methoxyacenaphthylene-1-carbaldehyde (B41) (entry 42, Table 2) as a crucial step. Treatment of the resulting crosscoupling product, C36, with $\mathrm{Zn} / \mathrm{TiCl}_{4}$ in THF[140] under McMurry conditions, followed by deprotection of the hydroxy groups using pyridine hydrochloride at $140-150{ }^{\circ} \mathrm{C}$ gave compound 44 in 57.8 yield (Scheme 36).[119]
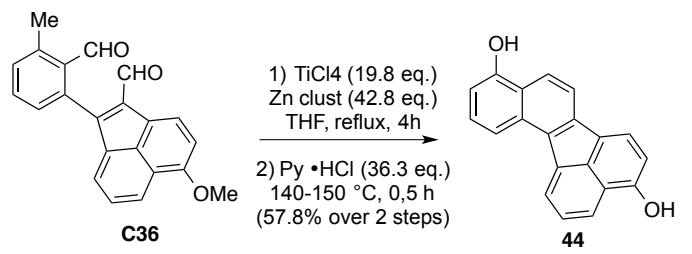

Scheme 36. Synthesis of compound 44 from C36

Still in 2013, Tang and co-workers developed an efficient synthesis of michellamine B (45) from the advanced intermediates 135 and 136 (Scheme 37).[120] Compound 135 was converted into bromide $\mathbf{B 4 2}$ by treatment with $\mathrm{C}_{5} \mathrm{H}_{5} \mathrm{NHBr}_{3}$ in $\mathrm{CHCl}_{3}$ and $\mathrm{AcOH}$ and compound $\mathbf{1 3 6}$ gave boronic acid $\mathbf{A 3 9}$ by bromination with $\mathrm{C}_{5} \mathrm{H}_{5} \mathrm{NHBr}_{3}$ and metal-halogen exchange, followed by treatment with $\mathrm{B}(\mathrm{O}-$ $i \operatorname{Pr})_{3}$ and hydrolysis of the resulting boronic ester. The S.-M. reaction between $\mathbf{B} 42$ and $\mathbf{A 3 9}$ in the presence of a catalytic amount of $\mathrm{Pd}\left(\mathrm{PPh}_{3}\right)_{4}$ gave compound $\mathbf{C 3 7}$ in $84 \%$ yield (entry 43, Table 2). Finally, removal of all benzyl groups of 139 by $\mathrm{Pd} / \mathrm{C}$-catalyzed hydrogenolysis led to compound $\mathbf{4 5}$ in $93 \%$ yield (Scheme 37). [120] 
<smiles>COc1cc(C(=O)c2ccccc2)ccc1-c1ccc(OCc2ccccc2)c2c1CC(C)N(Cc1ccccc1)C2C</smiles>

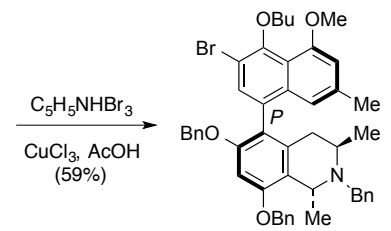<smiles>CCCCOc1cccc2c(OCC)c(OCc3ccccc3)cc(OCC(C)(C)C)c12</smiles>

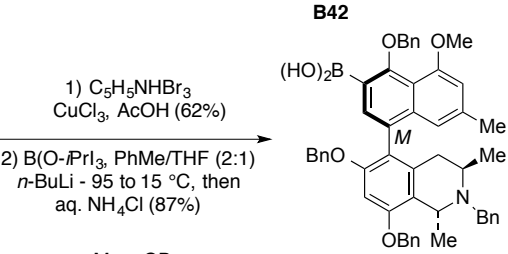

136<smiles>CCCc1c(Br)cc(Br)c2c1C[C@H](C)N(Cc1ccccc1)C2C(C)C</smiles>

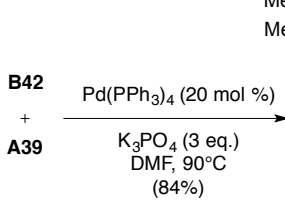

$\mathrm{Me}$

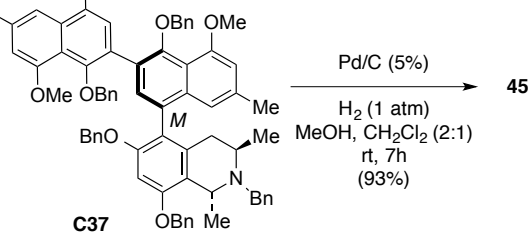

Scheme 37. Synthesis of michellamine B (45) from compounds 135 and 136

\section{TOTAL SYNTHESES VIA S.-M. REACTIONS PROMOTED BY $\mathrm{PdCl}_{2}\left(\mathrm{PPh}_{3}\right)_{2}$ OR A COMBINATION OF $\mathrm{PPh}_{3}$ WITH Pd(OAc) $)_{2}$ OR Pd2 (dba)}

$\mathrm{PdCl}_{2}\left(\mathrm{PPh}_{3}\right)_{2}$ or systems composed by a combination of $\mathrm{Pd}(\mathrm{OAc})_{2}$ with $\mathrm{PPh}_{3}$ have frequently been used as catalyst precursors of S.-M. couplings due to their stability and favourable activity.[141,142] They are known to be readily reduced to active $\operatorname{Pd}(0)$ species by organoboron reagents or $\mathrm{PPh}_{3}$. However, reduction of $\mathrm{PdCl}_{2}\left(\mathrm{PPh}_{3}\right)_{2}$ yields not $\mathrm{Pd}\left(\mathrm{PPh}_{3}\right)_{2}$ but several anionic species in equilibrium of the types $\left[\mathrm{PdCl}_{2}\left(\mathrm{PPh}_{3}\right)_{2}\right]^{2-},\left[\mathrm{PdCl}\left(\mathrm{PPh}_{3}\right)_{2}\right]^{-}$and $\left[\mathrm{Pd}(\mu \mathrm{Cl})\left(\mathrm{PPh}_{3}\right)_{2}\right]^{2-}$ , which are formed in the presence of chloride ions.[143] These species have been thought to undergo oxidative addition more rapidly than does $\operatorname{Pd}\left(\mathrm{PPh}_{3}\right)_{3}$. Similarly, the acetate anions introduced through $\mathrm{Pd}(\mathrm{OAc})_{2}$ give the anionic species $\mathrm{Pd}\left(\mathrm{PPh}_{3}\right)_{2}(\mathrm{OAc})^{-}$in the reduction of $\mathrm{Pd}(\mathrm{OAc})_{2}$ with $\mathrm{PPh}_{3}$ in DMF.[144]

On the contrary, the catalyst system consisting of a combination of $\mathrm{PPh}_{3}$ and $\mathrm{Pd}_{2}(\mathrm{dba})_{3}$, an air stable $\mathrm{Pd}(0)$ compound which is considered as a source of $\operatorname{Pd}(0)$ complexes formed upon interaction with suitable ligands and substitution of dba,[145] has been relatively little used in S.M. reactions to date.[146]

Table 3 lists the structures of the natural products $\mathbf{1 3 7}$ 152 which have been synthesized via S.-M. reactions involving the use of a catalyst precursor consisting of $\mathrm{PdCl}_{2}\left(\mathrm{PPh}_{3}\right)_{2}$ or a combination of $\mathrm{PPh}_{3}$ with $\mathrm{Pd}(\mathrm{OAc})_{2}$ or $\mathrm{Pd}_{2}(\mathrm{dba})_{3}$. Table 3 also reports the literature data on the isolation of these natural products.

\section{TABLE 3 HERE}

Fosfotriecin (137) is a phosphorylated polyene derivative isolated from Streptomyces pulveraceous,[147] which was shown to possess significant activity against tumor cell lines[148a] and antitumor activity against leukemia in vivo.[148b] In 2010, Gao and O'Doherty achieved an enantioselective total synthesis of $\mathbf{1 3 7}$ in 24 steps starting from 2-penten-4-yn-1-ol (153) (Figure 8).[149]

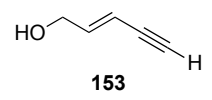

Figure 8. Structure of compound 153

The conjugated $E, Z, Z$-triene moiety of the natural product was introduced with excellent stereoselectivity $(>20: 1)$ by the $\mathrm{Pd}\left(\mathrm{PPh}_{3}\right)_{4}$-catalyzed reaction of vinyl boronate 154 with dienyl iodide 155 in the presence of 3.1 equiv of $\mathrm{Ag}_{2} \mathrm{O}, 5$ mol\% $\mathrm{Pd}_{2}(\mathrm{dba})_{3} \cdot \mathrm{CHCl}_{3}$ and $40 \mathrm{~mol}_{0} \mathrm{PPh}_{3}$. As shown in Scheme 38, the coupling reaction provided compound $\mathbf{1 8 0}$ in $80 \%$ yield. The latter compound was an advanced intermediate in the synthesis of fosfotriecin (137).[149]

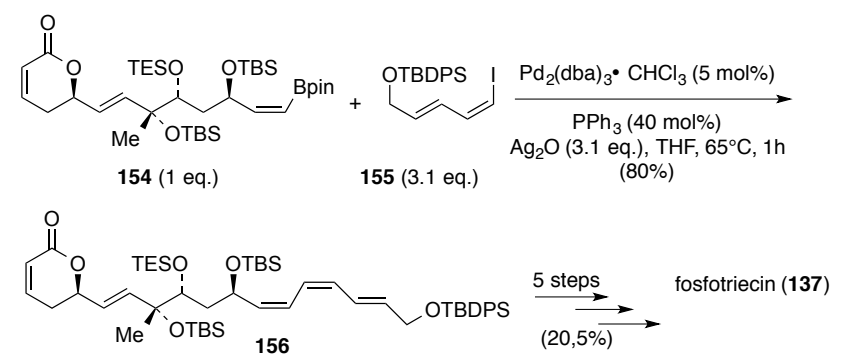

Scheme 38. Synthesis of compound 156, an advanced intermediate in the synthesis of fosfotriecin (137)

Still in 2010, Takahashi and co-workers established the structure of the natural pigment atromentin (138) via a total synthesis based on a double S.-M. reaction and X-ray analysis of the synthetic material thereby obtained.[150] Compound $\mathbf{1 3 8}$ had been isolated from the edible mushroom Thelephora ganbajun[151a] and from the inedible mushrooms T. aurantiotincta $[151 \mathrm{~b}, \mathrm{c}]$ and Hydnellum caeruleum.[151d] The total synthesis of $\mathbf{1 3 8}$ featured the $\mathrm{Pd}(\mathrm{OAc})_{2} / \mathrm{PPh}_{3}$-catalyzed reaction between 2 equiv of boronic acid $\mathrm{A25}$ and dibromobenzene 157 in aqueous propanol at $100{ }^{\circ} \mathrm{C}$ in the presence of $\mathrm{Na}_{2} \mathrm{CO}_{3}$ as the key step (Scheme 39).[150] Acidic hydrolysis of the resulting product 158 and subsequent oxidation with dioxygen in methanol provided compound 138 (Scheme 39). [150]

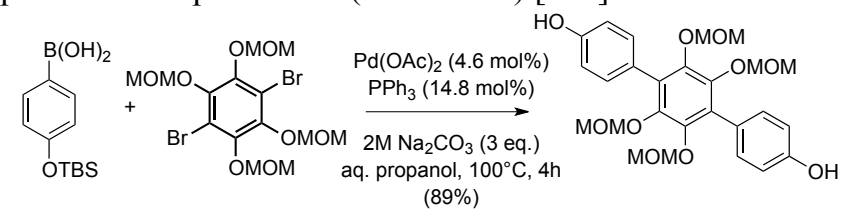

$\begin{array}{llll}\text { A25 (2.5 eq.) } & 157 \text { (1 eq.) } & 158\end{array}$

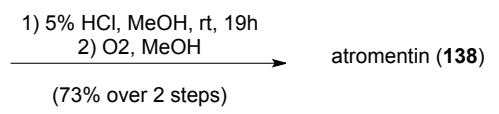


Scheme 39. Synthesis of atromentin (138) from compounds A25 and 157

Remarkably, the S.-M. coupling occurred with deprotection of the TBS-protected hydroxyl groups.[150] However, when the $\mathrm{Pd}(\mathrm{OAc})_{2} / \mathrm{PPh}_{3}$-catalyzed reaction of A25 with 157 was carried out in aqueous THF at $70{ }^{\circ} \mathrm{C}$ in the presence of $\mathrm{K}_{3} \mathrm{PO}_{4}$, TBS ether 159 was obtained in $84 \%$ yield. Compound 159 was then selectively oxidized with cerium ammonium nitrate (CAN) providing compound 160 in $86 \%$ yield. Reduction of $\mathbf{1 6 0}$ with $\mathrm{Na}_{2} \mathrm{~S}_{2} \mathrm{O}_{4}$ in $\mathrm{MeOH}$ followed by treatment of the hydroquinone thereby obtained with $\mathrm{MeI} / \mathrm{K}_{2} \mathrm{CO}_{3}$ furnished compound $\mathbf{1 6 1}$ in $36 \%$ yield. Compound 161 was an advanced precursor to 2-Omethylatromentin (139) and telephantin I (140) (Scheme 40).[150]

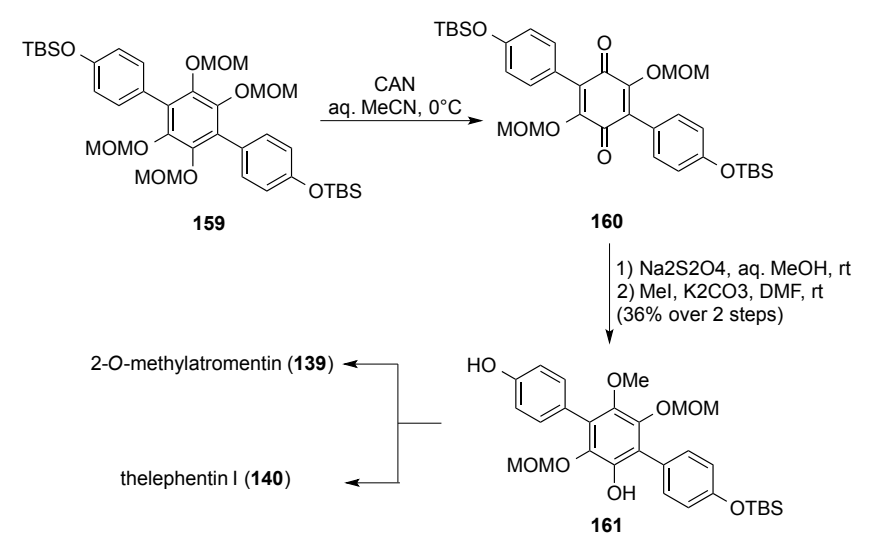

Scheme 40. Synthesis of naturally-occurring compounds 139 and 140

2-O-Methylatromentin (139) and telephantin I (140) are two $p$-terphenyl derivatives isolated from the methanolic extract of fruit bodies of the thelephoraceous basidiomycete T. aurantiotincta.[151c]

In 2012, the first total synthesis of 7-methyl-8-(4methylfuryl)-2H-chromen-2-one (141), a natural product with antileishmanial activity recently isolated from the plant Galipea panamensis (Rutaceae),[152] was accomplished by Schmidt and co-workers using the $\mathrm{PdCl}_{2}\left(\mathrm{PPh}_{3}\right)_{2}$-catalyzed reaction of 4-methylfuran-3-ylboronic acid (162) with sterically congested 8 -iodo-7-methoxy- $2 H$-chromen-2-one (163) as the key step.[153] As shown in Scheme 41, the cross-coupling reaction gave the natural product in $77 \%$ yield.

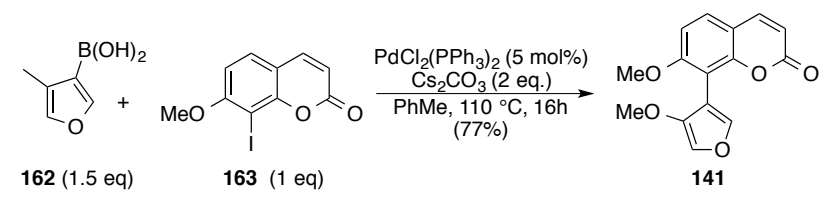

Scheme 41. Synthesis of naturally-occurring compound 141 by S.-M. reaction
It was also found that $\mathrm{PdCl}_{2}\left(\mathrm{PPh}_{3}\right)_{2}$ was a better catalyst precursor compared to $\mathrm{Pd} / \mathrm{C}$ and $\left[\mathrm{Pd}\left(\eta^{3}-\mathrm{C}_{3} \mathrm{H}_{5}\right) \mathrm{Cl}\right]_{2}$.[153]

In 2011, the $\mathrm{PdCl}_{2}\left(\mathrm{PPh}_{3}\right)_{2}$-catalyzed reaction between 3,4dihydro-6,7-methylenedioxynaphthylboronic acid (165) and aryl bromide 166a was used to prepare compound 167, [154] a precursor to nornitidine (142), a benzo[c]phenanthridine alkaloid isolated from the bark of Zanthoxylum microcarpum (Rutaceae).[155] As shown in Scheme 42, compound 165 was prepared in $41.9 \%$ yield via a 8 -step protocol in which 2-allyl-4,5-methylenedioxyphenol (164) was the starting material and the cross-coupling reaction between 166a and $\mathbf{1 6 5}$ gave compound $\mathbf{1 6 7}$ in an excellent yield.[154]

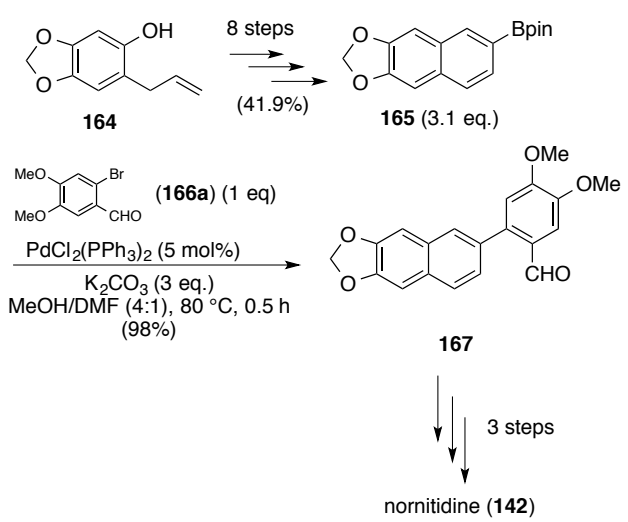

Scheme 42. Synthesis of nornitidine (142) via S.-M. reaction of boronate 165 with bromide 166a

Pinacol boronate 165 was also used in the $\mathrm{PdCl}_{2}\left(\mathrm{PPh}_{3}\right)_{2}-$ catalyzed reaction with 6-bromo-2,3dimethoxybenzaldehyde (166b), which gave 6-(3,4dihydroxy-6,7-methylenedioxy-2-naphthyl)-2,3-

dimethoxybenzaldehyde (168) in $75 \%$ yield (Scheme 43 ). Compound 168 was then used as a precursor to norchelerythrine (143),[154] a cytotoxic alkaloid isolated from Zanthoxylum integrifolium,[156a] Z. capense[156b ]and Z. scadens. [156c]

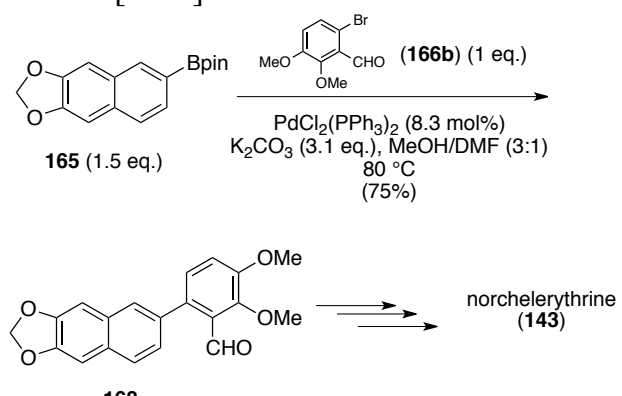

Scheme 43. Synthesis of compound 168, a precursor to norchelerythrine (143)

Moreover, the $\mathrm{PdCl}_{2}\left(\mathrm{PPh}_{3}\right)_{2}$-catalyzed reaction between boronate 165 and 2-acetoxy-6-bromo-3methoxybenzaldehyde (169) was employed by Coshi, Hibino and co-workers as the first step of a total synthesis of isodecarine (149),[154] another benzo[c]phenanthridine 
alkaloid isolated from Z. integrifolium.[156a] The crosscoupling reaction (Scheme 44) gave compound $\mathbf{1 7 0}$ in $96 \%$ yield.

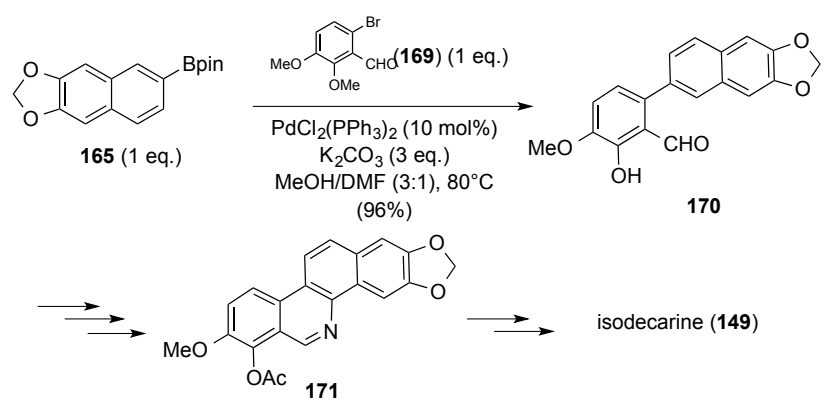

Scheme 44. Synthesis of compound 170, a precursor to isodecarine (149)

The conversion of $\mathbf{1 7 0}$ to isodecarine was achieved using a microwave-assisted electrocyclic reaction of the 2-acetoxy derivative of the benzaldoxime methyl ether prepared from 170 and subsequent dehydrogenation of the thereby obtained 10,11-dihydrobenzo[cf]phenanthridine 171, followed by saponification.[154] It should be noted that a microwaveassisted electrocyclic reaction of 2cycloalkenylbenzaldoxime methyl ethers as aza $6 \pi$-electron systems was also employed as the key step in the synthesis of compounds 142 and 143 via aldehydes 166 and 168.[154]

In 2011, Zhang and co-workers described a regio- and stereoselective synthesis of anibamine (144),[157] a pyridine quaternary alkaloid isolated from Aniba panurensis (Lauraceae),[158] which was found to effectively inhibit the chemokine receptor CC35 over-expressed in more aggressive forms of prostate cancer.[158a] The synthesis was achieved via a 7-step protocol in which the high yielding $\mathrm{Pd}(\mathrm{OAc})_{2} / \mathrm{PPh}_{3}$-catalyzed cross-coupling reaction between dibromopyridine 172 and diisopropyl (Z)-1-decenylboronate (173) in toluene and water under reflux in the presence of $\mathrm{Na}_{2} \mathrm{CO}_{3}$ as the base was a crucial step (Scheme 45). The coupling furnished compound $\mathbf{1 7 4}$ in $94 \%$ yield. Removal of the PMB protecting group from $\mathbf{1 7 4}$ under acidic conditions, followed by treatment of the resulting alcohol with $\mathrm{MsCl}$ and $\mathrm{Et}_{3} \mathrm{~N}$ at room temperature allowed ring closure providing 144 in 56.8\% yield from 174 (Scheme 45).[157]
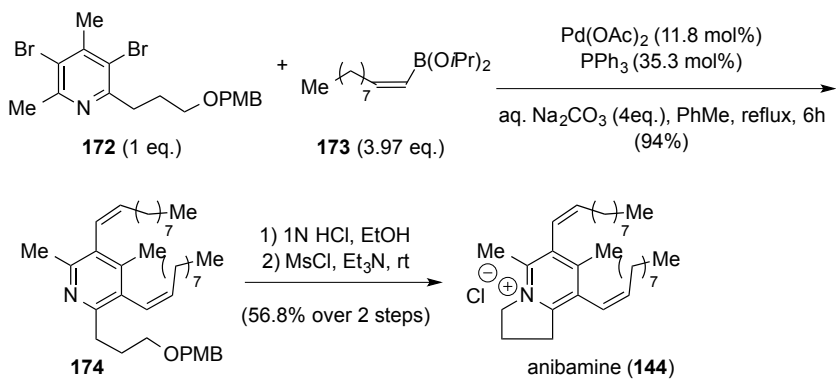

Scheme 45. Synthesis of anibamine (144) via S.-M. coupling of 177 with 173
(2S)-Pterosin A (145) is a sesquiterpenoid present in Pteridinium aquilinium (bracken fern)[159] which revealed to be a potent hypoglycemic agent.[160] In 2013, Uang and co-workers reported a practical synthesis of the racemic form of this compund in $10 \%$ yield starting from commercially available 2-bromo-1,3-dimethylbenzene (171).[161] The synthesis was based on the retrosynthetic analysis shown in Scheme 46.[161]

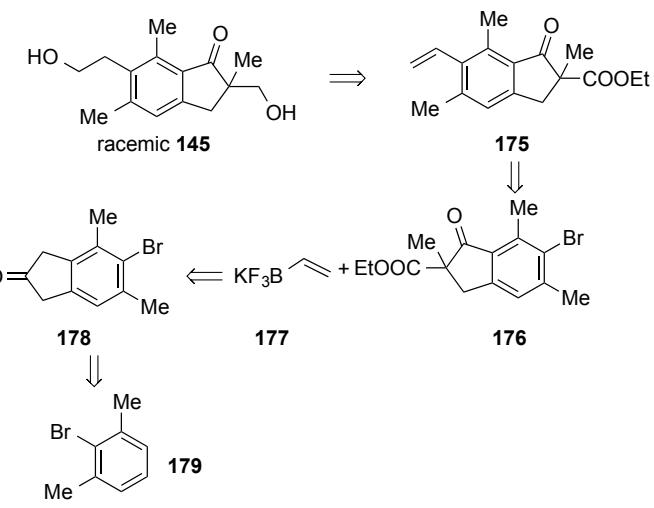

Scheme 46. Retrosynthesis of racemic pterosin A (145)

The $\mathrm{PdCl}_{2} / \mathrm{PPh}_{3}$-catalyzed reaction of the C6 bromoindanone 176 with vinyltrifluoroborate (177), which under the optimized conditions reported in Scheme 47 gave an inseparable 95:5 mixture of $\mathbf{1 7 5}$ and the reduction product 180 in $90 \%$ yield, was the key step of the reaction. Compound $\mathbf{1 7 6}$ was in turn prepared from aryl bromide 179 via a 4-step reaction sequence in which $\mathbf{1 7 8}$ was an intermediate.

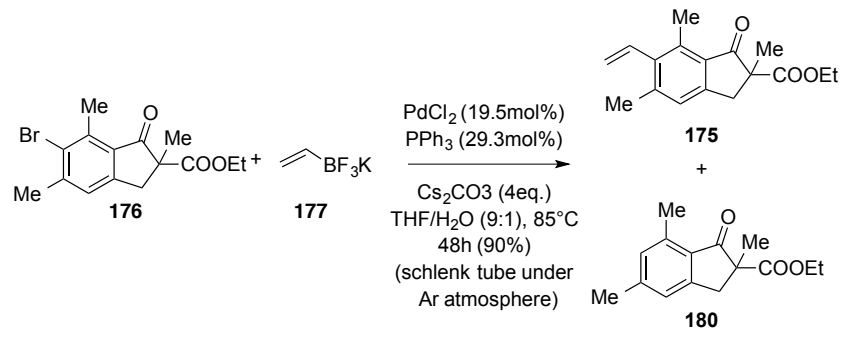

Scheme 47. S.-M. reaction between bromide 176 and potassium vinyltrifluoroborate (177)

In 2013, Hutchison and co-workers synthesized eutypoid A (146), a 4-benzyl-3-arylbutenoliode isolated from the marine fungus Eutypa sp. (\#424),[162] using a series of 8 reactions in which compound $\mathbf{1 8 2}$, the direct precursor to 146, was obtained in $98 \%$ by $\mathrm{PdCl}_{2}\left(\mathrm{PPh}_{3}\right)_{2}$-catalyzed reaction of 4-benzyl-3-bromofuranone (181) with 4methoxyphenylboronic acid (A40) in a refluxing mixture of toluene and water in the presence of $\mathrm{CsF}$ as base and a catalytic quantity of $\mathrm{BnEt}_{3} \mathrm{NCl}$ (Scheme 48).[163] 

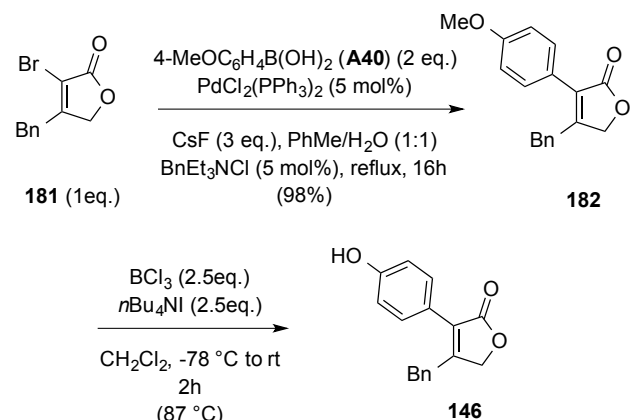

Scheme 48. Synthesis of eutypoid A (146) from butenolide 181

It was also found that the reaction of 181 with phenylboronic acid (186) under experimental conditions similar to those illustrated in Scheme 48 gave in $91 \%$ yield gymnoascolide A (148),[163] a 4-benzyl-3-arylbutenolide isolated from the soil ascomycete Gymnoascus reessii [164a] and Malbranchea filamentosa.[164b] Moreover, the $\mathrm{PdCl}_{2}\left(\mathrm{PPh}_{3}\right)_{2}$-catalyzed reaction of 3-bromo-2(5H)-furanone 185 with phenylboronic acid (186) was employed to prepare 3-phenylfuranone $\mathbf{1 8 7}$ in an excellent yield. Acidic hydrolysis of the methoxyacetal moiety of $\mathbf{1 8 7}$ provided racemic microperfuranone (147) (Scheme 49), a butenolide isolated from the terrestrial and marine fungi Anixiella micropertusa, [165a] Emericella quadrilineata, $[165 \mathrm{~b}]$ and $E$. nidulans. [165c] As illustrated in Scheme 49, compound 184, the direct precursor to $\mathbf{1 8 5}$, was prepared from 3phenylpropionaldehyde (183) via Mannich-type aminoalkylation and subsequent elimination reaction.[163]
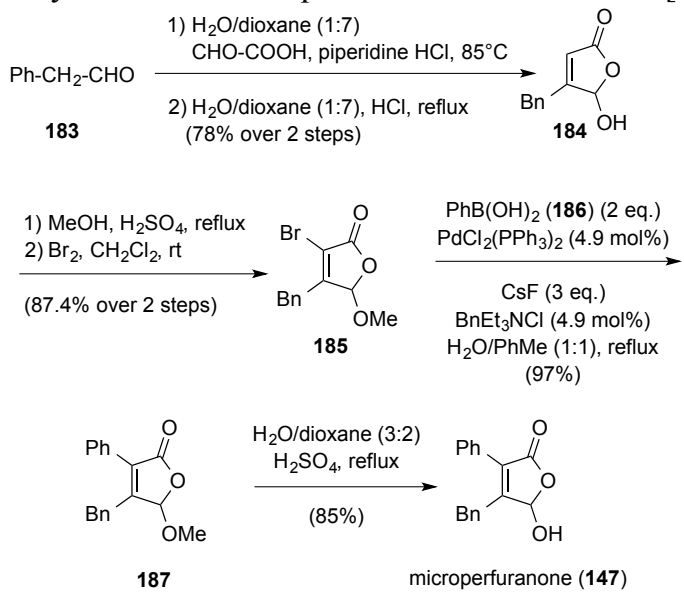

Scheme 49. Synthesis of microperfuranone (147) from aldehyde $\mathbf{1 8 3}$

In 2010, Denton and Scragg described a concise synthesis of the neosesquilignan dunnianol (150),[166] a compound isolated from the bark of Illicium dunnianum.[167] The synthesis featured a $\mathrm{Pd}(\mathrm{OAc})_{2} / \mathrm{PPh}_{3}$-catalyzed double S.-M. reaction of boronic acid 188 with dibromobenzene 189 (Scheme 50). The reaction, which was carried out in a mixture of $i-\mathrm{PrOH}$ and water under reflux in the presence of $\mathrm{Na}_{2} \mathrm{CO}_{3}$ gave compound $\mathbf{1 9 0}$ in $70 \%$ yield without isomerization of the allyl groups. Subsequent $O$ demethylation of 190 with $\mathrm{BCl}_{3} \cdot \mathrm{Me}_{2} \mathrm{~S}$ in refluxing DCE gave dunnianol (150) in $70 \%$ yield.[166] Unfortunately, the experimental details of the reactions summarized in Scheme 50 were not reported.

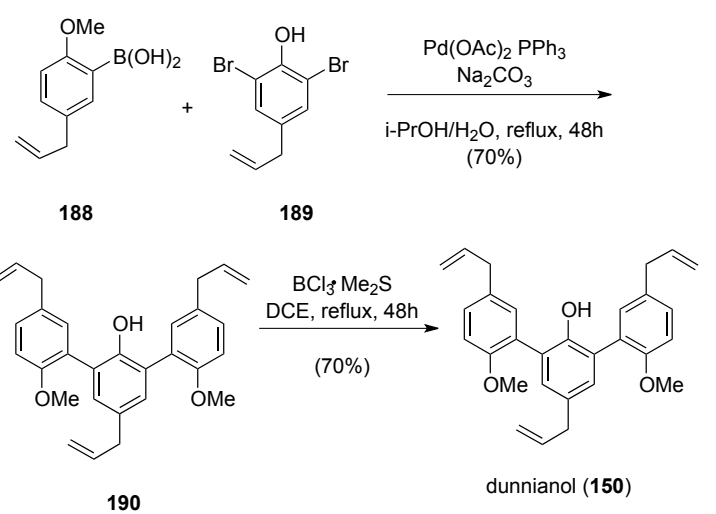

Scheme 50. Synthesis of dunnianol (150) from compounds 188 and 189

In 2014, Podlech and co-workers elucidated the structure of altenuic acid III[168] a micotoxin isolated from the mold Alternaria tenuis, $[169]$ and confirmed by total synthesis that the structure of this metabolite was that of compound 151.[168] The convergent synthesis of $\mathbf{1 5 1}$ was accomplished according to the retrosynthetic analysis given in Scheme 51 where the key intermediate could be accessible by the S.-M. reaction of boronate 192 with alkenyl halide 193.[168] Thus, boronate 192 was synthesized in 4 steps from phloroglucinic acid (194) according to a known procedure[170] and iodide $\mathbf{1 9 3}$ was prepared from the protected ketone 196 in $30.4 \%$ yield via a series of 4 reactions involving the halolactonization reaction of allenecarboxylic acid 195 with iodine.[168] 


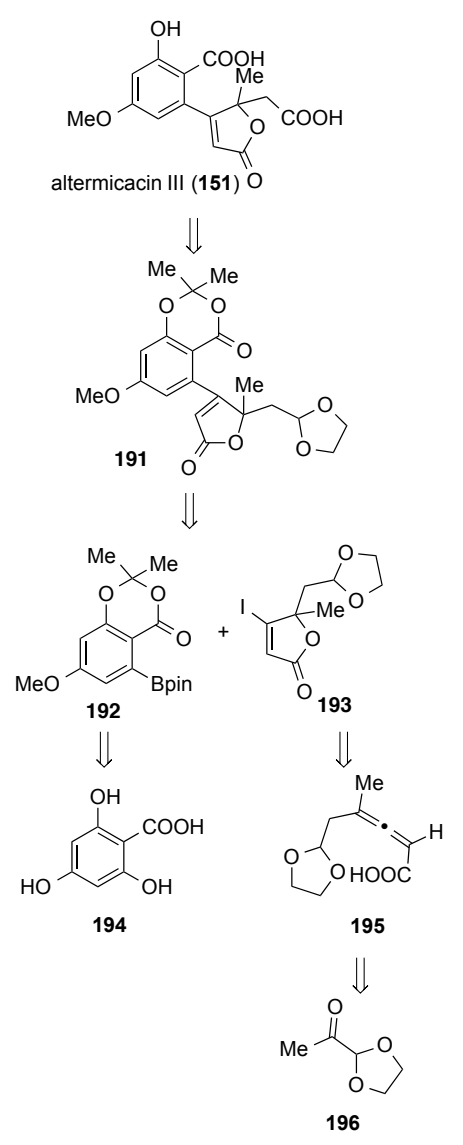

Scheme 51. Retrosynthesis of altenuic acid III (151)

The cross-coupling reaction of 1.5 equiv of $\mathbf{1 9 2}$ with 1 equiv of 193 in a mixture of dioxane and water at $80{ }^{\circ} \mathrm{C}$ in the presence of 3 equiv of $\mathrm{Cs}_{2} \mathrm{CO}_{3}, 5 \mathrm{~mol} \% \mathrm{Pd}(\mathrm{OAc})_{2}$ and $30 \mathrm{~mol}^{\prime} \mathrm{PPh}_{3}$ gave compound 191 in $92 \%$ yield (Scheme 52). Subsequent deprotection of 191 with TFA at $0{ }^{\circ} \mathrm{C}$ and Jones oxidation of the aldehyde thereby obtained, followed by acetal cleavage with a large excess of $\mathrm{BCl}_{3}$ in $\mathrm{CH}_{2} \mathrm{Cl}_{2}$ provided altenuic acid III (151) in $82.9 \%$ yield based on $\mathbf{1 8 1}$ (Scheme 52).[168]

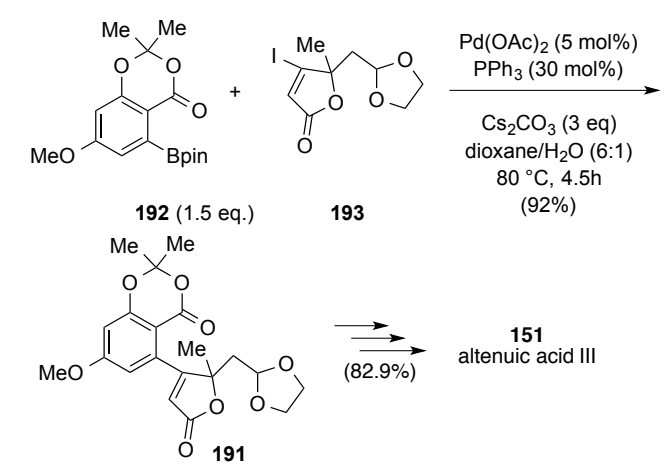

Scheme 52. Synthesis of altenuic acid III (151) via S.-M. cross-coupling of boronate 192 with iodide 193

In 2010, iterative S.-M. cross-coupling reactions were employed by Burke and co-workers in a stereoselective synthesis of (-)-peridinin (152),[171] the major lightharvesting pigment of planktonic dinoflagellates,[172] which is the major biological carotenoid quencher of singlet oxygen in marine algae Gonyaulax polyedra173 and is distinguished by its antitumor activity.[174] The $\mathrm{PdCl}_{2}\left(\mathrm{PPh}_{3}\right)_{2}$-catalyzed reaction of pinacol ester 201 with trienyl iodide (202) (Scheme 53) was a key step of the synthesis of 152.[171]

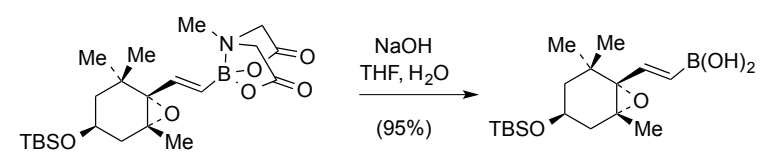

197
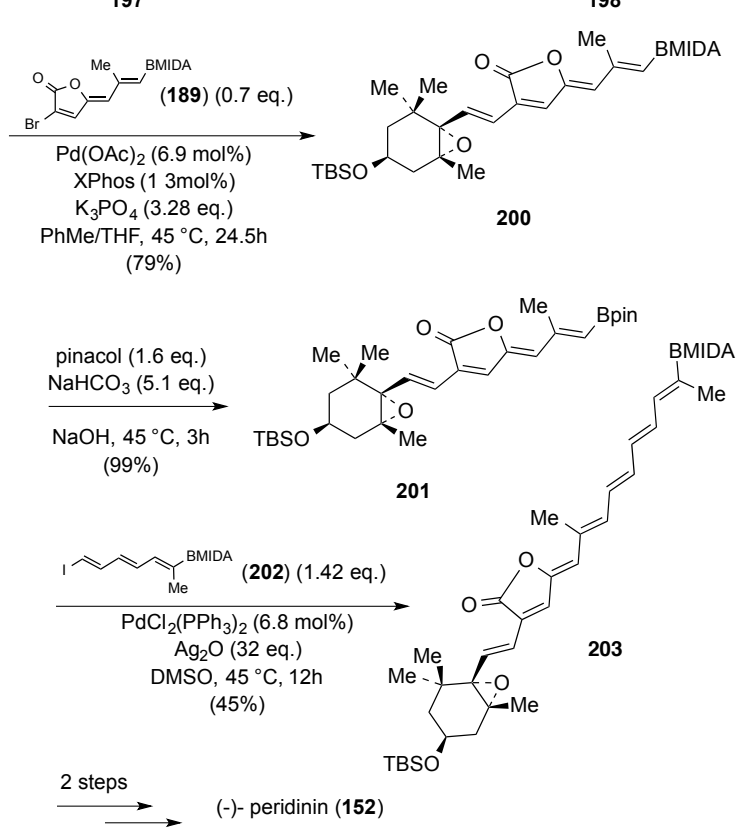

Scheme 53. Synthesis of (-)-peridinin (152) from the MIDA boronate 197

Compound 201 was in turn obtained via a 3-step reaction sequence in which boronic acid 198, prepared by hydrolysis of the MIDA boronate 197, was coupled with bromide 199 using a $\mathrm{Pd}(\mathrm{OAc})_{2} / \mathrm{XPhos}$ catalyst system and the resulting cross-coupling product $\mathbf{2 0 0}$ was converted in the required boronate 201 by treatment with pinacol in the presence of $\mathrm{NaHCO}_{3}$ (Scheme 53).[171]

\section{TOTAL SYNTHESES VIA trans $-\operatorname{PdBr}(N$ - Succ)(PPh $\left.{ }_{3}\right)_{2}$-CATALYZED S.-M. REACTIONS}

In recent years, trans- $\mathrm{PdBr}\left(N\right.$-Succ) $\left(\mathrm{PPh}_{3}\right)_{2}$ (204) (Figure 9) has been used as an effective precatalyst for S.-M. crosscouplings of (hetero)arylboronic acids with benzylic halides, substituted aryl halides and halogenated cyclic enones[175] as well as for S.-M. reactions of alkenyl tosylates with alkenyl MIDA boronates.[176] Nevertheless, to our knowledge, complex 204 served as the precatalyst of a single S.-M. reaction invoved in a total symthesis of a natural product. 


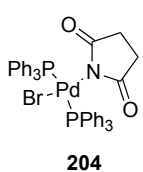

Figure 9. Structure of complex 204

In fact, in 2010, Taylor and co-workers used the 204catalyzed reaction of $(S)$-iodoenone 205 with MIDA boronate 206 in the first step of a 12-step synthesis and structural reassignment of (+)-dictyosphaeric acid A (208),[177] a polyketide-derived compound isolated from a fungal isolate (F01V25) obtained from the green macroalgae Dictyospaeria versluysii.[178] The cross-coupling reaction (Scheme 54), which was carried out in dioxane at $60{ }^{\circ} \mathrm{C}$ in the presence of $3 \mathrm{M}_{\text {aq }} \mathrm{K}_{3} \mathrm{PO}_{4}$, gave compound 207 in $82 \%$ yield.

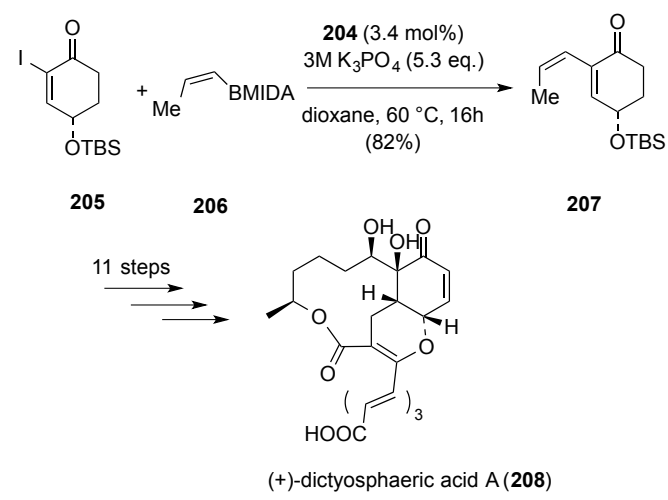

Scheme 54. Synthesis of (+)-dictyosphaeric acid A (208) via the 204-catalyzed S.-M. reaction of iodoenone 205 with MIDA boronate 206

Interestingly, compound 208 was found to exhibit antibacterial activity against methicillin-resistant Staphilococcus aureus, vancomycin-resistant Enterococcus faecium, and Candida albicans.[178]

\section{TOTAL SYNTHESES VIA S.-M. REACTIONS PROMOTED BY A COMBINATION OF Pd(o-Tol) 3 OR A TRI(CYCLO)ALKYLPHOPSPHANE WITH A Pd(0) OR A Pd(II) DERIVATIVE}

Table 4 lists the structures of natural compounds 209-213 that have been synthesized via S.-M. cross-couplings involving the use of a precatalyst composed by a combination of $\mathrm{P}(o-\mathrm{Tol})_{3}$ or a tri(cyclo)alkylphosphane with a $\operatorname{Pd}(0)$ or a $\mathrm{Pd}(\mathrm{II})$ derivative. Literature data on the isolation of these natural substances are also reported in this table.

In 2011, Waldmann, Arndt and co-workers accomplished a total synthesis of biphenomycin B (209), a peptide antibiotic isolated from cultured broth of Streptomyces griseorubiginosus No 43708,[179]. The 14-step synthesis involving the use of aminoacids $\mathbf{2 1 5}$ and $\mathbf{2 1 6}$ was carried out according to the retrosynthetic disconnection shown in Scheme 55 and occurred in $15 \%$ overall yield.

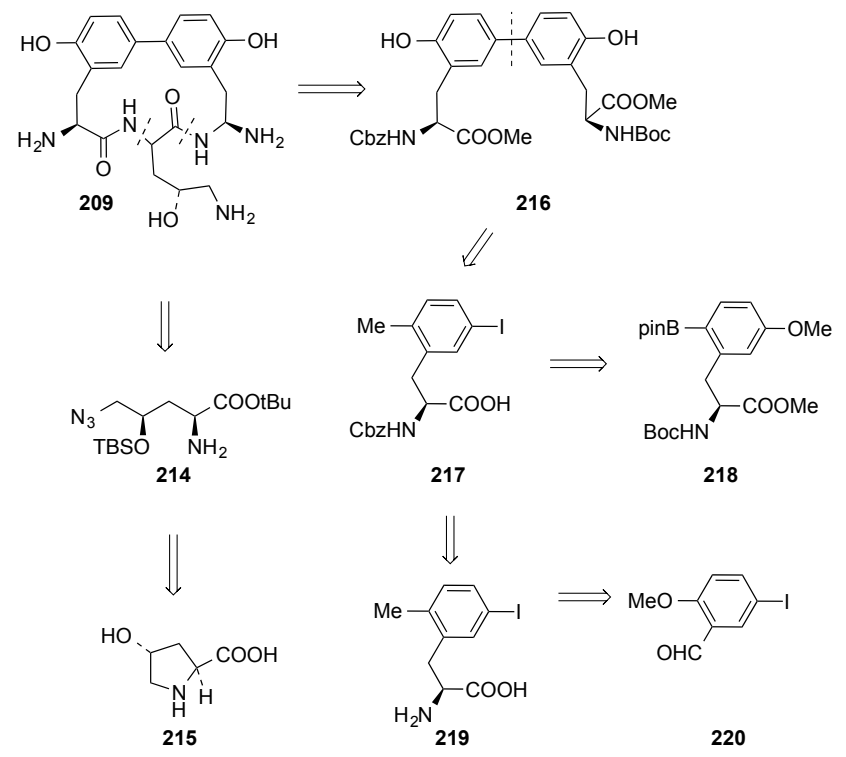

Scheme 55. Retrosynthetic disconnection of biphenomycin B (209)

Thus, the ornitine derivative $\mathbf{2 1 4}$ was prepared from trans- 4-hydroxyproline (215) and the biaryl building block 216 was synthesized in $74 \%$ yield by $\mathrm{Pd}(\mathrm{OAc})_{2} / \mathrm{P}(o-\mathrm{Tol})_{3}$ catalyzed reaction of $(S)$-2-(benzyloxycarbonylamino)-3-(5iodo-2-methoxyphenyl)propionic acid $\mathbf{2 1 7}$ with pinacol boronate 218 (Scheme 56).

\section{TABLE 4 HERE}

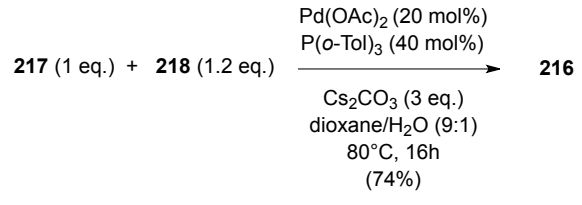

Scheme 56. Cross-coupling reaction of aryl iodide 217 with pinacol boronate $\mathbf{2 1 8}$

Compound 217 was prepared from aminoacid 219 which in turn was obtained from aldehyde 220 in $79.3 \%$ yield via a 4-step reaction sequence. On the other hand, 218 was obtained in an excellent yield from 219 by introduction of a Boc-group, methyl ester formation, and $\mathrm{PdCl}_{2}$ (dppf)catalyzed borylation with (Bpin)2.[180]

In 2011 and 2012, Ishikura and co-workers reported a concise total synthesis of calothrixin B (210),[181] an indolo[3,2-j]phenanthridine alkaloid originally isolated

from Calothrix cyanobacteria,[182] which was found to inhibit the growth of a chloroquine-resistant strain of the human malaria parasite Plasmodium falciparumn and the growth of human HeLa cancer cells.[183] Under optimized conditions, triene 223, which was the key intermediate of the synthesis, was prepared in $68 \%$ yield by the $\mathrm{Pd}_{2}(\mathrm{dba})_{3} \cdot \mathrm{CHCl}_{3} / \mathrm{P}(o \text {-Tol })_{3}$-catalyzed tandem cyclization/cross-coupling reaction of triethylindolylborate 
221 with vinyl bromide 222 (Scheme 57). Compound 223 was produced with a small amount $(5 \%)$ of 2-vinylindole 224. [181] It was also found that the cross-coupling reaction using $\mathrm{PdCl}_{2}\left(\mathrm{PPh}_{3}\right)_{2}$ as the precatalyst was slower and produced 223 in $20 \%$ yield.[181a]

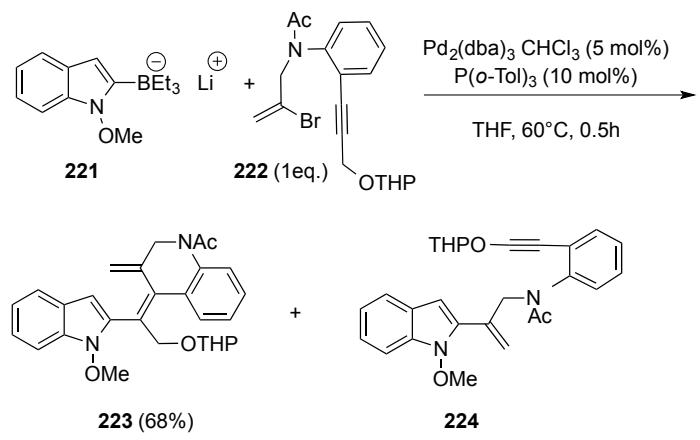

Scheme 57. Pd-catalyzed tandem cyclization/crosscoupling reaction of compound $\mathbf{2 2 1}$ with vinyl bromide 222

The catalytic cycle of the reaction leading to 223 was proposed to involve the transfer of the indole ring from indolylborate $\mathbf{2 2 1}$ to the tricoordinate complex $\mathbf{A}$, leading to 223 via complex B (Scheme 58).
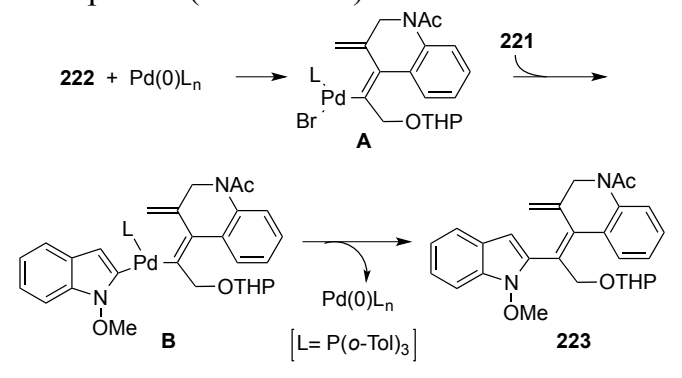

Scheme 58. Catalytic cycle for the Pd-catalyzed reaction between 221 and 222

Another key step of the total synthesis of calothrixin B (210) was the generation of indolo[3,2-j]phenanthridine 226 by the unprecedented use of $(\mathrm{CuOTf})_{2} \cdot \mathrm{PhMe}$ for the $6 \pi$ electrocyclization of compound 225, which was obtained by removal of the THP group from 223 (Scheme 59).[181]
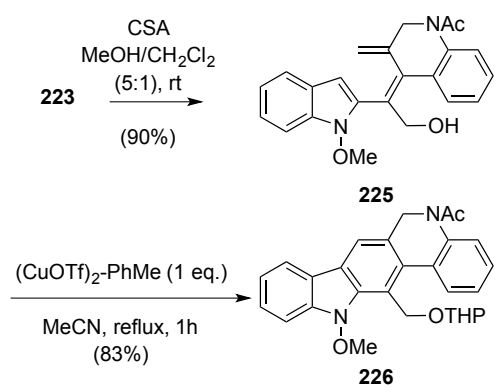

Scheme 59. Synthesis of compound 226 from 223

In 2010, the first synthesis of rubrolide L (211), a butenolide isolated from the ascidian Synoicum blochmani [184] which was found to inhibit human aldolase reductase,[185] was achieved by Boukouvalas and McCann by a pathway in which 3-chlorotetronic acid (227) was the starting material and the key intermediate $\mathbf{2 2 9}$ was synthesized in $87 \%$ yield by the $\mathrm{Pd}(\mathrm{OAc})_{2} / \mathrm{PCy}_{3}$-catalyzed regio- and chemoselective reaction between triflate 328 and 4-methoxyphenylboronic acid (A40) (Scheme 60).[186]

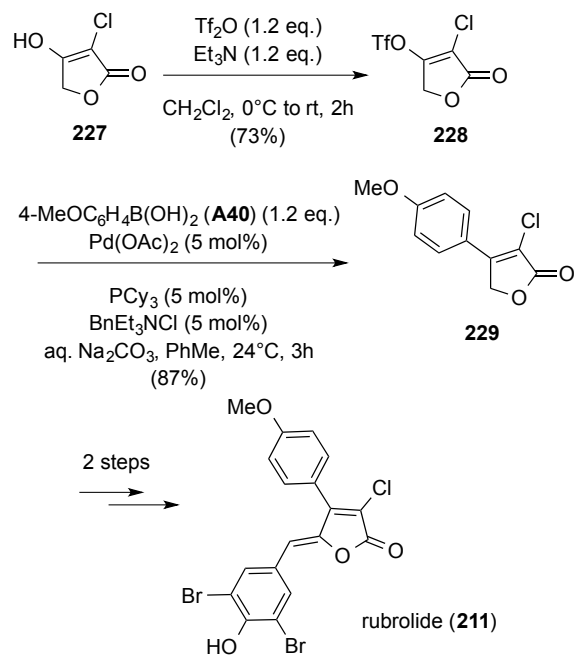

Scheme 60. Synthesis of rubrolide L (211) from commercially available 3 -chlorotetronic acid (227)

In 2011, Cao and co-workers used a catalyst system composed of a combination of $\mathrm{Pd}(\mathrm{OAc})_{2}$ and $\left[\mathrm{P}\left(t-\mathrm{Bu}_{3}\right) \mathrm{H}_{3} \mathrm{BF}_{4}\right.$ in the last step of a total synthesis of malyngamide $\mathrm{K}$ (212),[187] a natural product isolated from the marine cyanophyte Lygbya majuscola.[188] In this step, compound 212 was chemoselectively prepared in $89 \%$ yield by the S.M. reaction of boronic acid 231 with (Z)-1-chloro-2iodoalkene 233 (Scheme 61). Compound 231 was in turn obtained in $32.9 \%$ yield from enone $\mathbf{2 3 0}$ via a 4-step reaction sequence and compound $\mathbf{2 3 3}$ was synthesized in $11.8 \%$ yield from ethyl propiolate (232) through a series of seven reactions (Scheme 61).[187] 


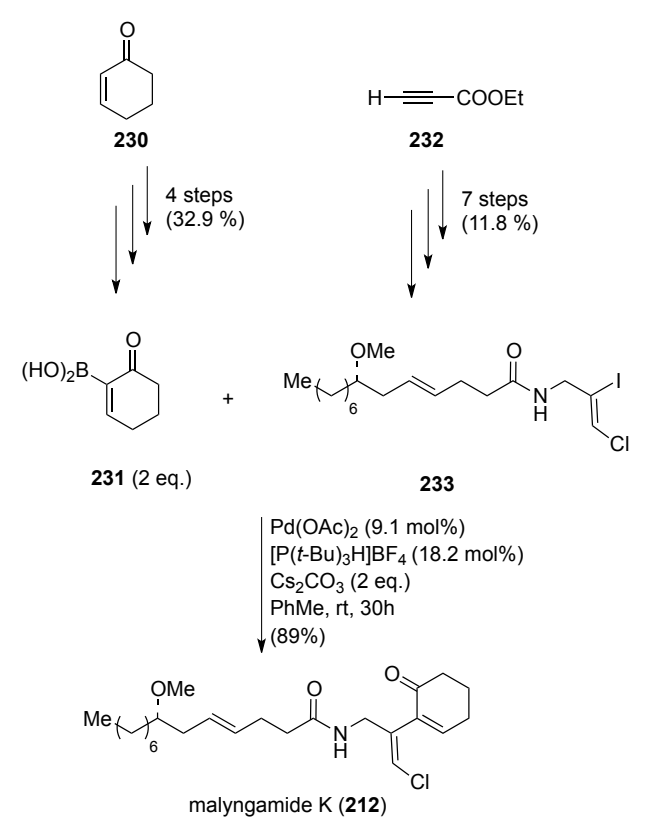

Scheme 61. Total synthesis of malyngamide K (212)

In the same year, Ichikawa, Usami and co-workers described a synthesis of withasomnine (213),[189] a pyrazole derivative isolated from the root bark of Withania somnifera (Solanaceae)[190] which is known to inhibit $\mathrm{TBL}_{4}, \mathrm{COX}-1, \mathrm{COX}-2$ and to exhibit depression of the CNS and cyrculatory systems.[191] In the 9-step reaction sequence used to prepare 213 , 4-formylpyrazole 234 was the starting material and compound 236, an early precursor to 213, was obtained by alkaline hydrolysis of the BayerVilliger oxidation and $O$-allylation of $\mathbf{2 3 4}$ followed by Claisen rearrangement of the thereby obtained 4allylpyrazole 231 (Scheme 62). [189] The total synthesis of 213 then featured the $\mathrm{Pd}_{2}(\mathrm{dba})_{3} / \mathrm{PCy}_{3}$-catalyzed crosscoupling of triflate 237 with phenylboronic acid (186), which provided the required natural product in $88 \%$ yield(Scheme 62).[189]

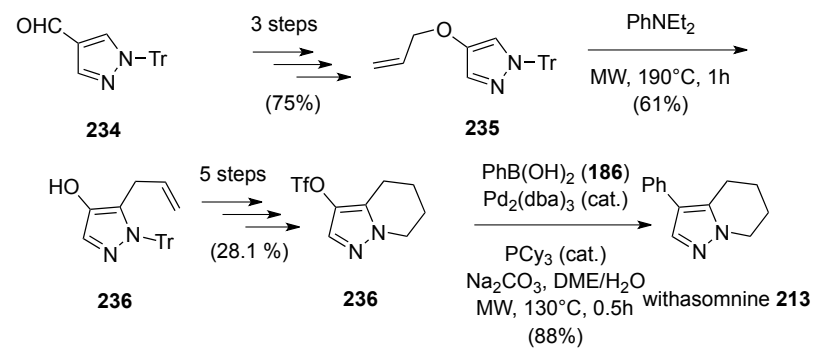

Scheme 62. Total synthesis of withasomnine (213)

4. TOTAL SYNTHESES VIA S.-M. REACTIONS
PROMOTED BY A COMBINATION OF A
DICYCLOALKYLBIARYLPHOSPHANE WITH A
Pd(II) OR A Pd(0) DERIVATIVE

Since 1998, Buchwald and co-workers have introduced the use of dicycloalkylbiarylphosphane ligands such as SPhos (238a), Ru-Phos (238b), X-Phos (238c) and JohnPhos (238d) (Figure 10) for Pd-catalyzed S.-M. reactions involving a variety of electrophiles.[192]

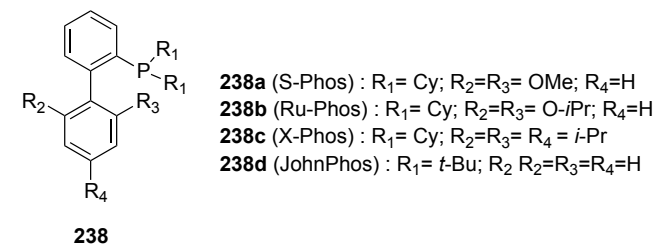

Figure 10. Structures of ligands 238a-d

Remarkably, the use of some of these supporting ligands was found to allow S.-M. couplings at low catalyst loadings.

As shown in this section, catalyst precursors consisting of a combination of a dicycloalkylbiarylphosphane with a $\operatorname{Pd}(\mathrm{II})$ or a $\operatorname{Pd}(0)$ derivative have also been frequently used in S.-M. reactions involved in total syntheses of natural products. Table 5 lists the structures of natural compounds which have been synthesized via $\mathrm{Pd}(\mathrm{II}) / \mathrm{S}$-Phos-catalyzed S.M. reactions in the period January 2010-December 2013. Table 5 also includes literature data on the isolation of these natural compounds.

\section{TABLE 5 HERE}

These natural compounds include: $(+)$-korupensamine B (239), which was originally isolated from the Cameroonian liana Ancistrocladus korupensis and was found to exhibit good antimalarial activity in vitro and in vivo;[193] graphislactone G (240), which was isolated from the endophytic fungus Cephalosporium acremomium IFBE007;[194] (-)-rhazinilam (241), a strained nine-membered lactam originally isolated from the poisonous plant Rhazya stricta (Apocynaceae),[195] which was found to interfer with tubulin polymerization and dynamycs;[205] malyngamide L (242), a metabolite of the marine cyanophyte Lyngbya majuscola; [188] altenuisol (243), a toxin isolated from the fungus Alternaria tenuis; [196] hydroxy- $\alpha$-sanshool (244), which was isolated from the dried fruit of the Japanese pepper Zanthoxylum piperitum;[197] altenusin (245), a minor toxin produced by Alternaria fungi[198] showing a broad antimicrobial activity against several multidrug-resistant bacterial and fungal strains;[206] alterlactone (246), a resorcylic lactone produced by Alternaria sp., which was found to exhibit moderate cyytotoxicity agains L5178Y cells;[199] lysilactone A (247), a $6 H$-dibenzo[ $[b, d]$ pyran-6-one glycoside recently isolated from endophytic Aspergillus sp. Yxf3;[201] phenaglydon (249), an alkaloid isolated from Glycosmis cyanocarpa (Rutaceae);[202] racemic cepharatine A (250), an alkaloid which in levorotatory form was isolated from Stephania cepharantha (Menispermaceae);[203] and arylomycin $\mathrm{A}_{2}$ (251), a biaryl-bridged lipopeptide antibiotic produced by Streptomyces sp. Tu 6075.[204] 
In addition, Table 6 shows the structures and the literature data on the isolation of the natural compounds that have been synthesized via $\mathrm{Pd}_{2}(\mathrm{dba})_{3}-\mathrm{S}-\mathrm{Phos}-$ catalyzed S.-M. reactions.

\section{TABLE 6 HERE}

These substances include: honokiol (252), a biaryl neolignan originally isolated from Magnolia officinalis (Magnoliaceae)[207a] and more recently from $M$. obovata; [207b] (-)-myxalamide A (253), a polyene antibiotic first isolated from the gliding bacterium Myxococcus xanthus; [208] quebecol (254), a polyphenolic compound formed in racemic form during maple syrup production from Acer saccharum's syrup;[209] and riccardin $\mathrm{C}$ (255), a cyclic bibenzyl derivative originally isolated from the liverwort Reboulia hemisphaerica,[210] which was found to function as a liver $\mathrm{X}$ receptor $\alpha$ agonist and a liver $\mathrm{X}$ receptor $\beta$ antagonist.[211]

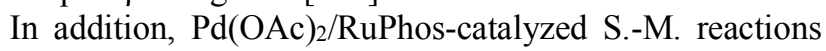
were used in the total synthesis of 4-O-methylhonokiol (256),[212] trienomycin A (257),[223] and virgatolide (258)[224] (Figure 11), and a $\mathrm{Pd}_{2}(\mathrm{dba})_{3} / \mathrm{J}$ ohnPhos-catalyzed S.-M. reaction was used to prepare a key intermediate of the enantioselective total syntheses of (-)-mersicarpine (259), ()-leuconalam (260) and (-)-leuconoxine (261) (Figure 11),[215] three polycyclic Aspidosperma alkaloids.

4-O-Methylhonokiol (256) was isolated from Magnolia species[216a] and was found to exhibit higher antiinflammatory activity than honokiol (252).[216b] (+)Trienomycin A (257) was isolated from the culture broth of Streptomyces sp. No 83-16 and was found to exhibit aantineoplastic activity.[217] Spiroketal virgatolide B (258) was isolated from the endophytic fungus Pestalotiopsis virgatula (L147)[218] and (-)-mersicarpine (259), an indole alkaloid having a fused 6/5/6/7 ring system centered around a hemiaminal carbon, was isolated from the bark of Kopsis fruiticosa and $K$. arborea.[232] (-)-Leuconalam (260), a tetracyclic alkaloid containing a nine-membered lactam and a 1,5-dihydro- $2 \mathrm{H}$-pyrrol-2-one moiety, was isolated from Leuconotis plants,[233] and (-)-leuconoxine (261) was isolated from Leuconotis eugenifolius (Apocynaceae).[234]
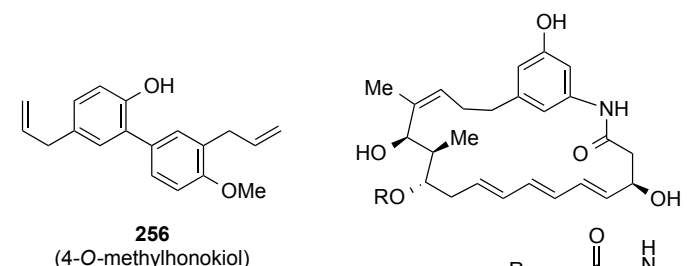

(4-O-methylhonokiol)
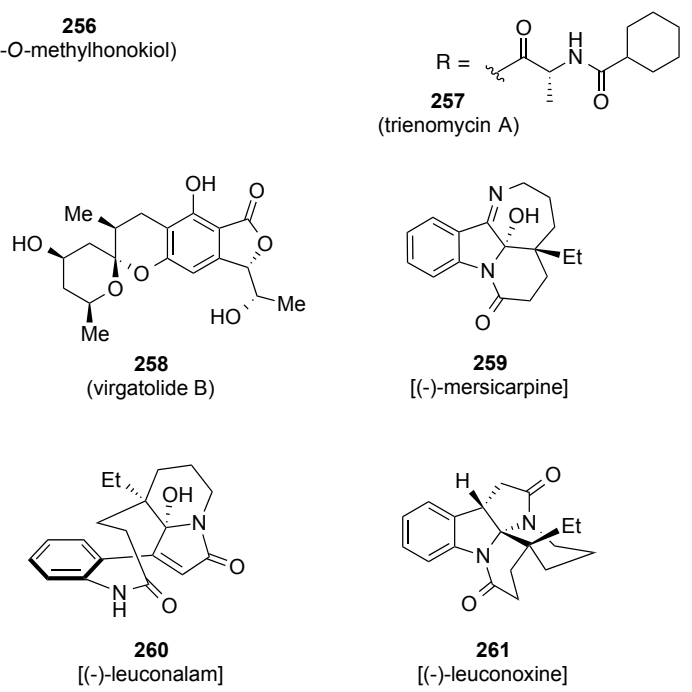

Figure 11. Structures of compounds 256-261

Table 7 shows the S.-M. cross-couplings used in the total syntheses of compounds 239-261, the experimental conditions and yields of these Pd-catalyzed reactions. Entries 1-16 of this table regard reactions in which S-Phos was used as the ligand, entries 17-19 concern reactions involving the use of Ru-Phos as the ligand, and entry 20 illustrates the S.M. reaction that provided compound C52, a precursor to natural compounds 259-261. The organoboron reagents that were used in the reactions of Table 7 included boronic acids A40, A43, A45, A50 and A54, pinacol boronates A41, A42, AB1 and AB2, MIDA boronates A44 and A49, 9-alkyl-9BBN A52, potassium organotrifluoroborates A51 and A53, and trioxaborinane $\mathbf{A 4 7}$. It should be noted that methoxysubstituted pinacol boronate A41, which was synthesized in 3 steps starting from commercially available acetal-protected phloroglucinic acid (262) via $\mathrm{Pd}\left(\mathrm{PPh}_{3}\right)_{4}$-catalyzed borination of aryl triflate $\mathbf{2 6 3}$ (Scheme 63),[223] was employed in the total syntheses of graphislactone (240)[219] (entry 2, Table 7), altenuisol (243)[231] (entry 5, Table 7), altenusin (245), and alterlactone (246)[223] (entry 7, Table 7), and lysilactone A (247)[200] (entry 8, Table 7).

\section{TABLE 7 HERE}

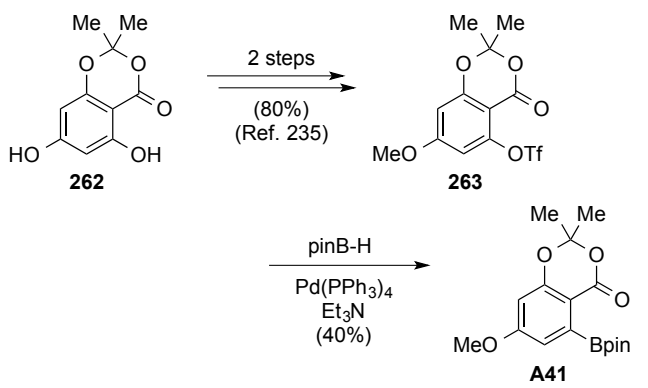




\section{Scheme 63. Synthesis of pinacol boronate A41}

Trioxaborinane A47 was synthesized in 3 steps starting from 2-methoxy-5-methylphenol (244) via treatment of (4bromo-2-methoxy-5-methylphenoxy)-t-butyldimethylsilane (265) with $n$-BuLi at $-78^{\circ} \mathrm{C}$ followed by addition of a large molar excess of triisopropylborate (Scheme 64).[226]
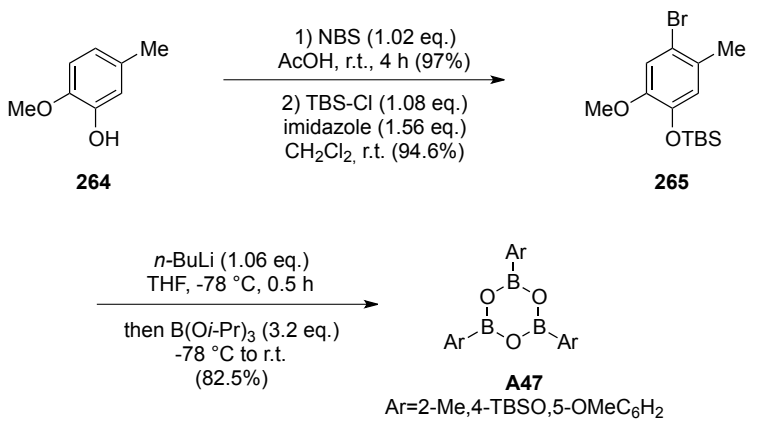

Scheme 64. Synthesis of trioxaborinane A47

Potassium aryltrifluoroborate A51 was obtained as a crystalline solid through methylation of 2-allyl-4bromophenol (266) and treatment of the resulting 2-allyl-4bromo-1-methoxybenzene (267) with $n$-BuLi and triisopropylborate, followed by addition of $\mathrm{KHF}_{2}$ (Scheme 65).[212]
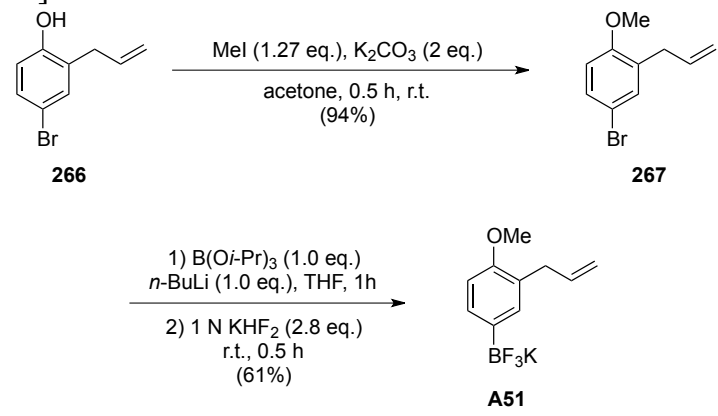

Scheme 65. Synthesis of potassium aryltrifluoroborate A51

Potassium (S)-3-(trifluoroborato)- $N$-[(1R,2R)-1-hydroxy1-phenylpropan-2-yl]- $N$-2-dimethylpropanamide (A53), which was used in the synthesis of virgatolide B (258), [214] was prepared by the reaction of $(R, R)$-pseudoephedrine (268) with propionic anhydride in the presence of $\mathrm{Et}_{3} \mathrm{~N}$, metalation of the resulting compound $\mathbf{2 6 9}$ with $n$-BuLi, followed by addition of pinB- $\mathrm{CH}_{2} \mathrm{I}(\mathbf{2 7 0})$ and subsequent conversion of pinacol boronate 271 thereby obtained into trifluoroborate A53 by the reaction with $\mathrm{KHF}_{2}$ in $\mathrm{MeCN} / \mathrm{H}_{2} \mathrm{O}$ according to Molander's procedure[236] (Scheme 66).

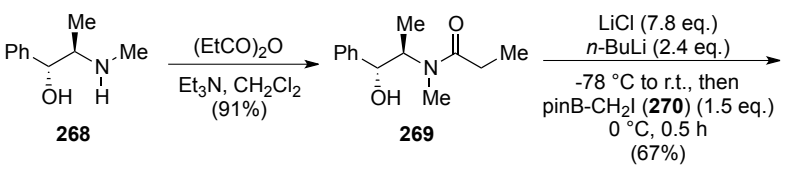

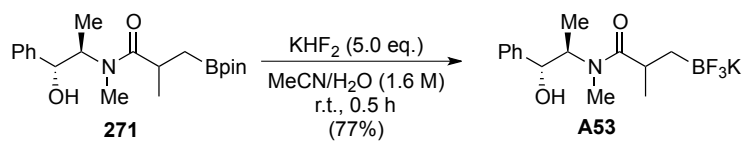

Scheme 66. Synthesis of potassium alkyltrifluoroborate A53

(E,E)-N-Methyliminodiacetic (MIDA) boronate ester A44, which was used in the total synthesis of hydroxy- $\alpha$ sanshool (244) (entry 6, Table 7),[222] was prepared via the reaction sequence illustrated in Scheme 67.[237]

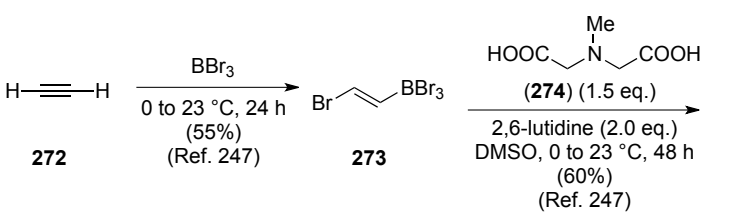

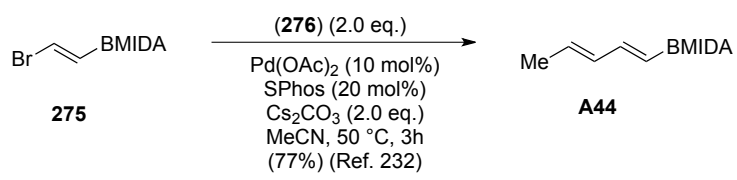

Scheme 67. Synthesis of MIDA boronate A44

In particular, (E)-(2-bromoethenyl)dibromoborane (273), which was prepared in 55\% yield from acetylene (272) and $\mathrm{BBr}_{3}$, was reacted with $N$-methyliminodiacetic acid (274) in DMSO in the presence of 2,6-lutidine to give $(E)$-MIDA boronate 275.[237] The subsequent $\mathrm{Pd}(\mathrm{OAc})_{2} / \mathrm{S}-\mathrm{Phos}-$ catalyzed reaction of $\mathbf{2 7 5}$ with $(E)$-1-propenylboronic acid (276) gave A44 in 77\% yield.[222]

MIDA boronate A49, which was used in the total synthesis of (-)-myxalamide A (253) (entry 14, Table 7),[229] was synthesized as depicted in Scheme 68.

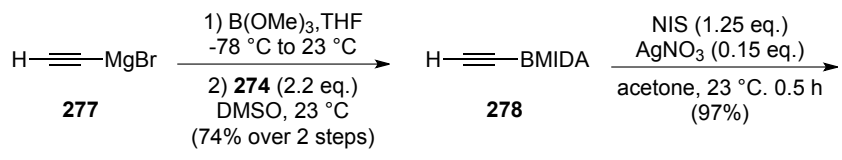

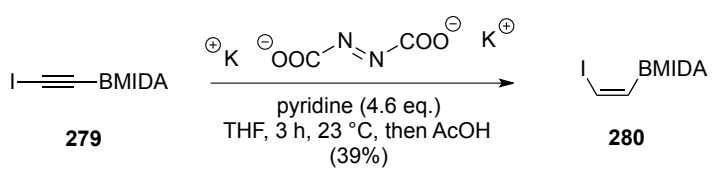

$$
\begin{aligned}
& \underset{\substack{\mathrm{J} \text { JohnPhos }(20 \mathrm{~mol} \%), \mathrm{DMF} / \mathrm{MeCN} \\
-10^{\circ} \mathrm{C}, 21 \mathrm{~h}(99 \%)}}{\mathrm{Pd}_{2}(\mathrm{dba})_{3} \xi \mathrm{CHCl}_{3}(5 \mathrm{~mol} \%)}
\end{aligned}
$$

Scheme 68. Synthesis of MIDA boronate A49 
Specifically, ethynylmagnesium bromide (277) was converted to ethynylboronate ester $\mathbf{2 7 8}$, which by treatment with NIS in the presence of $\mathrm{AgNO}_{3}$, provided 2(iodoethynyl)boronate ester 279.[238] (Z)-Stereoselective reduction of 279 with diimide generated in situ from dipotassium azodicarboxylate and $\mathrm{AcOH}$, gave stereochemically pure (Z)-280 in 39\% yield.[238] Finally, the $\mathrm{Pd}_{2}(\mathrm{dba})_{3} \cdot \mathrm{CHCl}_{3}$-catalyzed Stille-type cross-coupling reaction of $\mathbf{2 8 0}$ with dienylstannane $\mathbf{2 8 1}$ gave MIDA boronate $\mathbf{A 4 9}$ in almost quantitative yield (Scheme 68).[229]

Some reactions reported in Table 7 and/or some total syntheses that have been performed using these crosscouplings deserve comments. Thus, the optimized conditions developed for the S.-M. reaction between boronic acid A40 and aryl iodide $\mathbf{B 4 3}$ (entry 1, Table 7), which was used in the total synthesis of $(+)$-korupensamine B (239), led to compound $\mathbf{C 3 8}$ with an unprecedented atropodiastereoselectivity $(M: P=11: 1) \cdot[218]$

The $\mathrm{Pd}(\mathrm{OAc})_{2} / \mathrm{S}-\mathrm{Phos}-$ catalyzed reaction between pinacol boronate A42 and 2-iodoaniline (B45) (entry 3, Table 7) provided compound $\mathbf{C 3 9}$ in $91 \%$ yield.[220] As shown in Scheme 69, C39 was used in a 7-step synthesis of (-)rhazinilam (241) that involved as key features the separation of the enantiomers of lactam $\mathbf{2 8 2}$ by preparative chiral HPLC and the highly enantiospecific $\mathrm{Pd}\left(\mathrm{PPh}_{3}\right)_{4}$-catalyzed transannular Heck-type cyclization of $(R a)$-282, which provided 1-alkene 283, the direct precursor to (-)-rhazinilam (241).[220]
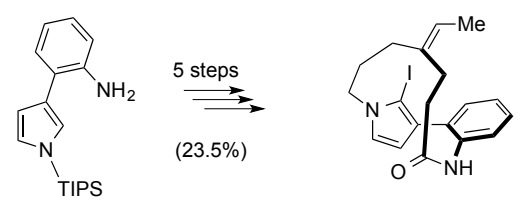

(Sa)-282

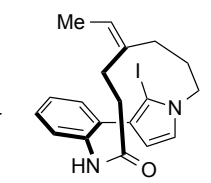

(Ra)-282

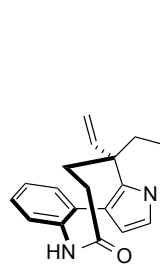

283

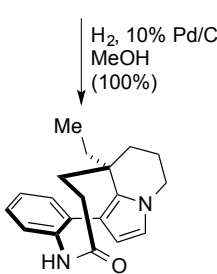

$(-)-241$ (rhaziniliam)

Scheme 69. Synthesis of (-)-rhazinilam (241) from compound C39

The chemoselective $\mathrm{Pd}(\mathrm{OAc})_{2} / \mathrm{S}$-Phos-catalyzed reaction of boronic acid A43 with unsaturated carboxyamide B46 possessing a chlorovinyl moiety (entry 4, Table 7), which gave compound $\mathbf{C 4 0}$ in 38\% yield, was the key step of an enantioselective total synthesis of malyngamide L (242).[187] The determination of the absolute configuration of C(3") and C(4") in the amine portion of the natural compound was accomplished by the synthesis of 3",4"-epimalyngamide L (284) and 242 (Figure 12). [187]

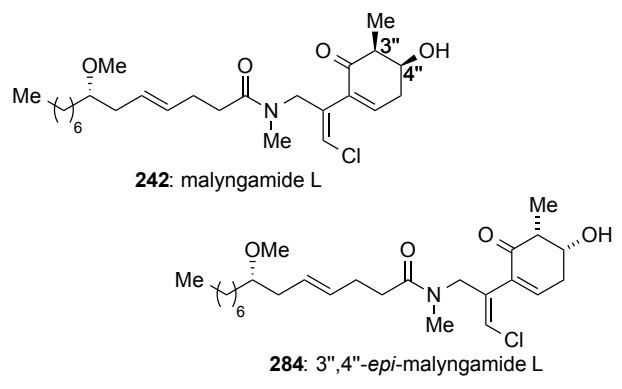

Figure 12. Structures of compounds 242 and 284

A key step in the synthesis of $\mathbf{2 8 4}$ was the $\mathrm{Pd}(\mathrm{OAc})_{2} /$ SPhos-catalyzed S.-M. reaction of boronic acid ent-43 with B46 that provided compound 285 in $42 \%$ yield (Scheme 70).[187]

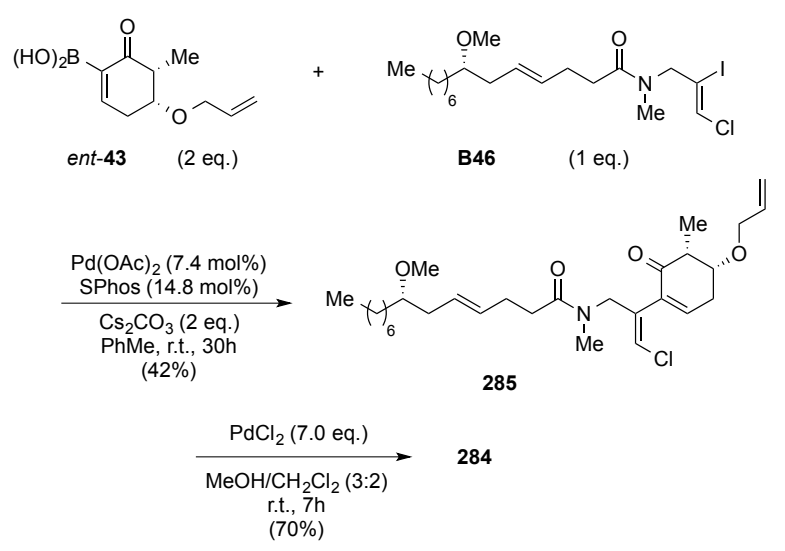

Scheme 70. Synthesis of 3",4"-epi-malyngamide L (284) from compounds ent-43 and B46

It is worth noting that when $t$ - $\mathrm{Bu}_{3} \mathrm{P} \cdot \mathrm{HBF}_{4}$ was used as the ligand of the Pd-catalyzed S.-M. reaction between ent-43 and B46 no desired product resulted. The synthesis of 3",4"-epimalyngamide L was then completed by removal of the allyl group of 285 with $\mathrm{PdCl}_{2}$ in a mixture of $\mathrm{MeOH}$ and $\mathrm{CH}_{2} \mathrm{Cl}_{2}$.[187]

The $\mathrm{Pd}(\mathrm{OAc})_{2} / \mathrm{SPhos}-$ catalyzed reaction between pinacol boronate A41 and aryl bromide B47 (entry 5, Table 7) was the key step of a total synthesis of altenuisol (243), which was achieved in 10 steps and $23 \%$ yield starting from phloroglucinic acid (286) and aldehyde 287 (Figure 12).[221] The S.-M. coupling led to benzyl-protected resorcylic lactone $\mathbf{C 4 1}$ in a single step. The subsequent hydrogenolysis of the benzyl group of $\mathbf{C 4 1}$ with $\mathrm{H}_{2}(5 \mathrm{bar})$ in the presence of $\mathrm{Pd} / \mathrm{C}$ led to altenuisol in quantitative yield. This total synthesis allowed Podlech and co-workers to establish that the originally proposed structure 243 of the natural product was nor correct. Consequently, two isomers 
of 243, i.e. compounds $\mathbf{2 8 8}$ and $\mathbf{2 8 9}$ (Figure 12) were synthesized.<smiles>O=C(O)c1c(O)cc(O)cc1O</smiles><smiles></smiles><smiles>O=Cc1ccc(O)c(O)c1</smiles>

287

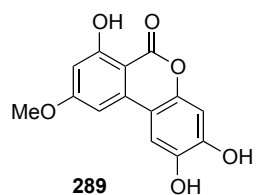

Figure 12. Structures of compounds 286-289

The key step of the synthesis of $\mathbf{2 8 8}$ was the S.-M. reaction illustrated in Scheme 7, which involved boronate A41 and aryl bromide 290 producing compound 291 in 77\% yield. On the other hand, the key step of the synthesis of $\mathbf{2 8 9}$ was the S.-M. reaction between boronate 292 and aryl bromide 293, which gave compound 294 in 39\% yield (Scheme 71).<smiles>COc1cc(O)c(Br)cc1OCCNC(=O)O</smiles>

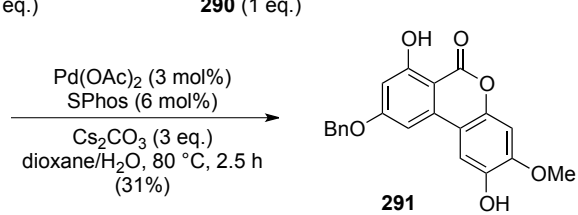<smiles>COc1cc([18OH])c2c(c1)OC(C)(C)OC2=O</smiles>

$$
\begin{gathered}
\mathrm{Pd}(\mathrm{OAc})_{2}(5 \mathrm{~mol} \%) \\
\mathrm{SPhos}(10 \mathrm{~mol} \%) \\
\underset{\mathrm{Cs}_{2} \mathrm{CO}_{3}(3 \mathrm{eq} .)}{\longrightarrow} \\
\text { dioxane } / \mathrm{H}_{2} \mathrm{O}, 80{ }^{\circ} \mathrm{C}, 2.5 \mathrm{~h} \\
(30 \%)
\end{gathered}
$$

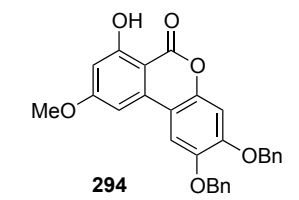

Scheme 71. Synthesis of compounds 291 and 294

The comparison of the NMR spectra of compounds 243 , $\mathbf{2 8 8}$ and $\mathbf{2 8 9}$ and their peracetylated derivatives with those of naturally-occurring altenuisol and its triacetate showed that the spectra of $\mathbf{2 8 9}$ matched perfectly with those of the natural product.[221]

In 2012, Igarashi and co-workers described the first total synthesis of hydroxy- $\alpha$-sanshool (244).[232] It involved the $\mathrm{Pd}(\mathrm{OAc})_{2} /$ SPhos-catalyzed S.-M. coupling of bromoalkyne B48 with boronate A44 (entry 6, Table 7).[232] (Z)Stereoselective reduction of the triple bond of the cross- coupling product $\mathbf{C 4 2}$ by treatment with $\mathrm{Zn}$ dust in water and $\mathrm{MeOH}, \mathrm{Cu}(\mathrm{OAc})_{2}$ and $\mathrm{AgNO}_{3}$ at room temperature gave 244 in $84 \%$ yield.[222]

In the same year, the $\mathrm{Pd}(\mathrm{OAc})_{2} / \mathrm{SPhos}$-catalyzed crosscoupling reaction of pinacol boronate $\mathbf{A 4 1}$ with aryl bromide B49 (entry 7, Table 7) was achieved with concomitant translactonization in a similar manner to the reaction of entry 5, Table 7 and to those illustrated in Scheme 71.[223] The reaction of entry 7 gave in $81 \%$ yield compound $\mathbf{C 4 2}$, which is the common precursor to naturally-occurring alterlactone (246) and altenusin (245).[223] In fact, hydrogenolysis of C42 in a 1:10 mixture of AcOEt and EtOH in the presence of $\mathrm{Pd} / \mathrm{C}$ quantitatively led to 246, while use of AcOEt as the sole sovent led to $\mathbf{2 4 5}$ (Scheme 72). [223

]
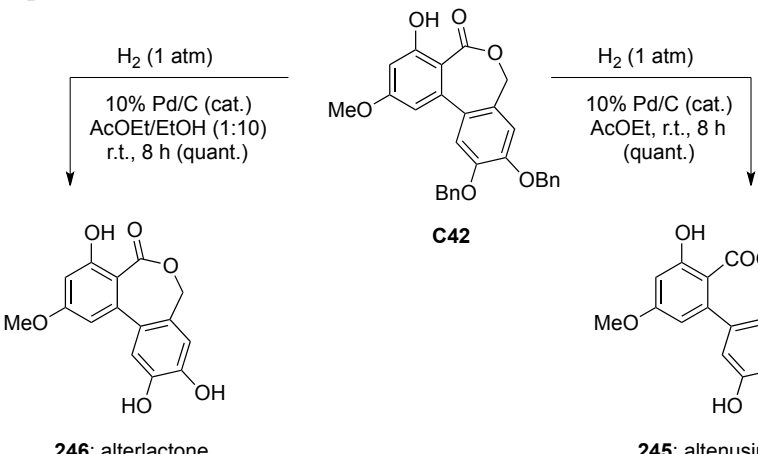

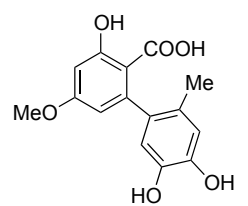

245: altenusin
Scheme 72. Synthesis of altenusin (245) and alterlactone (246) from $\mathrm{C42}$

More recently, concomitant cross-coupling and translactonization reactions were also found to occur when A41 was reacted with aryl bromide B50 in the presence of catalytic amounts of $\mathrm{Pd}(\mathrm{OAc})_{2}$ and SPhos (entry 8, Table 7).[200] Phase-transfer glycosylation of the resulting alternariol 9-methyl ether (C43) with commercially available acetobromoglucose produced glycoside 295 (Figure 13), which was converted to lysilactone A (247) (Figure 13) by treatment with sodium methoxide in $\mathrm{MeOH}$.[200]

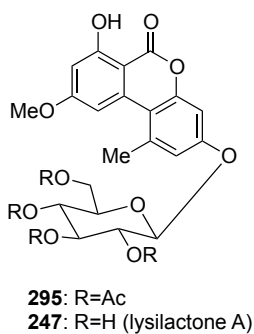

Figure 13. Structures of compounds 247 and 295

In 2013, compound C45, which was prepared in 70\% yield by $\mathrm{Pd}(\mathrm{OAc})_{2} / \mathrm{SPhos}-$ catalyzed reaction of $\mathbf{A 4 7}$ with aryl bromide $\mathbf{B 5 3}$ (entry 11, Table 7), was used as a key intermediate in a concise synthesis of the hasubanan alkaloid cepharatine A (250). [226] In particular, compound $\mathbf{C 4 5}$ was converted to $O$-alkylated biaryl 296 by treatment with the dibromide in situ generated by addition of bromine to ethyl 
vinyl ether. The subsequent key step was the reaction of $\mathbf{2 9 6}$ with $\mathrm{CsF}$ in $\mathrm{DMF}$ at $80{ }^{\circ} \mathrm{C}$, which gave compound 296 (Scheme 73). Finally, reductive amination of 298 followed by treatment of the resulting crude product with aqueous $1 \mathrm{M}$ $\mathrm{HCl}$ gave cepharatine A (250) in $42 \%$ yield (Scheme 73).[226]
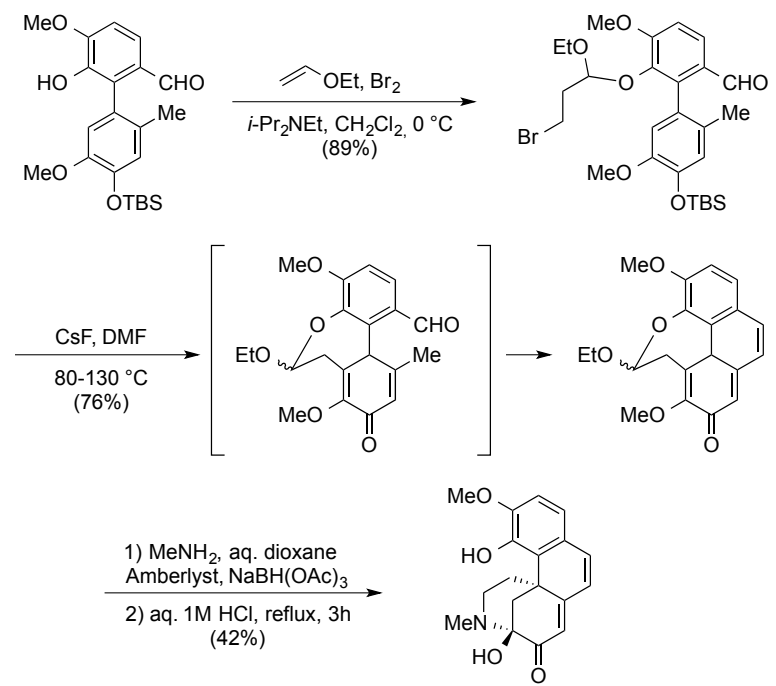

250: cepharatine A

Scheme 73. Synthesis of cepharatine A (250) from compound $\mathbf{C 4 5}$

In 2011, naturally-occurring 4- $O$-methylhonokiol (256) was synthesized in $72 \%$ yield by the microwave-promoted $\mathrm{Pd}(\mathrm{OAc})_{2} / \mathrm{RuPhos}-$ catalyzed reaction illustrated in entry 17 of Table 7.[212 ]Remarkably, when the microwave-mediated cross-coupling reaction was conducted using $\mathrm{PdCl}_{2}$ (dppf) $\cdot \mathrm{CH}_{2} \mathrm{Cl}_{2}$ as the catalyst precursor and $\mathrm{K}_{2} \mathrm{CO}_{3}$ as the base in a mixture of toluene and water the desired natural product was not obtained.[212]

In 2013, Del Valle and Krische accomplished the total synthesis of (+)-trienomycin A (257) on the basis of the retrosynthetic analysis shown in Scheme 74, which invoked a convergent assembly of fragments $\mathbf{A}, \mathbf{B}$ and dienylsilane C.[213]
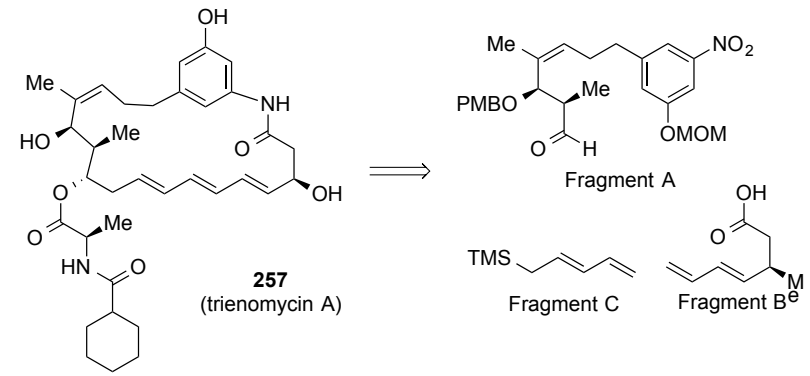

Scheme 74. Retrosynthesis of (+)-trienomycin A (257)

Fragment A was prepared through a reaction sequence in which intermediate C50 was obtained in 90\% yield by $\mathrm{Pd}(\mathrm{OAc})_{2} / \mathrm{RuPhos}$-catalyzed reaction of crude organoborane
A52 with vinyl iodide $\mathbf{B 5 8}$ (entry 18, Table 7).[213] Compound $\mathbf{A 5 2}$ was in turn prepared by S.-M. coupling of 3bromo-5-nitrophenol (299) with potassium ethenyltrifluoroborate (177) and MOM protection of the resulting cross-coupling product, followed by regioselective hydroboration with 9-BBN-H (Scheme 75).[213]

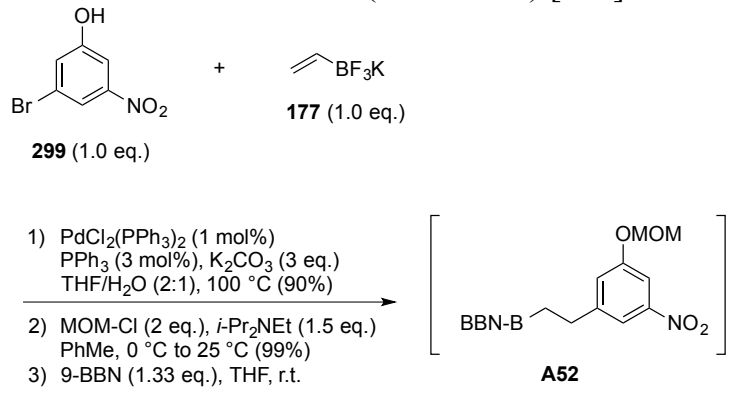

Scheme 75. Synthesis of alkylborane A52

Again in 2013, the $\mathrm{sp}^{3}-\mathrm{sp}^{3}$ S.-M. cross-coupling reaction of enantiomerically enriched (S)-3-(trifluoroborato)- $N$-2dimethylpropanamide A53 with electron rich aryl bromide B59 in a mixture of toluene and water in the presence of $\mathrm{K}_{2} \mathrm{CO}_{3}$ as the base and a catalysts system consisting of a mixture of $\mathrm{Pd}(\mathrm{OAc})_{2}$ and RuPhos (entry 19, Table 7) was a key feature of the first total synthesis of the benzannulated spiroketal virgatolide B (258).[214c] The cross-coupling reaction proceeded cleanly producing compound C51 in $52 \%$ yield. A 6 -step reaction sequence in which intermediate aryl iodide $\mathbf{3 0 0}$ was converted into phthalide $\mathbf{3 0 1}$ by carbonylation with concomitant intramolecular alkoxylation (Scheme 76) allowed then to obtain 258 in $13.6 \%$ yield based on C51.[214c]
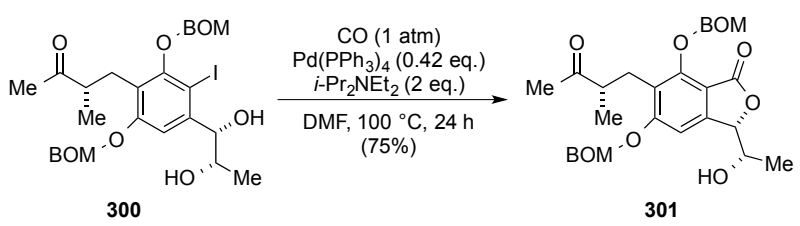

Scheme 76. Synthesis of phthalide 301 from compound 300

Very recently, compound $\mathbf{C 5 2}$, the key intermediate in an enantioselective total synthesis of (-)-mersicarpine (259), ()-leuconalam (260) and (-)-leoconoxine (261) was synthesized in $75 \%$ yield by the $\mathrm{Pd}_{2}(\mathrm{dba})_{3} / \mathrm{John}$-Phoscatalyzed S.-M. coupling of alkenyl iodide B60 with 2nitrophenylboronic acid (A54) (entry 20, Table 7).[215] Compound $\mathbf{C 5 2}$ was subsequently diversified into the three natural products by controlled oxidation/reduction/polycyclization sequences.[215]

\section{TOTAL SYNTHESES VIA $\mathrm{PdCl}_{2}(\mathrm{dpp} f$ ) OR $\mathrm{PdCl}_{2}(\mathrm{dppf}) \cdot \mathrm{CH}_{2} \mathrm{Cl}_{2}$-CATALYZED S.-M. REACTIONS}

Dichloro[1,1'-bis(diphenylphosphino)ferrocene]palladium $\left[\mathrm{PdCl}_{2}(\mathrm{dppf})\right]$ is a complex that in 1984 Hayashi 
and Higuchi found to be an effective catalyst for crosscouplings of primary and secondary alkyl Grignard and alkylzinc reagents with organic halides.[239] In 1986, it was employed by Suzuki and co-workers for very efficient crosscoupling reactions of 9-alkyl-9-BBN derivatives or trialkylboranes with aryl and 1-alkenyl halides.[240] $\mathrm{PdCl}_{2}$ (dppf) or its complex with $\mathrm{CH}_{2} \mathrm{Cl}_{2}$ was subsequently used as catalyst precursor for borylation of aryl halides,[241a,b] triflates,[241c] or diazonium salts with a dialkoxyborane[241b] or a tetraalkoxydiborane[241a,c] and for a wide range of reactions such as $B$-alkyl S.-M. crosscouplings of trialkylboranes with diversely functionalized aryl bromides,[242] S.-M. vinylation of hindered aryl bromides with potassium vinyltrifluoroborate,[243] intramolecular double or triple S.-M. coupling reactions of substituted di- or tribromobenzenes, [244] the arylation reaction of 4(5)-bromo- $1 H$-imidazole with arylboronic acids under phase-transfer conditions,[245] cross-couplings of alkenyl bromides with potassium alkyltrifluoroborates,[246] cross-couplings of diverse potassium $\beta$ aminotrifluoroborates with aryl halides, [247] crosscouplings of aryl-and electron-rich heteroaryltrifluoroborates with aryl and activated heteroaryl bromides,[248] crosscouplings of benzyl halides with potassium aryltrifluoroborates, [249] reaction of (organo-1,2,3-triazol-4yl)trifluoroborates with aryl and alkenyl bromides;[,50] and cyanomethylation of aryl halides through domino S.-M. coupling-isoxazole fragmentation.[251] In addition, $\mathrm{PdCl}_{2}$ (dppf) and its complex with $\mathrm{CH}_{2} \mathrm{Cl}_{2}$ have been used in several S.-M. reactions and one-pot borylation/S.-M. couplings involved in total syntheses of naturally-occurring substances.

Table 8 lists the structures of naturally-occurring compounds 43, 255 amd 302-335 that, during the period January 2010-December 2013 were synthesized through $\mathrm{PdCl}_{2}$ (dppf) or $\mathrm{PdCl}_{2}(\mathrm{dppf}) \cdot \mathrm{CH}_{2} \mathrm{Cl}_{2}$-catalyzed S.-M. reactions. Table 8 also reports the literature data on the isolation of these natural substances.

Edaxadiene (302) is a halimane-type diterpenoid produced by the pathogen Mycobacterium tuberculosis.[252] Hirtellanine A (303) is a cumarochromone derivative isolated from the roots of Campylotropis hirtella (Fabaceae), which was found to exhibit in vivo very strong lymphocyte suppression activity.[253] Canthin-6-one (304) is a $\beta$ carboline alkaloid first isolated from Pentaceras australis (Rutaceae),[254] and 9-methoxycanthin-6-one (305) is a cytotoxic compound isolated from the roots of Eurycoma longifolia (Simaroubaceae). [255] (+)-Ottelione A (306) is a potently cytotoxic 4-methylene-2-cyclohexenone which was isolated from the fresh water plant Ottelia alismoides (Hydrocharitaceae) collected in the Nile Delta.[256] Riccardin C (255), as previously mentioned, is a macrocyclic bis(bibenzyl) compound, which was isolated from the liverwort Reboulia hemisphaerica (Aytoniaceae).[210] (-)Brevisin (307) is a polycyclic ether, which was isolated from the red tide dinoflagellate Karenia brevis. [257] Brevenal (308) is another member of the family of marine polycyclic ethers, which was isolated from $K$. brevis.[258] (-)-
Brevisamide (309) is a monocyclic ether amide, which was isolated from K. brevis.[259] $\mathrm{SCH} 351448$ (310) is a dimeric polyketide, which was isolated from an unspecified Micromonospora sp.[260] and was found to be a selective activator of low-sensity lipoprotein receptor promotor. $(R)-(-$ )-Tylophorine (311) is an alkaloid, which was isolated from the Indian plant Tylophora indica (Asclepiadaceae).[261] Mycocyclosin (312) is a diketopiperazine produced by $M$. tuberculosis.[262] Ajudazol B (313) is a polyketide produced by a myxobacterium Chondramyces crocatus strain,[263a] which proved to be an highly effective inhibitor of the mitochondrial respiratory chain.[263b] Lycoramines A (314) and B (315) are two alkaloids isolated from the bulbs of Lycoris radiata (Amaryllidaceae), a Chinese plant the crude extract of which have been used as folk remedies for laringal problems as well as for the treatment of carbuncles and boils.[264] 2-Methoxypratosin (316) is an alkaloid isolated from whole plants of Narcissus serotinus (Amaryllidaceae).[265] Acerogenin E (317) is a macrocyclic diarylheptanoid, which was isolated from the stem bark of Acer nikoense (Aceraceae), a plant traditionally used in Japan as a folk medicine for the treatment of eye-related diseases and hepatic disorders.[266] Ginkgolic acid (13:0) (318) is a salicylic acid derivative found in several plant materials including cashew nuts.[267] Didemnaketal B (319) is a spiroacetal derivative isolated from the magenta ascidian Didemnum sp., which was found to exhibit potent inhibitory activity against HIV-1 protease.[268] Lodopyridone (320) is a cytotoxic alkaloid isolated from the marine bacterial strain Narcissus serotinus collected near the mouth of la Jolla Canyon.[269] Primin (321) is an allergenic 1,4benzoquinone first isolated from the plant Primula obconica (Primulaceae) [270a] and subsequently from the endophytic fungus Botryosphaeria mamane PSU-M76.[270b] (+)Cacospongionolide B (322) is a secondary metabolite of the marine sponge Fasciospongia cavernosa, which was shown to possess aantimicrobial and cytotoxic activitites.[271] Norchelerythrine (323) is a benzo[c]phenanthridine alkaloid isolated from Zanthoxylum simulans,[282a] $Z$. integrifolium, [272b] and Z. capense.[272c] Norsanguinarine (324) is another benzo[c]phenanthridine alkaloid isolated from callus tissue of Papaver somniferum (Papaveraceae),[273a] from Fumaria indica (Papaveraceae)[273b] and Corydalis tashiroi (Papaveraceae).[273c] Narseronine (325) is an Amaryllidaceae alkaloid, which was isolated from the flowering plant Narcissus serotinus. [274] (+)-Spiculoic acid (326) is a secondary metabolite produced from the Caribbean marine sponge Plakortis angulospicatus.[275] (+)Zyggomphic acid (327) is a bioactive marine polyketide, which was isolated from $P$. angulospicatus[276a] and $P$. zyggompha.[276b] Dictyobiphenyls A (328) and B (329) and dictyoterphenyls A (330) and B (331) are four aromatic compounds, which were isolated from the fruiting bodies of the cellular slime mold Dictyostelium discoideum.[277] Cedrelin A (332) is a dihydrophenthrapyran isolated from the flowering plant Cedrelinga catenaeformis (Fabaceae).[278] Paracaseolide A (333) is a natural product featuring oxa-bowl architecture, which was isolated from the 
stem bark of Sonneratia paracaseolaris (Lythraceae), an endemic mangrovia found in China, and was shown to exhibit significant bioactivity against dual specificity phosphatase CDC25B, a key enzyme for cell progression.[279] Synechoxanthin (334) is an aromatic C40 xanthophyll that is a major carotenoid in the cyanobacterium Synechoccus sp. PCC 7002.[280] Dyctyodendrins A (335) and $\mathrm{B}(\mathbf{4 3})$ are two marine alkaloids isolated from the marine sponge Dictyodendrilla verongiformis that posseses inhibitory activity against telomerase.[79]

\section{TABLE 8 HERE}

The $\mathrm{PdCl}_{2}$ (dppf)- or $\mathrm{PdCl}_{2}$ (dppf) $\cdot \mathrm{CH}_{2} \mathrm{Cl}_{2}$-catalyzed S.-M. cross-coupling reactions used in the total syntheses of naturally compounds 43,255 , and $\mathbf{3 0 2}-\mathbf{3 3 5}$ are illustrated in Table 9, which also contains the detailed experimental conditions and yields of the reactions. Applications of these couplings are outlined after this table.

\section{TABLE 9 HERE}

The $\mathrm{sp}^{3}-\mathrm{sp}^{2}$ coupling of alkylborane A54 with alkenyl bromide B60 (entry 1, Table 9) was used in a protocol developed for the synthesis of the M. tuberculosis-produced diterpene edaxadiene.[281] However, discrepancies between the spectroscopic data of the natural product and those of the synthetic construct raised questions regarding the proposed structure $\mathbf{3 0 2}$ of edaxadiene. Re-evaluation of the spectral data led to propose that edaxadiene is nosyberkol (336) (Figure 14), a diterpene previously isolated from a marine sponge Raspailia sp.[282] The structural reassignment was then validated by a synthesis of the correct structure of the natural product.[281]

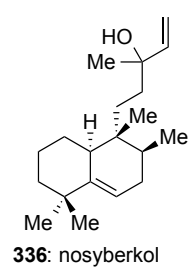

Figure 14. Structure of compound 336

The key step of a regioselective total synthesis of hirtellanine $\mathrm{A}$ (303) was the high yielding $\mathrm{PdCl}_{2}(\mathrm{dppf})$ catalyzed reaction between crude pinacol boronate $\mathbf{A 5 5}$ and iodide B61 (entry 2, Table 9).[283] Compound A55 was prepared by $\mathrm{PdCl}_{2}\left(\mathrm{PPh}_{3}\right)_{2}$-catalyzed boronation of aryl bromide 337 with pinacol borane (Scheme 77).

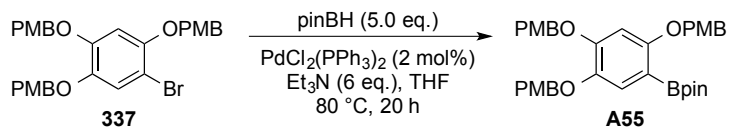

Scheme 77. Synthesis of compound $\mathbf{A 5 5}$

Iodide B61 was in turn synthesized in $30.7 \%$ overall yield starting from acetylphloroglucinol (338) through a reaction sequence (Scheme 78) involving formation of compound 342 by a $\mathrm{Ca}(\mathrm{OH})_{2}$-induced tandem regioselective Knoevenagel electrocyclic reaction of 5,7dihydroxychromen-4-one (339) with 5 equiv of 3-methyl-2butenal (340) in $\mathrm{MeOH}$ at room temperature that provided the chromone derivative $\mathbf{3 4 1}$ in $40 \%$ yield.[283]

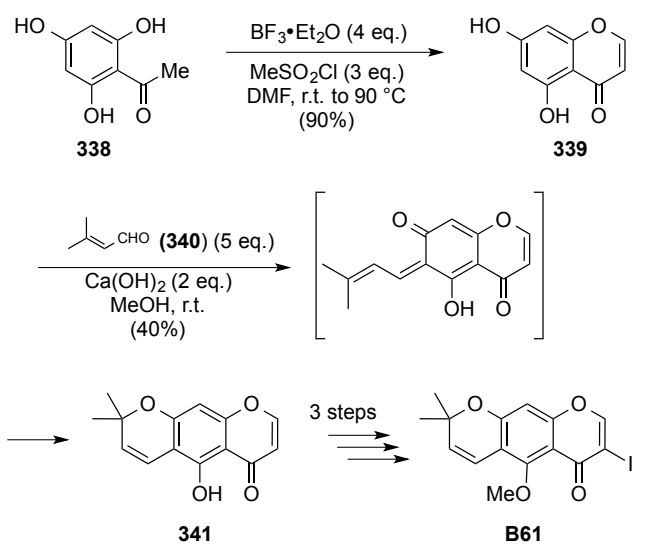

Scheme 78. Synthesis of iodide B61

Compounds C54 and C55, which were synthesized in high yields by the reactions illustrated in entries 3 and 4 of Table 9, were used as advanced intermediate in the synthesis of canthin-6-one (304) and 9-methoxycanthin-6-one (305), respectively.[284] In particular, compounds $\mathbf{3 4 2}$ and 343, which were obtained by demethylation of $\mathbf{C 5 4}$ and C55, were converted into $\mathbf{3 0 5}$ and $\mathbf{3 0 6}$ respectively,[284] via $\mathrm{Cu}-$ catalyzed intramolecular amidation using Buchwald's conditions[285] (Scheme 79).
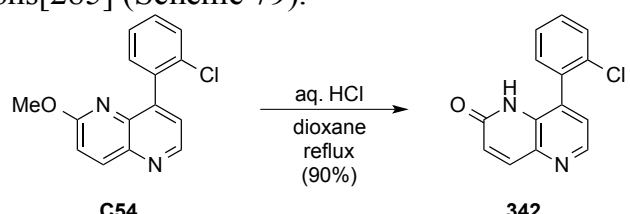

342
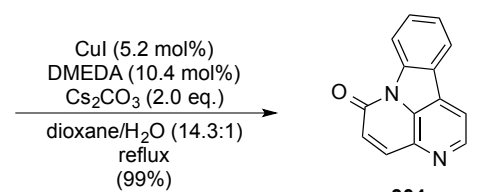

304
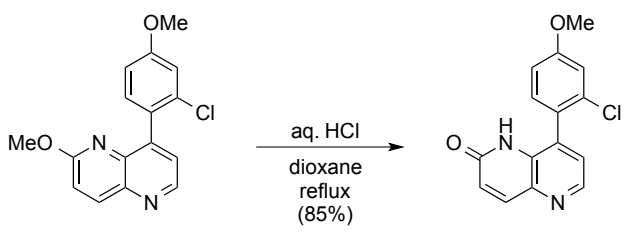

C55

343
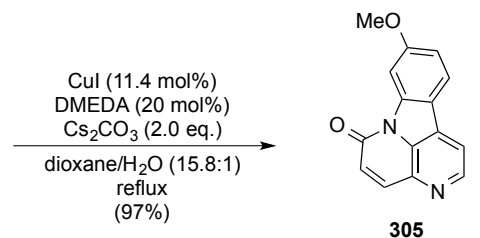
Scheme 79. Synthesis of compounds 304 and 305 starting from C54 and C55, respectively

It is also worth mentioning that canthin-6-one and 9methoxycanthin-6-one were also synthesized in 95 and $92 \%$ yield, respectively, using a simple one-pot protocol involving a sequential $\mathrm{PdCl}_{2}(\mathrm{dppf}) \cdot \mathrm{CH}_{2} \mathrm{Cl}_{2}$-catalyzed S.-M. cross-coupling reaction, followed by a CuI/DMEDAcatalyzed C-N coupling.[284a]

In 2010, compound C56, which was synthesized in $65 \%$ yield by the S.-M. reaction of entry 5 of Table 9 , followed by treatment of the cross-coupling product thereby obtained with TBAF in THF at $60{ }^{\circ} \mathrm{C}$, was used by Sha and coworkers as a key intermediate in an enantioselective total synthesis of $(+)$-ottelione A (306) involving the use of chiral enone 344[286] as the starting material (Scheme 80). [287] It was also reported that treatment of $\mathbf{3 0 6}$ with $\mathrm{NaOH}$ at $0{ }^{\circ} \mathrm{C}$ gave (-)-ottelione $\mathrm{B}(\mathbf{3 4 5})$ and (+)-ottelione $\mathrm{A}(\mathbf{3 0 6})$ in a 10:1 ratio, respectively. Silica gel chromatography allowed to isolate pure 345 (Scheme 80),[287] a natural compound isolated from Ottelia alismoides (Hydrocharitaceae).[256]
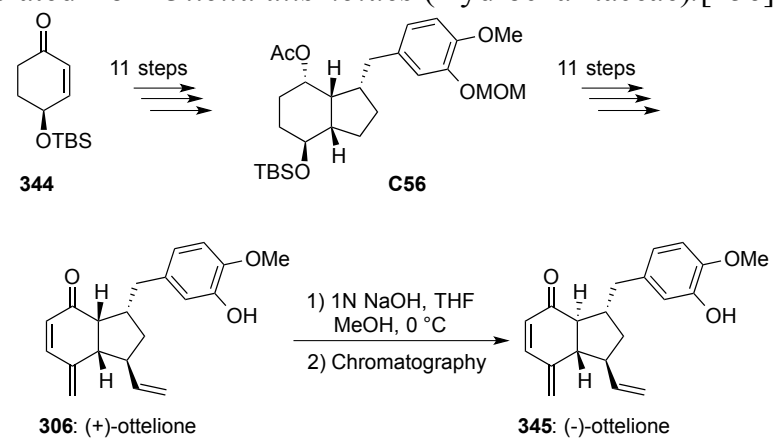

Scheme 80. Synthesis of (+)-ottelione A (306) and (-)ottelione B (345) from enone 344

In 2011, an efficient total synthesis of riccardin C (255) was accomplished by Kagechika and co-workers in 16 steps and $7.4 \%$ overall yield by using the $\mathrm{PdCl}_{2}(\mathrm{dppf})$-catalyzed S.-M. reaction of pinacol boronate $\mathbf{A 5 9}$ with aryl bromide B64 (entry 6, Table 9) to link the $\mathrm{B}$ and $\mathrm{C}$ rings of the natural product.[288] The cross-coupling reaction, which was carried out in a 50:1 mixture of DMF and water in the presence of $\mathrm{K}_{3} \mathrm{PO}_{4}$ as base, provided compound $\mathbf{C 5 7}$ in $76 \%$ yield.[288]

In the same year, the first total synthesis of the hexacyclic polyether (-)-brevisin (307) was achieved connecting the side chain fragments $\mathbf{X}$ and $\mathbf{Y}$ of the natural product (Figure 16) by means of the $\mathrm{PdCl}_{2}(\mathrm{dppf}) \cdot \mathrm{CH}_{2} \mathrm{Cl}_{2}$-catalyzed S.-M. cross-coupling reaction of $B$-methoxyboronate $\mathbf{A 6 0}$ with vinyl bromide B64 (entry 7, Table 9).[289]

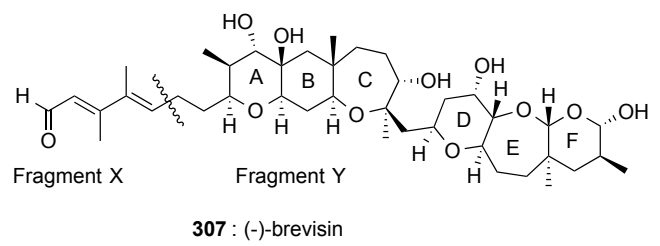

Figure 15. Structure of (-)-brevisin (307)

On the other hand, the $\mathrm{PdCl}_{2}(\mathrm{dppf}) \cdot \mathrm{CH}_{2} \mathrm{Cl}_{2}$-catalyzed S.$\mathrm{M}$. reaction between ketene acetal phosphate 347 and the organoboron reagent obtained by the reaction of alkene 346 with 9-BBN-H was a key step in the synthesis of the ABC fragment of 307.[289] As shown in Scheme 81, the crosscoupling reaction provided compound 348 in $86 \%$ yield.[289]

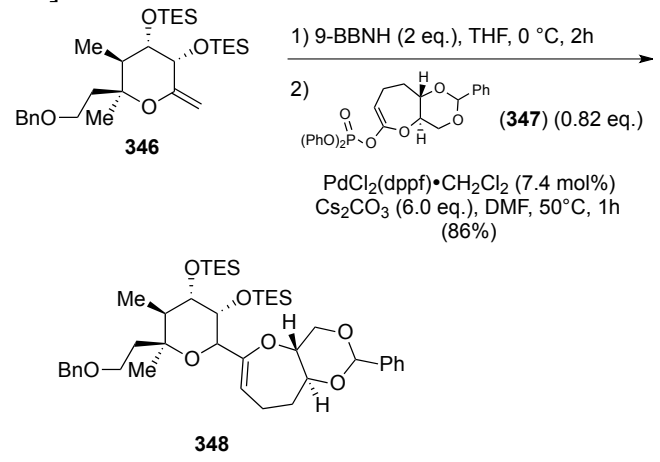

Scheme 81. Pd-catalyzed synthesis of compound 348

The $\mathrm{PdCl}_{2}(\mathrm{dppf})$-catalyzed S.-M. reaction of alkylmethoxyboronate A61 with ketene acetal phosphate B65 (entry 8, Table 9) had previously been employed in a convergent total synthesis of brevenal (308).[290] Compound A61 was prepared from the known iodide 349[291] (Figure 16) and compound B65 was synthesized in 11 steps starting from the known alcohol 350[292] (Figure 16). Compound $\mathbf{C 5 8}$ resulting from the S.-M. coupling was then used in the synthesis of the $\mathrm{ABC}$ ring segment 351 (Figure 16) of the natural product.[290]

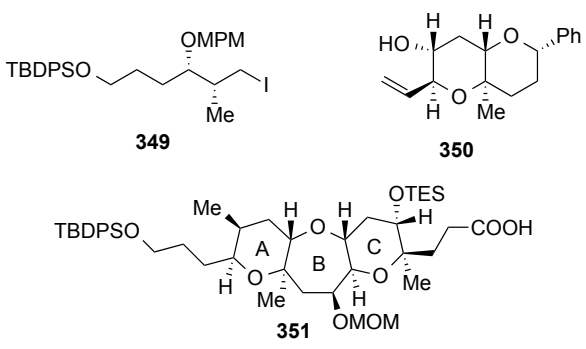

Figure 16. Structures of compounds 349-351

In 2010, Satake, Tachibana and co-workers accomplished a total synthesis of $(-)$-brevisamide (309) that featured the preparation of compound $\mathbf{C 5 9}$ by the $\mathrm{PdCl}_{2}$ (dppf)-catalyzed S.-M. reaction of alkylmethoxyboronate $\mathbf{A 6 2}$ with alkenyl bromide B66 (entry 9, Table 9) as key step.[293] Alkyl 
iodide 356, the direct precursor to $\mathbf{A 6 2}$, was synthesized from 3-benzyloxy-1-propanol (352) via a 13 step reaction sequence involving formation of $\alpha, \beta$-unsaturated lactone 355 by treatment of $\beta$-hydroxyaldehyde $\mathbf{3 5 3}$ with methyl diphenylphosphono-acetate (354) and $\mathrm{NaH}$ in THF (Scheme 82).[293]
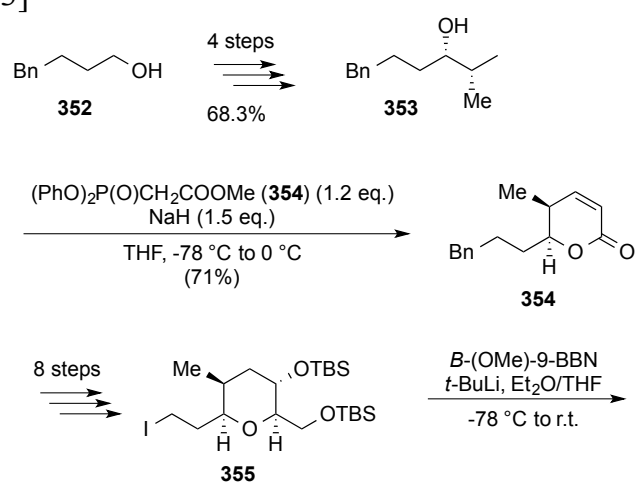

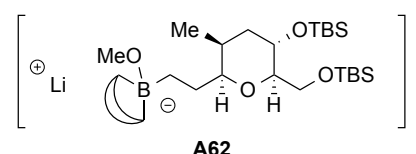

Scheme 82. Synthesis of compound A62

Alkenyl bromide B66 was prepared starting from methyl methacrylate (357) through a stereoselective HornerWadsworth-Emmons reaction of the intermediate bromoenone 358 with ethyl diethylphosphonoacetate (359) that provided compound $\mathbf{3 6 0}$ in $31 \%$ yield from $\mathbf{3 5 7}$ (Scheme 83).[293]

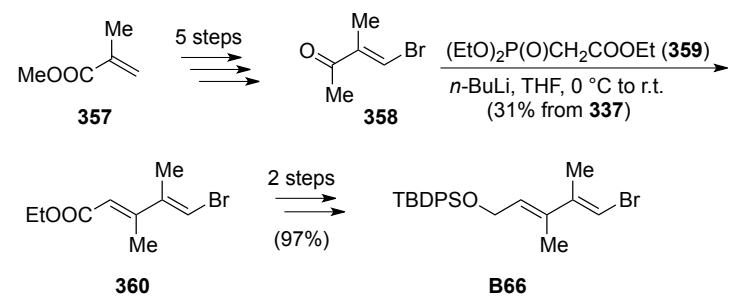

Scheme 83. Synthesis of dienyl bromide $\mathbf{B 6 6}$

In 2011, Hong and co-workers accomplished an elegant enantioselective formal synthesis of SCH 351448 (310) using the S.-M. reaction illustrated in entry 10 of Table 9 that provided compound $\mathbf{C 6 0}$ in 73\% yield.[294] Compound C60 was then converted via a 5-step reaction sequence into compound 361 (Figure 17), which had previously been reported to be a precursor to SCH 351448.[295]

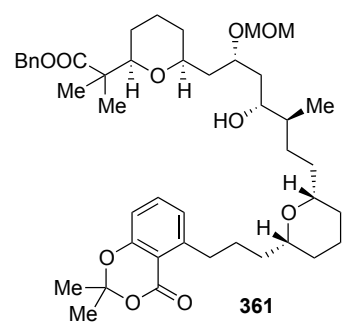

Figure 17. Structure of compound 361

In 2013, Lin and Ho synthesized the phenanthrolidine alkaloid tylophorine (312) in racemic form via a route involving the $\mathrm{PdCl}_{2}(\mathrm{dppf})$-catalyzed reaction between (Z)-1benzyl-5-[2,3-bis(4,4,5,5-tetramethyl-1,3,2-dioxaborolan-2yl)allyl]-2-pyrrolidinone (A64) and 2,2'-dibromo-4,5,4',5'tetramethoxybiphenyl (B68) (entry 11, Table 9).[296] The reaction provided in $61 \%$ yield compound $\mathbf{C 6 1}$ which was then deoxygenated on reaction with $\mathrm{LiAlH}_{4}$ and further $N$ debenzylated by treatment with $\mathrm{H}_{2}$ in the presence of $\mathrm{Pd} / \mathrm{C}$ to give compound 362. Finally, the Pictet-Spengler reaction of 362 with a formalin solution in concentrated $\mathrm{HCl}$ gave 312 in $84 \%$ yield (Scheme 84).[296]

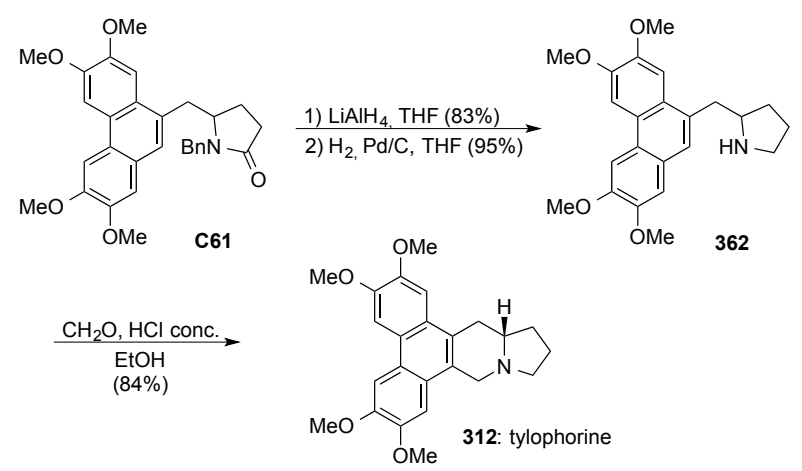

Scheme 84. Synthesis of racemic tylophorine from compound $\mathbf{C 6 1}$

In 2012, Hutton and co-workers accomplished the first total synthesis of mycocyclosin (312) starting from $L$ iodotyrosine (363) via a series of reactions involving a onepot Pd-catalyzed borylation/S.-M. cross-coupling reaction to generate the biaryl linkage of the natural product (Scheme 85).[297] In particular, cyclodi(3-iodo-4-O-benzyl- $L$ tyrosine) (364) was reacted with bispinacolatodiboron in the presence of $\mathrm{PdCl}_{2}$ (dppf) $\cdot \mathrm{CH}_{2} \mathrm{Cl}_{2}$ and $\mathrm{K}_{2} \mathrm{CO}_{3}$ in DMSO at 90 ${ }^{\circ} \mathrm{C}$ to give bis $(O$-benzyl)mycocyclosin $(\mathbf{C 6 2})$ in $42 \%$ yield (entry 12, Table 9). Compound $\mathbf{C 6 2}$ was the treated with trifluoroacetic acid (TFA) in pentamethylbenzene for $1 \mathrm{~h}$ to give 312 in 74\% yield (Scheme 85).[297] 

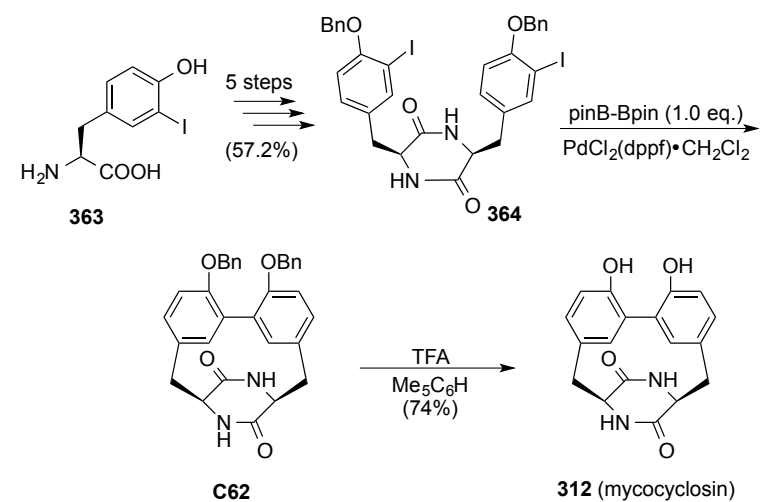

Scheme 85. Synthesis of mycocyclosin (3120) from compound 363

In the same year, Menche and co-workers assigned the full stereochemistry of ajudazol (313) by an innovative bioinformatic approach and validated this assignment by a total synthesis in which the key step was the late-stage stereocontrolled $\mathrm{PdCl}_{2}(\mathrm{dppf})$-catalyzed S.-M. reaction of $(Z)$ boronate ester $\mathbf{A 6 5}$ with (Z)-vinyl iodide B69 (entry 13, Table 9).[298]

In 2013, Banwell and co-workers synthesized the amaryllidaceae alkaloids lycoranines $\mathrm{A}(\mathbf{3 1 4})$ and $\mathrm{B}(\mathbf{3 1 5})$ in 88 and $65 \%$ yield, respectively, by the $\mathrm{PdCl}_{2}(\mathrm{dppf}) \cdot \mathrm{CH}_{2} \mathrm{Cl}_{2}-$ catalyzed reactions of aryl bromide $\mathbf{B 7 0}$ with borylindoles A66 and A67, respectively, in a mixture of THF and water in the presence of $\mathrm{Et}_{3} \mathrm{~N}$ as base (entries 14 and 15, respectively, Table 9).[299] They also reported that the $\mathrm{PdCl}_{2}$ (dppf) $\cdot \mathrm{CH}_{2} \mathrm{Cl}_{2}$-catalyzed reactions of pinacol boronate A68 with 2-bromobenzoate B71 in a mixture of THF and water in the presence of $\mathrm{Et}_{3} \mathrm{~N}$ (entry 16, Table 9) gave 2methoxypratosine (316) in 83\% yield.[299] Remarkably, Banwell and coworkers also synthesized employed the reversal of the polarity of the cross-coupling process used in the synthesis of $\mathbf{3 1 6}$ for the efficient preparation of compounds 314 and 315 . For instance, compound 314 was obtained in $81 \%$ yield by the $\mathrm{PdCl}_{2}(\mathrm{dppf}) \cdot \mathrm{CH}_{2} \mathrm{Cl}_{2}$-catalyzed reaction between the bromoindole derivative $\mathbf{A 7 1}$ and pinacol boronate 365 (Scheme 86).[299]

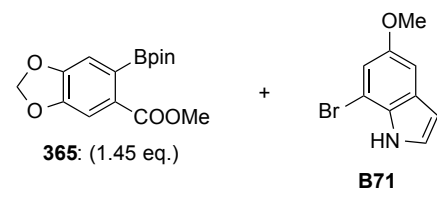
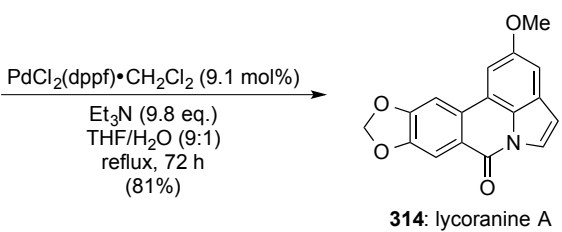

Scheme 86. Synthesis of lycoranine A (314) from pinacol boronate $\mathbf{3 6 5}$ and bromide $\mathbf{B 7 1}$

It is also worth pointing out that efficient intermolecular $\mathrm{C}-\mathrm{C}$ bond formation and intramolecular amidation occurred in the $\mathrm{PdCl}_{2}$ (dppf) $\mathrm{CH}_{2} \mathrm{Cl}_{2}$-catalyzed S.-M. reactions used to prepare compounds 314-316.[299]

In the same year, Ogura and Usuki achieved the first total synthesis of acerogenin E (317) using a domino process involving a Miyaura borylation-intermolecular S.-M. crosscoupling. [300] In particular, the diiodo derivative 367, which was prepared in $37.6 \%$ overall yield starting from methyl 4methoxybenzoate (366), was reacted with 1.2 equiv of bis(pinacolato)diboron, $9.7 \mathrm{~mol} \% \mathrm{PdCl}_{2}(\mathrm{dppf})$ and 10 equiv of AcOK in DMSO at $100{ }^{\circ} \mathrm{C}$ to give compound $\mathbf{C 6 4}$ (entry 17, Table 9). Deprotection of this dimethylether with $\mathrm{BBr}_{3}$ provided acerogenin E (317) in 94\% yield. Moreover, reduction of 317 with $\mathrm{NaBH}_{4}$ gave acerogenin $\mathrm{K}$ (368) (Scheme 87),[300] another diarylheptanoid isolated from Acer nikoense.[266]

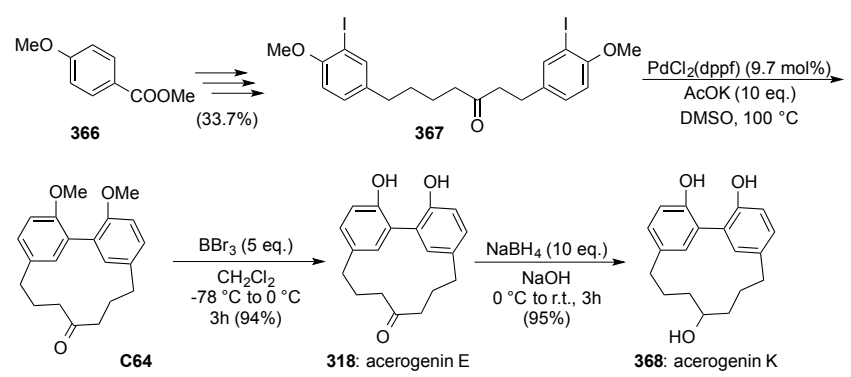

Scheme 87. Synthesis of acerogenins E (317) and K (368) from compound 366

More recently, ginkgolic acid (13:0) (318) was synthesized using the $\mathrm{PdCl}_{2}$ (dppf)-catalysed reaction of aryl triflate $\mathbf{B 7 2}$ with organoborane $\mathbf{A 6 8}$, which was prepared by hydroboration of 1-tridecene with 9-BBN-H (entry 18, Table 9).[301] The cross-coupling product $\mathbf{C 6 5}$ was hydrolyzed with $\mathrm{KOH}$ in DMSO at $80^{\circ} \mathrm{C}$ for $2 \mathrm{~h}$ and then acidified with $\mathrm{HCl}$ to give 318 in an unspecified low yield.[301] In order to explain this disappointing results, the cross-coupling reaction was examined and it was found that compound 369 (Figure 18) a byproduct of the reaction was which presumably was generated directly from the $\mathrm{PdCl}_{2}(\mathrm{dppf})$-catalysed coupling of 1-tridecene with triflate $\mathbf{B 7 2}$ without the assistance of BBN-H.[301]
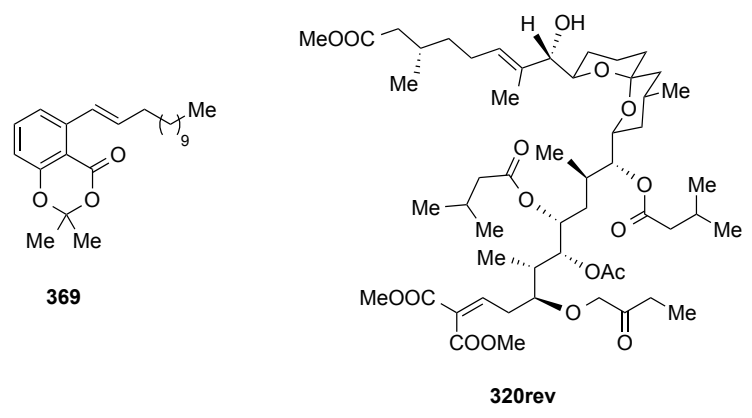

Figure 18. Structures of compounds 369 and 320rev

In 2013, Fuwa and co-workers accomplished the first total synthesis of the proposed structure of didemnakel B (319) 
according to a synthetic plan in which compound $\mathbf{C 6 5}$, a key intermediate was synthesized in $84 \%$ yield by means of the $\mathrm{PdCl}_{2}$ (dppf) $\cdot \mathrm{CH}_{2} \mathrm{Cl}_{2}$-catalyzed reaction of $B$ methoxyboronate $\mathbf{A 7 0}$ with ketene acetal phosphate B73 (entry 19, Table 9).[302a] However, comparison of the NMR data of the synthetic material with those of an authentic sample of the natural product revealed that the proposed structure $\mathbf{3 2 0}$ of natural didemnaketal $\mathrm{B}$ required stereochemical reassignment.[302a] Interestingly, the NMR data of compound 320rev (Figure 18), which was synthesized in 2014, were in good agreement with those of naturally occurring didemnakel B .[302b]

Still in 2013, Moody and co-workers performed the total synthesis of the 4-pyridone marine metabolite lodopyridone (320) using the $\mathrm{PdCl}_{2}(\mathrm{dppf}) \cdot \mathrm{CH}_{2} \mathrm{Cl}_{2}$-catalyzed S.-M. coupling of pinacol boronate A71 with bromopyrone B74 (entry 20, Table 11) to form the key pyrone-thiazole bond of this unusual metabolite.[303] The total synthesis also involved the installation of the ethanolamide side-chain of 320 by a modified Corey-Ganem-Gilman reaction[304] of the primary alcohol $\mathbf{3 7 0}$, obtained by deprotection of the cross-coupling product C67, with silylethanamine 371 (Scheme 88).[333] The reaction, which achieved both oxidation and carboxyamide formation, provided pyrone $\mathbf{3 7 2}$ in an excellent yield. A disappointing $27 \%$ yield was then obtained in the conversion of $\mathbf{3 7 2}$ into pyridone 373. The synthesis of $\mathbf{3 2 0}$ was then completed in 3 steps and $32.7 \%$ yield based on 373 (Scheme 88). [303]
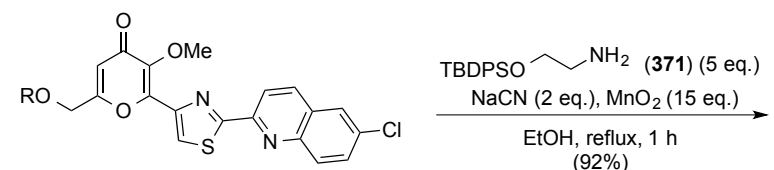

$$
\begin{array}{ll}
\text { C67: } \mathrm{R}=\mathrm{THP} \quad \longrightarrow & \begin{array}{l}
2 \mathrm{M} \mathrm{HCl} \\
\mathrm{MeOH}, \text { r.t., } 40 \mathrm{~min} \\
(99 \%)
\end{array}
\end{array}
$$

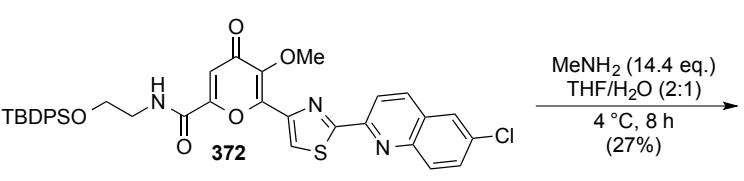<smiles></smiles>

1) $\mathrm{PyH} \cdot \mathrm{Br}_{3}$ (36.5 eq.), Py, reflux, $3 \mathrm{~h}$

2) $\mathrm{NaSMe}\left(10.7\right.$ eq.), dioxane, $90^{\circ} \mathrm{C}, 3 \mathrm{~h}$

3) $\mathrm{Py} \cdot \mathrm{HF}$ (5 eq.), Py, r.t., $2 \mathrm{~h}$

$\checkmark(32.7 \%$ over 3 steps $)$

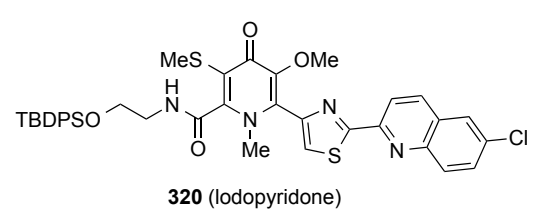

Scheme 88. Synthesis of lodopyridone (320) from the cross-coupling derivative $\mathbf{C 6 7}$
A year earlier, Katoh and co-workers synthesized the contact allergen primin (321) in 6 steps and $57 \%$ overall yield starting from commercially available 5-iodovanillin (374) (Scheme 89).[305] A crucial step of the synthesis was the $\mathrm{PdCl}_{2}$ (dppf)-catalyzed reaction of alkylborane $\mathbf{A 7 2}$ with aryl iodide B75 (entry 21, Table 9) that installed the alkyl side chain on the aromatic ring providing compound $\mathbf{C 6 8}$ in $92 \%$ yield. The synthetic method also involved elaboration of the quinone functionality by degradative oxidation of compound 375 using Frémy's salt (Scheme 89). [305]
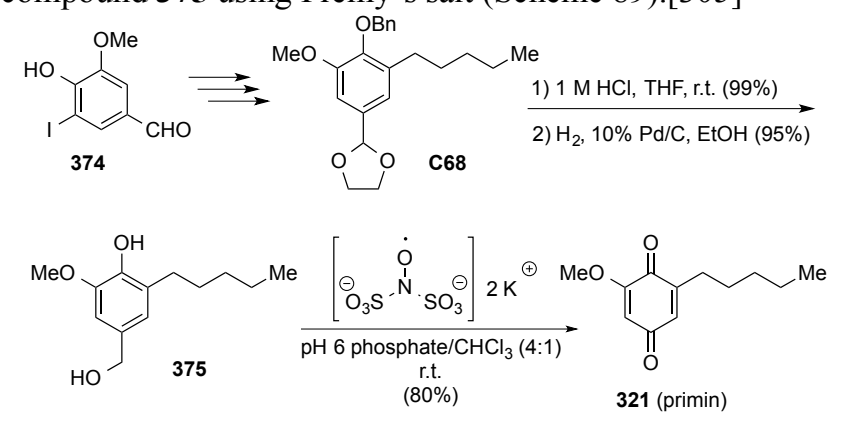

Scheme 89. Synthesis of primin (321) starting from iodide 374

The $\mathrm{PdCl}_{2}$ (dppf) $\cdot \mathrm{CH}_{2} \mathrm{Cl}_{2}$-catalyzed coupling reaction of crude alkylborane $\mathbf{A 7 3}$, generated by hydroboration of vinyl trans-decalin 376, with alkenyl triflate B76 (entry 22, Table 9) had previously been employed as a key step of a convergent synthesis of the Mediterranean sponge metabolite (+)-cacospongionolide B (322).[306] Scheme 90 illustrates the retrosynthesis of this natural compound. The pivotal transformations included the highly stereoselective $C$ glycosylation of glycal 379, derived from $D$-arabinose,[307] with 3-furylboronic acid (380). in NMP at room temperature for $12 \mathrm{~h}$ under $1 \mathrm{~atm}$ of dioxygen by using 2 equiv of $\mathbf{3 8 0}$ and $9.7 \mathrm{~mol} \% \mathrm{Pd}(\mathrm{OAc})_{2}$ and the conversion of the resulting cross-coupling product 378 into B76 via enone 377 . The synthesis of $\mathbf{3 2 2}$ also involved the preparation of $\mathbf{3 7 6}$ via a series of 6 reactions in which ester $\mathbf{3 8 1}$ was synthesized from 2-methylcyclohexan-1,3-dione (383) through enone 382 (Scheme 90).[306] 


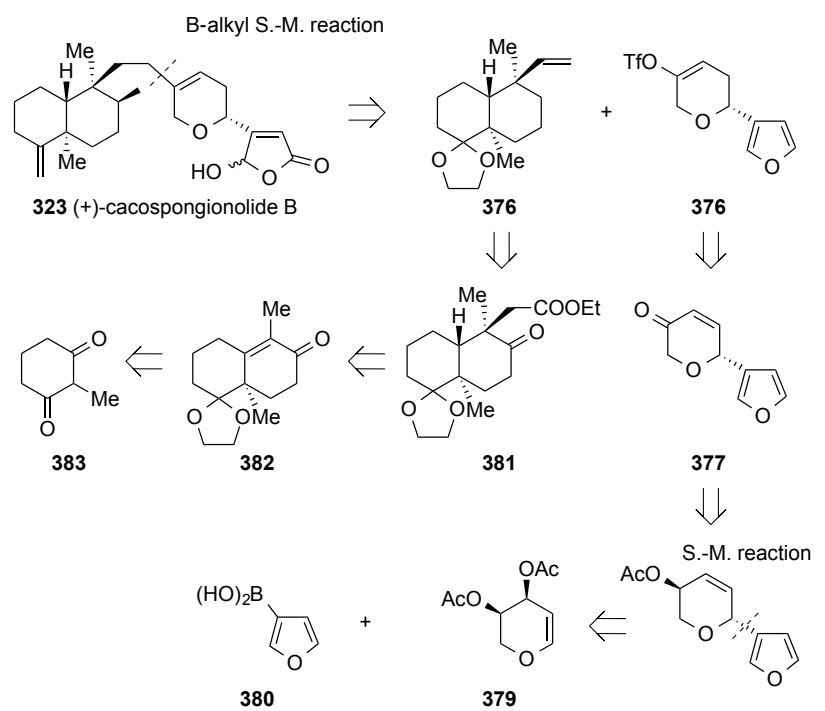

Scheme 90. Retrosynthesis of $(+)$-cacospongionolide B (322)

In 2011, the first step of a total synthesis of norchelerythrine (323) was carried out by using the $\mathrm{PdCl}_{2}$ (dppf)-catalyzed cross-coupling reaction between pinacol boronate 165 and aryl bromide 167 in $\mathrm{MeOH}$ at 80 ${ }^{\circ} \mathrm{C}$ in the presence of $\mathrm{K}_{2} \mathrm{CO}_{3}$ as base, which provided compound $\mathbf{C 7 0}$ in $75 \%$ yield (entry 23, Table 9).[154] In addition, compound $\mathbf{C 7 1}$, which was used as a precursor to norsanguinarine (324), was synthesized in $97 \%$ yield by the $\mathrm{PdCl}_{2}$ (dppf)-catalyzed S.-M. reaction of $\mathbf{1 6 5}$ with aryl bromide $\mathbf{B} 77$ in a mixture of DMF and $\mathrm{MeOH}$ at $80{ }^{\circ} \mathrm{C}$ in the presence of $\mathrm{K}_{2} \mathrm{CO}_{3}$ as base (entry 24, Table 9).[154] Microwave-assisted electrocyclic reactions of the aza $6 \pi$ electron systems of the 2-cycloalkenylbenzaldoxime methyl ethers 384 and 385 (Figure 20) derived from C70 and C71, respectively, were then used as key steps of the syntheses of compounds 323 and 324. [154]

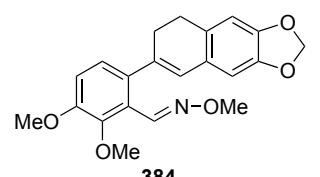

384

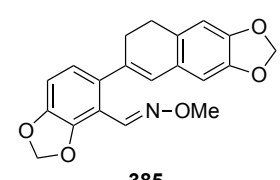

385

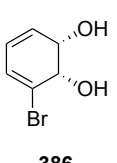

386
Figure 20. Structures of compounds 384-386

In the same year, compound $\mathbf{C 7 2}$, which was prepared in $75 \%$ yield by S.-M. reaction of pinacol boronate A74 with cycloalkenyl bromide B78 (entry 25, Table 9),[308a] was used as a precursor to the Amaryllidaceae alkaloid narsorenine (325) in a 15-step and fully stereocontrolled total synthesis in which enantiomerically pure and enzymaticallyderived cis-1,2-dihydroxycatechol 386[308b] (Figure 20) was the starting material. In the final step of the total synthesis, carbamate 387, which was obtained in 6 steps from C72, was treated with a molar excess of dimedone (388) and $2 \mathrm{~mol} \% \mathrm{Pd}\left(\mathrm{PPh}_{3}\right)_{4}$ to give narsorenine (325) in
$82 \%$ yield, presumably through amine 389 (Scheme 91).[308a]

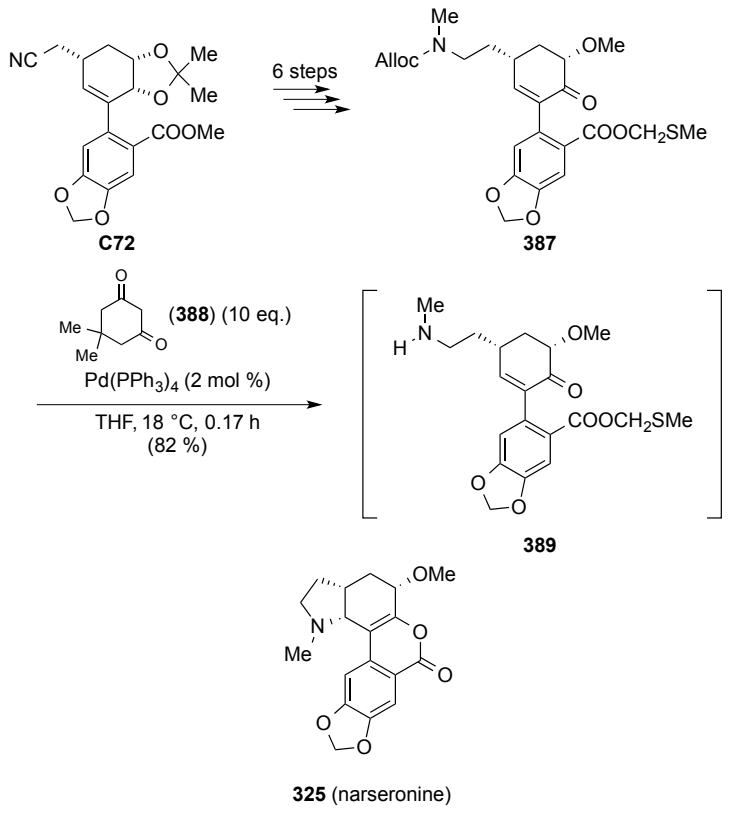

Scheme 91. Synthesis of narsorenine (325) from compound $\mathbf{C 7 2}$

It should be noted that compound $\mathbf{C 7 2}$ had previously been employed in the first synthesis of compound 391 (Figure 21), a degradation product of the alkaloid (-)lycorine (390) (Figure 21).[308b]
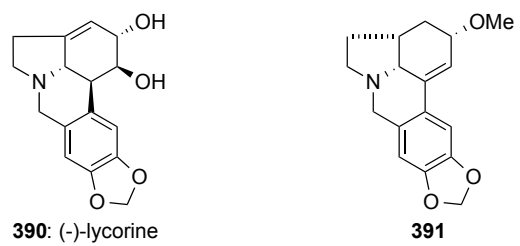

Figure 21. Structures of compounds 390 and 391

Again in 2011, the first total syntheses of the cytotoxic marine natural products (+)-spiculoic acid (326) and (+)zyggomphic acid (327) were accomplished on the basis of the retrosynthetic analysis depicted in Scheme 92 in which the central feature was the highly stereoselective and high yielding intramolecular Diels-Alder reaction of the $(E, E, E)$ dodecatrienal derivatives $\mathbf{3 9 2}$ and 393, respectively.[309] These compounds were obtained by Dess-Martin oxidation of the cross-coupling products $\mathbf{C 7 3}$ and $\mathbf{C 7 4}$, respectively, which were synthesized by the stereoselctive S.-M. reactions reported in entries 26 and 27 of Table 9, respectively.[309] (E)-Vinylboronates A75 and A76, which were employed in these cross-couplings, were in turn synthesized from known enantiomerically pure $(S)-2-[(t-$ butyldimethylsilyloxy)methyl]butan-1-ol (394) (Scheme 


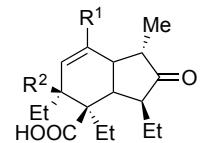

$326: \mathrm{R}^{1}=\mathrm{Et} ; \mathrm{R}^{2}=(E)-\mathrm{Ph}-\mathrm{CH}=\mathrm{CH}-\quad[(+)$-spiculoic acid $]$ $327: \mathrm{R}^{1}=\mathrm{Me} ; \mathrm{R}^{2}=(E, E)-\mathrm{CH}=\mathrm{C}(\mathrm{Et}) \mathrm{CH}=\mathrm{CHPh}[(+)$-zyggomphic acid $]$<smiles>[R]C=CC([Y])=CC(C=C([R])CC)C(OC)OC</smiles>

392: $\mathrm{Y}=\mathrm{CHO} ; \mathrm{R}^{1}=\mathrm{Et} ; \mathrm{R}^{2}=\mathrm{CH}_{2} \mathrm{OTBS}$ C73: $\mathrm{Y}=\mathrm{CH}_{2} \mathrm{OH} ; \mathrm{R}^{1}=\mathrm{Et} ; \mathrm{R}^{2}=\mathrm{CH}_{2} \mathrm{OTBS}$ 393: $\mathrm{Y}=\mathrm{CHO} ; \mathrm{R}^{1}=\mathrm{Me} ; \mathrm{R}^{2}=(E)-\mathrm{CH}=\mathrm{C}(\mathrm{Et}) \mathrm{CH}_{2} \mathrm{OTBS}$ C74 : $\mathrm{Y}=\mathrm{CH}_{2} \mathrm{OH} ; \mathrm{R}^{1}=\mathrm{Me} ; \mathrm{R}^{2}=(E)-\mathrm{CH}=\mathrm{C}(\mathrm{Et}) \mathrm{CH}_{2} \mathrm{OTBS}$

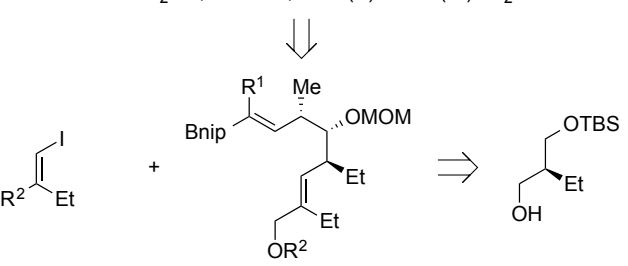

B79: $\mathrm{R}^{2}=$ OTBS $\quad$ A75: $\mathrm{R}^{1}=\mathrm{Et} ; \mathrm{R}^{2}=\mathrm{H}$ B80 : $\mathrm{R}^{2}=\mathrm{TBSOCH}_{2}-(\mathrm{Et})=\mathrm{CH} \quad$ A79: $\mathrm{R}^{1}=\mathrm{Me} ; \mathrm{R}^{2}=\mathrm{H}$

394

Scheme 92. Retrosynthesis of (+)-spiculoic acid (326) and (+)-zyggomphic acid (327)

In 2012, Kikuchi and co-workers reported the divergent syntheses of dictyobiphenyls A (328) and B (329) from the intermediate compound C75.[311] The latter compound was obtained in $93 \%$ yield by the $\mathrm{PdCl}_{2}$ (dppf) $\cdot \mathrm{CH}_{2} \mathrm{Cl}_{2}$-catalyzed S.-M. reaction of pinacol boronate $\mathbf{A 7 7}$ with aryl bromide $\mathbf{B 8 1}$ in dioxane in the presence of $\mathrm{K}_{3} \mathrm{PO}_{4}$ (entry 28, Table 9). Compound A77 was prepared in $64 \%$ yield by the $\mathrm{PdCl}_{2}$ (dppf)-catalyzed boronation of methyl 3-bromo-4methoxybenzoate (395) with bis(pinacolato)diboron (Scheme 93).[311]

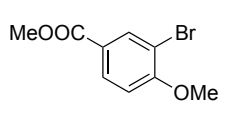

395

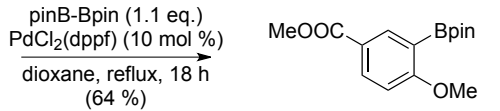

A77
Scheme 93. Synthesis of compound A77

Kikuchi and co-workers aloso found that, unfortunately, the synthesis of compound C76, which they used as an advanced common precursor to dictyoterphenyls A (330) and $\mathrm{B}$ (331), occurred in a modest yield. In fact, the $\mathrm{PdCl}_{2}$ (dppf) $\cdot \mathrm{CH}_{2} \mathrm{Cl}_{2}$-catalyzed S.-M. reaction of pinacol boronate $\mathbf{A} 77$ with biaryl triflate $\mathbf{B 8 2}$ in refluxing dioxane in the presence of $\mathrm{K}_{3} \mathrm{PO}_{4}$ yielded $\mathbf{C 7 7}$ in $43 \%$ yield (entry 29 , Table 9).[311] Compound $\mathbf{B 8 2}$ was in turn synthesized through a reaction sequence involving the preparation of compound 398 by the $\mathrm{PdCl}_{2}(\mathrm{dppf})$-catalyzed reaction of aryl bromide 396 with pinacol boronate 397 (Scheme 94). [311]

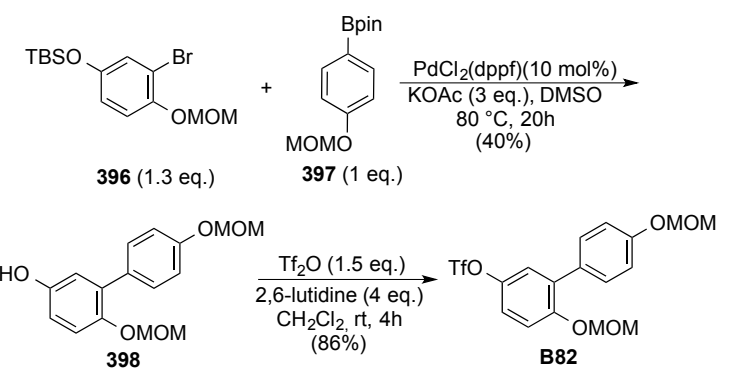

Scheme 94. Synthesis of compound B82

Interstingly, dictyoterphenyl A (330) was shown to inhibit the proliferation of several human cancer cell lines in a concentration dependent manner.[311]

More recently, Hamada and co-workers described the first enantioselective synthesis of cedrelin A (332), wherein $\alpha, \beta$ unsaturated ester $\mathbf{C 7 7}$ was an intermediate.[312] This highly functionalized biphenyl derivative was synthesized in an excellent yield by the S.-M. cross-coupling reaction illustrated in entry 30 of Table 9 . The key step of the total synthesis was the preparation of compound $\mathbf{4 0 0}$ by $\operatorname{Pd}(\mathrm{dba})_{2} /(R, R)$-L1-catalyzed asymmetric intramolecular Friedel-Crafts allylic alkylation of compound 399 which was obtained in 3 steps from C77 (Scheme 95).[312]
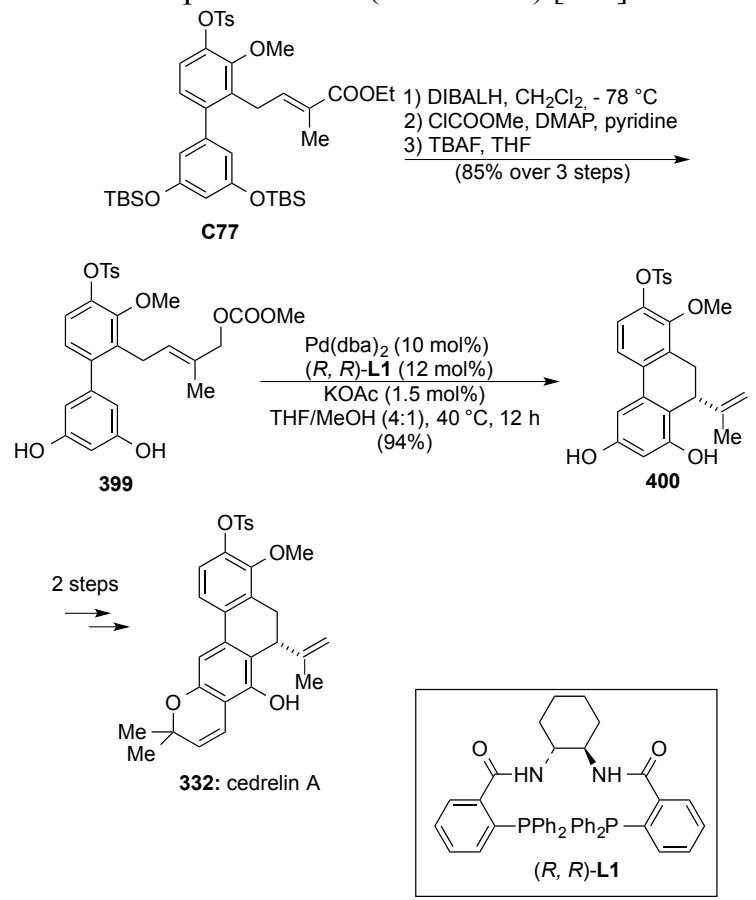

Scheme 95. Synthesis of cedrelin A (332) from compound $\mathbf{C 7 7}$

In 2013, Vasamsetty, Khan and Mehta accomplished a concise total synthesis of the novel oxa-bowl natural product paracaseolide A (333) via a series of reactions in which compound 402, a key intermediate, was obtained by methoxy deprotection of butenolide C78, which was prepared in $60 \%$ yield by the $\mathrm{PdCl}_{2}$ (dppf)-catalyzed reaction of pinacol boronate A79 with iodobutenolide B84 in a 
mixture of THF and water in the presence of $n$-Bu4NBr and CsF (entry 31, Table 9).[313] The key step of the total synthesis, in which 5-methyl-2-furfural (401) was used as the starting material, was the thermal [4+2]-dimerization of 402 (Scheme 96). Unfortunately, this reaction was not clean and led to the formation of $\mathbf{3 3 3}$ together with its stereoisomer and the ring-opened compound $\mathbf{4 0 4}$ in $66 \%$ yield and in a ratio of 4.9:1:2.4, respectively (Scheme 96).[313]

$$
\begin{gathered}
\text { [333: } 403: 404=4.9: 1: 2.4] \\
\text { neat, sealed tube } \\
\text { (66\%) }
\end{gathered}
$$$$
\underset{\text { TFA/acetone } / \mathrm{H}_{2} \mathrm{O}}{\stackrel{{ }^{\circ} \mathrm{C} \text { to rt, } 13 \mathrm{~h}}{\longrightarrow}}
$$

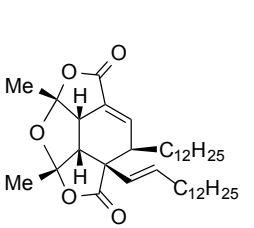

333: paracascalide $A$

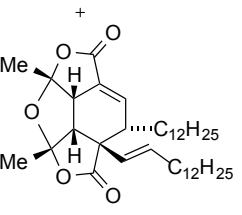

403<smiles>CCCCCCCCCCCCCC(=O)[O-]</smiles>

404

Scheme 96. Synthesis of paracaseolide A (333) starting from compound $\mathbf{4 0 1}$

Two years earlier, Burke and co-workers used an iterative cross-coupling strategy for the total synthesis of the aromatic $\mathrm{C}_{40}$ dicarboxylate xanthophyll synechoxanthin (334).[314] The $\mathrm{PdCl}_{2}$ (dppf) $\cdot \mathrm{CH}_{2} \mathrm{Cl}_{2}$-catalyzed S.-M. reaction of bisborylated compound $\mathbf{A 8 0}$ with the activated aryl iodide B85 in DMSO in the presence of $\mathrm{K}_{3} \mathrm{PO}_{4}$ gave MIDA boronate $\mathbf{C 7 9}$ in 79\% yield (entry 32, Table 9).[324] Iododeborylation of $\mathbf{C 7 9}$ gave dienyl iodide $\mathbf{4 0 5}$ in $99 \%$ yield, which was then reacted with the bifunctional building block 406 in DMSO in the presence of $\mathrm{K}_{3} \mathrm{PO}_{4}$ and a catalytic amount of $\mathrm{PdCl}_{2}$ (dppf) $\cdot \mathrm{CH}_{2} \mathrm{Cl}_{2}$ providing stereoisomerically pure tetraenyl MIDA boronate $\mathbf{4 0 7}$ in $65 \%$ yield (Scheme 97). The total synthesis of $\mathbf{3 3 4}$ was then completed via a concise and efficient route in which an in situ MIDA boronate hydrolysis/two-directional double $\mathrm{Pd}(\mathrm{OAc})_{2} / \mathrm{XPhos}$-catalyzed cross-coupling reaction between 2.2 equiv of $\mathbf{4 0 7}$ and $(E)$-1-bromo-2-iodoethene (408) yielded diester 409 in 53\% yield. Finally, hydrolysis of the methyl esters of $\mathbf{4 0 9}$ provided 335 in 53\% yield (Scheme 97).[314]
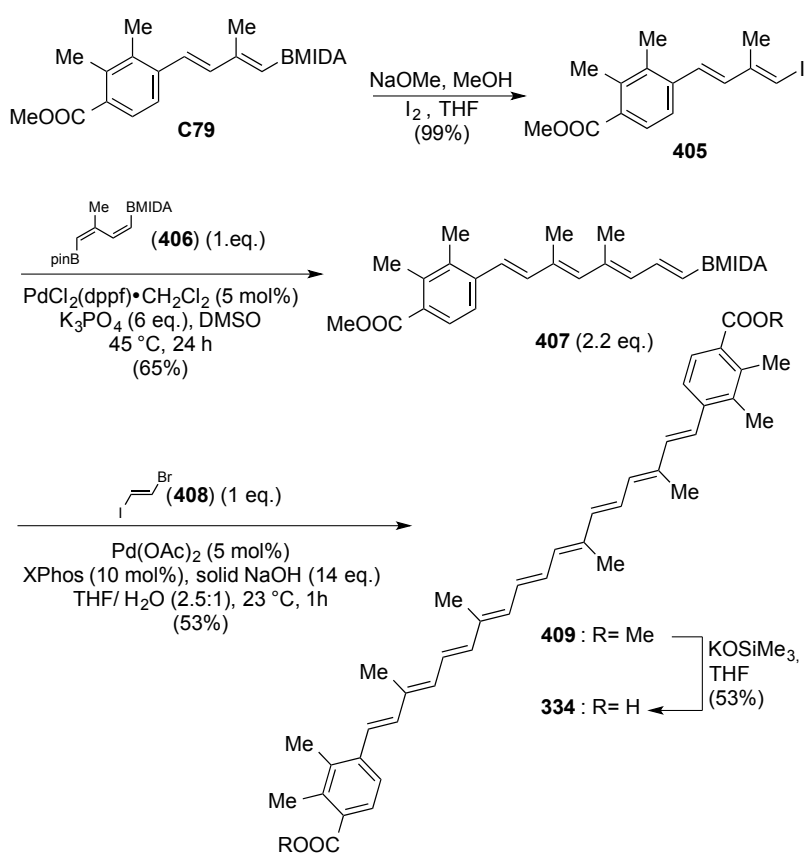

Scheme 97. Synthesis of synechoxanthin (334) from compound $\mathbf{C 7 9}$

Tokuyama and co-workers had previously accomplished the total synthesis of dictyodendrin A (335) using the $\mathrm{PdCl}_{2}$ (dppf) $\cdot \mathrm{CH}_{2} \mathrm{Cl}_{2}$-catalyzed reaction of pinacol boronate A81 with iodide B86 (entry 33, Table 9) for the construction of the pyrrole $[2,3-c]$ carbazole skeleton of the natural product.[315 ]Interestingly, the azido group of $\mathbf{B 8 6}$ remained untouched in this reaction which provided compound $\mathbf{C 8 0}$ in $79 \%$ yield. Thermolysis of $\mathbf{C 8 0}$ at $180{ }^{\circ} \mathrm{C}$ and subsequent insertion of the thereby obtained nitrene into the adjacent $\mathrm{Csp}^{2}-\mathrm{H}$ bond gave compound 410, which was converted into 335 via a 4-step-reaction sequence (Scheme 98).[315]

Tokuyama and co-workers also used an analogous reaction sequence in a highly efficient total synthesis of dictyodendrin B (43), which involved the preparation of compound $\mathbf{C 8 1}$ as a key intermediate by the S.-M. reaction of pinacol boronate $\mathbf{A 8 2}$ with aryl iodide B86 (entry 34, Table 9).[315] 

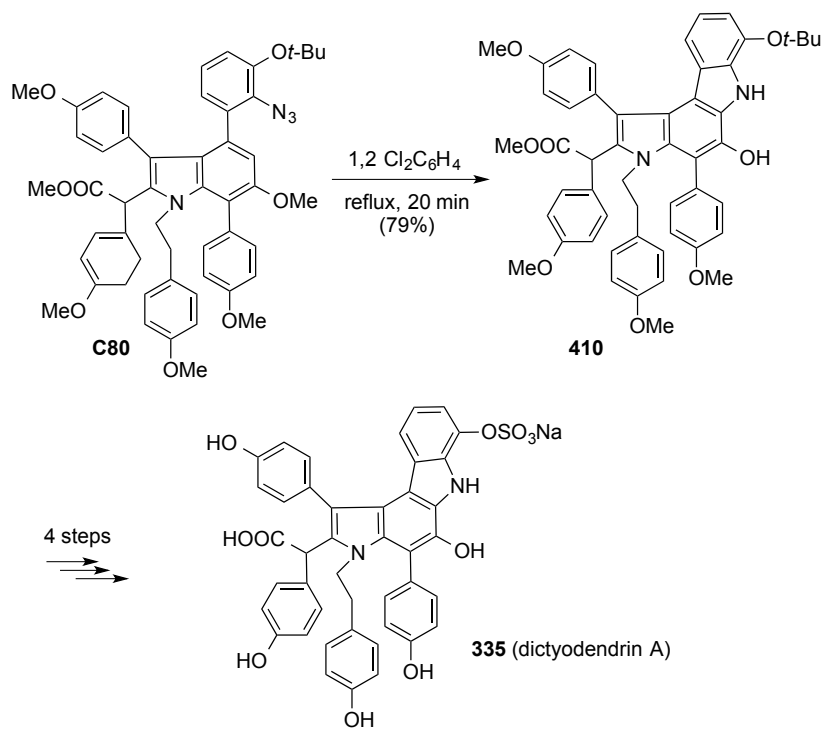

Scheme 98. Synthesis of dictyodendrin A (335) from compound $\mathbf{C 8 0}$

\section{TOTAL SYNTHESES VIA S.-M. REACTIONS PROMOTED BY PdCl 2 (dppf) WITH As(Ph)}

Several papers testify that an excellent catalyst system for $B$-alkyl S.-M. reactions consists of a combination of $\mathrm{PdCl}_{2}$ (dppf) with $\mathrm{AsPh}_{3}$.[316] As early as 1983, Johnson and Braun noticed that when the $\mathrm{PdCl}_{2}$ (dppf)-catalyzed crosscoupling reaction of an $\alpha$-iodoenone with a $B$-alkyl-9-BBN derivative was carried out in the presence of $\mathrm{AsPh}_{3}$ as a coligand a higher turnover rate and a cleaner reaction was observed.[317] In fact, a Pd species with a large bite angle when associated to an electron-rich and weakly coordinating ligand such as $\mathrm{AsPh}_{3}$ improves the reaction rate of $\mathrm{sp}^{2}-\mathrm{sp}^{3}$ $\mathrm{C}-\mathrm{C}$ bond forming reactions by making reductive elimination more facile than the competing $\beta$-hydride elimination.

Thus, despite that $\mathrm{AsPh}_{3}$ is a compound very toxic to aquatic life with long lasting effects, the catalyst system consisting of a combination of $\mathrm{AsPh}_{3}$ with $\mathrm{PdCl}_{2}$ (dppf) has been extensively used in S.-M. reactions involved in total syntheses of natural products. Table 10 lists the natural substances synthesized from January 2010 to December 2013 via $\mathrm{PdCl}_{2}(\mathrm{dppf}) / \mathrm{AsPh}_{3}$-catalyzed S.-M. crosscouplings. These natural products include: anguinomycins $\mathrm{C}$ (411) and D (412), two antitumor antibiotics isolated from a strain belonging to Streptomyces, which were reported as selective agents targeting immortalized cells;[318] the cyclic peptide antillatoxin (413), a potent toxin which was isolated from the marine cyanobacterium Lyngbya majuscola; [319] aspergillides A (414) and B (415), which were isolated from the marine fungus Aspergillus ostianus strain 01F313, cultured in a bromine-modified medium; [320] indolizine (+)195B (416), an alkaloid isolated from a population of the Colombian poison-frog Dendrobates histrionicus; [321] the toxic pyrrolizidine alkaloid $(+)$-xenovenine (417), which was isolated from the skin of the frog Solenopsis xenoveneum; $[322$ ] the resorcylic acid lactone $(R)-(+)-$ lasiodiplodin (418), which was isolated form the fungus Botrysdiplodia theobromae and from the wood of Euphorbia splendens and E. fidjiana;[323] the potent cytotoxic 20membered macrolide iriomoteolide-1a, which was isolated from a benthic dinoflagellate Amphidinium sp. (strain HYA024) and possessed the proposed structure 419; [324] the marine lethal toxin (-)-polycarvenoside A (420), which was isolated from the edible red alga Gracilaria edulis (Polycavernosa tsudai); [325] the polyketide apiosporic acid (421), a secondary metabolite isolated from the marine endophytic fungus Apiospora montagnei;[326] the potent antifungal polycyclic ether metabolite gambieric acid A (422), which was isolated from the cultured cells of the ciguatera causative dinoflagellate Gambierdiscus toxicus;[327] the effective HIV-1 protease inhibitor didemnaketal A, which was isolated from the Ascidian Didemnum sp. and for which the structure 423 was proposed;[328] the antimitotic macrocyclic polyketide spirastrellolide A (424), which was isolated from the Caribbean marine sponge Spirastrella coccinea; [329] the jatrophane diterpenes (-)-15-O-acetyl-3-Opropionylcharaciol (425) and 15- $O$-acetyl-3- $O$ benzoylcharaciol- $(5 R, 6 R)$-oxide (426), which were isolated from Euphorbia characias (Euphorbiaceae); [330] (+)lycoposerramine Q (427), an alkaloid which was isolated from the club moss Lycopodium serratum (Huperzia serrata);[331] (+)-fawcettidine (428), a compound which was first isolated from the Jamaican Lycopodium plant $L$. fawcettii; [332] and the oxylipin (-)-ecklonialactone B (429), which was isolated from the brown alga Ecklonia stolonifera[333] and the Oregon phaephyte Egregia menziesii.[334]

\section{TABLE 10 HERE}

Entries 1-19 of Table 11 illustrate the detailed experimental conditions and yields of $\mathrm{PdCl}_{2}(\mathrm{dppf}) / \mathrm{AsPh}_{3}-$ catalyzed S.-M. reactions which were used in the syntheses of compounds 411-429. Some comments on these couplings and the application of these reactions in the total syntheses of compounds 411-429 are reported below.

\section{TABLE 11 HERE}

The $\mathrm{Csp}^{3}-\mathrm{Csp}^{2}$ bond forming reactions of entries 1, 2, 810,13 and 19 of Table 11 were carried out using $B$-alkyl S.M. reactions via the 9-methoxy-9-BBN variant in which the necessary organolithium reagent was generated in the presence 9-MeO-9-BBN and immediately intercepted by this additive to give the corresponding boronate complex. On the other hand, the $\mathrm{Csp}^{3}-\mathrm{Csp}^{2}$ bond forming reactions of entries 4-7, 11, 12 and 14-18 of Table 11 were performed using crude 9-alkyl-9-BBN derivatives which were prepared by treatment of the corresponding 1-alkene with 9-BBN-H dimer in THF. Finally, the $\mathrm{Csp}^{2}-\mathrm{Csp}^{2}$ bond forming reaction of entry 3 of Table 11 was carried out using alkenyl iodide $\mathbf{B 8 8}$ and alkenyl pinacol boronate $\mathbf{A 8 5}$, which was prepared 
by hydroboration of the corresponding 1-alkyne with pinacolborane.[351]

Compounds C82 and C83, which were synthesized in entries 1 and 2, respectively, of Table 11, were used as advanced intermediates in the first total syntheses of anguinomycins $C$ (411) and D (412), respectively, which were achieved in total 29 steps with a longest linear sequence of 18 steps from $(R)$-4-isopropyl-5,5diphenyloxazolidin-2-one (430)[352] and in an overall yield of 6.7 and $6.0 \%$, respectively.[335] Vinyl iodide B87, which was the electrophile of the $\mathrm{sp}^{3}-\mathrm{sp}^{2}$ 9-MeO-9-BBN-mediated cross-coupling reactions of entries 1 and 2 of Table 11, was synthesized from $\mathbf{4 3 0}$ via a 13 step reaction sequence (Scheme 99).[335 ]In addition, the known aldehyde 431 [363] was used as the starting material in the synthesis of alkyl iodides $\mathbf{4 3 2}$ and $\mathbf{4 3 3}$, the direct precursors to boronates A53 and A54, respectively (Scheme 99).[335]
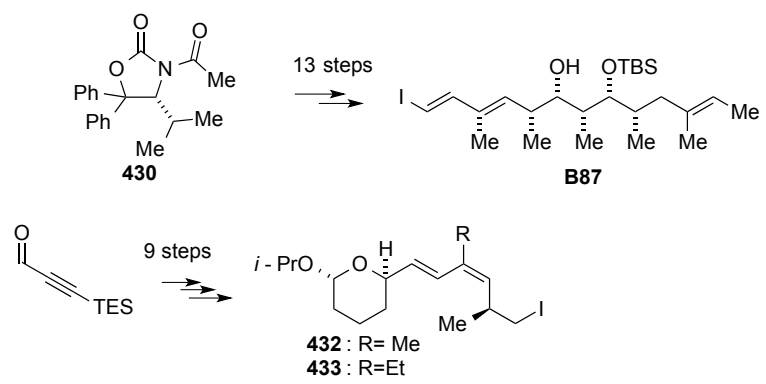

9-MeO-9-BBN (1.0 M in hexane) (3.42 eq.) $t$ - $\mathrm{Bu} \mathrm{Li}(1.5 \mathrm{M}$ in pentane) (3.0 eq.) $\mathrm{Et}_{2} \mathrm{O}$, then $\mathrm{THF},-78^{\circ} \mathrm{C}$ to $\mathrm{rt}$

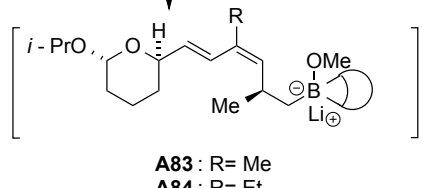

A84: $R=E t$

Scheme 99. Synthesis of compounds B87, A83 and A84

The high yielding S.-M. reaction between pinacol boronate $\mathbf{A 8 5}$ vinyl iodide $\mathbf{B 8 8}$ (entry 3, Table 11) was the last stage of a 13 step total synthesis of the potent toxin antillatoxin (413),[336] which began with an anti-selective asymmetric aldol reaction between aldehyde 434[354] and silyl ether $\mathbf{4 3 5}$ to set the two stereocenters at C-4 and C-5 and produced compound $\mathbf{4 3 6}$ in $80 \%$ yield with $96 \%$ ee (Scheme 100).[336]

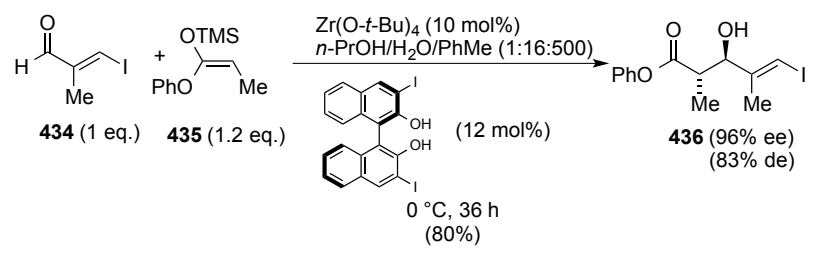

Scheme 100. Asymmetric synthesis of compound 436

In 2010, Fuwa and co-workers accomplished an enantioselective synthesis of (-)-aspergillide B (415), a 14- membered macrolide embedded with a tetrahydropyrane ring, on the basis of the retrosynthetic analysis shown in Scheme 101.[337] A key step of this synthesis was the $\mathrm{PdCl}_{2}$ (dppf)/AsPh3-catalyzed S.-M. reaction of vinyl iodide B90 with alkylborane $\mathbf{A 8 6}$ (entry 5, Table 11) derived from 1-alkyne 437, which delivered trans-olefin C85b in $73 \%$ yield. Iodide B90 was in turn obtained from the known homoallylic alcohol 440[355] through a 11-step reaction sequence in which compound trans-438, which was obtained by intramolecular oxa-conjugate cyclization of alcohol 439 in $\mathrm{THF}$ at $-78{ }^{\circ} \mathrm{C}$ in the presence of 0.05 equiv of $\mathrm{KO} t-\mathrm{Bu}$, was converted to iodide $\mathbf{B 9 0}$ by ozonolysis followed by Takai olefination[356] $\left(\mathrm{CrCl}_{2}, \mathrm{CHI}_{3}, \mathrm{THF} /\right.$ dioxane, rt $)$ (Scheme 101).[337]

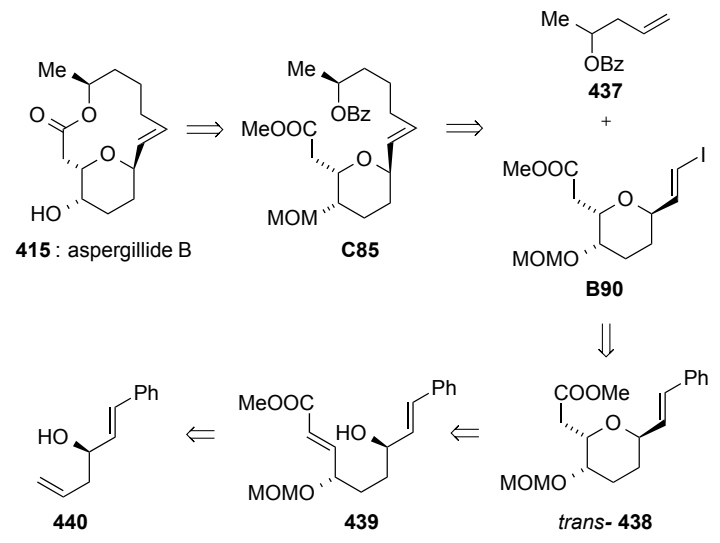

Scheme 101. Retrosynthesis of (-)-aspergillide B (415)

Fuwa and co-workers also carried out the total synthesis of aspergillide A (414) by using compound cis-438 as an intermediate, which was obtained in $85 \%$ yield with $7: 1$ diastereoselectivity by exposure of alcohol 439 to 10 equiv of DBU in toluene at $100{ }^{\circ} \mathrm{C}$ (Scheme 102).[337]

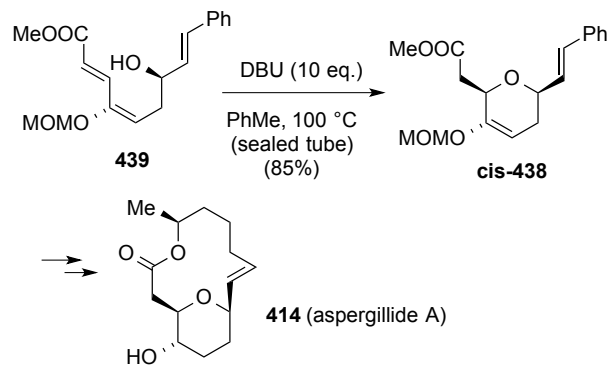

Scheme 102. Synthesis of aspergillide A (414) starting from compound 439

In 2011, Helmchen and co-workers developed a high quality enantioselective total synthesis of the indolizidine alkaloid (+)-195B (416) in which compound C86, a key intermediate, was prepared using a reaction sequence, which involved the asymmetric iridium-catalyzed allylic amination of allylic carbonate 441 with the pronucleophile 442 , the $N$ formyl deprotection of the resulting compound 443 and hydroboration with $9-\mathrm{BBN}-\mathrm{H}$ of the thereby obtained amine 
444, followed by $\mathrm{PdCl}_{2}$ (dppf)/ $\mathrm{AsPh}_{3}$-catalyzed reaction with methyl (E)-3-iodoacrylate (B91) (Scheme 103).[338] As shown in entry 6 of Table 11, this cross-coupling reaction gave compound $\mathbf{C 8 6}$ in $80 \%$ yield. The subsequent intramolecular aza-Michael addition reaction of $\mathbf{C 8 6}$ yielded the trans-2,5-disubstituted pyrrolidine 445 , which was then converted to 416 via a 6-step reaction sequence (Scheme 103).[338 ]Unfortunately, compound $\mathbf{4 1 6}$ proved to be contaminated by $5 \%$ of an epimer.[338]

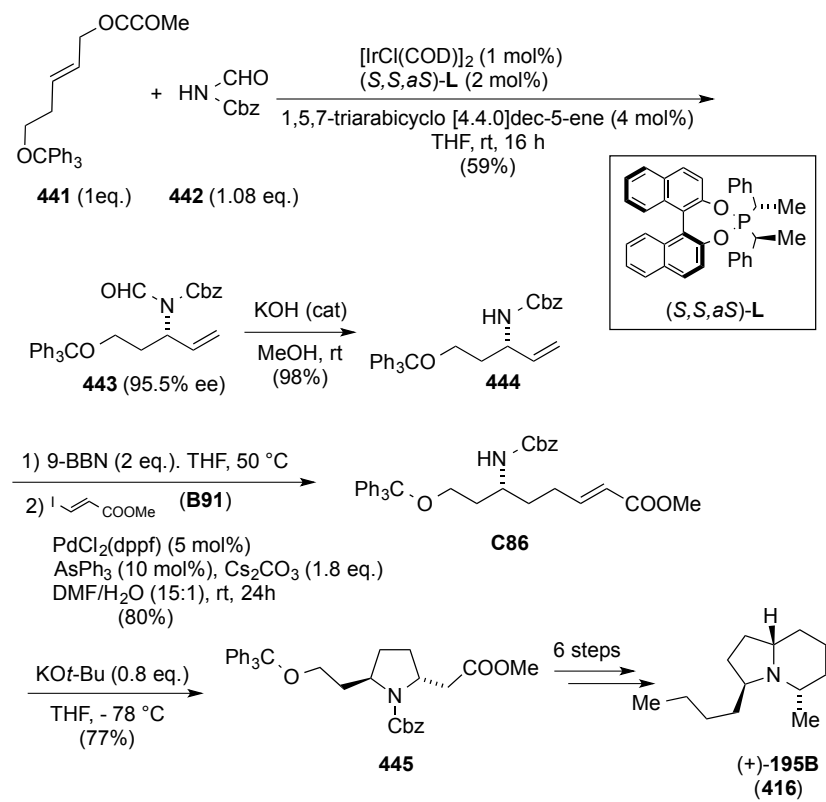

Scheme 103. Synthesis of (+)-195B (416) from allylic carbonate 441

A combination of an asymmetric Ir-catalyzed allylic amination, a $\mathrm{PdCl}_{2}(\mathrm{dppf}) / \mathrm{AsPh}_{3}$-catalyzed S.-M. reaction and an intramolecular Michael addition was also employed for a total synthesis of the alkaloid $(+)$-xenovenine (417) in $95.5 \%$ ee.[338] Key intermediates of this process were compounds $\mathbf{C 8 7}$ and the trans-2,5-disubstituted pyrrolidine (446) (Figure 22). Compound C87 was obtained in $80 \%$ yield by the S.-M. reaction between alkylborane $\mathbf{A 8 8}$ and methyl $(E)$-3-iodoacrylate (B91) illustrated in entry 7 of Table 11. Compound 446 was in turn obtained by azaMichael cyclization of compound 447 (Figure 22). [338]<smiles>CCCCN1C(C)CCC1CC(C)=O</smiles>

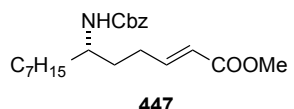

Figure 22. Structures of compounds 446 and 447

In the same year, Feringa and co-workers used the $\mathrm{sp}^{3}-\mathrm{sp}^{2}$ 9-MeO-9-BBN-mediated coupling reaction illustrated in entry 8 of Table 11 as a key step of a formal synthesis of $(R)$ $(+)$-lasiodiplodin (418), which they accomplished on the basis of the retrosynthetic analysis shown in Scheme 104.[339]

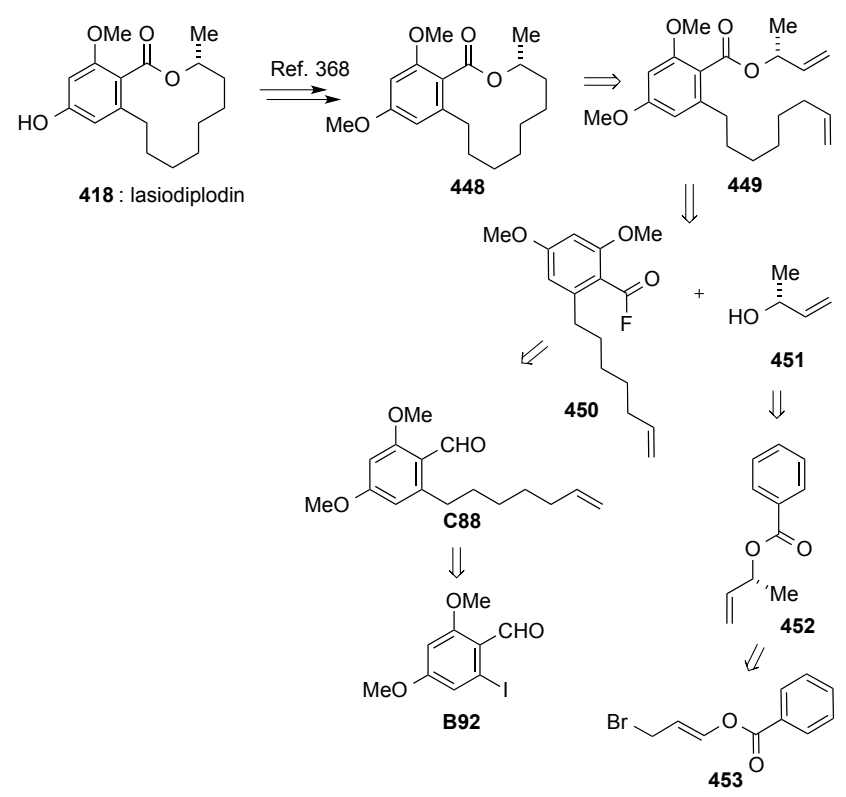

Scheme 104. Retrosynthesis of $(R)-(+)$-lasiodiplodin (418)

In particular, compound 448 containing the macrolactone ring of 418 was planned to be formed by ring-closing metathesis of diene $\mathbf{4 4 9}$ followed by catalytic hydrogenation. Compound 449 could be available from the tetrasubstituted benzene derivative 450 and allylic alcohol 451, which could be accessible in high yield and enantioselectivity by $\mathrm{CuBr} / \mathrm{TaniaPhos}$-catalyzed asymmetric allylic alkylation of allyl bromide 453[357] followed by hydrolysis of the resulting ester 452.[339] Thus, compound $\mathbf{4 5 0}$ was synthesized from $\mathbf{C 8 8}$, which in turn was obtained in $52 \%$ yield by the $\mathrm{PdCl}_{2}(\mathrm{dppf}) / \mathrm{AsPh}_{3}$-catalyzed reaction of aryl iodide $\mathbf{B 9 2}$ with boronate $\mathbf{A 8 9}$ (entry 8, Table 11). Interestingly, the presence of $\mathrm{AsPh}_{3}$ as a coligand was essential for the successful outcome of this cross-coupling reaction. In fact, isomerization of the terminal $\mathrm{C}-\mathrm{C}$ double bond of $\mathbf{C 8 8}$ was observed when the reaction was carried out in the absence of $\mathrm{AsPh}_{3}$.[339] Finally, $(R)-(+)$-lasiodiplodin methyl ether 448, which was obtained in the last step of the formal synthesis of $(R)$-(+)-lasiodiplodin (418), was converted into the natural compound according to literature procedures, [358] although in a low yield. [339]

Still in 2011, Horne and co-workers performed the total synthesis of the proposed structure of iriomoteolide-1a (419) via an approach in which the $\mathrm{C} 7-\mathrm{C} 23$ fragment of this compound was assembled by the $\mathrm{PdCl}_{2}(\mathrm{dppf}) / \mathrm{AsPh}_{3}-$ catalyzed reaction of boronate $\mathbf{A 9 0}$ with vinyl iodide $\mathbf{B 9 3}$ (entry 9, Table 11).[340] The latter compound was synthesized in a 4:1 dr by the Sakurai reaction of allylsilane $\mathbf{4 5 4}$ with aldehyde $\mathbf{4 5 5}$ followed by acetylation (Scheme 105).

In a second generation synthesis of the C7-C23 fragment of 419, the $\mathrm{PdCl}_{2}(\mathrm{dppf}) / \mathrm{AsPh}_{3}$-catalyzed $B$-alkyl S.-M. reaction between vinyl iodide 456 and alkyl iodide 457 produced fragment $\mathbf{4 5 8}$ in 84\% yield (Scheme 106).[340] 


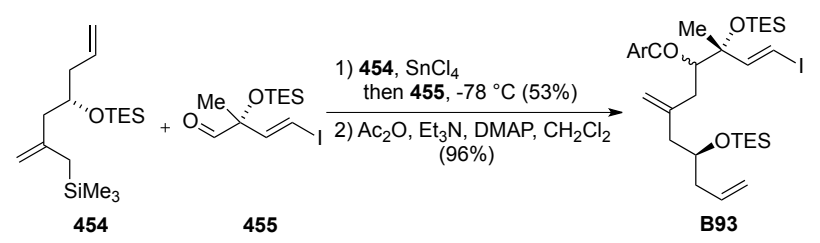

Scheme 105. Synthesis of vinyl iodide B93

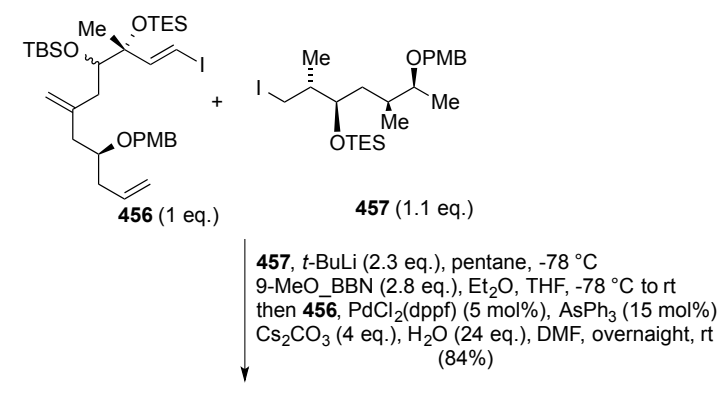

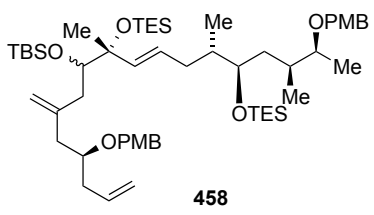

Scheme 106. Synthesis of compound 458

In 2012, Sasaki and co-workers accomplished a total synthesis of the marine lethal toxin (-)-polycarvenoside A (420) in 29 steps and $2.4 \%$ overall yield via a convergent approach (Scheme 107) in which intermediate 459 was prepared from bis-pyran $\mathbf{C 9 1}$ and the latter compound was obtained by the $\mathrm{PdCl}_{2}(\mathrm{dppf}) \cdot \mathrm{CH}_{2} \mathrm{Cl}_{2} / \mathrm{AsPh}_{3}$-catalyzed reaction of enol triflate B95 with alkylborane A91 (entry 11, Table 11) generated by hydroboration of exo-olefin 460 with 9-BBN-H in THF.[341]
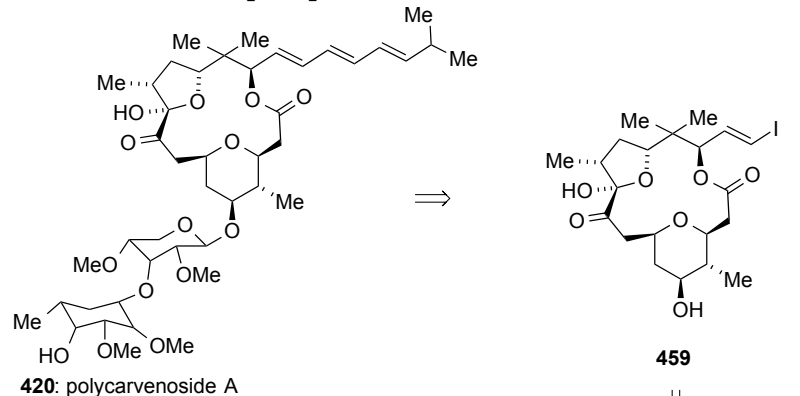

420: polycarvenoside $A$

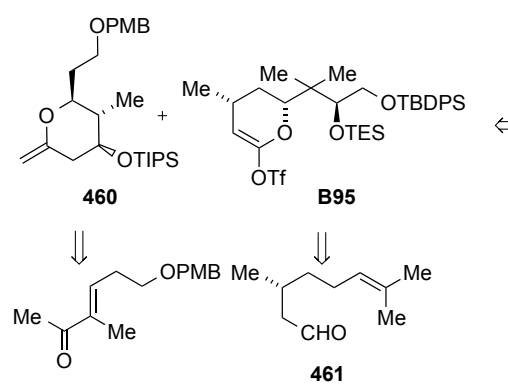

459

$\Downarrow$

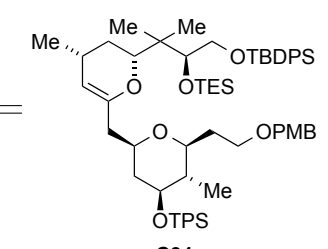

C91
Scheme 107. Retrosynthesis of (-)-polycarvenoside A (420)

Enol triflate B95 was asymmetrically generated in 15 steps starting from $(R)$-citronellol (461) and exo-olefin 460 was prepared through a catalytic asymmetric synthesis starting from the known enone 462, which was available from 1,3-propanediol.[360] On the other hand, the macrolactone core of the natural product was formed by using the Keck macrolactonization protocol[361] in which DCC, pyridine and PPTS under reflux were used.[362]

In the same year, the $\mathrm{PdCl}_{2}(\mathrm{dppf}) / \mathrm{AsPh}_{3}$-catalyzed coupling of methyl (E)-3-iodoacrylate (B91) with alkylborane A92 (entry 12, Table 11) was used by Helmchen and co-workers as a key step of the first enantioselective total synthesis of apiosporic acid (421).[342] Crucial for the success of the reaction was a short reaction time of the hydroboration reaction of trityl $(2 S, 4 E, 6 E)$-2-vinylocta-4,6dien-1-yl ether (463) with 9-BBN-H, which provided crude alkylborane A92 (Scheme 108).[342]

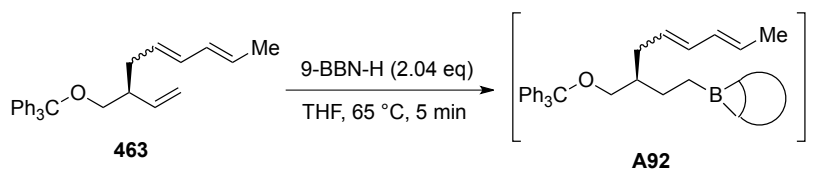

Scheme 108. Synthesis of crude alkylborane A92

Compound 463 was in turn synthesized in $69 \%$ yield by the reaction of 1-phenyl-5-\{(3S)-3-[(trityloxy)methyl]pent-4en-1-yl sulfonyl-1 $H$-tetrazole (464) with crotonaldehyde (465) in the presence of KHMDS as base (Scheme 109).[342]

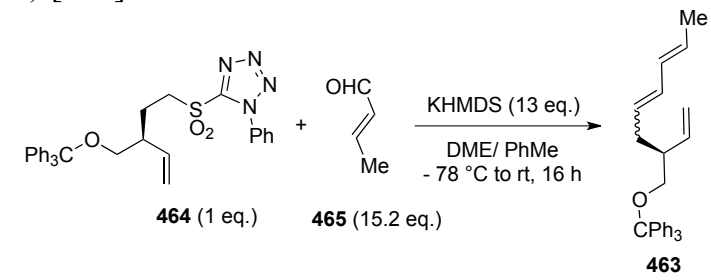
464

Scheme 109. Synthesis of compound 463 from tetrazole

Another key step of the total snthesis of $\mathbf{4 2 1}$ was the EtAlCl $\mathrm{Al}_{2}$-mediated intramolecular Diels-Alder reaction of the cross-coupling product $\mathbf{C 9 2}$ of the S.-M. reaction between A92 and B91. (Scheme 110). Hydrolysis of the resulting compound 466 provided apiosporic acid (421) (Scheme 110).[342]
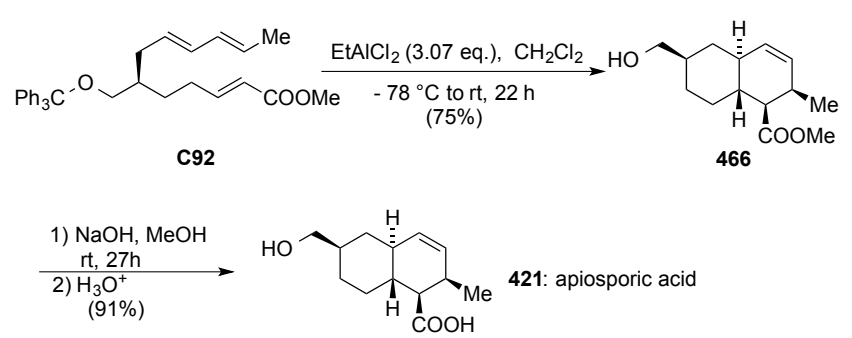
Scheme 110. Synthesis of apiosporic acid (421) from compound $\mathbf{C 9 2}$

In the same year, Fuwa, Sasaki and co-workers synthesized in quantitative yield compound $\mathbf{C 9 3}$, an early precursor to gambieric acid A (422), by the $\mathrm{PdCl}_{2}$ (dppf)/AsPh3-catalyzed reaction of ( $Z$ )-vinyl iodide B96 with boronate $\mathbf{A 9 3}$ which was generated in situ from the corresponding alkyl iodide (entry 13, Table 11).[343 ]Furthermore, compound 469, a more advanced intermediate in the first total synthesis of $\mathbf{4 2 2}$, was synthesized in $95 \%$ yield by the $\mathrm{PdCl}_{2}$ (dppf) $\cdot \mathrm{CH}_{2} \mathrm{Cl}_{2}$-catalyzed reaction of crude enol phosphate 468 with the alkylborane prepared in situ by hydroboration of alkene $\mathbf{4 6 7}$ with 9-BBN-H (Scheme 111).[343]

Interestingly, synthetic gambieric acid A (422) was found to display antifungal activity against Aspergillus niger, resulting equipotent to that of the natural product.[353]

Still in 2012, a notable total synthesis of the proposed structure of didemnaketal A (423) was described by Tu and co-workers.[344] This compound featuring a spiroketal moiety and a main chain containing 23 carbons and 12 stereocenters was synthesized in 31 steps for the longest linear sequence.

The $\mathrm{Csp}^{3}-\mathrm{Csp}^{2}$ bond forming reactions of entries 1, 2, 8-10, 13 and 19 of Table 11 were carried out using $B$-alkyl S.-M. reactions via the 9-methoxy-9-BBN variant in which the necessary organolithium reagent was generated in the presence 9-MeO-9-BBN and immediately intercepted by this additive to give the corresponding boronate complex. On the other hand, the $\mathrm{Csp}^{3}-\mathrm{Csp}^{2}$ bond forming reactions of entries 4-7, 11, 12 and 14-18 of Table 11 were performed using crude 9-alkyl-9-BBN derivatives which were prepared by treatment of the corresponding 1-alkene with 9-BBN-H dimer in THF. Finally, the $\mathrm{Csp}^{2}-\mathrm{Csp}^{2}$ bond forming reaction of entry 3 of Table 11 was carried out using alkenyl iodide $\mathbf{B 8 8}$ and alkenyl pinacol boronate $\mathbf{A 8 5}$, which was prepared by hydroboration of the corresponding 1-alkyne with pinacolborane.[351]

Compounds $\mathbf{C 8 2}$ and $\mathbf{C 8 3}$, which were synthesized in entries 1 and 2, respectively, of Table 11 , were used as advanced intermediates in the first total syntheses of anguinomycins $C$ (411) and D (412), respectively, which were achieved in total 29 steps with a longest linear sequence of 18 steps from $(R)$ 4-isopropyl-5,5-diphenyloxazolidin-2-one (430)[352] and in an overall yield of 6.7 and $6.0 \%$, respectively.[335] Vinyl iodide B87, which was the electrophile of the $\mathrm{sp}^{3}-\mathrm{sp}^{2} 9$ MeO-9-BBN-mediated cross-coupling reactions of entries 1 and 2 of Table 11, was synthesized from 430 via a 13 step reaction sequence (Scheme 99).[335 ]In addition, the known aldehyde 431[363] was used as the starting material in the synthesis of alkyl iodides 432 and $\mathbf{4 3 3}$, the direct precursors to boronates A53 and A54, respectively (Scheme 99).[335]

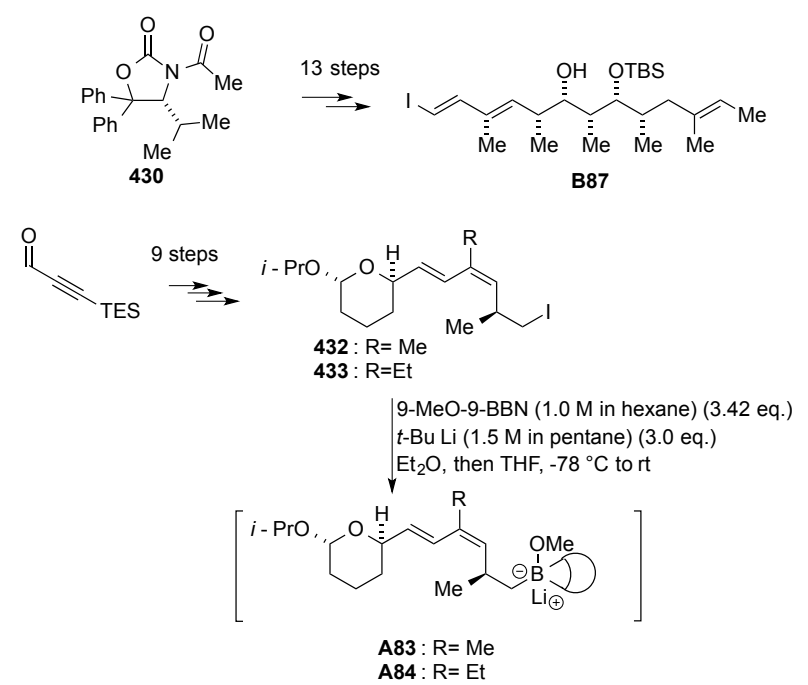

Scheme 99. Synthesis of compounds B87, A83 and A84

The high yielding S.-M. reaction between pinacol boronate A85 vinyl iodide $\mathbf{B 8 8}$ (entry 3, Table 11) was the last stage of a 13 step total synthesis of the potent toxin antillatoxin (413),[336] which began with an anti-selective asymmetric aldol reaction between aldehyde 434[354] and silyl ether 435 to set the two stereocenters at C-4 and C-5 and produced compound 436 in $80 \%$ yield with $96 \%$ ee (Scheme 100).[336]

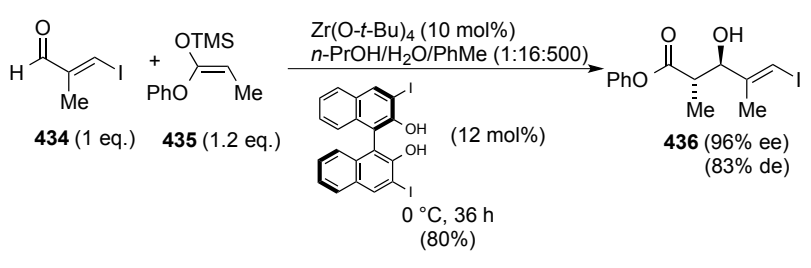

Scheme 100. Asymmetric synthesis of compound 436

In 2010, Fuwa and co-workers accomplished an enantioselective synthesis of (-)-aspergillide B (415), a 14membered macrolide embedded with a tetrahydropyrane ring, on the basis of the retrosynthetic analysis shown in Scheme 101.[337] A key step of this synthesis was the $\mathrm{PdCl}_{2}$ (dppf)/AsPh3-catalyzed S.-M. reaction of vinyl iodide B90 with alkylborane $\mathbf{A 8 6}$ (entry 5, Table 11) derived from 1-alkyne 437, which delivered trans-olefin C85b in $73 \%$ yield. Iodide $\mathbf{B 9 0}$ was in turn obtained from the known homoallylic alcohol 440[355] through a 11-step reaction sequence in which compound trans-438, which was obtained by intramolecular oxa-conjugate cyclization of alcohol 439 in THF at $-78{ }^{\circ} \mathrm{C}$ in the presence of 0.05 equiv of $\mathrm{KO} t-\mathrm{Bu}$, was converted to iodide $\mathbf{B 9 0}$ by ozonolysis followed by Takai olefination[356] $\left(\mathrm{CrCl}_{2}, \mathrm{CHI}_{3}, \mathrm{THF} /\right.$ dioxane, $\left.\mathrm{rt}\right)$ (Scheme 101).[337] 


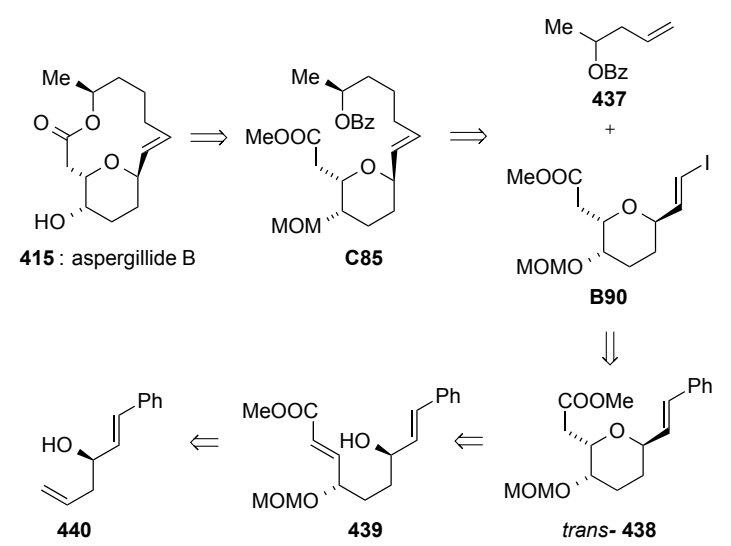

Scheme 101. Retrosynthesis of (-)-aspergillide B (415)

Fuwa and co-workers also carried out the total synthesis of aspergillide A (414) by using compound cis-438 as an intermediate, which was obtained in $85 \%$ yield with $7: 1$ diastereoselectivity by exposure of alcohol $\mathbf{4 3 9}$ to 10 equiv of DBU in toluene at $100{ }^{\circ} \mathrm{C}$ (Scheme 102).[337]

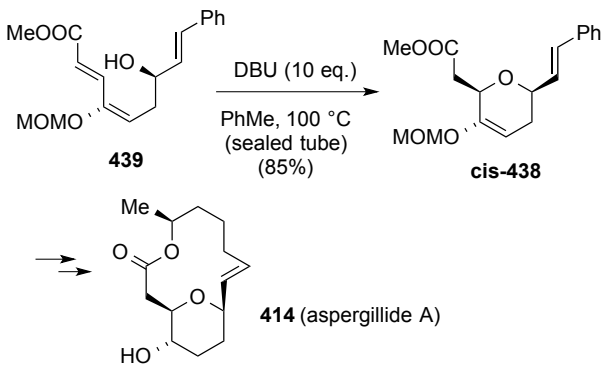

Scheme 102. Synthesis of aspergillide A (414) starting from compound 439

In 2011, Helmchen and co-workers developed a high quality enantioselective total synthesis of the indolizidine alkaloid (+)-195B (416) in which compound C86, a key intermediate, was prepared using a reaction sequence, which involved the asymmetric iridium-catalyzed allylic amination of allylic carbonate 441 with the pronucleophile $\mathbf{4 4 2}$, the $N$-formyl deprotection of the resulting compound $\mathbf{4 4 3}$ and hydroboration with 9-BBN-H of the thereby obtained amine 444, followed by $\mathrm{PdCl}_{2}(\mathrm{dppf}) / \mathrm{AsPh}_{3}$-catalyzed reaction with methyl (E)-3-iodoacrylate (B91) (Scheme 103).[338] As shown in entry 6 of Table 11, this cross-coupling reaction gave compound $\mathbf{C 8 6}$ in $80 \%$ yield. The subsequent intramolecular aza-Michael addition reaction of $\mathbf{C 8 6}$ yielded the trans-2,5-disubstituted pyrrolidine $\mathbf{4 4 5}$, which was then converted to 416 via a 6-step reaction sequence (Scheme 103).[338 ]Unfortunately, compound $\mathbf{4 1 6}$ proved to be contaminated by $5 \%$ of an epimer.[338]

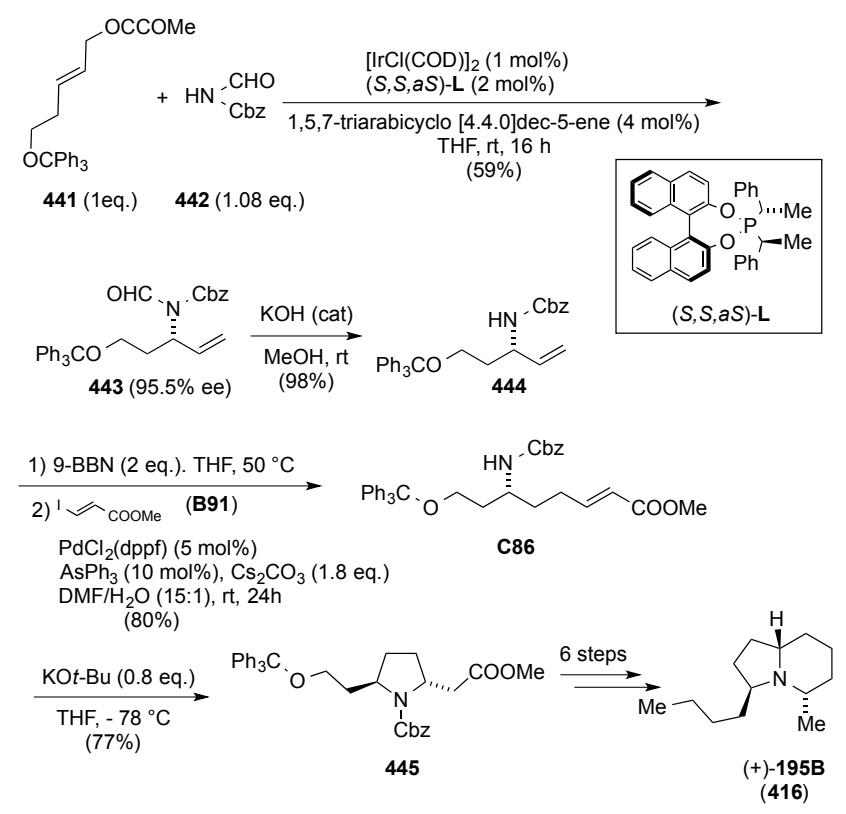

Scheme 103. Synthesis of $(+)-195 B$ (416) from allylic carbonate 441

A combination of an asymmetric Ir-catalyzed allylic amination, a $\mathrm{PdCl}_{2}(\mathrm{dppf}) / \mathrm{AsPh}_{3}$-catalyzed S.-M. reaction and an intramolecular Michael addition was also employed for a total synthesis of the alkaloid $(+)$-xenovenine (417) in $95.5 \%$ ee.[338] Key intermediates of this process were compounds $\mathbf{C 8 7}$ and the trans-2,5-disubstituted pyrrolidine (446) (Figure 22). Compound C87 was obtained in 80\% yield by the S.-M. reaction between alkylborane $\mathbf{A 8 8}$ and methyl (E)-3-iodoacrylate (B91) illustrated in entry 7 of Table 11. Compound $\mathbf{4 4 6}$ was in turn obtained by azaMichael cyclization of compound 447 (Figure 22). [338]

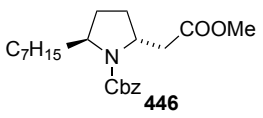

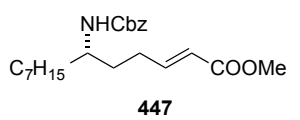

Figure 22. Structures of compounds 446 and 447

In the same year, Feringa and co-workers used the $\mathrm{sp}^{3}-\mathrm{sp}^{2}$ 9MeO-9-BBN-mediated coupling reaction illustrated in entry 8 of Table 11 as a key step of a formal synthesis of $(R)-(+)-$ lasiodiplodin (418), which they accomplished on the basis of the retrosynthetic analysis shown in Scheme 104.[339] 
<smiles>C=CCCCCc1cc(OC)cc(OC)c1C(=O)OC(C)C=C</smiles>

Scheme 104. Retrosynthesis of (R)-(+)-lasiodiplodin (418)

In particular, compound 448 containing the macrolactone ring of 418 was planned to be formed by ring-closing metathesis of diene 449 followed by catalytic hydrogenation. Compound 449 could be available from the tetrasubstituted benzene derivative 450 and allylic alcohol 451, which could be accessible in high yield and enantioselectivity by $\mathrm{CuBr}$ /TaniaPhos-catalyzed asymmetric allylic alkylation of allyl bromide 453[357] followed by hydrolysis of the resulting ester 452.[339] Thus, compound $\mathbf{4 5 0}$ was synthesized from $\mathbf{C 8 8}$, which in turn was obtained in $52 \%$ yield by the $\mathrm{PdCl}_{2}$ (dppf)/ $\mathrm{AsPh}_{3}$-catalyzed reaction of aryl iodide B92 with boronate $\mathbf{A 8 9}$ (entry 8, Table 11). Interestingly, the presence of $\mathrm{AsPh}_{3}$ as a coligand was essential for the successful outcome of this cross-coupling reaction. In fact, isomerization of the terminal $\mathrm{C}-\mathrm{C}$ double bond of $\mathbf{C 8 8}$ was observed when the reaction was carried out in the absence of $\mathrm{AsPh}_{3}$.[339] Finally, $(R)-(+)$-lasiodiplodin methyl ether 448, which was obtained in the last step of the formal synthesis of $(R)$-(+)-lasiodiplodin (418), was converted into the natural compound according to literature procedures,[358] although in a low yield.[339]

Still in 2011, Horne and co-workers performed the total synthesis of the proposed structure of iriomoteolide-1a (419) via an approach in which the C7-C23 fragment of this compound was assembled by the $\mathrm{PdCl}_{2}(\mathrm{dppf}) / \mathrm{AsPh}_{3}-$ catalyzed reaction of boronate $\mathbf{A 9 0}$ with vinyl iodide $\mathbf{B 9 3}$ (entry 9, Table 11).[340] The latter compound was synthesized in a 4:1 dr by the Sakurai reaction of allylsilane $\mathbf{4 5 4}$ with aldehyde $\mathbf{4 5 5}$ followed by acetylation (Scheme $105)$.

In a second generation synthesis of the $\mathrm{C} 7-\mathrm{C} 23$ fragment of 419, the $\mathrm{PdCl}_{2}$ (dppf)/AsPh 3 -catalyzed $B$-alkyl S.-M. reaction between vinyl iodide $\mathbf{4 5 6}$ and alkyl iodide $\mathbf{4 5 7}$ produced fragment 458 in 84\% yield (Scheme 106).[340]

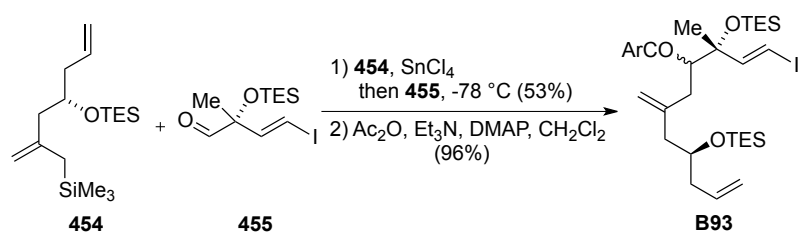

Scheme 105. Synthesis of vinyl iodide $\mathbf{B 9 3}$
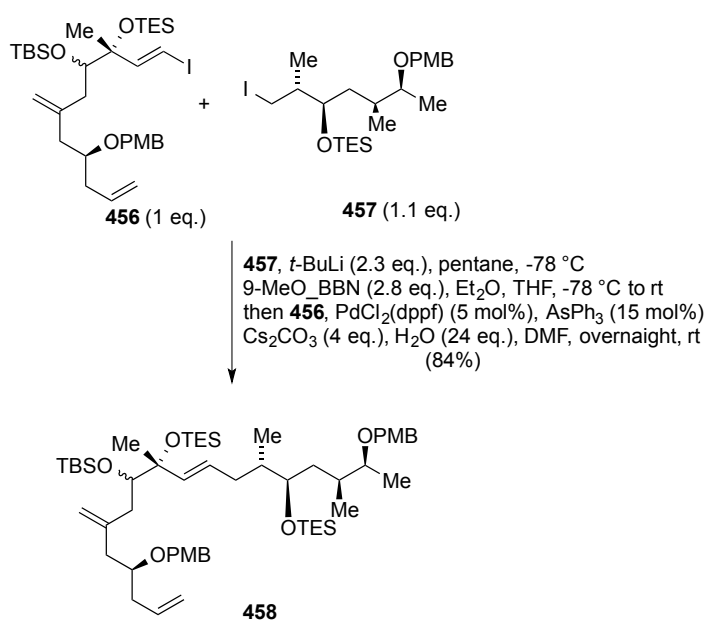

Scheme 106. Synthesis of compound 458

In 2012, Sasaki and co-workers accomplished a total synthesis of the marine lethal toxin (-)-polycarvenoside A (420) in 29 steps and 2.4\% overall yield via a convergent approach (Scheme 107) in which intermediate 459 was prepared from bis-pyran $\mathbf{C 9 1}$ and the latter compound was obtained by the $\mathrm{PdCl}_{2}(\mathrm{dppf}) \cdot \mathrm{CH}_{2} \mathrm{Cl}_{2} / \mathrm{AsPh}_{3}$-catalyzed reaction of enol triflate $\mathbf{B 9 5}$ with alkylborane $\mathbf{A 9 1}$ (entry 11, Table 11) generated by hydroboration of exo-olefin 460 with 9-BBN-H in THF.[341]

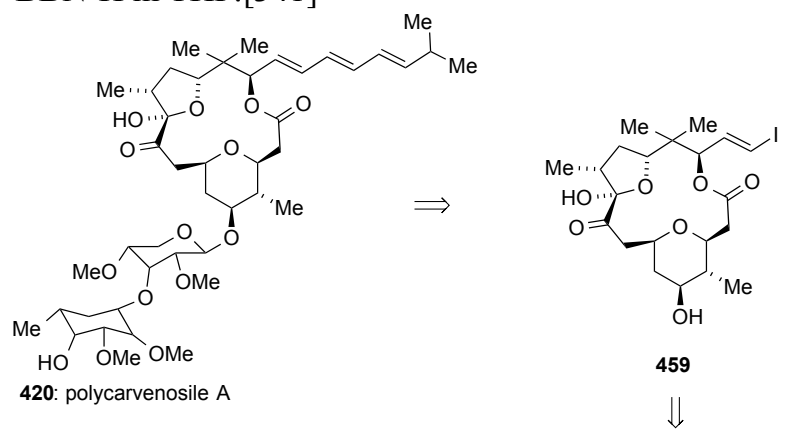

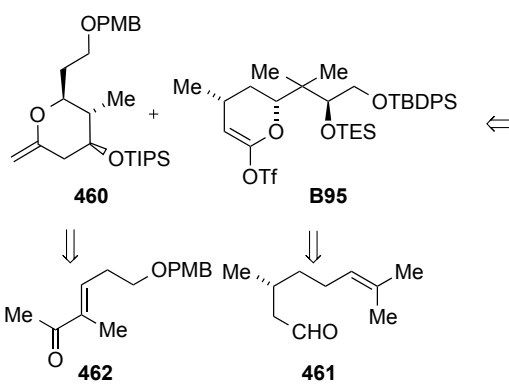

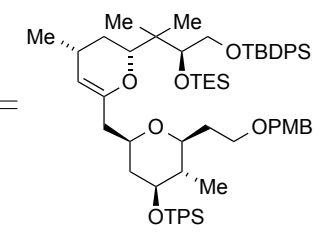

C91

Scheme 107. Retrosynthesis of (-)-polycarvenoside A (420) 
Enol triflate B95 was asymmetrically generated in 15 steps starting from $(R)$-citronellol (461) and exo-olefin 460 was prepared through a catalytic asymmetric synthesis starting from the known enone 462, which was available from 1,3propanediol.[360] On the other hand, the macrolactone core of the natural product was formed by using the Keck macrolactonization protocol[361] in which DCC, pyridine and PPTS under reflux were used.[362]

In the same year, the $\mathrm{PdCl}_{2}(\mathrm{dppf}) / \mathrm{AsPh}_{3}$-catalyzed coupling of methyl $(E)$-3-iodoacrylate (B91) with alkylborane $\mathbf{A 9 2}$ (entry 12, Table 11) was used by Helmchen and co-workers as a key step of the first enantioselective total synthesis of apiosporic acid (421).[342] Crucial for the success of the reaction was a short reaction time of the hydroboration reaction of trityl $(2 S, 4 E, 6 E)$-2-vinylocta-4,6-dien-1-yl ether (463) with 9-BBN-H, which provided crude alkylborane $\mathbf{A 9 2}$ (Scheme 108).[342]

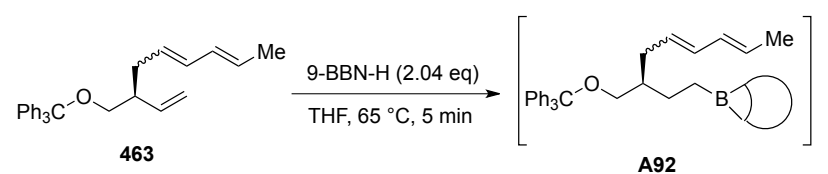

Scheme 108. Synthesis of crude alkylborane $\mathbf{A 9 2}$

Compound 463 was in turn synthesized in $69 \%$ yield by the reaction of 1-phenyl-5-\{(3S)-3-[(trityloxy)methyl]pent-4-en1-yl\} sulfonyl-1 $H$-tetrazole (464) with crotonaldehyde (465) in the presence of KHMDS as base (Scheme 109).[342]

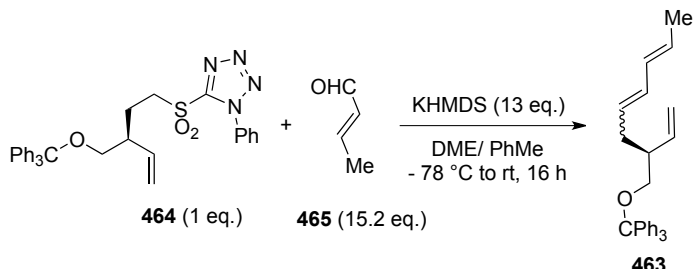

Scheme 109. Synthesis of compound 463 from tetrazole 464

Another key step of the total snthesis of $\mathbf{4 2 1}$ was the $\mathrm{EtAlCl}_{2}$-mediated intramolecular Diels-Alder reaction of the cross-coupling product $\mathbf{C 9 2}$ of the S.-M. reaction between A92 and B91. (Scheme 110). Hydrolysis of the resulting compound 466 provided apiosporic acid (421) (Scheme 110).[342]<smiles>COC(=O)/C=C/CCC(C/C=C\C=C/C(=O)OCc1ccccc1)COCc1ccccc1</smiles>

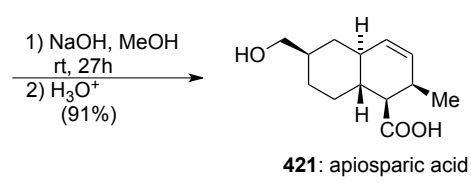

Scheme 110. Synthesis of apiosporic acid (421) from compound C92

In the same year, Fuwa, Sasaki and co-workers synthesized in quantitative yield compound C93, an early precursor to gambieric acid $\mathrm{A}$ (422), by the $\mathrm{PdCl}_{2}$ (dppf)/ $\mathrm{AsPh}_{3}$-catalyzed reaction of (Z)-vinyl iodide $\mathbf{B 9 6}$ with boronate $\mathbf{A 9 3}$ which was generated in situ from the corresponding alkyl iodide (entry 13, Table 11).[343 ]Furthermore, compound 469, a more advanced intermediate in the first total synthesis of 422, was synthesized in $95 \%$ yield by the $\mathrm{PdCl}_{2}$ (dppf) $\cdot \mathrm{CH}_{2} \mathrm{Cl}_{2}$-catalyzed reaction of crude enol phosphate 468 with the alkylborane prepared in situ by hydroboration of alkene $\mathbf{4 6 7}$ with 9-BBN-H (Scheme 111).[343]

Interestingly, synthetic gambieric acid A (422) was found to display antifungal activity against Aspergillus niger, which was equipotent to that of the natural product.[353]

Still in 2012, a notable total synthesis of the proposed structure of didemnaketal A (423) was described by Tu and co-workers.[344] This compound featuring a spiroketal moiety and a main chain containing 23 carbons and 12 stereocenters was synthesized in 31 steps for the longest linear sequence.

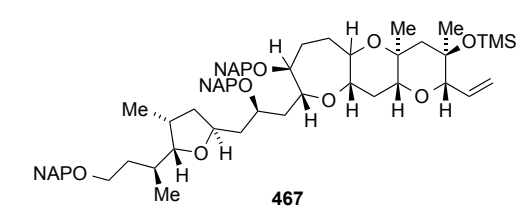
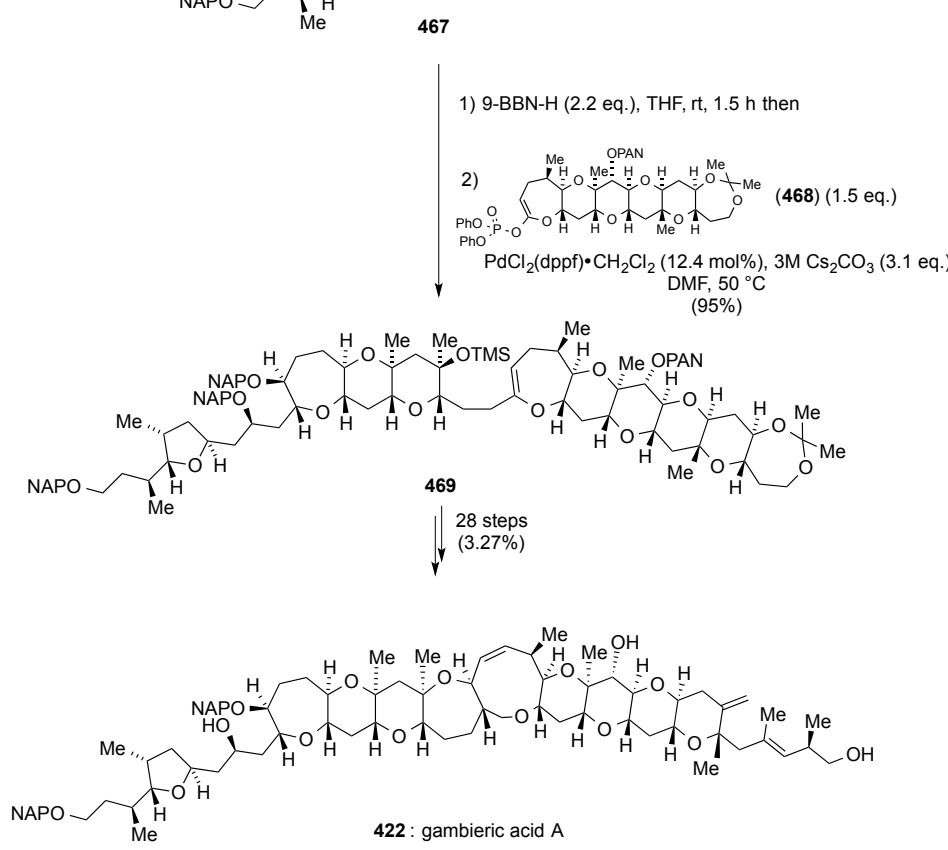

Scheme 111. Synthesis of gambieric acid A (422) from compound 467 


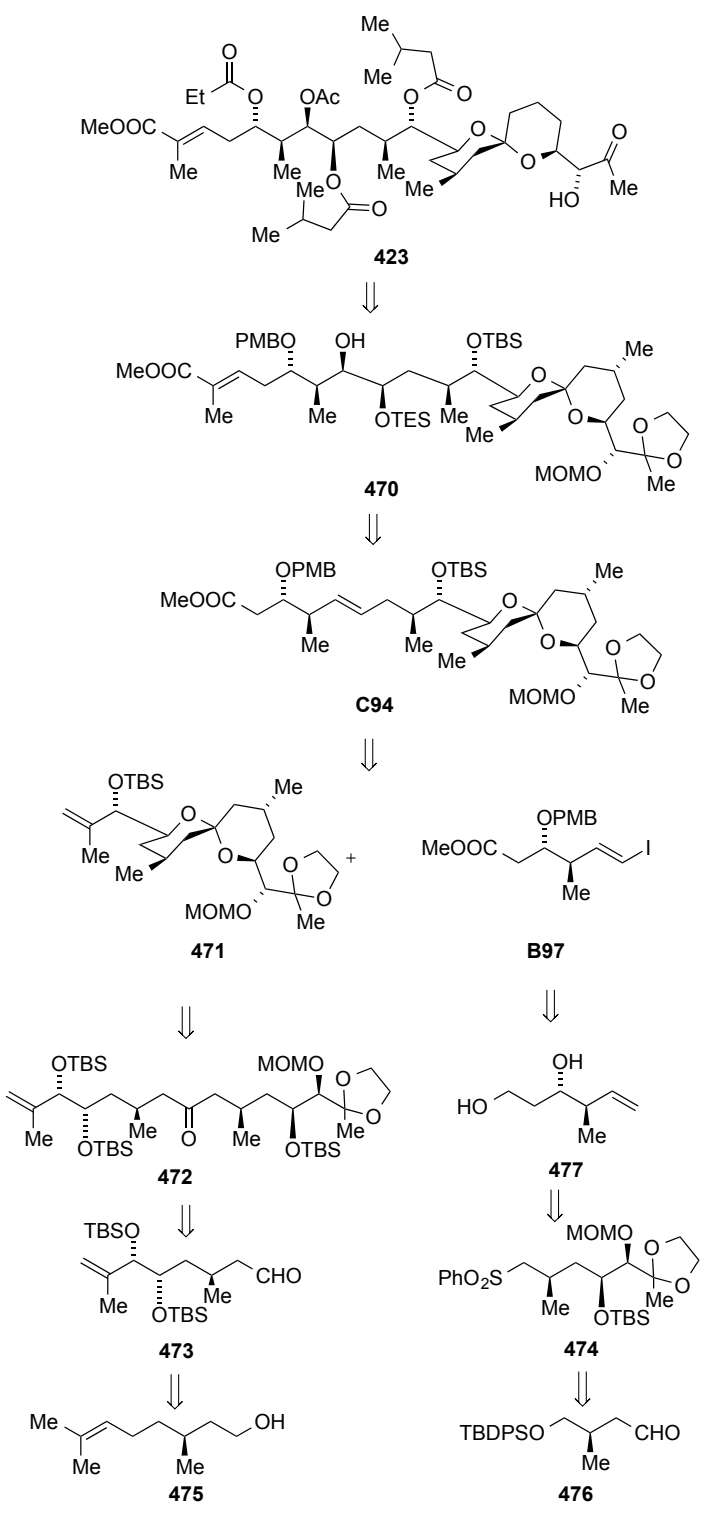

Scheme 112. Retrosynthesis of the nominal didemnaketal A

As shown in the retrosynthesis illustrated in Scheme 112, the advanced intermediate $\mathbf{4 7 0}$ containing all stereocenters and the entire $\mathrm{C} 1-\mathrm{C} 23$ chain was available from compound C94 containing the $\mathrm{C} 3-\mathrm{C} 23$ chain. It was synthesized in 77\% yield from vinyl iodide B97 and alkylborane $\mathbf{A 9 4}$ (entry 14, Table 11), which was prepared by hydroboration of alkene 471 with 9-BBN-H. Iodide B97 was obtained from the known diol 477 [363] in $42.5 \%$ overall yield via a 6 -step reaction sequence. Alkene $\mathbf{4 7 1}$ was in turn obtained via $\mathrm{NH}_{4} \mathrm{~F} \cdot \mathrm{HF}$-promoted spirocyclization of compound $\mathbf{4 7 2}$, which was available in $82 \%$ yield from aldehyde 473 and sulfone 474. In turn, 473 was synthesized in $22.4 \%$ yield starting from $(S)$-citronellol (475) via a series of five reactions and sulfone 474 was prepared from aldehyde 476[364] in $30.4 \%$ overall yield through a series of five reactions.[344]
A few month before the publication of this synthesis of didemnaketal A, Paterson and co-workers successfully developed a total synthesis of the methyl ester of the antimitotic marine macrolide spirastrellolide A (424).[345] The synthesis that proceeded in $6 \%$ overall yield over 23 steps was carried out starting from the known bis(spiroacetal) intermediate $\mathbf{4 7 6}$ according to the retrosynthesis shown in Scheme 113.[365]
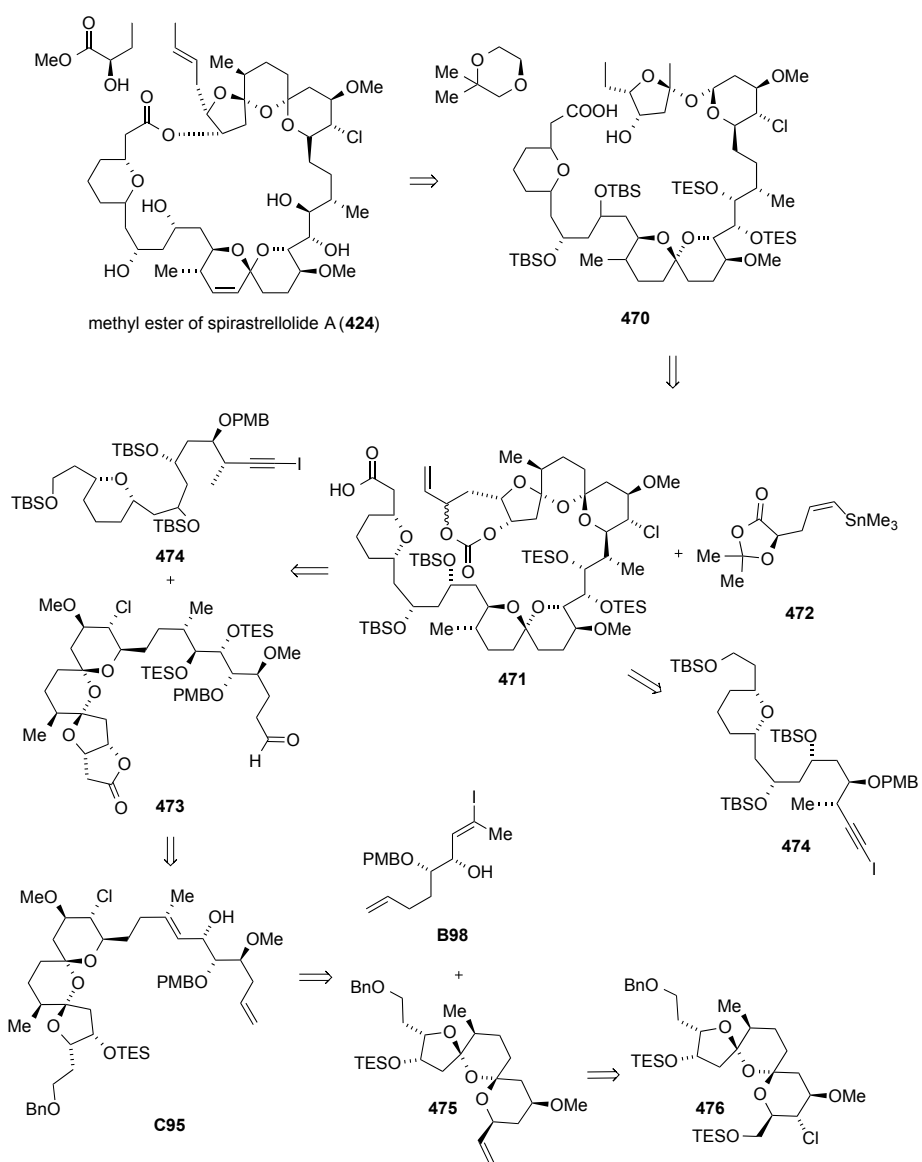

Scheme 113. Retrosynthesis of the methyl ester of spirastrellolide A (424)

The synthesis commenced with the selective desilylation of $\mathbf{4 7 6}$ and oxidation of the resulting alcohol, followed by a methylenation reaction $\left(\mathrm{MePPh} \mathrm{B}_{3} \mathrm{Br}, n\right.$-BuLi), which provided alkene 475 in $70 \%$ overall yield. Hydroboration of $\mathbf{4 7 5}$ with 9-BBN-H gave alkylborane $\mathbf{A 9 5}$, which was subjected to $\mathrm{PdCl}_{2}$ (dppf)/ $/ \mathrm{AsPh}_{3}$-catalyzed reaction with vinyl iodide $\mathbf{B 9 8}$ in a mixture of $\mathrm{THF}$ and $\mathrm{DMF}$ at room temperature in the presence of $\mathrm{Cs}_{2} \mathrm{CO}_{3}$ as base delivering diene $\mathbf{C 9 5}$ in quantitative yield (entry 15, Table 11). A subsequent 5-step reaction sequence allowed to convert $\mathbf{C 9 5}$ into the building block 473, which was coupled with iodoalkyne 474 under Nozaki-Hiyama-Kishi conditions $\left(\mathrm{NiCl}_{2}, \mathrm{CrCl}_{2}\right)$.[366] The resulting propargylic alcohol was converted into the $\mathrm{C} 1-\mathrm{C} 42$ carboxylic acid $\mathbf{4 7 1}$ in $30 \%$ overall yield by using a 9 -step reactions sequence. The full spirastrellolide A side chain was then assembled by the $\mathrm{PdCl}_{2}(\mathrm{MeCN})_{2}$-catalyzed smooth coupling of 471 with the C43-C47 stannane 472, which gave 
the $\mathrm{C} 1-\mathrm{C} 47$ diene $\mathbf{4 7 0}$ as a single stereoisomer in $86 \%$ yield. Finally, a series of reactions involving removal of the silyl groups, Yamaguchi macrolactonization[367] and cleavage of the dioxolane protecting group provided the methyl ester of spirastrellolide A (Scheme 113).[345]

More recently, a second total synthesis of spirastrellolide A methyl ester was accomplished by Fürstner and coworkers.[356] A crucial step of this concise synthesis was the $\mathrm{PdCl}_{2}$ (dppf) $\cdot \mathrm{CH}_{2} \mathrm{Cl}_{2} / \mathrm{AsPh}_{3}$-catalyzed reaction between alkenyl triflate $\mathbf{B 9 9}$ and alkylborane $\mathbf{A 9 6}$ in THF at room temperature in the presence of $1 \mathrm{M}$ aq $\mathrm{NaOH}$ (entry 16 , Table 11). The coupling, which gave compound $\mathbf{C 9 6}$ in 65\% yield, allowed to join the northern and eastern sectors of the target compound. Another crucial step was the Yamaguchi lactonization of C96, which forged the macrocyclic ring of the methyl ester of 424. Finally, the lateral side-chain of this compound, comprising the remote C46 stereocenter, was attached to the core structure via a Julia-Kocienski olefination reaction[368] of aldehyde 477 with the known sulfone 478[369] (Scheme 114).
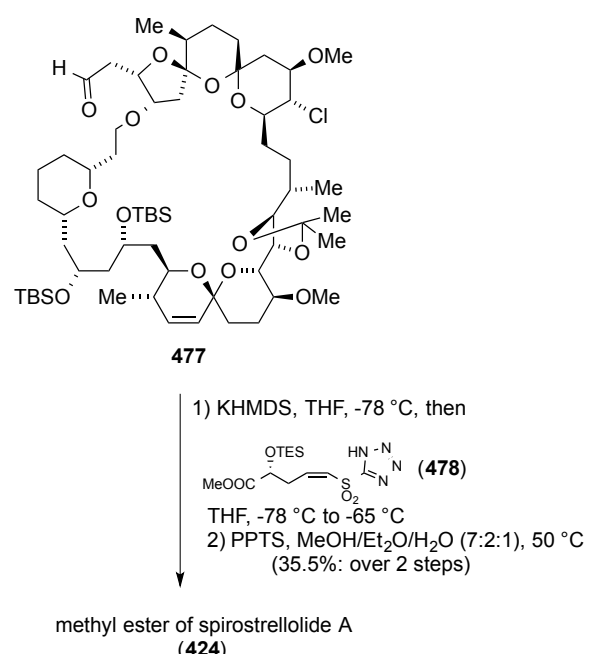

Scheme 114. Synthesis of the methyl ester of spirastrellolide A from compound 477

In 2011, Wiese, Hiersemann and co-workers reported the details of the total syntheses of (-)-15-O-acetyl-3-Opropionylcharaciol (425), a compound which was found to be cytotoxic against human cancer cell lines and to possess multidrug resistance-modulating properties, [370] and of 15$O$-acetyl-3- $O$-benzoylcharaciol $(5 R, 6 R)$-oxide (426).[347] The tactic used for the assembly of the transbicyclo[10.3.0]pentadecane scaffold of $\mathbf{4 2 5}$ involved the formation of the $\mathrm{C} 5-\mathrm{C} 6$ double bond of this natural compound via the $\mathrm{PdCl}_{2}(\mathrm{dppf}) / \mathrm{AsPh}_{3}$-catalyzed reaction between alkylborane $\mathbf{A 9 7}$ and alkenyl iodide $\mathbf{B 1 0 0}$ in a mixture of DMF, THF and water at $80{ }^{\circ} \mathrm{C}$ in the presence of $\mathrm{Cs}_{2} \mathrm{CO}_{3}$ as base (entry 17, Table 11).[347 ]Furthermore, a $\mathrm{Ru}$-catalyzed ring-closing metathesis of compound 479, which was obtained in 6 steps from the S.-M. cross-coupling product C97, was used to establish the fully substituted trans-bicyclo[10.3.0]pentadecane framework of $\mathbf{4 2 5}$
(Scheme 115). Diene 480 resulting from the ring-closing metathesis reaction was then used as the common precursor to compounds 425 and 426 (Scheme 115). [347]

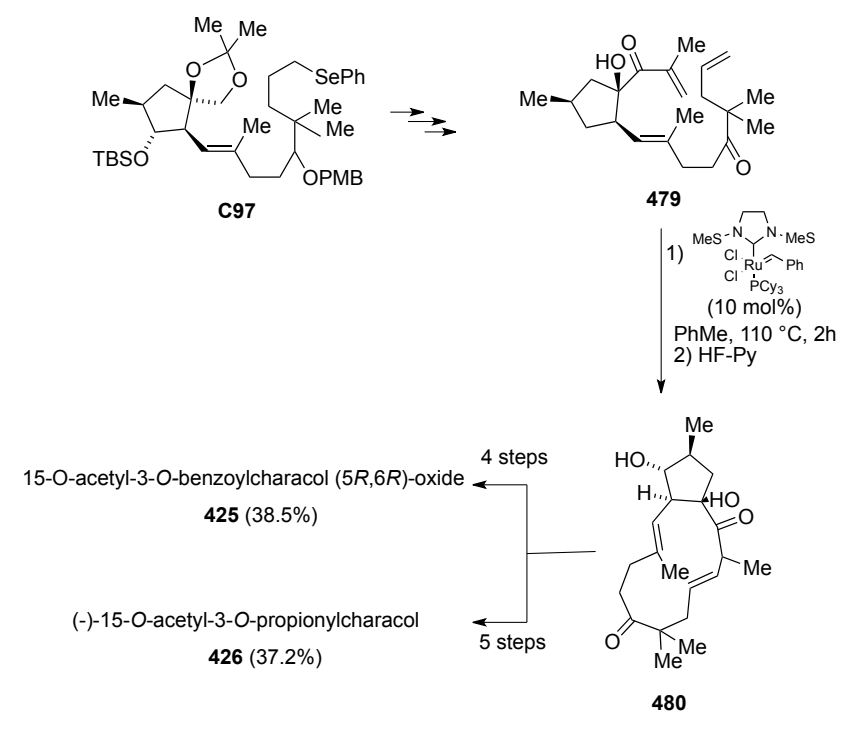

Scheme 115. Synthesis of compounds 425 and 426 from the cross-coupling product $\mathbf{C 9 7}$

In 2013, G. Zhao and co-workers performed the total syntheses of (+)-lycoposerramine Q (427) and (+)fawcettidine (428) from the common intermediate $\mathbf{C 9 8}$, which was obtained in $92 \%$ yield by the $\mathrm{PdCl}_{2}(\mathrm{dppf}) / \mathrm{AsPh}_{3}-$ catalyzed reaction of alkylborane $\mathbf{A 9 8}$ with cycloalkenyl triflate B101 in a mixture of THF, water and DMF at $60{ }^{\circ} \mathrm{C}$ in the presence of $\mathrm{C}_{2} \mathrm{CO}_{3}$ as base (entry 18, Table 11).[348] The Hajos-Parrish-like diketone 481 (Figure 23), which was used as the starting material of the total syntheses, was easily prepared from 1,3-cyclopentanedione through a 3-step procedure.[371]

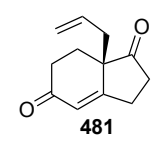

Figure 23. Structure of diketone 481

Still in 2013, Hiersemann and co-workers described a notable synthesis of (-)-ecklonialactone B (429) in $2 \%$ overall yield starting from allyl vinyl ether 482.[349] The building block 483 was prepared on a gram scale in $91 \%$ yield, $\mathrm{dr} \leq 95: 5$ and $>99 \%$ ee by catalytic asymmetric Gosteli-Claisen rearrangement[372] of 482 (Scheme 116).[349] 


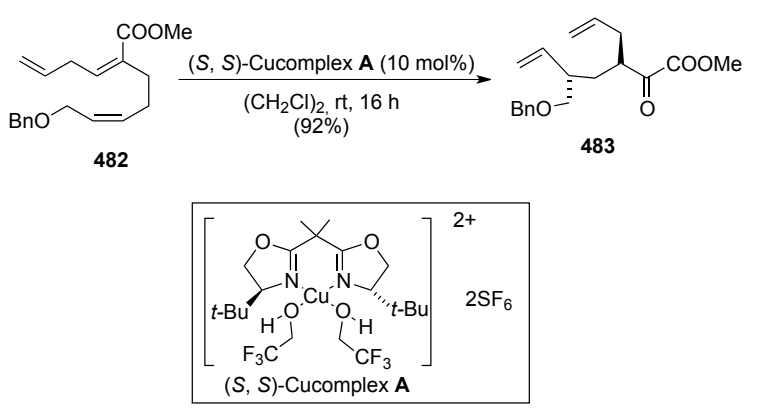

Scheme 116. Synthesis of compound 483

The total synthesis also included the efficient preparation of intermediate $\mathbf{C 9 9}$ by $\mathrm{PdCl}_{2}(\mathrm{dppf}) / \mathrm{AsPh}_{3}$-catalyzed reaction of $B$-alkyl borate complex A99 with vinyl iodide B102 in a mixture of THF and DMF at room temperature in the presence of $\mathrm{Cs}_{2} \mathrm{CO}_{3}$ as base (entry 19, Table 11). However, compound $\mathbf{C 9 9}$ proved to be contaminated by ca. $10 \%$ of the corresponding $E$-stereoisomer.[349] Finally, the last step of the total synthesis of $\mathbf{4 2 9}$ was the regio- and diastereoselective epoxidation of diene 484, which was accomplished by a two-step procedure involving the reaction of 484 with 1 equiv of NBS in aqueous acetone and subsequent treatment of the resulting isolated and purified bromohydrin with $\mathrm{Ag}_{2} \mathrm{O}$ in refluxing toluene (Scheme 117).[349]

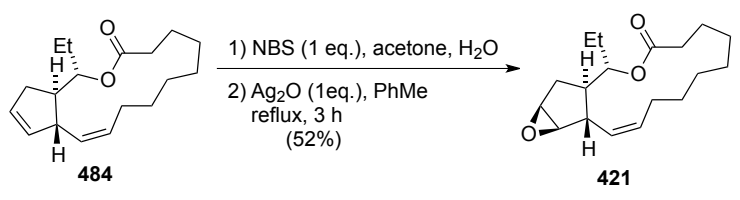

Scheme 117. Epoxidation of diene 484

\section{CONCLUSION}

Although in the last years a wide variety of new palladium-based catalyst systems have been developed for the S.-M. cross-coupling reaction, a large number of recent total syntheses of natural products have continued to benefit from efficient and chemoselective S.-M. couplings involving the use of "classical" phosphane-based Pd-catalysts. In such total syntheses, the construction of $\mathrm{Csp}^{3}-\mathrm{Csp}^{2}$ bonds and iterative cross-coupling reactions have often been performed by using organoboron reagents such as 9-alkyl-9-BBN derivatives, 9-MeO-9-BBN boronates and MIDA boronates.

Nevertheless, despite the good results achieved so far and illustrated in this review through the use of phosphane-based Pd-catalyst systems, which are also testified by those reported in some papers published in the early months of $2014,[373]$ we can expect that, given the remarkable progress recently gained on the catalyst systems and the experimental conditions of the S.-M. reaction, future studies on the synthesis, especially on a large scale, of natural products that are particularly important for their bioactivity are aimed at developing the use of Pd-catalysts of S.-M. reactions that operate with high turnover numbers and in the absence of ligands as well as at identifying experimental conditions in which such cross-couplings are carried out in the absence of organic solvents, at mild temperatures and without the use of a large molar excess of bases.

\section{LIST OF ABBREVIATIONS}

Ac, acetyl; acac, acetylacetonate; Ar, aryl; AIBN, 2,2'azobisisobutyronitrile; $9-\mathrm{BBN}-\mathrm{H}, \quad 9-$ borabicyclo[3.3.1]nonane; 9-BBN, 9borabicyclo[3.3.1]nonyl; BMIDA, $N$-methyliminodiacetic acid-protected boronate; Bn, benzyl; Boc, $t$-butoxycarbonyl; $n$-Bu, $n$-butyl; $t$-Bu, $t$-butyl; $\mathrm{Bz}$, benzoyl; CAN, ceric ammonium nitrate; Cbz, carbobenzyloxy; Cy, cyclohexyl; $\mathrm{dba}$ dibenzylideneacetone; DBU, 1,5diazabicyclo[5.4.0] undec-5-ene; DCC, dicyclohexylcarbodiimide; DDQ, 2,3-dichloro-5,6-dicyano1,4-benzoquinone; DIAD, diisopropyl azodicarboxylate; DIBAL-H, diisobutylaluminum hydride; DMAP, 4- $(N, N$ 'dimethylamino)pyridine; DMEDA, $N, N^{\prime}$-dimethyl-1,2ethanediamine; DMF, N,N-dimethylformamide; dppf, 1,1'bis(diphenylphosphino)ferrocene; d.r., diastereomeric ratio; ee, enantiomeric excess, EE, ethoxyethyl; Et, ethyl; Ipc, isopinocampheyl; JohnPhos, (2-biphenyl)di-tbutylphosphine; KHMDS, potassium hexamethyldisilazane; Me, methyl; MPM, 4-methoxybenzyl; MOM, methoxymethyl; MW, microwave; NaHMDS, sodium hexamethyldisilazane; NBS, $\mathrm{N}$-bromosuccinimide; NIS, $\mathrm{N}$ iodosuccinimide; n.r., not reported; $N$-Succ, $N$-succinimidyl; $\mathrm{Ph}$, phenyl; pin, pinacol; Piv, pivaloyl; $\mathrm{PMB}, p$ methoxybenzyl; PPTS, pyridinium $p$-toluenesulfonate; $i$-Pr, $i$-propyl; $n$-Pr, $n$-propyl; Py, pyridine; rt, room temperature; RuPhos, 2-dicyclohexylphosphino-2',6'diisopropoxybiphenyl; SEM, 2-(trimethylsilyl)ethoxymethyl; SPhos, 2-dicyclohexylphosphino-2',6'-dimethoxybiphenyl; TBAB, tetrabutylammonium bromide; TBAF, tetrabutylammonium fluoride; TBDPS, $t$-butyldiphenylsilyl; TBS, t-butyldimethylsilyl; TES, triethylsilyl; Tf, trifluoromethanesulfonyl; TFA, trifluoroacetic acid; THF, tetrahydrofurane; THP, tetrahydropyranyl; TIPS, triisopropylsilyl; TMS, trimethylsilyl; $o$-Tol, $o$-tolyl; Tr, trityl; $\quad p$-Ts, $\quad p$-toluenesulfonyl; XPhos, 2dicyclohexylphosphino-2',4',6'-triisopropylbiphenyl

\section{REFERENCES}

[1] For leading reviews on the Suzuki-Miyaura reactions, see: (a) Palladium Catalyzed Coupling Reactions; Molnar, A. Ed.; Wiley-VCH: Weinheim, Germany, 2013; (b) Lennox, J. J.; Lloyd-Jones, G. C., Chem. Soc. Rev. 2014, 43, 412-443; (c) Rossi, R.; Bellina, F.; Lessi, M. Adv. Synth. Catal. 2012, 354, 1181-1255; (d) Li, H.; Seechurn, C. C. C. J.; Colacot, T. J. ACS Catal. 2012, 2, 1147-1164; (e) Heravi, M. M.; Hashemi, E. Tetrahedron 2012, 68, 9145-9178; (f) Valente, C.; Calimsiz, S.; Hoi, K. H.; Mallik, D.; Sayah, M.; Organ, M. G. Angew. Chem. Int. Ed. 2012, 51, 3314-332; (g) Rossi, R.; Bellina, F. Lessi, M. Tetrahedron 2011, 67, 6969-7025; (h) Fihri, A.; Bouhrara, M.; Nekeouishahraki, B.; Basset, J.-M. Polsiettivar, Chem. Soc. Rev. 2011, 40, 5181-5203; (i) Narayanan, R. Molecules 2010, 15, 2124-2138; (j) 
Polshettivar, V.; Decottignes, A.; Len, C.; Fihri, A. ChemSusChem 2010, 3, 502-522; (k) Molander, G. A.; Canturk, B. Angew. Chem. Int. Ed. 2009, 48, 9240-9261; (1) Littke, A. F. in Modern Arylation Methods; Ackermann, L. Ed.; Wiley-VCH: Weinheim, Germany, 2009, pp 25-67; (m) Martin R.; Buchwald, S. L. Acc. Chem. Res. 2008, 41, 14611473; (n) Weng, Z.; Teo, S.; Hor, T. S. Acc. Chem. Res. 2007, 40, 676-684; (o) Molander, G. A.; Ellis, N. Acc. Chem. Res. 2007, 40, 275-286; (p) Felpin, F.-X.; Ayad, T.; Mitra, S. Eur. J. Org. Chem. 2006, 2679-2690; (q) Phan, N. T. S.; Van Der Sluys, M.; Jones, C. W. Adv. Synth. Catal. 2006, 348, 609679; (r) Bai, L.; Wang, J.-X. Curr. Org. Chem. 2005, 9, 535553; (s) Nicolaou, K. C.; Bulger, P. G.; Sarlach, D. Angew. Chem. Int. Ed. 2005, 44, 4442-4489; (t) Bellina, F.; Carpita, A.; Rossi, R. Synthesis 2004, 2419-2440; (u) Tyrrell, E.; Brookes, P. Synthesis 2004, 469-483; (v) Kohta, S.; Lahiri, K.; Kashinati, D. Tetrahedron 2002, 58, 9633-9695; (w) Miyaura, N. Top. Curr. Chem. 2002, 219, 11-59; (x) Chemler, S. R.; Trauner, D.; Danishefsky, S. J. Angew. Chem. Int. Ed. 2001, 40, 4544-4568.

[2] For leading reviews on the synthesis of natural products via Suzuki-Miyaura cross-coupling reactions, see: (a) Selepe, M. A.; Van Heerden, F. R. Molecules 2013, 18, 4739-4765; (b) Ref. 1e; (c) Fuwa, H. Bull. Chem. Soc. Jpn. 2010, 83, 14011420; (d) Ref. 1s; (e) Sasaki, M.; Fuwa, H. Synlett 2004, 1851-1874; (f) Anctil, E. J.-G.; Snieckus, V. J. Organomet. Chem. 2002, 653, 150-160; (g) Ref. 1x.

[3] For selected references on the application of the SuzukiMiyaura reaction in the synthesis of biologically and pharmacologically active compounds, see: (a) Zhou, Q.; Zhang, B.; Su, L.; Jiang, T.; Chen, R.; Du, T.; Ye, Y.; Dai, G.; Han, D.; Jiang, H. Tetrahedron 2013, 69, 10996-1103; (b) Bort, G.; Veitia M. S.-I.; Ferroud, C. Tetrahedron 2013, 69, 7345-7353; (c) Coombs, T. C.; Tanega, C.; Shen, M.; Wang, J. L.; Auld, D. S.; Gerritz, S. W.; Schoenen, F. J.; Thomas, C. J.; Aubé, J. Bioorg. Med. Chem. Lett. 2013, 23, 3654-3661; (d) Li, C.-M.; Geng, H.-C.; Li, M.-M.; Xu, G.; Ling, T.-J.; Qin, H.-B. Nat. Prod. Bioprospect 2013, 3, 117-120; (e) Caldwell, J. J.; Veillard, N.; Collins, I. Tetrahedron 2012, 68, 9173-9728; (f) Keche, A. P.; Hatnapure, G. D.; Tale, R. H.; Rodge, A. H.; Birajdar, S. S.; Kamble, V. M. Bioorg. Med. Chem. Lett. 2012, 22, 3445-3448; (g) Neagoie, C.; Vedrenne, E.; Buron, F.; Mérour, J.-Y.; Rosca, S.; Bourg, S.; Lozach, O.; Meijer, L.; Baldeyrou, B.; Lansiaux, A.; Routier, S. Eur. J. Med. Chem. 2012, 49, 379-396; (h) Lin, J.; Jin, X.; Bu, Y.; Cao, D.; Zhang, N.; Li, S.; Sun, Q.; Tan, C.; Gao, C.; Jiang, Y. Org. Biomol. Chem. 2012, 10, 9734-9746; (i) Kim, T.; Lee, W.; Jeong, K. H.; Song, J. H.; Park, S.-H.; Choi, P.; Kim, S.N.; Lee, S.; Ham, J. Bioorg. Med. Chem. Lett. 2012, 22, 41224126; (j) Theeramunkong, S.; Caldarelli, A.; Massarotti, A.; Aprile, S.; Caprioglio, D.; Zaninetti, R.; Teruggi, A.; Pirali, T.; Grosa, G.; Tron, G. C.; Genazzani, A. A. J. Med. Chem. 2011, 54, 4977-4986; (k) Arthuis, M.; Pontikis, R.; Chabot, G. G.; Seguin, J.; Quentin, L.; Borg, S.; Morin-Allory, L.; Florent, J.C. ChemMedChem 2011, 6, 1693-1705; (1) Shetty, R. S.; Lee, Y.; Liu, B.; Husain, A.; Joseph, R. W.; Lu, Y.; Nelson, D.;
Mihelcic, J.; Chao, W.; Moffett, K. K.; Schumacher, A.; Flubacher, D.; Stojanovic, A.; Bukhtiyarova, M.; Williams, K.; Lee, K.-J.; Ochman, A. R.; Saportito, M. S.; Moore, W. R.; Flynn, G. A.; Dorsey, B. D.; Springman, E. B.; Fujimoto, T.; Kelly, M. J. J. Med. Chem. 2011, 54, 179-200; (m) Subramanyam, C.; Duplentier, A. J.; Dombrowski, M. A.; Chang, S.-P.; Gabel, C. A.; Whitney-Pickett, C.; Perregaux, D. G.; Labasi, J. M.; Yoon, K.; Shepard, R. M.; Fisher, M. Bioorg. Med. Chem. Lett. 2011, 21, 5475-5479; (n) Blum, C. A.; Caldwell, T.; Zheng, X.; Bakthavatchalam, R.; Capitosti, S.; Brielmann, H.; De Lombaert, S.; Kershaw, M. T.; Matson, D.; Krause, J. E.; Cortright, D.; Crandall, M.; Martin, W. J.; Murphy, B. A.; Boyce, S.; Jones, A. B.; Mason, G.; Rycroft, W.; Perrett, H.; Conley, R.; Burnaby-Davies, N.; Chenard, B. L.; Hodgetts, K. J. J. Med. Chem. 2010, 53, 3330-3348; (o) Nicolaou, K. C.; Peng, X.-S.; Sun, Y.-P.; Polet, D.; Zou, B.; Lim, C. S.; Chen, D. Y.-K. J. Am. Chem. Soc. 2009, 131, 10587-10597; (p) Hille, U. E.; Hu, Q.; Vock, C.; Negri, M.; Bartels, M.; Mueller-Vieira, U.; Lauterbach, T.; Hartmann, R. W. Eur. J. Med. Chem. 2009, 44, 2765-2775; (q) Jenkins, P. R.; Wilson, J.; Emmerson, D.; Garcia, M. D.; Smith, M. R.; Gray, S. J.; Britton, R. G.; Mahale, S.; Chaudhuri, B. Bioorg. Med. Chem. 2008, 16, 7728-7739; (r) Guillon, J.; Forfar, I.; Desplat, V.; Belisle-Fabre, S.; Thiolat, D.; Massip, S.; Carrie, H.; Mossalayi, D.; Jarry, C. J. Enz. Inhib. Med. Chem. 2007, 22, 541-549; (s) Riedl, Z.; Monsieurs, K.; Krajsovszky, G.; Dunkel, P.; Maes, B. U. W.; Tapolcsányi, P.; Egyed, O.; Boros, S.; Mátyus, P.; Pieters, L.; Lemière, G. L. F.; Hajós, G. Tetrahedron 2006, 62, 121-129; (t) Yan, H.; Kerns, J.; Jin, Q.; Zhu, C.; Barnette, M.; Callhan, J.; Hay, D.; Jolivette, L.; Luttmann, M.; Sarau, H.; Ward, K.; Widdowson, K. Synth. Commun. 2005, 35, 3105-3112; (u) Keen, S. P.; Cowden, C. J.; Bishop, B. C.; Brands, K. M. J.; Davies, A. J.; Dolling, U. H.; Lieberman, D. R.; Stewart, G. W. J. Org. Chem. 2005, 70, 1771-1779; (v) Baron, B. M.; Cregge, R. J.; Farr, R. A.; Friederich, D.; Gross, R. S.; Harrison, B. L.; Janowick, D. A.; Matthews, D.; McCloskey, T. C.; Meikrantz, S.; Nyce, P. L.; Vaz, R.; Metz, W. A. J. Med. Chem. 2005, 48, 995-1018; (w) Ismail, M. A.; Brun, R.; Wenzler, T.; Tanious, F. A.; Wilson, W. D.; Boykin, D. W. J. Med. Chem. 2004, 47, 3658-3664; (x) Hosoya, T.; Aoyama, H.; Ikemoto, T.; Kihara, Y.; Hiramatsu, T.; Endo, M.; Suzuki, M. Bioorg. Med. Chem. 2003, 11, 663673; (y) Richardson, M. L.; Stevens, M. F. G. J. Chem. Res. (S) 2002, 482-484; (z) Ugarkar, B. G.; Castellino, A. J.; DaRe, J. M.; Kopcho, J. J.; Wiesner, J. B.; Schanzer, J. M.; Erion, M. D. J. Med. Chem. 2000, 43, 2894-2905; (aa) Patel, M.; Rodgers, J. D.; McHugh R. J. Jr.; Johnson, B. L.; Cordova, B. C.; Klabe, R. M.; Bacheler, L. T.; Erickson-Vitanen, S.; Ko, S. S. Bioorg. Med. Chem. Lett. 1999, 9, 3217-3220.

[4] For selected references on the synthesis on a large scale of pharmacologically active compounds via Suzuki-Miyaura reactions, see: (a) Hicks, F.; Hou, Y.; Langston, M.; McCarron, A.; O’Brien, E.; Ito, T.; Ma, C.; Matthews, C.; O’Bryan, C.; Provencal, D.; Zhao, Y.; Huang, J.; Yang, Q.; Heyang, L.; Johnson, M.; Sitang, Y.; Yuqiang, L. Org. Process Res. Dev. 2013, 17, 829-837; (b) Boos, C.; Bowles, 
D. M.; Cai, C.; Casimiro-Garcia, A.; Chen, X.; Hulford, C. A.; Jennings, S. M.; Kiser, E. J.; Piotrowski, D. W.; Sammons, M.; Wade, R. A. Tetrahedron Lett. 2011, 52, 7025-7029; (c) Elitzin, V. I.; Harvey, K. A.; Kim, H.; Salmons, M.; Sharp, M. J.; Tabet, E. A.; Toczko, M. A. Org. Process Res. Dev. 2010, 14, 912-917; (d) Cann, R. O.; Waltermire, R. E.; Chung, J.; Oberholzer, M.; Kasparec, J.; Ye, Y. K.; Wethman, R. Org. Process Res. Dev. 2010, 14, 1147-1152; (e) Venugopal, S.; Ramanatham, J.; Devanna, N.; Kumar, A. S.; Gosh, S.; Soundararajan, R.; Kale, B.; Mehta, G. N. Asian J. Chem. 2010, 22, 2767-2773; (f) Kumar, A. S.; Ghosh, S.; Mehta, G. N.; Soundararajan, R.; Sarma, P. S. R.; Bhima, K. Synth. Commun. 2009, 39, 4149-4157; (g) Kumar, A. S.; Ghosh, S.; Soundararajan, R.; Mehta, G. N. ARKIVOC 2009, 247-254; (h) Hobson, L. A.; Nugent, W. A.; Anderson, S. R.; Deshmukh, S. S.; Haley III, J. J.; Liu, P.; Magnus, N. A. Sheeran, P.; Sherbine, J. P.; Stone, B. R. P.; Zhu, J. Org. Process Res. Dev. 2007, 11, 085-995; (i) Conlon, D. A.; Drahus-Paone, A.; Ho, G.-J.; Pipik, B.; Helmy, R.; McNamara, J. M.; Shi, Y.-J.; Williams, J. M.; Macdonald D.; Deschênes, D.; Gallant, M.; Mastracchio, A.; Roy, B. Scheigetz, J. Org, Process Res. Dev. 2006, 10, 36-45; (j) Kerdesky, F. A. J.; Leanna, M. R.; Zhang, J.; Wenke, L.; Lallaman, J. E.; Ji, J.; Morton, H. E. Org. Process Res. Dev. 2006, 10, 512-517; (k) Chung, J Y. L.; Cvetovich, R. J.; McLaughlin, M.; Amato, J.; Tsay, F.-R.; Jensen, M.; Weissman, S.; Zewge, D. J. Org. Chem. 2006, 71, 8602-8609; (1) Jacks, T. E.; Belmont, D. T.; Briggs, C. A.; Horne, N. M.; Kanter, G. D.; Karrick, G. L.; Krikke, J. J.; McCabe, R. J.; Mustakis, J. G.; Nanninga, T. N.; Risedorph, G. S.; Seamans, R. E.; Skeean, R.; Winkle, D. D.; Zennie, T. M. Org. Process Res. Dev. 2004, 8, 201-212; (m) Chen, C.-y.; Dagneau, P.; Grabowski, E. J. J.; Oballa, R.; O’Shea, P.; Prasit, P.; Robichaud, J.; Tillyer, R.; Wang, X. J. Org. Chem. 2003, 68, 2633-2638; (n) Lipton, M. F.; Mauragis, M. A.; Maloney, M. T.; Veley, M. F.; VanderBor, D. W.; Newby, J. J.; Appell, R. B.; Daugs, E. D. Org. Process Res. Dev. 2003, 7, 385-392; (o) Urawa, Y.; Naka, H.; Miyazawa, M.; Souda, S.; Ogura, K. J. Organomet. Chem. 2002, 653, 269-278.

[5] (a) Verdelet, T.; Mercey, G.; Correa, N.; Jean, L.; Renard, P.-Y. Tetrahedron 2011, 67, 8757-8762; (b) Gholap, A. R.; Toti, K. S.; Shirazi, F.; Deshpande, M. V.; Srinivasan, K. V. Tetrahedron 2008, 64, 10214-10223; (c) Kim, H. H.; Lee, C. H.; Song, Y. S.; Park, N. K.; Kim, B. T.; Heo, J.-N. Bull. Korean Chem. Soc. 2006, 27, 191-192; (d) Eicken, K.; Rack, M.; Wetterich, F.; Ammermann, E.; Lorenz, G.; Strathmann, S. (BASF AG, Ludwigshafen), German Patent DE 1999; Chem. Abstr. 1999, 130, 182464.

[6] For selected references on the synthesis of conjugated polymers via Suzuki-Miyaura cross-coupling reactions, see: (a) Wu, W.; Ye, C.; Qin, J.; Li, Z. ChemPlusChem 2013, 78, 1523-1529; (b) Ding, D.; Liu, J.; Feng, G.; Li, K.; Hu, Y.; Liu, B. Small 2013, 9, 3093-3102; (c) Ye, H.; Chen, D.; Liu, M.; Zhou, X.; Su, S.-J.; Cao, Y. Polymer 2013, 54, 162-173; (d) Chen, Y.; Guo, Y.; Sun, X.; Gao, D.; Liu, Y.; Yu, G. J. Polymer Sci. Part A: Polym. Chem. 2013, 51, 2208-2215; (e) Hendriks, K.
H.; Heintges, G. H. L.; Gevaerts, V. S.; Wienk, M. M.; Janssen R. A. J. Angew. Chem. Int. Ed. 2013, 52, 8341-8344; (f) Zhang, W.; Lu, P.; Wang, Z.; Ma, Y. J. Polymer Sci. Part A: Polym. Chem. 2013, 51, 1950-1955; (g) Shi, J.; Wu, Y.; Sun, S.; Tong, B.; Zhi, J.; Dong, Y. J. Polymer Sci. Part A: Polym. Chem. 2013, 51, 229-240; (h) Wen, Q.; Liu, L.; Yang, Q.; Lv, F.; Wang, S. Adv. Funct. Mater. 2013, 23, 764-769; (i) Zhao, B.; Li, X.; Tang, P.; Cao, Z.; Huang, H.; Shen, P.; Tan, S. Thin Solid Films 2013, 539, 267-273; (j) Deniz, T. K.; Nurioglu, A. G.; Unlu, N. A.; Sendur, M.; Toppare, L.; Cirpan, A. Polymer 2013, 54, 2243-2249; (k) Song, H. J.; Lee, T. H.; Han, M. H.; Lee, J. Y.; Moon, D. K. Polymer 2013, 54, 1072-1079; (1) Liu, Z.; Liu, J.; Yu, G.; Lei, G.; Qi, X. J. Inorg. Organomet. Polym. 2012, 22, 1350-1357; (m) Yamaguchi, I.; Makishi, S. J. Appl. Polym. Sci. 2013, 129, 397-403; (n) Agneeswari, R.; Tamilavan, V.; Song, M.; Kang, J.-W.; Jin, S.-H.; Hyun, M. H. J. Polym. Sci. Part A: Polym. Chem. 2013, 51, 2131-2141; (o) Lee, J. K.; Lee, S.; Yun, J. Bull. Korean Chem. Soc. 2013, 34, 2148-2154; (p) Liu, C.; Cai, W.; Guan, X.; Duan, C.; Xue, Q.; Ying, L.; Huang, F.; Cao, Y. Polym. Chem. 2013, 4, 39493958; (q) Fang, H.-P.; Lin, J.-W.; Chiang, I.-H.; Chu, C.-W.; Wei, K.-H.; Lin, H.-C. J. Polym. Sci. Part A: Polym. Chem. 2012, 50, 5011-5022; (r) Zhang, X.-J.; Bian, N.; Mao, L.-J.; Chen, Q.; Fang, L.; Qi, A.-D.;.Han, B.-H. Macromol. Chem. Phys. 2012, 213, 1575-1581; (s) Jo, J. W.; Kim, S. S.; Jo, W. H. Org. Electr. 2012, 13, 1322-1328; (t) Zou, Y.; Guan, Z.; Zhang, Z.; Huang, Y.; Wang, N.; Lu, Z.; Jiang, Q.; Yu, J.; Liu, Y.; Pu, X. J. Mater. Sci. 2012, 47, 5535-5545; (u) Kim, J.-H.; Kim, H. U.; Mi, D.; Jin, S.-H.; Shin, W. S.; Yoon, S. C.; Kang, I.-N.; Hwang, D.-H. Macromolecules 2012, 45, 2367-2376; (v) Lee, Y.; Jo, W. H. J. Phys. Chem. C 2012, 116, 83798386; (w) Poduval, M. K. K.; Hahn, S. J.; Kim, T.-H. Bull. Korean Chem. Soc. 2012, 33, 2040-2042; (x) Seyler, H.; Jones, D. J.; Holmes, A. B.; Wong, W. W. H. Chem. Commun. 2012, 48, 1598-1600; (y) Welterlich, I.; Charov, O.; Tieke, B. Macromolecules 2012, 45, 4511-4512; (z) Hohl, B.; Bertschi, L.; Zhang, X.; Schlüter, A. D.; Sakamoto, J. Macromolecules 2012, 45, 5418-5426; (aa) Liu, S.-Y.; Li, H.-Y.; Shi, M.-M.; Jiang, H.; Hu, X.-L.; Li, W.-Q.; Fu, L.; Chen, H.-Z. Macromolecules 2012, 45, 9004-9009; (ab) Wang, K.-L.; Leung, M.-K.; Hsieh, L.-G.; Chang, C.-C.; Lee, W.- R.; Wu, C.-L.; Jiang, J.-C.; Tseng, C.-Y.; Wang, H.-T. Org. Electr. 2011, 12, 1048-1062; (ac) Tamilavan, V.; Song, M.; Jin, S.H.; Hyun, M. H. Polymer 2011, 52, 2384-2390; (ad) Cheng, Y.-J.; Ho, Y.-J.; Chen, C.-H.; Kao, W.-S.; Wu, C.-E.; Hsu, S.L.; Hsu, C.-S. Macromolecules 2012, 45, 2690-2698; (ae) Song, J.; Zhang, C.; Li, C.; Li, W.; Qin, R.; Li, B.; Liu, Z.; Bo, Z. J. Polymer Sci. Part A: Polym. Chem. 2010, 48, 2571-2578; (af) Choi, J.; Lee, B.; Kim, J. H. Synth. Metals 2009, 159, 1922-1927; (ag) Murata, T.; Morita, Y.; Nakasuji, K. Tetrahedron 2005, 61, 6056-6063.

[7] Fu, G.; Netherton, M. Angew. Chem Int. Ed. 2002, 41, 39103912.

[8] Molander, G. A.; Yun, C.-S.; Ribagoroa, M.; Biolatto, B. J. Org. Chem. 2003, 68, 5534-5539. 
[9] Wong, P. Y.; Chow, W. K.; Chung, K. H.; So, C. M.; Lau, C. P.; Kwong, F. Y. Chem. Commun. 2011, 47, 8328-8330.

[10]Molander, G. A.; Shin, I. Org. Lett. 2013, 15, 2534-2537.

[11]Albaneze-Walker, J.; Raju, R.; Vance, J. A.; Goodman, A. J.; Reeder, M. R.; Liao, J.; Maust, M. T.; Irish, P. A.; Espino, P.; Andrews, D. R. Org. Lett. 2009, 11, 1463-1466.

[12]Maslak, V.; Tokic-Vujosevic, Z.; Saicic, R. N. Tetrahedron Lett. 2009, 50, 1858-1860.

[13]Molander, G. A.; Beaumard, F.; Niethamer, T. K. J. Org. Chem. 2011, 76, 8126-8130.

[14]Li, W.; Gao, J. J.; Zhang, Y.; Tang, W.; Lee, H.; Fandrick, K. R.; Lu, B.; Senanayake, C. H. Adv. Synth. Catal. 2011, 353, 1671-1675.

[15]Lindh, J.; Sävmarker, J.; Nilsson, P.; Sjöberg, P. J. R.; Larhed, M. Chem. Eur. J. 2009, 15, 4630-4636.

[16]Kang, F.-A.; Sui, Z.; Murray, W. V. J. Am. Chem. Soc. 2008, 130, 11300-11302.

[17](a) Miyaura, N.; Suzuki, A. J. Chem. Soc., Chem. Commun. 1979, 866-867; (b) Miyaura, N.; Yamada, K.; Suzuki, A. Tetrahedron Lett. 1979, 3437-3440.

[18]Rossi, R.; Carpita, A.; Quirici, M. G. Tetrahedron 1981, 37, 2617-2623.

[19]For reviews, see: (a) Woltermann, C. J. Pharm. Chem. 2002, 1, 11-14; (b) Singleton, J. Tetrahedron 2003, 59, 1837-1857; (c) Baillie, C.; Xu, L.; Xiao, J. In Catalysts for Fine Chemical Syntheses; Roberts, S. M.; Xiao, J.; Whittal. J.; Pickett, T. E. Eds; Wiley, 2004, 3, 77-81; (d) Ozawa, F.; Yoshifuji, M. Dalton Trans. 2006, 4987-4995; (e) Weng, Z.; Teo, S.; Hor, T. S. A. Acc, Chem. Res. 2007, 40, 676-684; (f) Fu, G. C. Acc. Chem. Res. 2008, 41, 1555-1564.

[20]For selected papers published in the period 1998-2009, see, see: (a) Littke, A. F.; Fu, G. C. Angew. Chem. Int. Ed. 1998, 37, 3387-3388; (b) Wolfe, J.P.; Buchwald, S. L. Angew. Chem. Int. Ed. 1999, 38, 2413-2416; (c) Bei, X.; Turner, H. W.; Weinberg, W. H.; Guram, A. S.; Peterson, J. L. J. Org.. Chem. 1999, 64, 6797-6803; (d) Zapf, A.; Ehrentraut, A.; Beller, M. Angew. Chem. Int. Ed. 2000, 39, 4153-4155; (e) Zapf, A.; Beller, M. Chem. Eur. J. 2000, 6, 6797-6803; (f) Kataoka, N.; Shelby, Q.; Stambuli, J. P.; Hartwig, J. F. J. Org. Chem. 2002, 67, 5553-5566; (g) Bedford, R. B.; Hazelwood (née Welch), S. L.; Limmert, M. E.; Albisson, D. A.; Draper, S. M.; Scully, P. N.; Coles, S. J.; Hursthouse, M. B. Chem. Eur. J. 2003, 9, 3216-3227; (h) Lee, H. M.; Zeng, J. Y.; Hu, C.-H.; Lee, M.-T. Inorg. Chem. 2004, 43, 6822-6829; (i) Uozumi, Y. Top. Curr. Chem. 2004, 242, 77-112; (j) Zhang, W.; Shi, M. Tetrahedron Lett. 2004, 45, 8921-8924; (k) Liu, D.; Gao, W.; Dai, Q.; Zhang, X. Org. Lett. 2005, 7, 49074910; (1) Shaughnessy, K. H. Eur. J. Org. Chem. 2006, 18271835; (m) Zhang, Z.; Mao, J.; Wang, R.; Wu, F.; Chen, H.; Wan, B. J. Mol. Catal. A: Chem. 2006, 243, 239-243; (n) Ciclosi, M.; Lloret, J.; Estevan, F.; Lahuerta, P.; Sanaú, M.; Pérez-Prieto, J. Angew. Chem. Int. Ed. 2006, 45, 6741-6744; (o) Cho, S.-D.; Kim, H.-K.; Yim, H.-s.; Kim, M.-R.; Lee, J.K.; Kim, J.-J.; Yoon, Y.-J. Tetrahedron 2007, 63, 1345-1352; (p) Garcia-Suárez, E. J.; Ruiz, A.; Castillón, S.; Oberhauser, W.; Bianchini, C.; Claver, C. Dalton Trans. 2007, 2859-2861; (q) Akozlov, V.; Aleksanyan, D. V.; Nelyubina, Yu. V.; Lyssenko, K. A.; Gutsul, E. F.; Puntus, L. N.; Vasil'ev, A. A.; Petrovskii, P. V.; Odinets, I. L. Organometallics 2008, 27, 4062-4070; (r) Yu, S.-B.; Hu, X.-P.; Deng, J.; Huang, J.-D.; Wang, D.- Y.; Duan, Z.-C.; Zheng, Z. Tetrahedron Lett. 2008, 49, 1253-1256; (s) Wong, F. Y.; Chan, A.-S. C. Synlett 2008, 1440-1448; (t) Sawai, K.; Tatumi, R.; Nakahodo, T.; Fujihara, H. Angew. Chem. Int. Ed. 2008, 47, 6917-6919; (u) Kang, P. S.; Ko, S. B.; Ko, J. M.; Park, J. H. Bull. Korean Chem. Soc. 2009, 30, 2697-2700; (v) Uozumi, Y.; Matsuura, Y.; Arakawa, T.; Yamada, Y. M. A. Angew. Chem. Int. Ed. 2009, 48, 27082710.

[21]For selected references on the use of Pd catalyst precursors containing NHC ligands in Suzuki-Miyaura reactions, see: (a) Herrmann, W. A.; Reisinger, C.-P.; Spiegler, M. J. Organomet. Chem. 1998, 557, 93-96; (b) Grasa, G. A.; Viciu, M. S.; Huang, J.; Zhang, C.; Trudell, M. L.; Nolan, S. P. Organometallics 2002, 21, 2866-2873; (c) Herrmann, W. A. Angew. Chem. Int. Ed. 2002, 41, 1290-1309; (d) Altenhoff, G.; Goddard, R.; Lehmann C. W.; Glorius, F. J. Am. Chem. Soc. 2004, 126, 15195-15201; (e) Clavier, H.; Nolan, S. P. Annu. Rep. Prog. Chem. Sect. B: Org. Chem. 2007, 103, 193222; (f) Yuan, D.; Huynh, H. V. Organometallics 2010, 29, 6020-6027; (g) Huang, J.; Hong, J.-T.; Hong, S. H. Eur. J. Org. Chem. 2012, 6630-6635; (h) Wang, Z.-Y.; Chen, G.-Q.; Shao, L.-X. J. Org. Chem. 2012, 77, 6608-6614; (i) Kuriyama, M.; Matsuo, S.; Shinozawa, M.; Onomura, O. Org. Lett. 2013, 15, 2716-2719; (j) Szulmanowicz, M. S.; Gniewek, A.; Gil, W.; Trzeciak, A. M. ChemCatChem 2013, 5, 1152-1160; (k) Gu, P.; Xu, Q.; Shi, M. Synlett 2013, 24, 1255-1259; (l) Meiries, S.; Le Duc, G.; Chartoire, A.; Collado, A.; Speck, K.; Arachige, K. S. A.; Slawin, A. M. Z.; Nolan, S. P. Chem. Eur. J. 2013, 19, 17358-17368.

[22]For selected references on palladacycle-catalyzed SuzukiMiyaura reactions, see: (a) Weissman, H.; Milstein, D. Chem. Commun. 1999, 1901-1902; (b) Alonso, D. A.; Nájera, C.; Pacheco, M. C. Org. Lett. 2000, 2, 1823-1826; (c) Iyer, S.; Jayanshi, A. Synlett 2003, 1125-1128; (d) Dupon, J.; Pfeffer, M. Palladacycles; Wiley-VCH: Wenheim, Germany, 2008; (e) Moreno, I.; SanMartin, R. ; Herrero, M. T.; Dominguez, E. Curr. Top. Catal. 2009, 8, 91-102; (f) Rao, G. K.; Kumar, A.; Ahmed, J.; Singh, A. K. Chem. Commun. 2010, 46, 59545956; (g) Alonso, D.; Nájera, C. Chem. Soc. Rev. 2010, 39, 2891-1902; (h) Cívicos, J. F.; Alonso, D. A.; Nájera, C. Adv. Synth. Catal. 2011, 353, 1683-1687; (i) Susanto, W.; Chu, C.Y.; Ang, W. J.; Chou, T.-C.; Lo, L.-C.; Lam, Y. J. Org. Chem. 2012, 77, 2729-2742; (j) Cívicos, J. F.; Alonso, D. A.; Nájera, C. Eur. J. Org. Chem. 2012, 3670-3676; (k) Zhang, M.; Cui, X.; Chen, X.; Wang, L.; Li, J.; Wu, Y.; Hou, L.; Wu, Y. Tetrahedron 2012, 68, 900-905; (1) Hajipour, A. R.; Karami, K.; Tavakoli, G. Appl. Organomet. Chem. 2012, 26, 401-405; (m) Yu, A.; Li, X.; Peng, D.; Wu, Y.; Chang, J. Appl. Organomet. Chem. 2012, 26, 301-304; (n) Hajipour, A. R.; Rafiee, F. Appl. Organomet. Chem. 2013, 27, 412-418; (o) Molander, G. A.; Shin, I. Org. Lett. 2013, 15, 2534-2537; (p) Zhang, H.-H.; Xing, C.-H.; Tsemo, G. B.; Hu, Q.-S. ACS 
Macro Letters 2013, 2, 10-13; (q) Rao, G. K.; Kumar, A.; Kumar, S.; Dupare, U. B.; Singh, A. K. Organometallics 2013, 32, 2452-2458; (r) Ros, A.; Estepa, B.; Ramirez-Lopez, P.; Alvarez, E.; Fernandez, R.; Lassaletta, J. M. J. Am. Chem. Soc. 2013, 135, 15730-15733.

[23]For selected references on Pd-catalyzed Suzuki-Miyaura reactions carried out in the presence of ligands different from phosphanes and NHCs, see: (a) Zhou, J.; Guo, X.; Tu, C.; Li, X.; Sun, H. J. Organomet. Chem. 2009, 694, 697-702; (b) Gülcemal, S.; Kani, I.; Yilmaz, F.; Çetinkaya, B. Tetrahedron 2010, 66, 5602-5606; (c) Darweesh, A. F.; Shaaban, M. R.; Farag, A. M.; Metz, P.; Dawood, K. M. Synthesis 2010, 3163 3173; (d) Fernandes, R. R.; Lasri, J.; da Silva, C. G.; Palavra, A. M. F.; da Silva, J. A. L. ; da Silva, J. J. R. F, ; Pombeira, A. J. L. Adv. Synth. Catal. 2011, 353, 1153-1160; (e) Mao, F.; Yang, L.; Xiao, Y.; Yuan, J.; Liu, X.; Song, M. J. Organomet. Chem. 2012, 708-709, 18-24; (f) Bank, B.; Tairai, A.; Shahnaz, N.; Das, P. Tetrahedron Lett. 2012, 53, 5627-5630; (g) Li, Y.; Huang, M.; Cai, R.; Wu, Y. Tetrahedron 2012, 68, 8502-8508; (h) Liu, F.-S.; Huang, Y.-T.; Lu, C.; Shen, D.-S.; Cheng, T. Appl. Organomet. Chem. 2012, 26, 425-429; (i) Trivedi, M.; Singh, G.; Nagarajan, R.; Rath, N. P. Inorg. Chim. Acta 2013, 394, 107-116; (j) Oaluru, D. K.; Dey, S.; Wadawale, A.; Jain, V. K. J. Organomet. Chem. 2013, 728, 52-56; (k) Kumar, A.; Rao, G. K.; Kumar, S.; Singh, A. K. Dalton Trans. 2013, 42, 5200-5223; (l) Potkin, V. I.; Bumagin, N. A.; Petkevich, S. K.; Lyakhov, A. S.; Rudakov, D. A.; Liventsov, M. V.; Golantsov, N. E. Synthesis 2013, 44, 151-157; (m) Gao, C.; Zhou, H.; Wei, S.; Zhao, Y.; You, J.; Gao, G. Chem. Commun. 2013, 49, 1127-1129; (n) Silerska, E.; Trzeciak, A. M.; Pernak, J.; Skazypczak, A. Appl. Catal. A.: General 2013, 466, 216-223; (o) Sahin, N.; Sémeril, D.; Brenner, E.; Matt, D.; Özdemir, I.; Kaya, C.; Toupet, L. ChemCatChem 2013, 5, 1116-1125; (p) Amadio, E.; Scrivanti, A.; Bortoluzzi, M.; Bertoldini, M.; Baghetti, V.; Matteoli, U.; Chessi, G. Inorg. Chim. Acta 2013, 405, 188-195;(q) Alizadeh, A.; Khodaei, M. M.; Kordestani, D.; Beygzadeh, M. Tetrahedron Lett. 2013, 54, 291-294; (r) Crisóstomo-Lucas, C.; Toscano, R. A.; Morales-Morales, D. Tetrahedron Lett. 2013, 54, 3116-3119; (s) da Costa, D. P.; Nobre, S. M. Tetrahedron Lett. 2013, 54, 4582-4584.

[24]For selected references on Pd-catalyzed Suzuki-Miyaura reactions carried out under ligandless conditions, see: (a) Liu, L.; Zhang, Y.; Wang, Y. J. Org. Chem. 2005, 70, 6122-6125; (b) Maegawa, T.; Kitamura, Y.; Sako, S.; Uzdu, T.; Sakurai, A.; Tanaka, A.; Kobayashi, Y.; Endo, K.; Bora, U.; Kutita, T.; Kozaki, A.; Minguxchi, Y.; Sajika, H. Chem. Eur. J. 2007, 13, 5937-5943; (c) Han, W.; Liu, C.; Jin, Z.-L. Org. Lett. 2007, 9, 4005-4007; (d) Liu, C.; Yang, W. Chem. Commun. 2009, 6267-6269; (e) Nencka, R.; Sinnaeve, D.; Karalic, I.; Martins, J. C.; Van Calenbergh, S. Org. Biomol. Chem. 2010, 8, 52345246; (f) Shi, Y.; Li, X.; Liu, J.; Jiang, W.; Sun, L. Appl. Organomet. Chem. 2011, 25, 514-520; (g) Qiu, J.; Wang, L.; Liu, M.; Shen, Q.; Tang, J. Tetrahedron Lett. 2011, 52, 64896491; (h) Rao, X.; Liu, C.; Qiu, J.; Jin, Z. Org. Biomol. Chem. 2012, 10, 7875-7883; (i) Chiummiento, L.; Funicello, M.;
Lupattelli, P.; Tramutola, F. Org. Lett. 2012, 14, 3928-3931; (j) Liu, N.; Liu, C.; Rao, X.; Jon, Z. Adv. Chem. Res. 2012, 16, 125-146; (k) Liu, C.; Zhang, Y.; Liu, N.; Qiu, J. Green Chem. 2012, 14, 2999-3003; (1) Enderlin, G.; Sartori, G.; Hervé, G.; Len, C. Tetrahedron Lett. 2013, 54, 3374-3377; (m) Ahmed, S.; Sharif, M.; Shoaib, K.; Reimann, S.; Iqbal, J.; Patonay, T.; Spannenberg, A.; Langer, P. Tetrahedron Lett. 2013, 54, 1669-1672; (n) Liu, C.; Rao, X.; Zhang, Y.; Li, X.; Qiu, J.; Jin, Z. Eur. J. Org. Chem. 2013, 4345-4350; (o) Liu, C.; Rao, X.; Song, X.; Qiu, J.; Jin, Z. RSC Adv. 2013, 3, 526-531; (p) Decottignies, A.; Fihri, A.; Azemar, G.; Djedaini-Pilard, F.; Len, C. Catal. Commun. 2013, 32, 101-107; (q) Jadhav, S.; Kumbhar, A.; Kamble, S.; More, P.; Salunkhe, R. Compt. Rend. Chim. 2013, 16, 957-961; (r) Siamaki, A. R.; Lin, Y.; Woodberry, K.; Connell, J. W.; Gupton, B. F. J. Mater. Chem. A: Materials for Energy and Sustainability 2013, 1, 12909 12918; (s) Xiang, L.; Xiaohua, Z.; Ming, L. Appl. Organomet. Chem. 2013, 27, 615-618.

[25]For selected references on Suzuki-Miyaura reactions catalyzed by supported Pd derivatives, see: (a) Uozumi, Y. Top. Curr. Chem. 2004, 242, 77-112; (b) Colacot, T. J.m Top. Catal. 2008, 48, 91-98; (c) Jana, S.; Haldar, S.; Koner, S. Tetrahedron Lett. 2009, 50, 4820-4823; (d) Borkowski, T.; Zawartka, W.; Pospiech, P.; Mizerska, U.; Trzeciak, A. M.; Cypryk, M.; Tylus, W. J. Catal. 2011, 282, 270-277; (e) Lasri, J.; Mac Leod, T. C. O.; Pombeiro, A. J. L. Appl. Catal. A: General 2011, 397, 94-102; (f) Islam, R. U.; Witcomb, M. J.; van der Lingen, E.; Scurrell, M. S.; Van Otterio, W.; Mallick, K. J. Organomet. Chem. 2011, 696, 2206-2210; (g) Bester, K.; Bukowska, A.; Bukowski, W. Appl. Catal. S: General 2012, 443-444, 181-190; (h) Sharma, R. K.; Pandey, A.; Gulati, S. Appl. Catal. A:General 2012, 431-432, 33-41; (i) Estrada, G. O. D.; Blanco, A. L. P.; da Silva, J. F. M.; Alonso, C. G.; Fernades-Machado, N. R. C.; Cardozo-Filho, L.; de Souza R. O. M. A.; e Miranda, L. S. M. Tetrahedron Lett. 2012, 53, 1089-1093; (j) Sarmah, C.; Sahu, D.; Das, P. Catal. Today 2012, 198, 197-203: (k) Mora, M.; Jimenez-Sanchidrian, C.; Ruiz, J. R. Curr. Org. Chem. 2012, 16, 1128-1150; (l) Kumbhar, A.; Kamble, S.; Mane, A.; Jha, R.; Salunkhe, R. J. Organomet. Chem. 2013, 738, 29-34; (m) Bakherad, M.; Keivanloo, A.; Bahramian, B.; Jajarmi, S. J. Organomet. Chem. 2013, 724, 206-212; (n) Mayer, M. G.; Nador, F.; Volpe, M. A.; Radivoy, G. Synlett 2013, 24, 338-342; (o) Navidi, M.; Rezaei, N.; Movassagh, B. J. Organomet. Chem. 2013, 743, 63-69; (p) Li, W.; Zhang, B.; Li, X.; Zhang, H.; Zhang, Q. Appl. Catal. A: General 2013, 459, 65-72; (q) Hassine, A.; Sebti, S.; Solhy, A.; Zahouily, M.; Len, C.; Hedhili, M. N.; Fihri, A. Appl. Catal. A: General 2013, 450, 13-18; (r) Kumbhar, A.; Jadhav, S.; Kamble, S.; Rashinkar, G.; Salunkhe, R. Tetrahedron Lett. 2013, 54, 1331-1337; (s) Corral, J.; Mora, M.; Jiménez-Sanchidrián, C.; Ruiz, J. R. Appl. Organomet. Chem. 2013, 27, 542-545; (t) Dickschat, A. T.; Surmiak, S.; Studer, A. Synlett 2013, 24, 1523-1528.

[26](a) Pérez-Lorenzo, M. J. Phys. Chem. Lett. 2012, 3, 167-174; (b) Narayanan, R. Molecules 2010, 15, 2124-2138. 
[27]For selected references, see: (a) Desforges, A.; Backov, R.; Deleuze, H.; Mondain-Monval, O. Adv. Funct. Mat. 2005, 15, 1689-1095; (b) Lyubimov, S. E.; Vasil'ev, A. A.; Korlyukov, A. A.; Ilyin, M. M.; Pisarev, S. A.; Matveev, V. V.; Chalykh, A. E.; Zlotin, S. G.; Davankov, V. A. React. Funct. Polym. 2009, 69, 755-758; (c) de Luna Martins, D.; Alvarez, H. M.; Aguiar, L. C. S. Tetrahedron Lett. 2010, 51, 6814-6817; (d) Liu, S.; Zhou, Q.; Jiang, H. Chin. J. Chem. 2010, 28, 589-593; (e) Jamwal, N.; Sodhi, R. K.; Gupta, P.; Paul, S. Int. J. Biol. Macromol. 2011, 49, 930-935; (f) Metin, Ö.; Durap, F.; Aydemir, Özkar, S. J. Mol. Catal. A: Chemical 2011, 337, 3944; (g) Okada, S.; Urata, T.; Kamegawa, T.; Mori, K.; Yamashita, H. Chem. Lett. 2011, 40, 609-611; (h) Islam, R. U.; Witcomb, M. J.; Scurrell, M. S.; van der Lingen, E.; Van Otterlo, W.; Mallick, K. Catal. Sci. Technol. 2011, 1, 308315; (i) Dutta, P.; Sarkar, A. Adv. Synth. Catal. 2011, 353, 2814-2822; (j) Khalafi-Nezhad, A.; Panahi, F. J. Organomet. Chem. 2012, 717, 141-146; (k) Magdesieva, T. V.; Nikitin, O. M.; Levitsky, A.; Zinovyeva, V. A.; Bezverkhyy, I.; Zolotukhina, E. V.; Vorotyntsev, M. A. J. Mol. Catal. A: Chemical 2012, 353-354, 50-57; (1) Wan, L.; Cai, C. Catal. Commun. 2012, 24, 105-108; (m) Ohtaka, A.; Sakaguchi, E.; Yamaguchi, T.; Hawasaka, G.; Uozumi, Y.; Shimomura, O.; Nomura, R. ChemCatChem 2013, 5, 2167-2169; (n) Karami, K.; Ghasemi, M.; Naeini, N. H. Catal. Commun. 2013, 38, 1015; (o) Bester, K.; Bukowska, A.; Bukowski, W. J. Mol. Catal. A: Chemical 2013, 378, 124-134; (p) Coccia, F.; Tonucci, L.; d'Alessandro, N.; D'Ambrosio, P.; Bressan, M. Inorg. Chim. Acta 2013, 399, 12-18; (q) Veerakumar, P.; Velayudham, M.; Lu, K.-L. Appl. Catal. A: General 2013, 455, 247-260; (q) Samarasimhareddy, M.; Prabhu, G.; Vishwanatha, T. M.; Sureshbabu, V. V. Synthesis 2013, 45, 1201-1206.

[28]For selected references, see: (a) Strimbu, L.; Liu, J.; Kaifer, A. E. Langmuir 2003, 19, 483-485; (b) Senra, J. D.; Malta, L. F. B.; da Costa, M. E. H. M.; Michel, R. C.; Aguiar, L. C. S.; Simas, A. B. C.; Antunes, O. A. C Adv. Synth. Catal. 2009, 351, 2411-2422; (c) Liang, L.; Diallo, A. K.; Salmon, L.; Ruiz, J.; Astruc, D. Eur. J. Inorg. Chem. 2012, 2950-2958.

[29]For selected references, see: (a) Kantam, M. L.; Roy, S.; Sreedhar, B.; Choudhary, B. M. Adv. Synth. Catal. 2005, 347, 2002-2008; (b) Zhou, S.; Johnson, M.; Veinot, J. G. C. Chem. Commun. 2010, 46, 2411-2413; (c) Monopoli, A.; Nacci, A.; Calò, V.; Ciminale, F.; Cotugno, P.; Mangone, A.; Giannossa, L. C.; Azzone, P.; Cioffi, N. Molecules 2010, 15, 4511-4525; (d) Sreedhar, B.; Yada, D.; Reddy, P. S. Adv. Synth. Catal. 2011, 353, 2823-2836; (e) Rosario-Amorin, D.; Gaboyard, M.; Clérac, R.; Vellutini, L.; Nlate, S.; Heuzé, K. Chem. Eur. J. 2012, 18, 3305-3315.

[30]For selected references, see: (a) Kim, S. W.; Kim, M.; Lee, W. Y.; Hyeon, T. J. J. Am. Chem. Soc. 2002, 124, 7642-7643; (b) Corma, A.; Garcia, N.; Leyva, A. J. Mol. Catal. A: Chem. 2005, 230, 97-105; (c) Pan, H.-B.; Yen, C. H.; Yoon, B.; Sato, M.; Wai, C. M. Synth. Commun. 2006, 36, 3473-3478; (d) Chen, X.; Hou, Y.; Wang, H.; Cao, Y.; He, J. J. Phys. Chem. C 2008, 112, 8172-8176; (e) Zhou, L.; Zhang, W. D.; Jiang, H.F. Science in China, Series B: Chemistry 2008, 51, 241-247; (f) Sullivan, J. A.; Flanagan, K. A.; Hain, H. Catal. Today 2009, 145, 108-113; (g) Chergui, S. M.; Ledebt, A.; Mammeri, F.; Herbst, F.; Carbonnier, B.; Romdhane, H. B.; Delamar, M.; Chehimi, M. M. Langmuir 2010, 26, 1611516121; (h) Cao, Y. Adv. Mat. Res. 2011, 284-286, 2404-2408; (i) Yang, F.; Li, Y.; Liu, T.; Xu, K.; Zhang, L.; Xu, C.; Gao, J. Chem. Engin. J. 2013, 226, 52-58.

[31]For selected references, see: (a) Liao, Y.; He, L.; Huang, J.; Zhang, J.; Zhuang, L.; Shen, H.; Su, C.-Y. Appl. Mat. Inter. 2010, 2, 2333-2338; (b) Xuan, S.; Jiang, W.; Gong, X. Dalton Trans. 2011, 40, 7827-7830; (c) Hu, J.; Wang, Y.; Han, M.; Zhou, Y.; Jiang, X.; Sun, P. Catal. Sci. Technol. 2012, 2, 2332-2340; (d) Senapati, K. K.; Roy, S.; Borgohain, C.; Phukan, P. J. Mol. Catal. A: Chem. 2012, 352, 128-134; (e) Jin, X.; Zhang, K.; Sun, J.; Wang, J.; Dong, Z.; Li, R. Catal. Commun. 2012, 26, 199-203; (f) Li, P.; Wang, L.; Wang, G.W. Adv. Synth. Catal. 2012, 354, 1307-1318; (g) Beygzadeh, M.; Alizadeh, A.; Khodari, M. M.; Kordestani, D. Catal. Commun. 2013, 32, 86-91; (h) Wang, J.; Xu, B.; Sun, H.; Song, G. Tetrahedron Lett. 2013, 54, 238-241; (i) Keller, M.; Colliére, V.; Reiser, O.; Caminade, A.-M.; Majoral, J.-P.; Ouali, A. Angew. Chem. Int. Ed. 2013, 52, 3626-3629; (j) Choi, K.-H.; Shokouhimehr, M.; Sung, Y.-E. Bull. Korean Chem. Soc. 2013, 34, 1477-1480.

[32]For selected references, see: (a) Li, Y.; El-Sayed, M. A. $J$. Phys. Chem. B 2001, 105, 8938-8943; (b) Pittelkow, M.; Moth-Poulsen, K.; Boas, U.; Christensen, J. B. Langmuir 2003, 19, 7682-7684; (c) Gopidas, K. R.; Whitesell, J. K.; Fox, M. A. Nano Lett. 2003, 3, 1757-1760; (d) Lu, F.; Ruiz, J.; Astruc, D. Tetrahedron Lett. 2004, 45, 9443-9445; (e) Xu, Y.; Zhang, Z.; Zheng, J.; Du, Q.; Li, Y. Appl. Organomet. Chem. 2013, 27, 13-18; (f) Gäbler, C.; Jeschke, J.; Nurgazina, G.; Dietrich, S.; Schaarschmidt, D.; Georgi, C.; Schlesinger, M.; Mehring, M.; Lang, H. Catal. Lett. 2013, 143, 317-323.

[33]For selected references, see: (a) Moreno-Mañas, M.; Pleixats, R.; Villaroya, S. Organometallics 2001, 20, 4524-4528; (b) Bernini, R.; Cacchi, S.; Fabrizi, G.; Forte, G.; Petrucci, F.; Prastaro, A.; Niembro, S.; Shafir, A.; Vallribera, A. Green Chem. 2010, 12, 150-158; (c) Wan, L.; Cai, C. Catal. Lett. 2011, 141, 839-843; (d) Wan, L.; Cai, C. Catal. Commun. 2012, 24, 105-108.

[34]For selected references, see: (a) Calò, V.; Nacci, A.; Monopoli, A.; Montingelli, F. J. Org. Chem. 2005, 70, 6040-6044: (b) Yang, X.; Fei, Z.; Zhoo. D.; Ang, W. H.; Li, Y.; Dyson, P. J. Inorg. Chem. 2008, 47, 3292-3297; (c) Safavi, A.; Maleki, N.; Iranpoor, H.; Firouzabadi, H.; Banazadeh, A. R.; Azadi, R.; Sedaghati, F. Chem. Commun. 2008, 6155-6157; (d) Prechtl, M. H. G.; Scholten, J. D.; Dupont, J. Molecules 2010, 15, 3441-3461; (e) Wang, J.; Song, G.; Peng, Y. Tetrahedron Lett. 2011, 52, 1477-1480; (f) Cotugno, P.; Monopoli, A.; Ciminale, F.; Cioffi, N.; Nacci, A. Org. Biomol. Chem. 2012, 10, 808-813.

[35]For syntheses of natural products that have been carried out using Pd-catalyzed Suzuki-Miyaura reactions under ligandless conditions, see: (a) St. Denis, J. D.; Gordon, J. S. IV; Carroll, V. M.; Priefer, R. Synthesis 2010, 1590-1592 (total synthesis 
of genistein); (b) Selepe, M. A.; Drewes, S. E.; Van Heerden, F. R. J. Nat. Prod. 2010, 73, 1680-1685 (total synthesis of kraussianone 1); (c) Biegasiewicz, K. F.; St. Denis, J. D.; Carroll, V. M.; Priefer, R. Tetrahedron Lett. 2010, 51, 44084410 (synthesis of daidzein); (d) Konakahara, T.; Kiran, Y. B.; Okuno, Y.; Ikeda, R.; Sakai, N. Tetrahedron Lett. 2010, 51, 2335-2338 (synthesis of ellipticine); (e) Dufour, J.; Neuville, L.; Zhu, J. Chem. Eur. J. 2010, 16, 10523-10534 (synthesis of arylomycins A2 and B2); (f) Selepe, M. A.; Drewes, S. E.; van Heerden, F. R. Tetrahedron 2011, 67, 8654-8658 (total synthesis of lupinalbin H); (g) Narita, S.; Ogura, T.; Usaki, T. J. Chem. 2013 ID 686242 (synthesis of magnolignan).

[36](a) Kong, K.-C.; Cheng, C.-H. J. Am. Chem. Soc. 1991, 113, 6313-6315; (b) O’Keefe, D. F.; Dannock, M. C.; Marcuccio, S. M. Tetrahedron Lett. 1992, 33, 6679-6680; (c) Goodson, F. E.; Wallow, T. I.; Novak, B. M. J. Am. Chem. Soc. 1997, 119, 12441-12453.

[37](a) Fauvarque, J.-F.; Pflüger, F.; Troupel, M. J. Organomet. Chem. 1981, 208, 419-427; (b) Amatore, C.; Jutand, A.; Khalil, F.; M'Barki, M. A.; Mottier, L. Organometallics 1993, 12, 3168-3178. For references on the [Pd] speciation in the

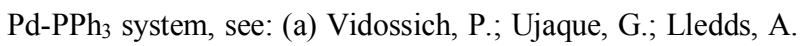
Chem. Commun. 2014, 50, 661-663; (b) Barrios,-Landeros, F.; Carrow, B. P.; Hartwig, J. F. J. Am. Chem. Soc. 2009, 131, 8141-8154; (c) Ahlquist, M. S. G. Norrby, P.-O. Angew. Chem. Int. Ed. 2011, 50, 11794-11797; (d) Negishi, E.-i.; Takahashi, T.; Akiyishi, K. J. Chem. Soc. Chem. Commun. 1986, 1338-1339; (d) Mann, B. E.; Musco, A. J. Chem. Soc. Dalton Trans. 1975, 1673-1677; (e) Tolamn, C. A.; Sedel, W. C.; Gerlach, D. H. J. Am. Chem. Soc. 1972, 94, 2669- 2676.

[38]Mikhailova, M. V.; Bemis, D. L.; Wise, M. L.; Gerwick, W. H.; Norris, J. N.; Jacobs, R. S. Lipids 1995, 30, 583-589.

[39]Mukherjee, P. K.; Marcheselli, V. L.; Serha, C. N.; Bazan, N. G. Proc. Natl. Acad. Sci. U.S.A. 2004, 101, 8491-8496.

[40]Franco, L.H.; de Kier Joffé, E. B.; Puricelli, L.; Tatian, M.; Seldes, A. M.; Palermo, J. A. J. Nat. Prod. 1998, 1130-1132.

[41]Levine, S. D.; Adams, R. D.; Chen, R.; Cotter, M. L.; Hirsch, A. F.; Kane, V. V.; Kanojia, R. M.; Shaw, C. J.; Wachter, M. P. J. Am. Chem. Soc. 1979, 102, 3404-3405.

[42]Urban, S.; Capon, R. J. Aust. J. Chem. 1996, 49, 711-713.

[43](a) Ferris, J. P. J. Org. Chem. 1962, 27, 2985-2990; (b) Rumalla, C. S.; Jadhav, J. N.; Smillie, T.; Fronczek, F. R.; Khan, I. A. Phytochemistry 2008, 69, 1756-1762.

[44](a) Majumder, P. L.; Banerjee, S. Phytochemistry 1988, 27, 245-248; (b) Wang, X.; Fu, J.-m.; Snieckus, V. Helv. Chim. Acta 2012, 95, 2080-2093.

[45]Wall, M. E.; Wani, M. C.; Cook, C. E.; Palmer, K. H.; McPhail, A. T.; Sim, G. A. J. Am. Chem. Soc. 1966, 88, 3888-3890.

[46](a) Pedres, M. S. C.; Yaya, E. E.; Glawischnig, E. Nat. Prod. Rep. 2011, 28, 1381-1405; (b) Glawischnig, E. Phytochemistry 2007, 68, 401-406.

[47]Hashomoto, T.; Tori, M.; Asakawa, Y.; Fukazawa, Y. Tetrahedron Lett. 1987, 28, 6285-6298.

[48]Mdee, L. K.; Yeboah, S. O.; Abegaz, B. M. J. Nat. Prod. 2003, $66,599-604$.
[49]Endo, T.; Tsuda, M.; Fromont, J.; Kobayashi, J. J. Nat. Prod. 2007, 70, 423-424.

[50]Reddy, M. V. R.; Rao, M. R.; Rhodes, D.; Hansen, M. S. T.; Rubins, K.; Bushman, F. D.; Venkataswarlu, Y.; Failkner, D. J. J. Med. Chem. 1999, 42, 1901-1907.

[51]Morita, H.; Oshimi, S.; Hirasawi, Y.; Koyama, K.; Honda, T.; Ekasari, W.; Indrayanto, G.; Zaini, N. C. Org. Lett. 2007, 9, 3691-3693.

[52]Steglich, W.; Steffan, B.; Kopanski, L.; Eckhardt, G. Angew. Chem. Int. Ed. Engl. 1980, 19, 459-460.

[53]Horton, P. A.; Longley, R. E.; McConnell, O. J.; Ballas, L. M. Experientia 1994, 50, 843-845.

[54]Wu, T.-S.; Huang, S.-C.; Wu, P.-L. Phytochemistry 1996, 43, 1427-1429.

[55]Wu, T.-S.; Huang, S.-C.; Wu, P.-L.; Kuoh, C.-S. Phytochemistry 1999, 52, 523-527.

[56]Songsiang, U.; Thongthoom, T.; Boonyarat, C.; Yenjai, C. J. Nat. Prod. 2011, 74, 208-212.

[57]Kunze, B.; Reichenbach, H.; Müller, R.; Höfle, G. J. Antibiot. 2005, 58, 244-251.

[58]Wellington, K. D.; Cambie, R. C.; Rutledge, P. S.; Bergquist, P. R. J. Nat. Prod. 2000, 63, 79-85.

[59]Ulubelen, A.; Topcu, G.; Tan, N.; Lin, L.-J.; Cordell, G. A. Phytochemistry 1992, 31, 2419-2421.

[60](a) Isaac, G. B.; Ayer, S. W.; Elliott, R. C.; Stonard, R. J. J. Org. Chem. 1992, 57, 7220-7226; (b) Miller-Wideman, M.; Makkar, N.; Tran, N.; Isaac, B.; Biest, N.; Stonard, R. J. Antibiot. 1992, 45, 914-921.

[61](a) Bourdelais, A. J.; Jacocks, H. M.; Wright, J. L. C.; Bigwarfe, P. M. Jr.; Baden, D. G. J. Nat. Prod. 2005, 68, 2-6; (b) Gold, E. P.; Jacocks, H. M.; Bourdelais, A. J.; Baden, D. G. Harmful Algae 2013, 26, 12-19.

[62](a) Kemal, M.; Khalil, S. K. W.; Rao, N. G. S; Woolsey, N. F. J. Nat. Prod. 1979, 42, 463-468; (b) Mitscher. L. A.; Gollapudi, S. R.; Drake, S.; Obum, D. S. Phytochemistry 1985, 24, 1481-1483; (c) Lee, W.; Ham. J.; Kwon, H. C.; Kim, Y. K.; Kim, S. N. Biochem. Biophys. Res. Commun. 2013, 432, 73-79.

[63]Höller, U.; Gloer, J. B.; Wicklow, D. T. J. Nat. Prod. 2002, 65, 876-882.

[64]Singh, S. B.; Goetz, M. A.; Jones, E. T.; Bills, G. F.; Giacobbe, R. A.; Herranz, L.; Stevens-Milaes, S.; Williams, D. L. Jr. J. Org. Chem. 1995, 60, 7040-7042.

[65]Lauquin, G. J. M.; Duplaa, A.-M.; Klein, G.; Rousseau. A.; Vignais, P. V. Biochemistry 1976, 15, 2323-2327.

[66]Coenye, T.; Holmes, B.; Kersters, K.; Govan, J. R. W.; Vandamme, P. Int. J. Syst. Bacteriol. 1999, 49, 37-42.

[67]Onose, J.-i.; Xie, C.; Ye, Y. Q.; Sugaya, K.; Takahashi, S.; Koshino, H., Yasunaga, K.; Abe, N.; Yoshikawa, K. Biol. Pharm. Bull. 2008, 31, 831-833.

[68](a) Rao, K. V.; Reddy, G. C. S. J. Nat. Prod. 1990, 53, 309312; (b) Choi, Y. L.; Kim, J. K.; Choi, S.-U.; Min, Y.-K.; Bae, M.-A.; Kim, B. T.; Heo, J.-N. Bioorg. Med. Chem. Lett. 2009, 19, 3036-3040.

[69]Kotoda, N.; Shinya, K.; Furihata, K.; Hayakawa, Y.; Seto, N. J. Antibiot. 1997, 50, 770-772. 
[70]Paterson, I.; Dalby, S. M.; Roberts, J. C.; Naylor, G. J.; Guzman, E. A.; Isbrucker, R.; Pitts, T. P.; Linley, P.; Divlianska, D.; Reed, J. K.; Wright, A. E. Angew. Chem. Int. Ed. 2011, 50, 3219-3223.

[71](a) Tsuji, N.; Kobayashi, M.; Nagashima, K.; Wakisaka, Y.; Koizumi, K. J. Antibiot. 1976, 29, 1-6; (b) Morioka, H.; Ishihara, M.; Takezawa, M.; Hirayama, K.; Suzuki, E.; Komoda, Y.; Shibai, H. Agric. Biol. Chem. 1985, 49, 13651370.

[72]Gould, S. J.; Chen, J.; Cone, M. C.; Gore, M. P.; Melville, C. R.; Tamayo, N. J. Org. Chem. 1996, 61, 5720-5721.

[73](a) Zhang, C.; Ondeyka, J. G.; Herath, K. B.; Guan, Z.; Collado, J.; Pelaez, F.; Leavitt, P. S.; Gurnett, A.; Nare, B.; Liberator, P.; Singh, S. B. J. Nat. Prod. 2006, 69, 710-712; (b) Nakazaki, A.; Huang, W.-Y.; Koga, K.; Yingyongnarongkul, B.-e.; Boonsombat, J.; Sawayama, Y.; Tsujimoto, T.; Nishikawa, T. Biosci. Biotechnol Biochem. 2013, 77, 15291532.

[74](a) Wright, A. E.; Forleo, D. A.; Gunawardana, G. P.; Gunasekara, S. P.; Koehn, F. E.; McConnell, O. J. J. Org. Chem. 1990, 55, 4508-4512; (b) Rinehart, K. L.; Holt, T. G.; Fregeau, N. L.; Stroh, J. G.; Keifer, P. A.; Sun, F.; Li, L. H.; Martin, D. G. J. Org. Chem. 1990, 55, 4512-4515; (c) Sakai, R.; Jares-Erijman, E. A.; Manzanares, I.; Elipe, M. V. S.; Rinehart, K. L. J. Am. Chem. Soc. 1996, 118, 9017-9023.

[75](a) Hamberg, M.; Samuelsson, B. Proc. Natl. Acad. Sci. U.S.A. 1974, 71, 3400-3404; (b) Hamberg, M.; Svensson, J.; Samuelsson, B. Proc.Natl. Acad. Sci. U.S.A. 1974, 71, 38243828; (c) Shimizu, T.; Kondo, K.; Hayaishi, O. Arch. Biochem. Biophys. 1981, 206, 271-276.

[76]Knöll, J.; Knölker, H.-J. Synlett 2006, 651-653.

[77]Tanaka, S.; Kondo, N.; Naito, S. J. Gen. Plant Physiol. 2007, 73, 242-249.

[78](a) Chin, Y.-W.; Park, E. Y.; Seo, S.-Y.; Yoon, K.-D.; Ahn, M.J.; Suh, Y.-G.; Kim, S. G.; Kim, J. Bioorg. Med. Chem. Lett. 2006, 16, 4600-4602; (b) Seo, S.-Y.; Jung, J.-W.; Jung, J.-K.; Kim, N.-Y.; Chin, Y.-W.; Suh, Y.-G. J. Org. Chem. 2007, 72, 666-668.

[79]Warabi, K.; Matsunaga, S.; van Soest, R. W. M.; Fusetani, N. J. Org. Chem. 2003, 68, 2765-2770.

[80]Zhang, Y. L.; Zhang, J.; Jiang, N.; Lu, Y. H.; Wang, L.; Xu, S. H.; Wang, W.; Zhang, G. F.; Xu, Q.; Ge, H. M.; Ma, J.; Song, Y. C.; Tan, R. X. J. Am. Chem. Soc. 2011, 133, 5931-5940.

[81](a) Manfredi, K. P.; Blunt, J. W.; Caerdellina, J. H. II; McMahon, J. B.; Pannell, L. L.; Cragg, G. M. J. Med. Chem. 1991, 34, 3402-3405; (b) Boyd, M. R.; Hallock, Y. F.; Cardellina, J. H. II; Manfredi, K. P.; Blunt, J. W.; McMahon, J. B.; Buckheit, R. W. Jr.; Bringmann, G.; Schaeffer, M. J. Med. Chem. 1994, 37, 1740-1745.

[82]Mohamed, Y. M. A.; Hansen, T. V. Tetrahedron Lett. 2011, 52, 1057-1059.

[83]Ogawa, N.; Kobayashi, Y. Tetrahedron Lett. 2011, 52, 30013004.

[84]Merkul, E.; Schäfer, E.; Müller, T. J. J. Org. Biomol. Chem. 2011, 9, 3139-3141.

[85]Raghavan, S.; Babu, V. S. Chem. Eur. J. 2011, 17, 8487-8494.
[86]Hasse, K.; Willis, A. C.; Banwell, M. G. Eur. J. Org. Chem. 2011, 88-99.

[87]Fukuda, T.; Ohta, T.; Saeki, S.; Iwao, M. Heterocycles 2010, 80, 841-846.

[88]Chausset-Boissarie, L.; Àrvai, R.; Cumming, G. R.; Guénée, L.; Kündig, E. P. Org. Biomol. Chem. 2012, 10, 6473-6479.

[89]Wang, X.; Fu, J.-m.; Snieckus, V. Helv. Chim. Acta. 2012, 95, 2680-2694.

[90]Wei, C.; Jiang, Z.; Tian, S.; Zhang, D. Tetrahedron Lett. 2013, $54,4515-4517$.

[91]Tasch, B. O. A.; Antovic, D.; Merkul, E.; Müller, T. J. J. Eur. J. Org. Chem. 2013, 4564-4569.

[92]Mihigo, S. O.; Mammo, W.; Bezabih, M.; Andrae-Marobela, K.; Abegaz, B. M. Bioorg. Med. Chem. 2010, 18, 2464-2473.

[93]Morales, J. C. C.; Torres, A. G.; González-Zamora, E. Eur. J. Org. Chem. 2011, 3165-3170.

[94]Tasch, B. O. A.; Merkul, E.; Müller, T. J. J. Eur. J. Org. Chem. 2011, 4532-4535.

[95]Deguchi, J.; Hirahara, T.; Oshimi, S.; Hirasawa, Y.; Ekasari, W.; Shirota, O.; Honda, T.; Morita, H. Org. Lett. 2011, 13, 4344-4347.

[96]Wang, K.; Liu, Z. Synth. Commun. 2010, 40, 144-150.

[97]Yang, W.; Zhou, J.; Wang, B.; Ren, H. Chem. Eur. J. 2011, 17, 13665-13669.

[98]Hartmann, O.; Kalesse, M. Org. Lett. 2012, 14, 3064-3067.

[99]Jang, B.; Li, M.-m.; Xing, P.; Huang, Z.-g. Org. Lett. 2013, 15, 871-873.

[100] Taj, R. A.; Green, J. R. J. Org. Chem. 2010, 75, 82588270.

[101] (a) Gosh, A. K.; Li, J. Org. Lett. 2011, 13, 66-69; (b) Pellicena M.; Krämer, K.; Romea, P.; Urpí, F. Org. Lett. 2011, 13, 5350-5353.

[102] Ebine, M.; Fuwa, H.; Sasaki, M. Chem. Eur. J. 2011, 17, 13754-13761.

[103] Kim, T.; Lee, W.; Jeong, K. H.; Song, J. H.; Park, S.-H.; Choi, P.; Kim, S.-N.; Lee, S.; Ham, J. Bioorg. Med. Chem, Lett. 2012, 22, 4122-4126.

[104] Hsu, D.-S.; Lin, S.-C. J. Org. Chem. 2012, 77, 61396146.

[105] Uchiro, H.; Shionozaki, N.; Tanaka, R.; Kitano, H.; Iwamura, N.; Makino, K. Tetrahedron Lett. 2013, 54, 506511.

[106] (a) Francais, A.; Leyva, A.; Etxebarria-Jardi, G.; Ley, S. V. Org. Lett. 2010, 12, 340-343; (b) Uenishi, J.; Breau, J. M.; Armstrong, R. W.; Kishi, Y. J. Am. Chem. Soc. 1987, 109, 4756-4758.

[107] Ye, Y. Q.; Koshino, H.; Onose, J.-i.; Yoshikawa, K.; Abe, N.; Takahashi, S. Biosci. Biotechnol. Biochem. 2010, 74, 140146.

[108] Heo, J.-N.; Kim, T.; Kim, J. K. Bull. Korean Chem. Soc. 2011, 32, 4431-4434.

[109] Hieda, Y.; Choshi, T.; Kishida, S.; Fujoka, H.; Hibino, S. Tetrahedron Lett. 2010, 51, 3593-3596.

[110] Willwacher, J.; Kausch-Busies, N.; Fürstner, A. Angew. Chem., Int. Ed. 2012, 51, 12041-12046. 
[111] Cosner, C. C.; Iska, V. B. R.; Chatterjee, A.; Markiewicz, J. T.; Corden, S. J.; Löfsted, J.; Ankner, T.; Richer, J.; Hulett, T.; Schauer, D. J.; Wiest, O.; Helquist, P. Eur. J. Org. Chem. 2013, 162-172.

[112] Kimura, S.; Kobayashi, S.; Kumamoto, T.; Akagi, A.; Sato, N.; Ishikawa, T. Helv. Chim. Acta 2011, 94, 578-591.

[113] Kawagishi, F.; Toma, T.; Inui, T.; Yokoshima, S.; Fukuyama, T. J. Am. Chem. Soc. 2013, 135, 13684-13687.

[114] Tojo, T.; Wang, Q.; Okuno, T.; Yokomizo, T.; Kobayashi, Y. Synlett 2013, 24, 1545-1548.

[115] Hieda, Y.; Choshi, T.; Fujioka, H.; Hibino, S. Eur. J. Org. Chem. 2013, 7391-7401.

[116] Kusakabe, T.; Kawai, Y.; Kato, K. Org. Lett. 2013, 15, 5102-5105.

[117] Jung, J.-W.; Jang, J.; Seo, S.-Y.; Jung, J.-K.; Suh, Y.-G. Tetrahedron 2010, 66, 6826-6831.

[118] Hirao, S.; Yoshinaga, Y.; Iwao, M.; Ishibashi, F. Tetrahedron Lett. 2010, 51, 533-536.

[119] Lahore, S.; Narkhede, U.; Merlini, L.; Dallavalle, S. J. Org. Chem. 2013, 78, 10860-10866.

[120] Xu, G.; Fu, W.; Liu, G.; Senanayake, C. H.; Tang, W. J. Am. Chem. Soc. 2014, 136, 570-573.

[121] For a discussion on the synthesis, properties and applications of MIDA boronates in Suzuki-Miyaura couplings, see: Lennox, A. J. J.; Lloyd-Jones, G. C. Chem. Soc. Rev. 2014, 43, 412-443.

[122] Boland, W.; Schroer, N.; Sieler, C.; Feigel, M. Helv. Chim. Acta 1987, 70, 1025-1040.

[123] (a) Murata, M.; Watanabe, S.; Masuda, Y. J. Org. Chem. 1997, 62, 6458-6459; (b) Murata, M.; Oyama, T.; Watanabe, S.; Masuda, Y. J. Org. Chem. 2000, 65, 164-168.

[124] Schmid, C. R.; Beck, C. A.; Cronin, J. S.; Staszak, M. A. Org. Process Res. Dev. 2004, 8, 670-673.

[125] For leading references on Pd-catalyzed decarboxylative arylation reactioons of heteroaromatic carboxylic acids, see: (a) Carrër, A.; Brion, J.-D.; Messaoudi, S.; Alami, M. Adv. Synth. Catal. 2013, 355, 2044-2054; (b) Li, X; Zou, D.; Leng, F.; Sun, C.; Li, J.; Wu, Y.; Wu, Y. Chem. Commun. 2013, 49, 312-314; (c) Hu, P.; Zhang, M.; Jie, X.; Su, W. Angew. Chem. Int. Ed. 2012, 51, 227-231; (d) Nandi, D.; Jhou, Y.-M.; Lee, J.-Y.; Kuo, B.-C.; Liu, C.-Y.; Huang, P.-W.; Lee, H. M. J. Org. Chem. 2012, 77, 9384-9390; (e) Xie, K: Yang, Z.; Zhou, X.; Li, X.; Wang, S.; Tan, Z.; An, X.; Guo, C.-C. Org. Lett. 2010, 12, 1564-1567; (f) Cornella, J.; Lu, P.; Larrosa, I. Org. Lett. 2009, 11, 5506-5509.

[126] Zhou, H. B.; Liu, G. S.; Liao, Z. J. Org. Lett. 2007, 9, 2003-2006.

[127] (a) Houben, J. Ber. Dtsch. Chem. Ges. A/B 1926, 59, 2878-2891; (b) Hoesch, K. Ber. Dtsch. Chem. Ges. 1915, 48, 1122-1133: (c) Cameron, D. W.; Deutscher, K. R.; Feutrill, G. I.; Hunt, D. E. Aust. J. Chem. 1982, 35, 1451-1468; (d) Sato, Y.; Yato, M.; Ohwada, T.; Saito, S.; Shudo, K. J. Am. Chem. Soc. 1995, 117, 3037-3043.

[128] Zuo, L.; Yao, S.; Wang, W.; Duan, W. Tetrahedron Lett. 2008, 49, 4054-4056.
[129] (a) Trost, B. M.; Pissot-Soldermann, C.; Chen, I.; Schroeder, G. M. J. Am. Chem. Soc. 2004, 126, 4480-4481; (b) Trost, B. M.; Pissot-Soldermann, C.; Chen, I. Chem. Eur. J. 2005, 11, 951-959; (c) Miesch, L.; Welsch, T.; Rietsch, V.; Miesch, M. Chem. Eur. J. 2009, 15, 4394-4401.

[130] (a) Ref 106b; (b) Frank, S. A.; Chen, H.; Kunz, R. K.; Schnardebeck, M. J.; Roush, W. R. Org. Lett. 2000, 2, 26912694.

[131] (a) Fürstner, A.; Mathes, C.; Lehmann, C. W. Chem. Eur. J. 2001, 7, 5299-5317; (b) Fürstner, A.; Mathes, C.; Lehmann, C. W. J. Am. Chem. Soc. 1999, 121, 9453-9454.

[132] Morioka, H.; Ishihra, M.; Takezawa, M.; Hirayama, K.; Suzuki, E.; Komoda, Y.; Shibai, H. Agric. Biol. Chem. 1985, 49, 1365-1370.

[133] (a) Ghielmini, M.; Colli, E.; Erba, E.; Bergamaschi, D.; Pamallona, S.; Jimeno, J.; Faircloth, G.; Sessa, C. Ann. Oncol. 1998, 9, 989-993; (b) Valoti, G.; Nicoletti, M. I.; Pellegrino, A.; Jimeno, J.; Hendriks, H.; D’Incalci, M.; Faircloth, G.; Giavazzi, R. Clin. Cancer Res. 1998, 4, 1977-1983; (c) D’Angelo, D.; Borbone, E.; Palmieri, D.; Uboldi, S.; Esposito, F.; Frapolli, R.; Pacelli, R.; D'Incalci, M.; Fusco, A. Eur. J. Cancer 2013, 49, 1142-1151.

[134] Kitano, Y.; Matsumoto, T.; Wakasa, T.; Okamoto, S.; Shimazaki, T.; Kobayashi, Y. Tetrahedron Lett. 1987, 28, 6351-6354.

[135] (a) Knight, D. W.; Qing, X. Tetrahedron Lett. 2009, 50, 3534-3537; (b) Avenoza, A.; Cataviela, C.; Peregrina, J. M.; Sucunza, D.; Zurbano, M. M. Tetrahedron: Asymmetry 2001, $12,1383-1388$

[136] Seo, S.-Y.; Jung, J.-W.; Jung, J.-K.; Kim. N.-J.; Chin, Y.W.; Kim, J.; Suh, Y.-G. J. Org. Chem. 2007, 72, 666-668.

[137] Fürstner, A.; Domostoj, M. M.; Scheiper, B. J. Am. Chem. Soc. 2005, 127, 11620-11621.

[138] Namy, J. L.; Souppe, J.; Kagan, H. B. Tetrahedron Lett. 1983, 24, 765-766.

[139] Iwao, M.; Takeuchi, T.; Fujikawa, N.; Fukuda, T.; Ishibashi, F. Tetrahedron Lett. 2003, 44, 4443-4446.

[140] Lenoir, D. Synthesis 1977, 553-554.

[141] For early references on $\mathrm{PdCl}_{2}\left(\mathrm{PPh}_{3}\right)_{2}$-catalyzed SuzukiMiyaura cross-coupling reactions, see: (a) Mattei, P.; Diederich, F. Helv. Chim. Acta 1997, 80, 1555-1588; (b) Bower, J. F.; Guillaneux, D.; Nguyen, T.; Wong, P. L.; Snieckus, V. J. Org. Chem. 1998, 63, 1514-1518; (c) Occhiato, E. G.; Trabocchi, A.; Guarna, A. J. Org. Chem. 2001, 66, 2459-2465; (d) Gong, Y.; He, W. Org. Lett. 2002, 4, 3803-3805; (e) Bussolari, J. C.; Rehborn, D. C. Org. Lett. 1999, 1, 965-967; (f) DeBoos, G. A.; Fullbrook, J. J.; Owton, W. M.; Percy, J. M.; Thomas, A. C. Synlett 2000, 963-964.

[142] For early references on $\mathrm{Pd}(\mathrm{OAc})_{2} / \mathrm{PPh}_{3}$-catalyzed SuzukiMiyaura reactions, see: (a) Larsen, R. D.; King, A. O.; Chen, C. Y.; Corley, E. G.; Foster, B. S.; Roberts, F. E.; Yang, C.; Lieberman, D. R.; Reamer, R. A.; Tschaen, D. M.; Verhoeven, T. R.; Reider, P. J. J. Org. Chem. 1994, 59, 6391-6394; (b) Markò, I. E.; Murphy, F.; Dolan, S. Tetrahedron Lett. 1996, 37, 2507-2510; (c) Huff, B. E.; Koenig, T. M.; Mitchell, D.; Staszak, M. A. Org. Synth. 1997, 75, 53-60; (d) Pan, R.-q.; 
Liu, X.-x.; Deng, M.-z. J. Fluorine Chem. 1999, 95, 167-170; (e) Schomaker, J. M.; Delia, T. J. J. Org. Chem. 2001, 66, 7125-7128; (f) Lando, V. R.; Monteiro, A. L. Org. Lett. 2003, 5, 2891-2894: (g) Thompson, A. E.; Hughes, G.; Batsanov, A. S.; Bryce, M. R.; Parry, P. R.; Tarbit, B. J. Org. Chem. 2005, 70, 388-390.

[143] (a) Amatore, C.; Azzabi, M.; Jutand, A. J. Am. Chem. Soc. 1991, 113, 8375-8384; (b) Amatore, C.; Carré, E.; Jutand, A.; M'Barki, M. A. Organometallics 1995, 14, 1818-1826; (c) Amatore, C.; Carré, E.; Jutand, A.; M’Barki, M. A.; Meyer, G. Organometallics 1995, 14, 5605-5614.

[144] Amatore, C.; Jutand, A.; Lemaitre, F.; Lucricard, J.; Kozuch, S.; Shaik, S. J. Organomet. Chem. 2004, 689, 37283734.

[145] Zalesskiy, S. S.; Ananikov, V. P. Organometallics 2012 , 31, 2302-2309.

[146] For recent representative examples, see: (a) Poláčková, V.; Toma, S.; Kappe, C. O. Tetrahedron 2007, 63, 8742-8745; (b) Imao, D.; Gosspoole, B. W.; Laberge, V. S.; Crudden, C. M. J. Am. Chem. Soc. 2009, 131, 5024-5025; (c) Gao, D.; O'Doherty, G. A. Org. Lett. 2010, 12, 3752-3755.

[147] (a) Tunac, J. B.; Graham, B. D.; Dobson, W. E. J. Antibiot. 1983, 36, 1595-1600; (b) Stampwala, S. S.; Bunge, R. H.; Hurley, T. R.; Wilmer, N. E.; Brankiewicz, A. J.; Steinman, C. E.; Smitka, T. A.; French, J. C. J. Antibiot. 1983, 36, 1601-1605; (c) Hokanson, G. C.; French, J. C. J. Org. Chem. 1985, 50, 462-466.

[148] (a) Lewy, D. S.; Gauss, C.-M.; Soenen, D. R.; Boger, D. L. Curr. Med. Chem. 2002, 9, 2005-2032; (b) Jackson, R. C.; Fry, D. W.; Boritzki, T.; Roberts, B. J.; Hook, K. E.; Leopold, W. R. Adv. Enzyme Regul. 1985, 23, 193-215.

[149] Gao, D.; O’Doherty, G. A. Org. Lett. 2010, 12, 37523755.

[150] Ye, Y. Q.; Koshino, H.; Abe, N.; Nakamura, T.; Hashizume, D.; Takahashi, S. Biosci. Biotechnol. Biochem. 2010, 74, 2342-2344.

[151] (a) Yang, W.-M.; Liu, J.-K.; Hu, L.; Dong, Z.-J.; Wu, W.L.; Chen, Z.-H. Z. Naturforsch. 2004, 59c, 359-362; (b) Hu, L.; Liu, J.-K. Z. Naturforsch. 2003, 58c, 452-454; (c) Quang, D. N.; Hashimoto, T.; Hitaka, Y.; Tanaka, M.; Nukada, M.; Yamamoto, I.; Asakawa, Y. Phytochemistry 2003, 63, 919924; (d) Quang, D. N.; Hashimoto, T.; Hitaka, Y.; Tanaka, M.; Nukada, M.; Yamamoto, I.; Asakawa, Y. Phytochemistry 2004, 65, 1179-1184.

[152] Arango, V.; Robledo, S.; Séon-Méniel, B.; Figadère, B.; Cardona, W.; Sáez, J.; Otálvaro, F. J. Nat. Prod. 2010, 73, 1012-1014.

[153] Schmidt, B.; Krehl, S.; Kelling, A.; Schilde, U. J. Org. Chem. 2012, 77, 2360-2367.

[154] Ishihara, Y.; Azuma, S.; Choshi, T.; Kohno, K.; Ono, K.; Tsutsumi, H.; Ishizu, T.; Hibino, S. Tetrahedron 2011, 67, $1320-1333$.

[155] Boulware, R. T.; Stermitz, F. R. J. Nat. Prod. 1981, 44, 200-205.

[156] (a) Chen, J.-J.; Fang, H.-Y.; Duh, C.-Y.; Chen, I.-S. Planta Med. 2005, 71, 470-475; (b) Luo, X.; Pedro, L.; Milic,
V.; Molhovo, S.; Duarte, A.; Duarte, N.; Ferreira, M.-J. Planta Med. 2012, 78, 148-153; (c) Nguyen, Q. A.; Van-Dufat, H. T.; Michel, S.; Tillequin, F.; Dumontet, V.; Sévenet, T. Z. Naturforsch. 2002, 57c, 986-989.

[157] Zhang, F.; Zaidi, S.; Haney, K. M.; Kellogg, G. E.; Zhang, Y. J. Org. Chem. 2011, 76, 7945-7952.

[158] (a) Jayasuriya, H.; Herath, K. B.; Ondeyka, J. G.; Polishook, J. D.; Bills, G. F.; Dombrowski, A. W.; Springer, M. S.; Siciliano, S.; Malkowitz, L.; Sanchez, M.; Guan, Z. Q.; Tiwari, S.; Stevenson, D. W.; Borris, R. P.; Singh, S. B. J. Nat. Prod. 2004, 67, 1036-1038; (b) Klausmeyer, P.; Chmurny, G. N.; McCloud, T. G.; Ticker, K. D.; Shoemaker, R. H. J. Nat. Prod. 2004, 67, 1732-1735.

[159] (a) Fukuoka, M.; Kuroyanagi, M.; Yoshihira, K.; Natori, S. Chem. Pharm. Bull. 1978, 26, 2365-2385; (b) Kuroyanagi, M.; Fukuoka, M.; Yoshihira, K.; Natori, S. Chem Pharm. Bull. 1974, 22, 723-726.

[160] Hsu, F.; Liu, S. H.; Uang, B. J. Taiwan Patent No TW 201039836, 2010 July 29.

[161] Hsu, S.-C.; Narsingam, M.; Lin, Y.-F.; Hsu, F.-L.; Uang, B.-J. Tetrahedron 2013, 69, 2572-2576.

[162] Lin, Y.; Li, H.; Jiang, G.; Zhou, S.; Vrijmoed, L. L. P., Jones, E. B. G. Indian J. Chem. Sect. B 2002, 41B, 15421544.

[163] Parker, A. N.; Lock, M. J.; Hutchison, J. M. Tetrahedron Lett. 2013, 54, 5322-5324.

[164] (a) Clark, B.; Capon, R. J.; Lacey, E.; Tennant, S.; Gill, J. H.; Bulheller, B.; Bringmann, G. J. Nat. Prod. 2005, 68, 12261230; (b) Hosoe, T.; Iisuka, T.; Komai, S.-i.; Wakana, D.; Itabashi, T.; Nozawa, K.; Fukushima, K.; Kawai, K.-i. Phytochemistry 2005, 66, 2776-2779.

[165] (a) Fujimoto, H.; Satoh, Y.; Yamaguchi, K.; Yamazaki, M. Chem. Pharm. Bull. 1998, 46, 1506-1510; (b) Fujimoto, H.; Takeshi, A.; Kim, Y.-P.; Ishibashi, M. Chem. Pharm. Bull. 2006, 54, 550-553; (c) Kralj, A.; Kehraus, S.; Krick, A.; Eguereva, E.; Kelter, G.; Maurer, M.; Wortmann, A. ; Fiebig, H.-H.; Konig, G. M. J. Nat. Prod. 2006, 69, 995-1000.

[166] Denton, R. M.; Scragg, J. T. Synlett 2010, 633-635.

[167] Kouno, I.; Morisaki, T.; Hara, Y.; Yang, C.-S. Chem. Pharm. Bull. 1991, 39, 2606-2608.

[168] Nemecek, G.; Thomas, R.; Goesmann, H.; Feldmann, C.; Podlech, J. Eur. J. Org. Chem. 2013, 6420-6432.

[169] Rosett, T.; Sankhala, R. H.; Stickings, C. E.; Taylor, M. E. U.; Thomas, R. Biochem. J. 1957, 67, 390-400.

[170] Altenmöller, M.; Gehring, T.; Cudaj, J.; Podlech, J.; Goesmann, H.; Feldmann, C.; Rothenberger, A. Eur. J. Org. Chem. 2009, 2130-2140.

[171] Woerly, E.; Cherney, A. H.; Davis, E. K.; Burke, M. D. J. Am. Chem. Soc. 2010, 132, 6941-6943.

[172] Hofmann, E.; Wrench, P. M.; Sharples, F. P.; Hiller, R. G.; Welte, W.; Diederichs, K. Science 1996, 272, 1788-1791.

[173] Pinto, E.; Catalani, L. H.; Lopes, N. P.; Di Mascio, P.; Colepicolo, P. Biochem. Biophys. Res. Commun. 2000, 268, 496-500.

[174] Nishino, H. Mutat. Res. 1998, 402, 159-163. 
[175] (a) Fairlamb, I. S.; Sehnal, P.; Taylor, R. J. K. Synthesis 2009, 508-510; (b) Burns, N. J.; Fairlamb, I. S.; Kapdi, A. R.; Sehnal, P.; Taylor, R. J. K. Org. Lett. 2007, 9, 5397-5400.

[176] Lüthy, M.; Taylor, R. J. K. Tetrahedron Lett. 2012, 53, 3444-3447.

[177] Burns, A. R.; Mc Allister, G. D.; Shanahan, S. E.; Taylor, R. J. K. Angew. Chem. Int. Ed. 2010, 49, 5574-5577.

[178] Bugni, T. S.; Janso, J. E.; Williamson, R. T.; Feng, X.; Bernan, V. S.; Greenstein, M.; Carter, G. T.; Maiese, W. M.; Ireland, C. M. J. Nat. Prod. 2004, 67, 1396-1399.

[179] Ezaki, M.; Iwami, M.; Yamashita, M.; Hashimoto, S.; Komori, T.; Umehara, K.; Minec, Y.; Kohsaka, M.; Aoki, N.; Imanaka, H. J. Antibiot. 1985, 38, 1453-1461.

[180] He, Y.-P.; Tan, H.; Baumann, S.; Waldmann, H.; Arndt, H.-D. Chem. Asian J. 2011, 6, 1546-1556.

[181] (a) Abe, T.; Ikeda, T.; Yanada, R.; Ishikura, M. Org. Lett. 2011, 13, 3350-3359; (b) Abe, T.; Ikeda, T.; Choshi, T.; Hibino, S.; Hatae, N.; Toyata, E.; Yaneda, R.; Ishikura, M. Eur. J. Org. Chem. 2012, 5018-5027.

[182] Rickards, R. W.; Rothschild, J. M.; Willis, A. C.; de Chazal, N. M.; Kirk, J.; Kirk, K.; Saliba, K. J.; Smith, G. D. Tetrahedron 1999, 55, 13513-13520.

[183] Bernardo, P. H.; Chai, C. L. L.; Heath, G. A.; Mahon, P. J.; Smith, G. D.; Waring, P.; Wilkes, B. A. J. Med. Chem. 2004, 47, 4958-4963.

[184] Ortega, M. J.; Zubía, E.; Ocaña, J. M.; Naranjo, S.; Salvá, J. Tetrahedron 2000, 56, 3963-3967.

[185] Manzanares, S.; Salvá, J.; de la Fuente, J. A'. J. Nat. Prod. 2006, 69, 1485-1487.

[186] Boukouvalas, J.; McCann, L. C. Tetrahedron Lett. 2010, $51,4636-4639$.

[187] Zhang, J.-T.; Qi, X.-L.; Chen, J.; Li, B.-S.; Zhou, Y.-B.; Cao, X.-P. J. Org. Chem. 2011, 76, 3946-3959.

[188] Wu, M.; Milligan, K. E.; Gerwick, W. H. Tetrahedron 1997, 53, 15983-15990.

[189] Ichikawa, H.; Watanabe, R.; Fujino, Y.; Usami, Y. Tetrahedron Lett. 2011, 52, 4448-4451.

[190] Schröter, H.-B.; Neumann, D.; Katritzky, A. R.; Swinbourne, F. J. Tetrahedron 1966, 22, 2895-2897.

[191] Wube, A. A.; Wenzih, E.-M.; Gibbsons, S.; Asres, K.; Bauer, R.; Bucar, F. Phytochemistry 2008, 69, 982-987.

[192] (a) Old, D. W.; Wole, J. P.; Buchwald, S. L. J. Am. Chem. Soc. 1998, 120, 9722-9723; (b) Wolfe, J. P.; Buchwald, S. L. Angew. Chem. Int. Ed. 1999, 38, 2413-2416; (c) Wolfe, J. P.; Singer, R. A.; Yang, B. H.; Buchwald, S. L. J. Am. Chem. Soc. 1999, 121, 9550-9561; (d) Yin, J.; Rainka, M. P.; Zhang, X.X.; Buchwald, S. L. J. Am. Chem. Soc. 2002, 124, 1163ì1163; (e) Martin, R.; Buchwald, S. L. Acc. Chem. Res. 2008, 41, 1461-1473.

[193] (a) Hallock, Y. F.; Manfredi, K. P.; Blunt, J. W.; Cardellina II, J. H.; Schaeffer, M.; Gulden, K.-P.; Bringmann, G.; Lee, A. Y.; Clardy, J. J. Org. Chem. 1994, 59, 6349-6355; (b) Bringmann, G.; Gulden, K.-P.; Hallock, Y. F.; Manfredi, K. P.; Cardellina II, J. H.; Boyd, M. R.; Kramer, B.; Fleischauer, J. Tetrahedron 1994, 50, 7807-7814.
[194] Zhang, H.-W.; Huang, W.-Y.; Song, Y.-C.; Chen, J.-R.; Tan, R.-X. Helv. Chim. Acta. 2005, 88, 2861-2864.

[195] Banerji, A.; Majumder, P. L.; Chatterjee, A. G. Phytochemistry 1970, 9. 1491-1493.

[196] (a) Rosett, T.; Sankhala, R. H.; Stickings, C. E.; Taylor, M. E. U.; Thomas, R. Biochem. J. 1957, 67, 390-400; (b) Pero, R. W.; Hrvan, D.; Blois, M. C. Tetrahedron Lett. 1973, 14, 945-948.

[197] Mizutani, K.; Fukunaga, Y.; Tanaka, O.; Takasugi, N.; Suruwatari, Y.; Fuwa, T.; Yamauchi, T.; Wang, J.; Jia, M.-R.; Li, F.-Y.; Ling, Y.-K. Chem. Pharm. Bull. 1988, 36, 23622365.

[198] Thomas, R. Biochem. J. 1961, 80, 234-240.

[199] Aly, A. H.; Edrada-Ebel, R. A.; Indriani, I. D.; Wray, V.; Müller, W. E. G.; Totzke, F.; Zirrglebel, C.; Scächtele, C.; Kubbutat, M. H. G.; Lin, W. H.; Proksch, P.; Ebel, R. J. Nat. Prod. 2008, 71, 972-980.

[200] Liang, D.; Luo, H.; Liu, Y.-F.; Hao, Z.-Y.; Wang, Y.; Zhang, C.-L.; Zhang, Q.-J.; Chen, R.-Y.; Yu, D.-Q. Tetrahedron 2013, 69, 2093-2097.

[201] Huang, H.; Feng, X.; Xiao, Z.; Liu, L.; Li, H.; Ma, L.; Lu, Y.; Ju, J.; She, Z.; Lin, Y. J. Nat. Prod. 2011, 74, 997-1002.

[202] Wurz, G.; Hofer, O.; Greger, H. Nat. Prod. Lett. 1993, 3, $177-182$

[203] He, L.; Zhang, Y.-H.; Zhang, J.-X.; Sun, Q.-Y.; Hao, X.J. J. Nat. Prod. 2011, 74, 181-184.

[204] Schimana, J.; Gebhardt, K.; Höltzel, A.; Schmid, D. G.; Sussmuth, R.; Müller, J.; Pukall, R.; Fiedler, H.-P. J. Antibiot. 2002, 565-570.

[205] Décor, A.; Bellocq, D.; Thoison, O.; Lekieffre, N.; Charoni, A.; Ouazzani, T.; Cresteil, T.; Guéritte, F.; Baudoin, O. Bioorg. Med. Chem. 2006, 14, 1558-1564.

[206] Kjer, J.; Wray, V.; Edrada-Ebel, R. A.; Ebel, R.; Pretsch, A.; Lin, W.; Proksch, P. J. Nat. Prod. 2009, 72, 2053-2057.

[207] (a) Fujita, M.; Itokawa, H.; Sashida, Y. Chem. Pharm. Bull. 1972, 20, 212-213; (b) Fukuyama, Y.; Otoshi, Y.; Miyoshi, K.; Nakamura, K.; Nagasawa, M.; Hasegawa, T.; Okazaki, H.; Sugawara, M. Tetrahedron 1992, 48, 377-392.

[208] (a) Jansen, R.; Reifenstahl, G.; Gert, K.; Reichenbach, H.; Höfle, G. Liebigs Ann. Chem. 1983, 1081-1095; (b) Jansen, R.; Sheldrick, W. S.; Höfle, G. Liebigs Ann. Chem. 1984, 7884; (c) Gerth, K.; Jansen, R.; Reifenstahl, G.; Höfle, G.; Irschik. H.; Kunze, B.; Reichenbach, H.; Thierbach, G. $J$. Antibiot. 1984, 1150-1156.

[209] (a) Li, L.; Seeram, N. P. J. Funct. Foods 2011, 3, 125128; (b) Seeram, N. P.; Liya, L.; Belard, G.; Bårbeau, J. PCT Int. Appl. WO 2012/021981.

[210] Asakawa, Y.; Matsuda, R. Phytochemistry 1982, 21, 2143-2144.

[211] Tamehiro, N.; Sato, Y.; Suzuki, T.; Hashimoto, T.; Asakawa, Y.; Yokoyama, S.; Kawanishi, T.; Ohno, Y.; Inoue, K.; Nagao, T.; Nishimaki-Mogami, T. FEBS Lett. 2005, 579, 5299-5304.

[212] Kwak, J.-H.; Cho, Y. A.; Jang, J.-Y.; Seo, S.-Y.; Lee, H.; Hong, J. T.; Han, S.-B.; Lee, K.; Kwak, Y.-S.; Jung, J.-K. Tetrahedron 2011, 67, 9401-9404. 
[213] Del Valle, D. J.; Krische, M. J. J. Am. Chem. Soc. 2013, 135, 10986-10989.

[214] (a) Li, J.; Li, L.; Si, Y.; Jiang, X.; Guo, L.; Che, Y. Org. Lett. 2011, 13, 2670-2673; (b) Ding, G.; Liu, S.; Guo, L.; Zhou, Y.; Che, Y. J. Nat. Prod. 2008, 71, 615-618; (c) Hume, P. A.; Furkert, D. P.; Brimble, M. A. Org. Lett. 2013, 15, 4588-4591.

[215] Xu, Z.; Wng, Q.; Zhu, J. J. Am. Chem. Soc. 2013, 135, 19127-19130.

[216] (a) Rao, K. V.; Davis, T. L. Planta Med. 1982, 45, 57-59; (b) Schühly, W.; Hüfner, A.; Pferschy-Wenzig, E. M.; Prettner, E.; Adams, M.; Bodensieck, A.; Kunert, O.; Oluwemimo, A.; Haslinger, E.; Bauer, R. Bioorg. Med. Chem. 2009, 17, 4459-4465.

[217] (a) Umezawa, I.; Funayama, S.; Okada, K.; Iwasaki, K.; Satoh, J.; Masuda, K.; Komiyama, K. J. Antibiot. 1985, 38, 699-705; (b) Smith II, A. B.; Wood, J. L.; Wong, W.; Gould, A. E.; Rizzo, C. J. J. Am. Chem. Soc. 1990, 112, 7425-7426.

[218] Huang, S.; Petersen, T. B.; Lipshutz, B. H. J. Am. Chem. Soc. 2010, 132, 14021-14023.

[219] Cudaj, J.; Podlech, J. Tetrahedron Lett. 2010, 51, 30923094.

[220] Gu, Z.; Zakarian, A. Org. Lett. 2010,12, 4224-4227.

[221] Nemecek, G.; Cdaj, J.; Podlech, J. Eur. J. Org. Chem. 2012, 3863-3870.

[222] Igarashi, Y.; Aoki, K.; Nishimura, H.; Morishita, I.; Usui, K. Chem. Pharm. Bull. 2012, 60, 1088-1091.

[223] Cudaj, J.; Podlech, J. Synlett 2012, 23, 371-374.

[224] Yajima, A.; Urao, S.; Yoshioka, Y.; Abe, N.; Katsuta, R.; Nukada, T. Tetrahedron Lett. 2013, 54, 4986-4989.

[225] Tanimoto, K.; Nakagawa, N.; Takeda, K.; Kirihata, M.; Tanimori, S. Tetrahedron Lett. 2013, 54, 3712-3714.

[226] Magnus, P.; Sepp, C. Org. Lett. 2013, 15, 4870-4871.

[227] Dufour, J.; Neuville, L.; Zhu, J. Chem. Eur. J. 2010, 16, 10523-10534.

[228] Denton, R. M.; Scragg, J. T.; Galofré, A. M.; Gui, X.; Lewis, W. Tetrahedron 2010, 66, 8029-8035.

[229] Fujita, K.; Matsui, R.; Suzuki, T.; Kobayashi, S. Angew, Chem. Int. Ed. 2012, 51, 7271-7274.

[230] Cardinal, S.; Voyer, N. Tetrahedron Lett. 2013, 54, 51785180.

[231] Harada, L, Makino, K.; Shima, N.; Okuyama, H.; Esumi, T.; Kubo, M.; Hioki, H.; Asakawa, Y.; Fukuyama, Y. Tetrahedron 2013, 69, 6959-6968.

[232] Kam, T.-S.; Subramaniam, G.; Lim, K.-H.; Choo, Y.-M. Tetrahedron Lett. 2004, 45, 5995-5998.

[233] Goh, S. H.; Wei, C.; Ali, A. R. M. Tetrahedron Lett. 1984, 25, 3483-3484.

[234] Abe, F.; Yamauchi, T. Phytochemistry 1994, 35, 169171.

[235] Kamisuki, S.; Takahashi, S.; Mizushina, Y.; Hanashima, S.; Kuramochi, K.; Kobayashi, S.; Sakaguchi, K.; Nakata, T.; Sugawara, F. Tetrahedron 2004, 60, 5695-5700.

[236] Molander, G. A.; Shin, I.; Jean-Gérard, L. Org. Lett. 2010, 12, 4384-4387.
[237] Lee, S. J.; Gray, K. C.; Paek, J. S.; Burke, M. D. J. Am. Chem. Soc. 2008, 130, 466-468.

[238] Lee, S. J.; Anderson, T. M.; Burke, M. D. Angew. Chem. Int. Ed. 2010, 49, 8860-8863.

[239] Hayashi, T.; Konishi, M.; Kobori, Y.; Kumada, M.; Higuchi, T.; Hirotsu, K. J. Am. Chem. Soc. 1984, 106, 158163.

[240] Miyaura, N.; Ishiyama, T.; Ishikawa, M.; Suzuki, A. Tetrahedron Lett. 1986, 27, 6369-6372.

[241] (a) Ishiyama, T.; Murata, M.; Miyaura, N. J. Org. Chem. 1995, 60, 7508-7510; (b) Murata, M.; Oyama, T.; Watanabe, S. Masuda, Y. J. Org. Chem. 2000, 65, 164-168; (c) Ishiyama, T.; Itoh, Y.; Kitano, T.; Miyaura, N. Tetrahedron Lett. 1997, 38, 3447-3450; (d) Willis, D. M.; Strongin, R. M. Tetrahedron Lett. 2000, 41, 8683-8686.

[242] Wang, B.; Sun, H.-X.; Sun, Z.-H.; Lin, G.-Q. Adv. Synth. Catal. 2009, 351, 415-422.

[243] Carter, R. R.; Wyatt, J. K. Tetrahedron Lett. 2006, 47, 6091-6094.

[244] Ma, S.; Ni, B.; Lin, S.; Liang, Z. J. Organomet. Chem. 2005, 690, 5389-5395.

[245] Bellina, F.; Cauteruccio, S.; Rossi, R. J. Org. Chem. 2007, 72, 8543-8546.

[246] Molander, G. A.; Ham, J.; Seapy, D. G. Tetrahedron 2007, 63, 768-775.

[247] Molander, G. A.; Vargas, F. Org. Lett. 2006, 71, 91989202.

[248] Molander, G. A.; Biolatto, B. J. Org. Chem. 2003, 68, $4302-4314$

[249] Molander, G. A.; Elia, M. D. J. Org. Chem. 2006, 71, 9198-9202.

[250] Kim, T.; Song, J. H.; Jeong, K. H.; Lee, S.; Ham, J. Eur. J. Org. Chem. 2013, 3992-3996.

[251] Velcicky, J.; Soicke, A.; Steiner, R.; Schmalz, H.-G. J. Am. Chem. Soc. 2011, 133, 6948-6951.

[252] (a) Mann, F. M.; Xu, M.; Chen, X.; Ultopn, D. B.; Russell, D. G.; Peters, R. J. J. Am. Chem. Soc. 2009, 131, 17526-17527; (b) Mann, F. M.; Prisic, S.; Hu, H.; Xu, M.; Coates, R. M.; Peters, R. J. J. Biol. Chem. 2009, 284, 23574 23579.

[253] Shuo, Q. Y.; Tan, Q.; Shen, Z. W. Bioorg. Med. Chem. Lett. 2009, 19, 3389-3391.

[254] Haynes, H. F.; Nelson, E. R.; Price, J. R. Aust. J. Res., Ser. A 1952, 5, 387-400.

[255] (a) Kardono, L. B. S.; Angerhofer, C. K.; Tsauri, S.; Padmawinata, K.; Pezzuto, J. M.; Kinghorn, D. J. Nat. Prod. 1991, 54, 1360-1367; (b) Kuo, P.-C.; Shi, L.-S.; Damu, A. G.; Su, C.-R.; Huang, C.-H.; Ke, C.-H.; Wu, J.-B.; Lin, A.-J.; Bastow, K. F.; Lee, K.-H.; Wu, T.-S. J. Nat. Prod. 2003, 66, 1324-1327; (c) Mahmood, M.; Normi, R.; Subramanian, S. Aust. J. Crop Sci. 2011, 5, 1565-1569.

[256] Ayyad, S.-E. N.; Judd, A. S.; Shier, W. T.; Hoye, T. R. J. Org. Chem. 1998, 63, 8102-8106.

[257] Satake, M.; Campbell, A.; Van Wagoner, R. M.; Bourdelais, A. J.; Jaecocks, H.; Baden, D. G.; Wright, J. L. C. J. Org. Chem. 2009, 74, 989-994. 
[258] (a) Bourdelais, A.; Campbell, S.; Jacocks, H.; Naar, J.; Wright, J. L. C.; Carsi, J.; Baden, D. G. Cell. Mol. Neurobiol. 2004, 24, 553-563; (b) Bourdelais, A. J.; Jacocks, H. M.; Wright, J. L. C.; Bigwarfe Jr. P. M.; Baden, D. G. J. Nat. Prod. 2005, 68, 2-6.

[259] (a) Satake, M.; Bourdelais, A. J.; Van Wagoner, R. M.; Baden, D. G.; Wight, J. L. C. Org. Lett. 2008, 10, 3465-3468; (b) Van Wagoner, R. M.; Satake, M.; Bourdelais, A. J.; Baden, D. G.; Wright, J. L. C. J. Nat. Prod. 2010, 73, 1177-1179.

[260] Hedge, V. R.; Puar, M. S.; Dai, P.; Patel, M.; Gullo, V. P.; Das, P. R.; Bond, R. W.; McPhail, A. T. Tetrahedron Lett. 2000, 41, 1351-1354.

[261] Rathnagiriswaran, A. N.; Venkatachalam, K. Indian, J. Med. Res. 1935, 22, 433-441.

[262] Belin, P.; Le Du, M. H.; Fielding, A.; Lequin, O.; Jacquet, M.; Charbonnier, J.-B.; Lecoq, A.; Thai, R.; Courçon, M.; Masson, C.; Dugave, C.; Genet, R.; Pernodet, J.-L.; Gondry, M. Proc. Natl. Acad. Sci. U.S.A. 2009, 106, 74267431.

[263] (a) Jansen, R.; Kunze, B.; Reichenbach, H.; Höfle, G. Eur. J. Org. Chem. 2002, 917-921; (b) Kunze, B.; Jansen, R.; Höfle, G.; Reichenbach, H. J. Antibiot. 2004, 57, 151-155.

[264] Wang, L.; Zhang, X.-Q.; Yin, Z.-Q.; Wang, Y.; Ye, W.C. Chem. Pharm. Bull. 2009, 57, 610-611.

[265] Pigni, N. B.; Ríos-Ruiz, S.; Martínez-Francés, V.; Nair, J. J.; Viladomat, F.; Codina, C.; Bastida, J. J. Nat. Prod 2012, $75,1643-1647$.

[266] Nagumo, S.; Kaji, N.; Inoue, I.; Nagai, M. Chem. Pharm. Bull. 1993, 41, 1255-1257.

[267] Tyman, J. H. P.; Tychopoulos, V.; P. Chan, P. J. Chromatogr. 1984, 303, 137-150.

[268] (a) Potts, B. C. M.; Faulkner, D. J.; Chan, J. A.; Simolike, G. C.; Offen, P.; Hemling, M. E.; Francis, T. A. J. Am. Chem. Soc. 1991, 113, 6321-6322; (b) Salomon, C. E.; Williams, D. H.; Lobkovsky, E.; Clardy, J. C.; Faulkner, D. J. Org. Lett. 2002, 4, 1699-1702.

[269] Maloney, K. N.; MacMillan, J. B.; Kauffman, C. A.; Jensen, E. R.; DiPasquale, A. G.; Rheingold, A. L.; Fenical, W. Org. Lett. 2009, 11. 5422-5424.

[270] (a) Bloch, B.; Karrer, P. Beiblatt Vierteljahressch. Naturforsch. Ges. Zuerich 1927, 13, 1-10; (b) Pongcharoen, W.; Rukachaisirikul, V.; Phongpaichit, S.; Sakayaroj, J. Chem. Pharm. Bull. 2007, 55, 1404-1405.

[271] (a) De Rosa, S.; Crispino, A.; De Giulio, A.; Iodice, C.; Amodeo, P.; Tancredi, T. J. Nat. Prod. 1999, 62, 1316-1318: (b) De Rosa, S.; Puliti, R.; Crispino, A.; De Giluio, A.; De Sena, C.; Iodice, C.; Matia, C. A. Tetrahedron 1995, 51, 10731-10736.

[272] (a) Wu, S.-J.; Chen, I.-S. Phytochemistry 1993, 34, 16591661; (b) Chen, J.-J.; Fang, H.-Y.; Chang, C.-Y.; Chen, I.-S. Planta Med. 2005, 71, 470-475; (c) Luo, X.; Pedro, L.; Milic, V.; Mulhovo, S.; Duarte, A.; Duarte, N.; Ferreira, M.-J. U. Planta Med. 2012, 78, 148-153.

[273] (a) Furuya, T.; Ikuta, A.; Syöno, K. Phytochemistry 1972, 11, 3041-3044; (b) Dasgupta, B.; Seth, K. K.; Pandey, V. B.; Ray, A. B. Planta Med. 1999, 65, 643-647.
[274] Pigni, N. B.; Berkov, S.; Elmrani, A.; Benaissa, M.; Viladomat, F.; Codina, C.; Bastida, J. Molecules 2010, 15, 7083-7089.

[275] Huang, X.-H.; van Soest, R.; Roberge, M.; Andersen, R. J. Org. Lett. 2004, 6, 75-78.

[276] (a) Ankisetty, S.; Gochfeld, D. J.; Diaz, M. C.; Khan, S. I.; Slattery, M. J. Nat. Prod. 2010, 73, 1494-1498; (b) Berrue, F.; Thomas, O. P.; Laville, R.; Prado, S.; Golebiowski, J.; Fernandez, R.; Amade, P. Tetrahedron 2007, 63, 2328-2334.

[277] Kikuchi, H.; Matsuo, Y.; Katou, Y.; Kubohara, Y.; Oshima, Y. Tetrahedron 2012, 68, 8884-8889.

[278] Ezaki, K.; Satake, M.; Kusumi, T.; Kakisawa, H. Tetrahedron Lett. 1991, 32, 2793-2796.

[279] Chen, X.-L-: Liu, H.-L.; Li, J.; Xin, G.-R.; Guo, Y.-W. Org. Lett. 2011, 13, 5032-5035.

[280] Graham, J. E.; Lecomte, J. T. J.; Bryant, D. A. J. Nat. Prod. 2008, 71, 1647-1650.

[281] Spangler, J. E.; Carson, C. A.; Sorensen, E. J. Chem. Sci. 2010, 1, 202-205.

[282] Rudi, A.; Aknin, M.; Gaydou, E.; Kashman, Y. J. Nat. Prod. 2004, 67, 1932-1935.

[283] Zheng, S.-y.; Li, X.-p.; Tan, H.-s.; Yu, C.-h.; Zhang, J.-h.; Shen, Z.-w. Eur. J. Org. Chem. 2013, 1356-1366.

[284] (a) Gollner, A.; Koutentis, P. A. Org. Lett. 2010, 12, 1352-1355; (b) Ioannidou, H. A.; Martin, A.; Gollner, A.; Koutentis, P. A. J. Org. Chem. 2011, 76, 5113-5122.

[285] Klapars, A.; Huang, X.; Buchwald, S. L. J. Am. Chem. Soc. 2002, 124, 7421-7428.

[286] Audia, J. E.; Boisvert, L.; Patten, A. D.; Villalobos, A.; Danishefsky, S. J. J. Org. Chem. 1989, 54, 3738-3740.

[287] Chen, C.-H.; Chen, Y.-K.; Sha, C.-K. Org. Lett. 2010, 12, 1377-1379.

[288] Iwashita, M.; Fujii, S.; Ito, S.; Hirano, T.; Kagechika, H. Tetrahedron 2011, 67. 6073-6082.

[289] Kuranaga, T.; Ohtani, N.; Tsutsumi, R.; Baden, G.; Wright, J. L. C.; Satake, M.; Tachibana, K. Org. Lett. 2011, 13, 696-699.

[290] Takamura, H.; Yamagami, Y.; Kishi, T.; Kikuchi, S.; Nakamura, Y.; Kadota, I.; Yamamoto, Y. Tetrahedron 2010, 66, 5329-5344.

[291] Ebine, M.; Fuwa, H.; Sasaka, M. Org. Lett. 2008, 10, $2275-2278$

[292] (a) Nicolaou, K. C.; Nugiel, D. A.; Couladouros, E.; Hwang, C.-K. Tetrahedron Lett. 1990, 46, 4517-4522; (b) Kadota, I.; Kadowaki, C.; Park, C.-H.; Takamura, H.; Sato, K.; Chan, P. W. H.; Thorand, S.; Yamamoto, Y. Tetrahedron 2002, 58, 1799-1816.

[293] Tsutsumi, R.; Kuranaga, T.; Wright, J. L. C.; Baden, D. G.; Ito, E.; Satake, M.; Tachibana, K. Tetrahedron 2010, 66, 6775-6782.

[294] Park, H.; Kim, H.; Hong, J. Org. Lett. 2011, 13, 37423745.

[295] Soltani, O.; De Brabander, J. K. Org. Lett. 2005, 7, 27912793.

[296] Lin, Q.-X.; Ho, T.-L. Tetrahedron 2013, 69, 2996-3001. 
[297] Cochrane, J. R.; White, J. M.; Wille, U.; Hutton, C. A. Org. Lett. 2012, 14, 2402-2405.

[298] Essig, S.; Bretske, S.; Müller, R.; Menche, R. J. Am. Chem. Soc. 2012, 134, 19362-19365.

[299] Kim, H. S.; Banwell, H. G.; Willis, A. C. J. Org. Chem. 2013, 78, 5103-5109.

[300] Ogura, T.; Usuki, T. Tetrahedron 2013, 69, 2807-2815.

[301] Fu, Y.; Hong, S.; Li, D.; Liu, S. J. Agric. Food Chem. 2013, 61, 5347-5352.

[302] (a) Fuwa, H.; Sekine, K.; Sasaki, M. Org. Lett. 2013, 15, 3970-3973; (b) Fuwa, H.; Muto, T.; Sekine, K.; Sasaki, M. Chem. Eur. J. 2014, 20, 1848-1860.

[303] George, I. R.; Lewis, W.; Moody, C. J. Tetrahedron 2013, 69, 8209-8215.

[304] Foot, J. S.; Kanno, H.; Giblin, G. M. P.; Taylor, R. J. K. Synlett 2002, 1293-1295.

[305] Watanabe, K.; Sugizaki, T.; Tozawa, Y.; Katoh, T. Heterocycles 2012, 86, 985-989.

[306] Oshida, M.; Ono, M.; Nakazaki, A.; Kobayashi, S. Heterocycles 2010, 80. 313-328.

[307] Smiatacz, Z.; Myszka, H.; Ciunik, Z. Carbohydr. Res. 1988, 172, 171-182.

[308] (a) Schwartz, B. D.; Banwell, M. G.; Cade, I. A. Tetrahedron Lett. 2011, 52, 4526-4528; (b) Jones, M. T.; Schwartz, B. D.; Willis, A. C.; Banwell, M. G. Org. Lett. 2009, 11, 3506-3509.

[309] Matsumura, D.; Takarabe, T.; Toda, T.; Hayamizu, T.; Sawamura, K.; Takao, K.-i.; Tadano, K.-i. Tetrahedron 2011, 67, 6730-6745.

[310] Ihara, M.; Setsu, F.; Shoda, M.; Taniguchi, N.; Tokunaga, Y.; Fukumoto, K. J. Org. Chem. 1994, 59, 5317-5323.

[311] Kikuchi, H.; Matsuo, Y.; Katou, Y.; Kubohara, Y.; Oshima, Y. Tetrahedron 2012, 68, 8884-8889.

[312] Suzuki, Y.; Matsuo, N.; Nemoto, T.; Hamada, Y. Tetrahedron 2013, 69, 5913-5919.

[313] Vasamsetty, L.; Khan, F. A.; Mehta, G. Tetrahedron Lett. 2013, 54, 3522-3525.

[314] Fujii, S.; Chang, S. Y.; Burke, M. D. Angew. Chem. Int. Ed. 2011, 50, 7862-7864.

[315] (a) Tokuyama, H.; Okano, K.; Fujiwara, H.; Noji, T.; Fukuyama, T. Chem. Asian J. 2011, 6, 560-572; (b) Okano, K.; Fujiwara, H.; Noji, T.; Fukuyama, T.; Tokuyama, H. Angew. Chem. Int. Ed. 2010, 49, 5925-5929.

[316] For examples of $\mathrm{PdCl}_{2}(\mathrm{dppf}) / \mathrm{AsPh}_{3}$-catalyzed SuzukiMiyaura couplings that have been used in the period 19962009 for the synthesis of natural producxts, see: (a) Ohba, M.; Kawase, N.; Fujii, T. J. Am. Chem. Soc. 1996, 118, 82508257; (b) Trost, B. M.; Lee, C. B. J. Am. Chem. Soc. 1998, 120, 6818-6819; (c) Trauner, D.; Danishefsky, S. Tetrahedron Lett. 1999, 40, 6513-6516; (d) Kallan N. C.; Halcomb, R. L. Org. Lett. 2000, 2, 2687-2690; (e) Nåkamura, N.; Shiozaki, M. Tetrahedron Lett. 2001, 42, 2701-2704; (f) Fenster, M. D. B.; Dake, G. R. Org. Lett. 2003, 5,4313-4316; (g) Dias, L. C.; Meira, P. R. R. J. Org. Chem. 2005, 70, 4762-4773; (h) Linghu, X.; Kennedy-Smith, J.; Tote, F. D. Angew. Chem. Int. Ed. 2007, 46, 7671-7673; (i) Xie, J.; Ma, Y.; Horne, D. A.
Org. Lett. 2009, 11, 2555-2558; (k) Yamanaka, H.; Sato, K.; Sato, H.; Iida, M.; Oishi, T.; Chida, N. Tetrahedron 2009, 65, 9188-9201.

[317] Johnson, C. R.; Braun, M. P. J. Am. Chem. Soc. 1993, $115,11014-11015$.

[318] (a) Hayakawa, Y.; Adachi, K.; Komeshima, N. J. Antibiot. 1987, 40, 1349-1352; (b) Hayakawa, Y.; Sohda, K. Y.; Shinya, K.; Hidaka, T.; Seto, H. J. Antibiot. 1995, 48, $954-$ 961.

[319] (a) Orjala, J.; Nagle, D. G.; Hsu, V.; Gerwich, W. H. J. Am. Chem. Soc. 1995, 117, 8281-8282; (b) Yokokawa, F.; Fujiwara, H.; Shiori, T. Tetrahedron Lett. 1999, 40, 19151916.

[320] Kito, K.; Ookura, R.; Yoshida, S.; Nåmikoshi, M.; Ooi, T. Org. Lett. 2008, 10, 225-228.

[321] Tokuyama, T.; Nishimori, N.; Karle, I. L.; Edwards, M. W.; Daly, J. W. Tetrahedron 1986, 42, 3453-3460.

[322] Jones, T. H.; Blum, M. S.; Fales, H. M.; Thompso, C. R. J. Org. Chem. 1980, 45, 4778-4780.

[323] (a) Aldridge, D. C.; Galt, S.; Giles, D.; Turner, B. J. Chem. Soc. C 1971, 1623-1627; (b) Cambie, R. C.;Lal, A. R.; Rutledge, P. S.; Woodgate, P. D. Phytochemistry 1991, 30, 287-292; (c) Lee, K.-H.; Hayashi, N.; Okano, M.; Hall, I. H.; Wu, R.-Y; McPhail, A. T. Phytochemistry 1982, 21, 11191121.

[324] Tsuda, M.; Oguchi, K.; Iwamoto, R.; Okamoto, Y.; Kobayashi, J.; Fukushi, E.; Kawabata, J.; Ozawa, T.; Masuda, A.; Kitay, Y.; Omåsa, K. J. Org. Chem. 2007, 72, 4469-4474.

[325] (a) Yotsu-Yamashita, M.; Haddock, R. L.; Yasumoto, T. J. Am. Chem. Soc. 1993, 115, 1147-1148; (b) YotsuYamashita, M.; Yasumoto, T.; Yamada, S.; Bajarias, F. F. A.; Formeloza, M. A.; Romero, M. L.; Fukuyo, Y. Chem. Res. Toxicol. 2004, 17, 1265-1271.

[326] Klemke, C.; Kehraus, S.; Wright, A. D.; König, G. M. J. Nat. Prod. 2004, 67, 1058-1063.

[327] (a) Nagai, H.; Torigoe, K.; Satake, M.; Murata, M.; Yasumoto, T.; Hirota, H. J. Am. Chem. Soc. 1992, 114, 11021103; (b) Nagai, H.; Murata, M.; Torigoe, K; Satake, M.; Yasumoto, T. J. Org. Chem. 1992, 57, 544-5453.

[328] (a) Potts, B. C. M.; Faulkner, D. J.; Chan, J. A.; Simolike, G. C.; Offen, P.; Hemling, M. E.; Francis, T. A. J. Am. Chem. Soc. 1991, 113, 6321-6322; (b) Pika, J.; Faulkner, D. J. Nat. Prod. Lett. 1995, 7, 291-296; (c) Salomon, C. E.; Williams, D. H.; Lobkovsky, E.; Clardy, J. C.; Faulkner, D. J. Org. Lett. 2002, 4, 1699-1702.

[329] (a) Williams, D. E.; Roberge, M.; Soest, R. V.; Andersen, R. J. J. Am. Chem. Soc. 2003, 125, 5296-5297; (b) Williams, D. E.; Lapawa, M.; Feng, X.; Tarling, T.;Roberge, M.; Andersen, R. J. Org. Lett. 2004, 6, 2607-2610.

[330] (a) Seip, E. H.; Hecker, E. Phytochemistry 1984, 23, 1689-1694; (b) Schnabel, C.; Hiersemann, M. Org. Lett. 2009, 11, 2555-2558.

[331] Takayama, H.; Katakawa, K.; Kitajima, M.; Yamaguchi, K.; Aimi, N. Tetrahedron Lett. 2002, 43, 8307-8311. 
[332] (a) Burnell, R. H. J. Chem. Soc. 1959, 3091-3093; (b) Burnell, R. H.; Chin, C. G.; Mootoo, B. S.; Taylor, D. R. Can. J. Chem. 1963, 41, 3091-3094.

[333] Kurata, K.; Taniguchi, K.; Shiraishi, K.; Hayama, N.; Tanaka, I.; Suzuki M. Chem. Lett. 1989, 267-270.

[334] Todd, J. S.; Proteau, P. J.; Gerwick, W. H. J. Nat. Prod. 1994, 57, 171-174.

[335] Bonazzi, S.; Eidam, O.; Güttinger, S.; Wach, J.-Y.; Zemp, I.; Kutay, U.; Gademann, J. Am. Chem. Soc. 2010, 132, 14321442.

[336] Okura, K.; Matsuoka, S.; Goto, R.; Inoue, M. Angew. Chem. Int. Ed. 2010, 66, 7492-7503.

[337] Fuwa, H.; Yamaguchi, H.; Sasaki, M. Tetrahedron 2010, 66, 7492-7503.

[338] Gärtner, M.; Weihofen, R.; Helmchen, G. Chem. Eur. J. 2011, 17, 7605-7622.

[339] Huang, Y.; Minnaard, A. J.; Feringa, B. L. Synthesis 2011, 1055-1058.

[340] Xie, J.; Ma, Y.; Horne, D. A. Tetrahedron 2011, 67, 7485-7501.

[341] Kasai, Y.; Ito, T.; Sasaki, M. Org. Lett. 2012, 14, 31863189.

[342] Gärtner, M.; Kossler, D.; Pflästerer, D.; Helmchen, G. J. Org. Chem. 2012, 77, 4491-4495.

[343] Fuwa, H.; Ishigai, K.; Hashizume, K.; Sasaki, M. J. Am. Chem. Soc. 2012, 134, 11984-11987.

[344] Zhang, F.-M.; Peng, L.; Li, H.; Ma, A.-J.; Peng, J.-B.; Guo, J.-J.; Yang, D.; Hou, S.-H.; Tu, Y.-Q.; Kitxching, W. Angew. Chem. Int. Ed. 2012, 51, 10846-10850.

[345] Paterson, I.; Maltas, P.; Dalby, S. M.; Lim, J. H.; Anderson, E. A. Angew. Chem. Int. Ed. 2012, 51, 2749-2753.

[346] Arlt, A.; Benson, S.; Schulthoff, S.; Gabor, B.; Fürstner, A. Chem. Eur. J. 2013, 19, 3956-3608.

[347] Schnabel, C.; Sterz, K.; Müller, H.; Rehbein, J.; Wiese, M.; Hiersemann, M. J. Org. Chem. 2011, 76, 512-522.

[348] Zeng, C.; Zheng, C.; Zhao, J.; Zhao, G. Org. Lett. 2013, $15,5846-5849$.

[349] Becker, J.; Butt, L.; von Kiedrawski, V.; Mischler, E.; Quentin, F.; Hiersemann, M. Org. Lett. 2013, 15, 5982-5985.

[350] (a) Sedell, G.; Fürstner, A. Chem. Commun. 2012, 48, 2055-2070; (b) Marshall, J. A.; Bourbeau, M. P. J. Org. Chem. 2002, 67, 2751-2753; (c) Dias, L. C.; Meira, P. R. R. J. Org. Chem. 2005, 70, 4762-4773; (d) Marshall, J. A.; Schaaf, G. M. J. Org. Chem. 2003, 68, 7428-7432; (e) Marshall, J. A.; Mikowski, A. M.; Bourbeau, M. P.; Schaaf, G. M.; Valeriote, F. Bioorg. Med. Chem. Lett. 2006, 16, 320-323; (f) Bonazzi, S.; Güttinger, S.; Zemp, I.; Kutay, U.; Gademann, K. Angew. Chem. Int. Ed. 2007, 46, 8707-8710.

[351] Tucker, C. E.; Davidson, J.; Knochel, P. J. Org. Chem. 1992, 57, 3482-3485.

[352] (a) Hintermann, T.; Seebach, D. Helv. Chim. Acta 1998, 81, 2093-2126; (b) Bull, S. D.; Davies, S. G.; Garner, A. C.; Kruchinin, D.; Key, M. S.; Roberts, P. M.; Savory, E. D.; Smith, A. D.; Thomson, J. E. Org. Biomol. Chem. 2006, 4, 2945-2964.
[353] Plater, M. J.; Aiken, S.; Bourhill, G. Tetrahedron 2002, $58,2415-2422$.

[354] Baker, R.; Castro, J. L. J. Chem. Soc., Perkin Trans. I 1990, 47-65.

[355] Hanawa, H.; Uraguchi, D.; Konishi, S.; Hashimoto, T.; Maruoka, K. Chem. Eur. J. 2003, 9, 4405-4413.

[356] (a) Takai, K.; Nitta, K.; Utimoto, K. J. Am. Chem. Soc. 1986, 108, 7408-7410; (b) Evans, D. A.; Black, W. C. J. Am. Chem. Soc. 1993, 115, 4497-4513.

[357] Geurts, K.; Fletcher, S. P.; Feringa, B. L. J. Am. Chem. Soc. 1990, 513-517.

[358] (a) Braun, M.; Mahler, U.; Houben, S. Liebigs Ann. Chem. 1990, 513-517; (b) Solladié, G.; Rubio, A.; Carrero, M. C.; Ruono, J. L. G. Tetrahedron: Asymmetry 1990, 1, 187198.

[359] Hosomi, A.; Sakurai, H. Tetrahedron Lett. 1976, 17, 1295-1298.

[360] Robertson, J.; Dallimore, J. W. P.; Meo, P. Org. Lett. 2004, 6, 3857-3859.

[361] Boden, E. P.; Keck, G. E. J. Org. Chem. 1985, 50., 2394 2395.

[362] Kageyama, M.; Tamura, T.; Nantz, M. H.; Roberts, J. C.; Somfai, P.; Whritenour, D. C.; Masamune, S. J. Am. Chem. Soc. 1990, 112, 7407-7408.

[363] Dhokte, U. P.; Khau, V. V.; Hutchison, D. R.; Martinelli, M. J. Tetrahedron Lett. 1998, 39, 8771-8774.

[364] Fuwa, H.; Naito, S.; Goto, T.; Sasaki, M. Angew. Chem. Int. Ed. 2008, 47, 4737-4739.

[365] Paterson, I.; Anderson, E. A.; Dalby, S. M.; Genovino, J.; Lim, J. H.; Moessner, C. Chem. Commun. 2007, 1852-1854.

[366] (a) Takai, K.; Kimura, K.; Kuroda, T.; Hiyama, T.; Nozaki, H. Tetrahedron Lett. 1983, 24, 5281-5284; (b) Jin, H.; Uenishi, J.; Christ, W. J.; Kishi, Y. J. Am. Chem. Soc. 1986, 108, 5644-5646; (c) Takai, K. Org. React. 2004, 64, 253-612.

[367] (a) Inanaga, J.; Hirata, K.; Saeki, H.; Katsuki, T.; Yamaguchi, M. Bull. Chem. Soc. Jpn. 1979, 52, 1989-1993; (b) Kawanami, Y.; Dainobu, Y.; Inanaga, J.; Katsuki, T.; Yamaguchi, M. Bull. Chem. Soc. Jpn. 1981, 54, 943-944.

[368] Blakemore, P. R.; Cole, W. J.; Kocienski, P. J.; Morley, A. Synlett 1998, 26-28.

[369] Benson, S.; Collin, M.-P.; Arlt, A.; Gabor, B.; Goddard, R.; Fürstner, A. Angew. Chem. Int. Ed. 2011, 50, 8739-8744.

[370] (a) Valente, C.; Ferreira, M. J. U.; Abreu, P. M.; Pedro, M.; Cerqueira, F.; Nascimento, M. S. J. Planta Med. 2003, 69, 361-366; (b) Valente, C.; Ferreira, M. J. U.; Abreu, P. M.; Gyémánt, N.; Ugocsai, K.; Hohmann, J.; Molnár, J. Planta Med. 2004, 70, 81-84.

[371] (a) Ruprah, P. K.; Cros, J.-P.; Pease, J. E.; Whittingham, W. G.; Williams, J. M. J. Eur. J. Org. Chem. 2002, 31453152; (b) Lacoste, E.; Vaique, E.; Berlande, M.; Pianet, I.; Vincent, J.-M.; Landais, Y. Eur. J. Org. Chem. 2007, 167177; (c) Zhang, X.-M.; Wang, M.; Tu, Y.-Q.; Fan, C.-A.; Jiang, Y.-J.; Zhang, S.-Y.; Zhang, F.-M. Synlett 2008, 28312835.

[372] (a) Abraham, L.; Czerwonka, R.; Hiersemann, M. Angew. Chem. Int. Ed. 2001, 40, 4700-4703; (b) Abraham, L.; Körner, 
M.; Schwab, P.; Hiersemann, M. Adv. Synth. Catal. 2004, 346, 1281-1294; (c) Abraham, L.; Körner, M.; Hiersemann, M. Tetrahedron Lett. 2004, 45, 3647-3650.

[373] For syntheses of natural products that have been described in the early months of 2014 and involve SuzukiMiyaura cross-couplings carried out using phosphane-based Pd catalysts, see: (a) Lan, P.; Banwell, M. G.; Ward, J. S.; Willis, A. C. Org. Lett. 2014, 16, 228-231 (total synthesis and reassignment of the absolute configuration of ribisin $\mathrm{C}$ ); (b) Jolibois, A. E. R.; Lewis, W.; Moody, C. J. Org. Lett. 2014, 16, 1064-1067 (total synthesis of racemic distomadines A and B); (c) Killander, D.; Sterner, O. Eur. J. Org. Chem. 2014, 1594-1596 (synthesis of pulchrol); (d) Ogawa, N.; Tojo, T.; Kobayashi, Y. Tetrahedron Lett. 2014, 55, 2738-2741 (synthesis of maresin 1); (e) Rosen, B. R.; Werner, E. W.; O'Brien, A. G.; Bara, P. S. J. Am. Chem. Soc. 2014 DOI: 10.1021/ja5013323 (total synthesis of dixiamycin B); (f) Gupton, J. T.; Telang, N.; Wormald, M.; Lescalleet, K.; Patteson, J.; Curry, W.; Harrison, A.; Hoerrner, M.; Sobieski, J.; Kimmel, M.; Kluball, E.; Perry, T. Tetrahedron 2014, 70, 2738-2745 (formal synthesis of polycitones A and B and polycitrin A); (g) Jolibois, A. E. R.; Lewis, W.; Moody, C. J. Org. Lett. 2014, 16, 1064-1067 (total synthesis of racemic distomadines A and B); (h) Beekman, A. M.; Barrow, R. A. J. Org. Chem. 2014, 79, 1017-1024 (syntheses of boletopsins 7, 11 and 12); (i) Zhang, C.; Liu, J.; Du, Y. Tetrahedron Lett. 2014, 55, 959-961 (total synthesis of ribisin A); (j) Ngernmeesri, P.; Soonkit, S.; Konkhum, A.; Kongkathip, B. Tetrahedron Lett. 2014, 55, 1621-1624 (formal synthesis of racemic cladoniamide G); (k) Kohno, Y.; Koso, M.; Kuse, M.; Takikawa, H. Tetrahedron Lett. 2014, 55, 1826-1828 (formal synthesis of soybean phytoalexin glyceollin 1); (1) Gao, Y.; Liu, J.; Wang, L.; Xiao, M.; Du, Y. Eur. J. Org. Chem. 2014, 2092-2098 (total syntheses of cochliomycin B and zeaenol); (m) Oblak, E. Z.; VanHeyst, M. D.; Li, J.; Wiemer, A. J.; Wright, D. L. J. Am. Chem. Soc. 2014, 136, 4309-4315 (total synthesis of (+)-frondosin A); (n) Parkan, K.; Pohl, R.; Kotora, M. Chem. Eur. J. 2014, 20, 4414-4419 (synthesis of bergenin); (o) Zhu, L.; Luo, J.; Hong, R. Org. Lett. 2014, 16, 2162-2165; (p) Zhu, L.; Luo, J.; Hong, R. Org. Lett. 2014, 16, 2162-2165 (total synthesis of racemic cafestol); (q) Ghavimi, B.; Magnus, P. Org. Lett. 2014, 16, 1708-1711 (synthesis of 8,14-dihydronorsalutaridine, 8,14-dihydrosalutaridine, norsinomenine, and isonomenine); (r) Lan, P.; Banwell, M. G.; Willis, A. C. J. Org. Chem. 2014, 79, 2829-2842 (total syntheses of ribisins $\mathrm{A}, \mathrm{B}$, and $\mathrm{D})$. 